\title{
harmed o abuso de idosss: determinantes sociais, económicas e de saúde
}

\section{Relatório Final}

\section{junho 2020}

Isabel Dias (IP)

Alexandra Lopes

Ana Henriques

Diogo Costa

João Miguel Aguiar

Rute Lemos

Sílvia Fraga

Projeto: PTDC/IVC-SOC/6782/2014

POCI-01 0145-FEDER 01670 
Título: HARMED - O abuso de idosos: determinantes sociais, económicas e de saúde Socio-economic and health determinants of elder abuse

Coordenação: Isabel Dias

Autores: Isabel Dias; Alexandra Lopes; Ana Henriques; Diogo Costa; João Miguel Aguiar; Rute Lemos \& Sílvia Fraga

Local: Porto

Editor: Universidade do Porto. Faculdade de Letras

Coeditor: Instituto de Saúde Pública da Universidade do Porto

Ano de edição: 2020

ISBN: 978-989-8969-53-8

DOI: https://doi.org/10.21747/978-989-8969-53-8/abu

URL: https://ler.letras.up.pt/site/default.aspx?qry=id022id1722\&sum=sim

Suporte: Eletrónico Formato: Pdf

\section{Com o apoio de:}

O projeto "O abuso de idosos: determinantes sociais, económicas e de saúde", foi financiado por fundos nacionais através da FCT - Fundação para a Ciência e a Tecnologia, I.P., na sua componente Orçamento de Estado (FCT PTDC/IVCSOC/6782/2014), e pelo orçamento do programa COMPETE - Programa Operacional e Competitividade na sua componente FEDER (POCI-01-0145-FEDER-016670). 


\section{Identificação do Projeto}

Título do Projeto: HARMED - O abuso de idosos: determinantes sociais, económicas e de saúde

Socio-economic and health determinants of elder abuse

Referência do Projeto: PTDC/IVC-SOC/6782/2014 POCI-01 0145-FEDER 01670

Instituição Proponente: Faculdade de Letras da Universidade do Porto - FLUP

Instituição Participante: Instituto de Saúde Pública da Universidade do Porto - ISPUP

Data de início:01-07-2016

Data de fim:31-01-2020 (com 6 meses de extensão).

Financiamento concedido: $€ 134.276,00$

\section{Equipa de Investigação}

Maria Isabel Correia Dias - Investigadora Responsável

Alexandra Cristina Ramos da Silva Lopes Gunes - Investigadora

Ana Lúcia Nunes Henriques - Investigadora (desde 17-05-2019)

Diogo André Neto Mendes da Costa - Investigador

Rute Isabel Carqueijeiro Lemos - Investigadora (desde 05/04/2018)

Sílvia de Jesus Silva Fraga - Investigadora

\section{Bolseiros de Investigação}

Ana Catarina Pacheco Barbosa (16-02-2017 a 15-08-2018)

Joana Alexandra Gouveia Anselmo (16-02-2017 a 15-02-2018)

Joana Cristina dos Reis Cavalheiro Sampaio (16-05-2017 a 15-05-2018)

João Miguel Barros Aguiar Pereira (15-06-2018 a 14-12-2019)

Rute Isabel Carqueijeiro Lemos (08-09-2016 a 31-12-2017) 


\section{Índice}

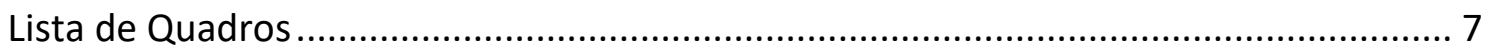

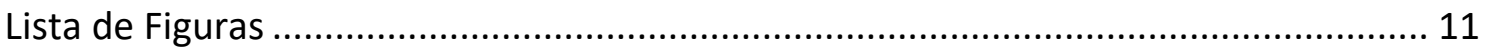

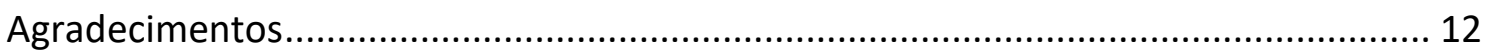

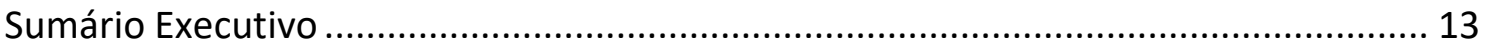

I - Introdução: Enquadramento Teórico e Metodológico do estudo.......................... 17

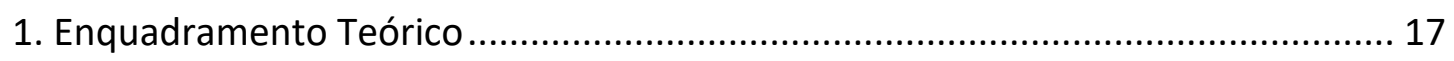

1.1. O abuso de idosos: definição do conceito, teorias e fatores de risco............. 18

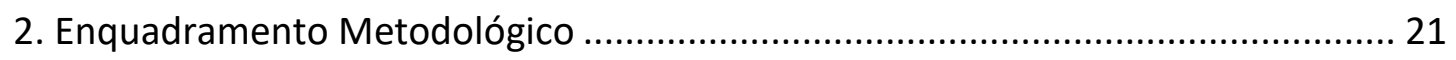

2.1. Métodos e desenho da investigação ............................................................. 21

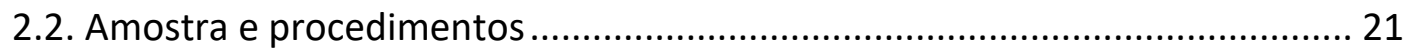

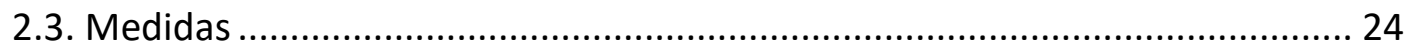

II - Estudo quantitativo: Determinantes sociais, económicas e de saúde do abuso de

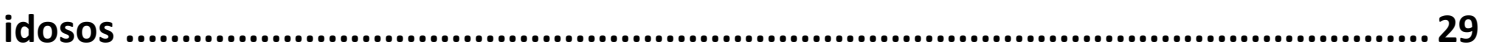

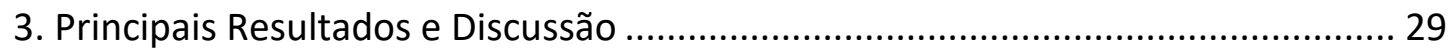

4. Características sociodemográficas, económicas, psicossociais e de habitação dos participantes no inquérito por questionário ......................................................... 30

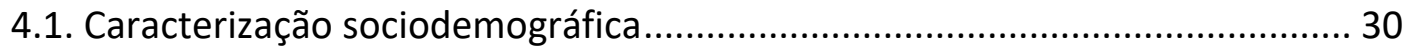

4.2. Caracterização socioeconómica dos participantes ...................................... 32

4.3. Caracterização psicossocial: suporte social e qualidade de vida .................... 36

4.4. Caracterização da habitação ..................................................................... 40

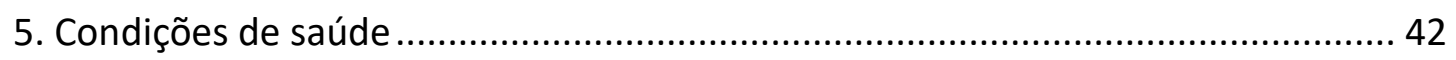

5.1. Caracterização global das condições de saúde ............................................. 43

5.2. Condições de saúde segundo as características sociodemográficas .............. 51

5.3. Cuidados de saúde e redes de apoio médico-social .................................... 55

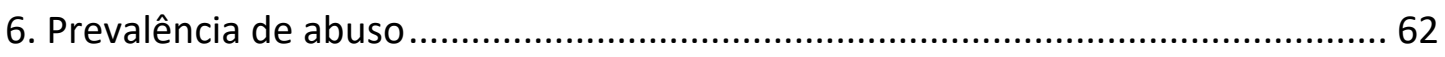

6.1. Prevalência de abuso segundo as características sociodemográficas e

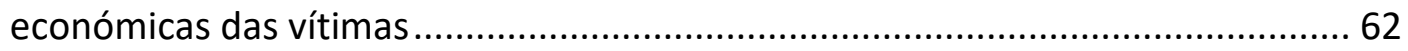

6.2. Prevalência de abuso segundo a condição de saúde das vítimas ................... 64 
6.3. Prevalência de abuso por tipos ................................................................... 66

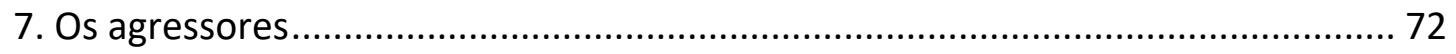

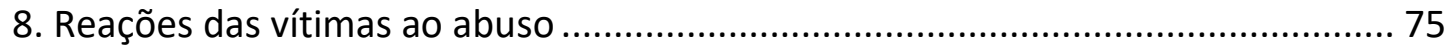

9. Crise socioeconómica e prevalência de abusos ....................................................... 82

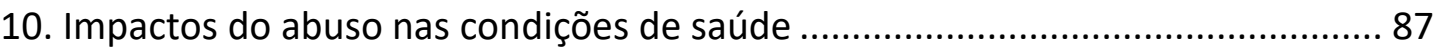

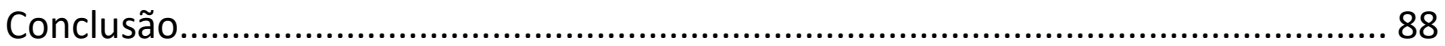

III - Estudo qualitativo: Representações, significados e narrativas sobre o abuso de

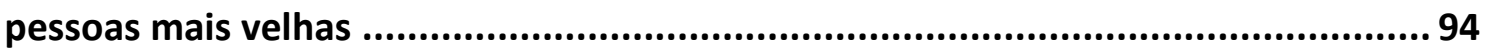

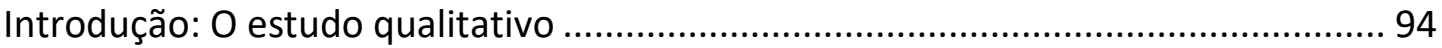

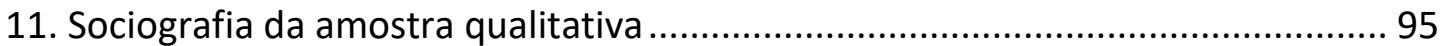

12. Representações e discursos sobre o envelhecimento e os abusos na idade avançada: o significado das determinantes socioeconómicas e de saúde ................ 98

12.1. Representações sobre a velhice e o envelhecimento: Ser idoso nas sociedades

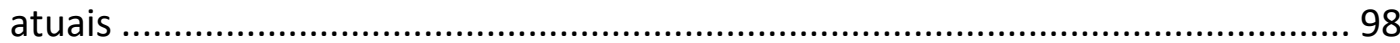

12.2. Representações sobre o abuso e violência contra as pessoas idosas: o desempoderamento dos mais velhos ............................................................ 107

13. Formas de violência na idade avançada: agressores e fatores de risco ............ 120

13.1. Violência conjugal na idade avançada.................................................... 120

13.2. A violência dos descendentes sobre os pais idosos .................................. 121

13.3. A violência perpetrada pelos cuidadores formais e informais................... 123

13.4. A violência perpetrada por desconhecidos ................................................ 125

14. Reações das vítimas aos abusos: os perfis ...................................................... 128

15. Perceções sobre o impacto da crise socioeconómica ....................................... 138

15.1 Família e estilo de vida das pessoas idosas ................................................. 138

15.2. Saúde, bem-estar e papel do Estado..................................................... 140

15.3. Crise socioeconómica e violência contra as pessoas idosas: "família onde não há pão todos ralham e ninguém tem razão" ................................................... 141

15.4. Representações sobre a (in)segurança dos idosos vítimas de violência..... 143

16. Papel do Estado, das forças de segurança pública e das redes familiares e comunitárias ................................................................................................... 145

16.1. Papel do Estado e abuso de idosos ......................................................... 145 
16.2. As forças de segurança pública e os profissionais de saúde 147

16.3. As Associações de proteção às vítimas e o (des)conhecimento da legislação 150

16.4. As redes: Família e comunidade............................................................ 152

17. Mensagens aos idosos vítimas de violência ....................................................... 155

18. Expectativas de bem-estar e felicidade ............................................................ 157

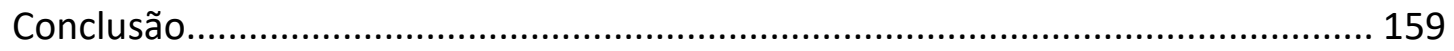

IV - Pessoas: narrativas e vivências de violência na idade avançada ....................... 163

V - Conclusões gerais e recomendações......................................................... 169

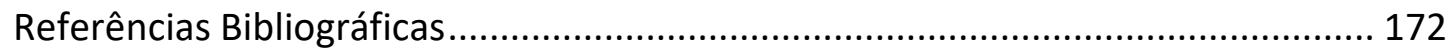




\section{Lista de Quadros}

Quadro 1. Caracterização sociodemográfica da amostra .......................................... 30

Quadro 2. Condição perante o trabalho ................................................................ 31

Quadro 3. Profissão (atual ou última antes de situação de desemprego, incapacidade para o trabalho ou reforma) segundo a Classificação Nacional das Profissões ............. 32

Quadro 4. Principal fonte de rendimentos do inquirido .............................................. 33

Quadro 5. Principal fonte de rendimentos das pessoas que vivem na mesma casa e que pertencem ao agregado familiar ( $n$ o. total de agregados $=520)$................................. 33

Quadro 6. Rendimento mensal líquido do adulto equivalente .................................... 34

Quadro 7. Escalões de rendimento do adulto equivalente......................................... 35

Quadro 8. Perceção sobre o rendimento atual ........................................................... 35

Quadro 9. Segurança alimentar do agregado familiar ............................................... 36

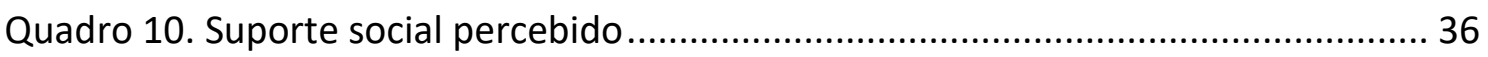

Quadro 11. Dados de referência para a pontuação bruta transformada (intervalo de 0 a 100) da pontuação total do módulo WHOQOL-OLD (Estudo HARMED) ......................... 37

Quadro 12. Dados de referência para a pontuação bruta transformada (intervalo de 0 a 100) das facetas/Score total do módulo WHOQOL-OLD, por sexo............................... 39

Quadro 13. Tipo de regime de propriedade da habitação ........................................... 40

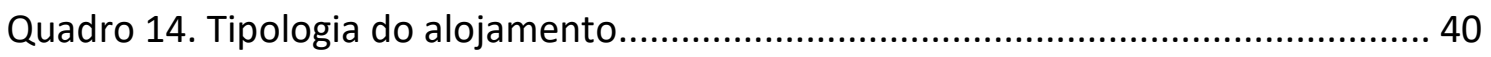

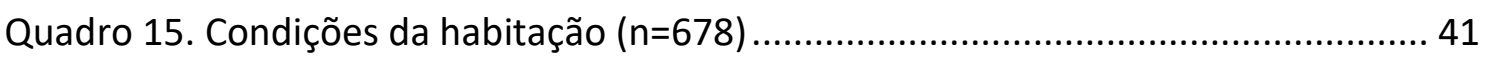

Quadro 16. Carência das condições de habitação ...................................................... 41

Quadro 17. Condições da zona envolvente à habitação (mais do que uma resposta

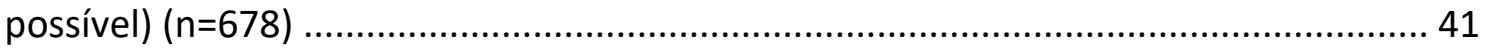

Quadro 18. Autoavaliação da condição de saúde ......................................................... 44

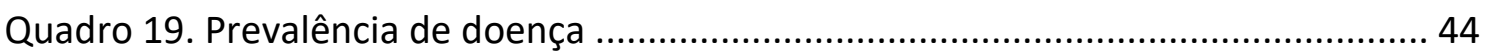

Quadro 20. Prevalência por tipo de doença (mais do que uma resposta possível) ( $n=678$ )

Quadro 21. Consumo de fármacos (mais do que uma resposta possível) ( $\mathrm{N}=678$ )...... 46

Quadro 22. Consumo diário de fármacos (mais do que uma resposta possível) ( $N=570)$

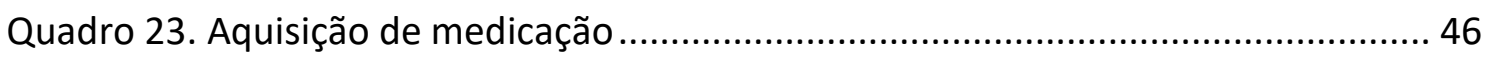

Quadro 24. Não adesão à terapia prescrita, apesar de não tomar medicação ............. 47

Quadro 25. Realização de tratamentos prescritos nos últimos 12 meses ..................... 47 
Quadro 26. Motivos para a não aquisição de medicação ou a não realização de tratamentos (mais do que uma resposta possível) .................................................... 48

Quadro 27. Satisfação com a vida (mais do que uma resposta possível) ( $N=543$ ) ........ 49

Quadro 28. Classificação na escala de depressão com 4 níveis ..................................... 49

Quadro 29. Presença de depressão (ponto de corte: maior ou igual a 5) ..................... 50

Quadro 30. Autoavaliação da condição de saúde segundo um conjunto de indicadores

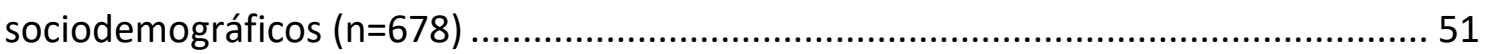

Quadro 31. Presença de doença segundo um conjunto selecionado de indicadores de

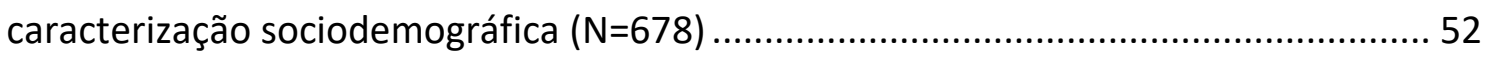

Quadro 32. Aquisição de medicação nos últimos 12 meses por fatores

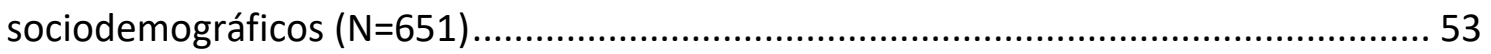

Quadro 33. Presença de depressão segundo o sexo dos inquiridos ( $N=651)$............... 54

Quadro 34. Frequência do contacto com um Médico de clínica geral ........................... 55

Quadro 35. Frequência do contacto com um Dentista ................................................ 56

Quadro 36. Frequência do contacto com um Oftalmologista....................................... 56

Quadro 37. Frequência do contacto com outro Médico especialista, para além do

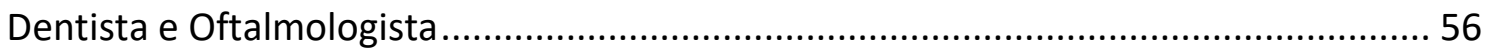

Quadro 38. Frequência do contacto com um Enfermeiro ........................................... 57

Quadro 39. Frequência do contacto com um Psicólogo ............................................... 57

Quadro 40. Frequência do contacto com um Assistente Social.................................... 57

Quadro 41. Frequência do contacto com outro profissional de saúde ou de apoio social

Quadro 42. Acesso a serviços de saúde nos últimos 12 meses (mais do que uma resposta

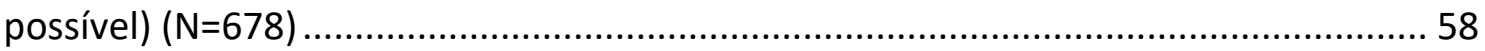

Quadro 43. Nível de satisfação em relação aos serviços de saúde públicos ( $N=567)$... 59

Quadro 44. Nível de satisfação em relação aos serviços de saúde privados ................. 59

Quadro 45. Ausência de utilização de serviços de saúde............................................. 59

Quadro 46. Principais razões para não ter utilizado os serviços de saúde (mais do que

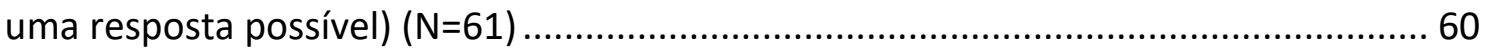

Quadro 47. Outra(s) razões para não ter utilizado os serviços de saúde $(\mathrm{N}=14)$.......... 60

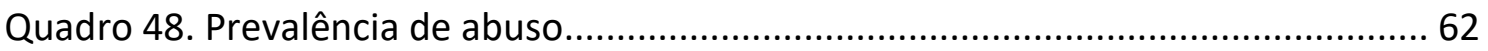

Quadro 49. Prevalência de abuso segundo um conjunto de indicadores sociodemográficos (OR brutos e risco relativo) 
Quadro 50. Prevalência de abuso segundo indicadores da condição de saúde ( $N=677)$

Quadro 51. Prevalência por tipo de abuso.

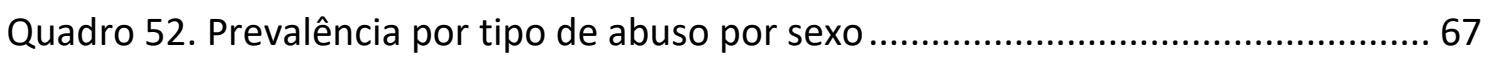

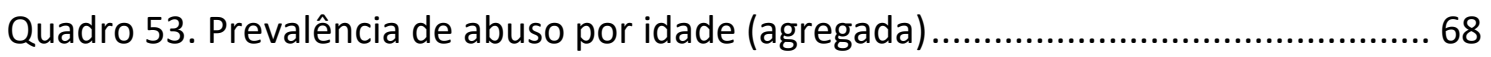

Quadro 54. Prevalência de abuso por composição do agregado habitacional............... 68

Quadro 55. Prevalência de abuso por nível de escolaridade (agregada)........................ 69

Quadro 56. Prevalência de abuso por perceção do rendimento do agregado como

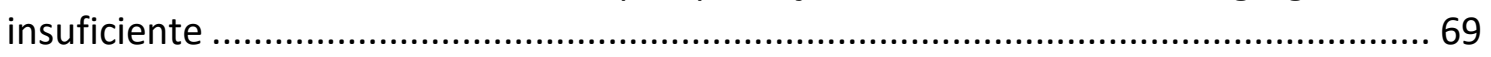

Quadro 57. Prevalência de abuso por nível de segurança alimentar (agregada) ........... 70

Quadro 58. Prevalência de abuso por nível de suporte social percebido....................... 70

Quadro 59. Identificação do(a) abusador(a) (mais do que uma resposta possível) ...... 72

Quadro 60. Identificação do(a) abusador(a), por tipo de abuso (mais do que uma

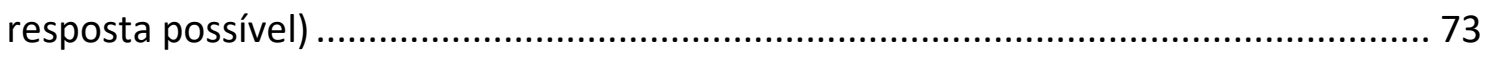

Quadro 61. Reações à situação de violência, por tipo de abuso (mais do que uma

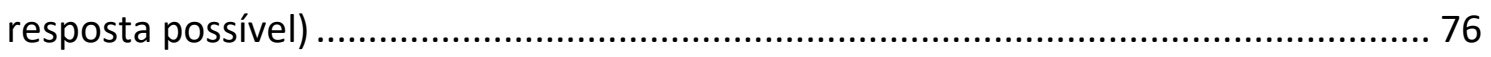

Quadro 62. A quem pediu ajuda ou aconselhamento/orientação sobre o que devia fazer, por tipo de abuso (mais do que uma resposta possível) ............................................ 77

Quadro 63. A quem relatou o incidente, por tipo de abuso (mais do que uma resposta possível)

Quadro 64. Razões pelas quais não pediu ajuda e/ou relatou o incidente de abuso, por tipo de abuso (mais do que uma resposta possível)....

Quadro 65. Sentir-se afetado pelas situações de abuso, por tipo de abuso (mais do que uma resposta possível)

Quadro 66. Impacto da crise económica na aquisição de bens e serviços ( $n=677)$....... 82

Quadro 67. Redução de despesas com bens e serviços em virtude da crise $(n=441) \ldots 82$

Quadro 68. Impacto da crise económica na vida quotidiana em virtude da crise $(n=677)$

Quadro 69. Situações ocorridas em virtude da crise $(n=294)$

Quadro 70. Prevalência de abuso, por redução de gastos/despesas em virtude da crise $(n=677)$.

Quadro 71. Prevalência de abuso, por alteração de circunstâncias da vida em virtude da crise $(n=677)$

Quadro 72. Prevalência por tipo de abuso, por redução de gastos/despesas em virtude da crise. 
Quadro 73. Prevalência por tipo de abuso, por alteração de circunstâncias da vida em virtude da crise

Quadro 74. Impacto do abuso num conjunto de indicadores de saúde ( $n=677)$ 87

Quadro 75. Sociografia da amostra qualitativa: Entrevistas... 96

Quadro 76. Trajetória de vitimização da amostra qualitativa 97

Quadro 77. Diferentes tipos de abuso, segundo o sexo dos entrevistados. 117

Quadro 78. Diferentes tipos de abuso, segundo a experiência de vitimização/ não vitimização dos entrevistados 119

Quadro 79. Reações das vítimas: Perfis 131 


\section{Lista de Figuras}

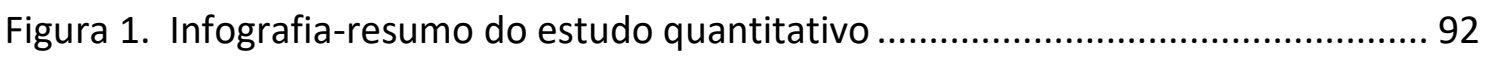

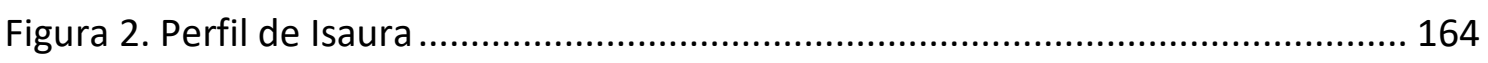

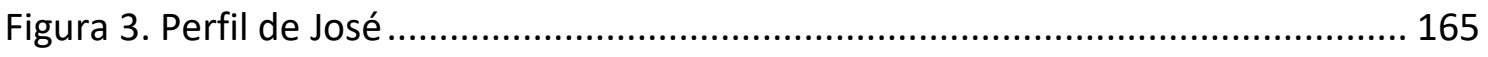

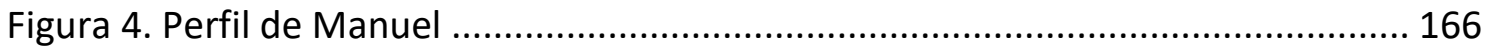

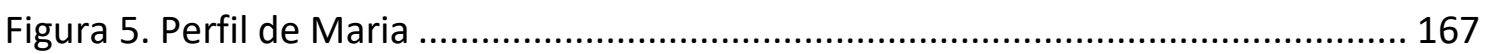

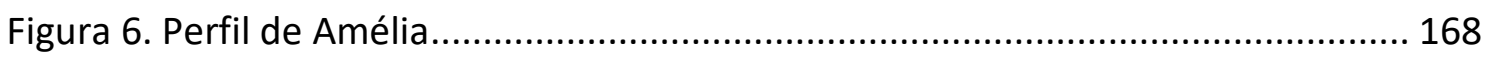




\section{Agradecimentos}

A equipa de investigação manifesta o seu profundo agradecimento aos idosos da coorte de base populacional - EPIPorto, pela participação no projeto Harmed - O abuso de idosos: determinantes sociais, económicas e de saúde. Foi excecional o seu interesse e colaboração na terceira reavaliação da referida base (2017-2018), da qual o presente projeto faz parte. O agradecimento é igualmente extensivo ao Prof. Doutor Henrique Barros, responsável pela criação e coordenação da coorte EPIPorto, o qual proporcionou à equipa de investigação todos os recursos disponíveis no Instituto de Saúde Pública da Universidade do Porto (ISPUP) e no Departamento de Ciências da Saúde Pública e Forenses, e Educação Médica da Faculdade de Medicina da Universidade do Porto para a realização deste projeto. A equipa de investigação agradece, de igual modo, o empenho de todos os que estiveram envolvidos no trabalho de campo, nomeadamente os coordenadores da base EPIPorto, o pessoal de enfermagem e técnicos de saúde, assim como os bolseiros de investigação.

Um agradecimento final ao Instituto de Sociologia da Universidade do Porto (ISUP) e ao Gabinete de Projetos da FLUP pelo apoio na execução financeira do projeto

Por último, este projeto foi financiado por Fundos FEDER através do Programa Operacional Competitividade e Internacionalização - COMPETE 2020 e por Fundos Nacionais através da FCT - Fundação para a Ciência e Tecnologia, instituição à qual a equipa de investigação expressa igualmente o seu reconhecimento. 


\section{Sumário Executivo}

O projeto que se apresenta neste relatório, tem como objetivo geral avaliar as determinantes sociais, económicas e de saúde do abuso de idosos em contexto de crise em Portugal. A opção por se empreender uma investigação neste âmbito decorreu do reconhecimento de que a relação entre os maus-tratos infligidos aos idosos e o contexto de crise socioeconómica que se viveu, sobretudo entre 2008 e 2011, a nível Europeu e, em particular, em Portugal, tem sido pouco estudada. A investigação realizada procurou, assim, evidenciar os efeitos da crise socioeconómica na população mais velha (60 e mais) e sua relação com o abuso de idosos, pelo que a sua relevância social reside no contributo que pode ter para colmatar a escassez de estudos e de investigação empírica que se observa, na sociedade portuguesa, acerca da referida relação, mas também na definição de um conjunto de recomendações dirigidas a todos os profissionais, em geral, e aos decisores de políticas sociais para a população idosa, em particular.

Mais especificamente, os objetivos analíticos que organizaram a investigação foram traçados em torno das seguintes dimensões centrais para o projeto: identificar os fatores que aumentam o risco de exposição de pessoas mais velhas a diferentes tipos de abuso e sua prevalência; avaliar as suas condições socioeconómicas e se o seu declínio conduziu à ocorrência de comportamentos agressivos e abusivos (e.g. abuso físico, psicológico, financeiro, sexual); analisar os indicadores gerais de saúde e em que medida o seu agravamento, por força do avançar da idade e de patologias diversas, os tornou mais vulneráveis à violência; caraterizar as áreas de residência dos idosos de acordo com o seu estatuto socioeconómico; avaliar se houve alteração da prevalência, dinâmicas e tipo de abusos entre os indivíduos da coorte EPIPorto que participaram no projeto "Abuse of the elderly in the European region" (ABUEL) (Soares et al., 2010a).

O desenho da investigação assentou numa abordagem metodológica mista, conduzindo à realização, num primeiro momento, de um estudo quantitativo, e posteriormente, de um estudo qualitativo. O suporte empírico da investigação teve por base uma coorte populacional da cidade Porto - EPIPorto, criada e coordenada pelo ISPUP, que acompanha 2485 residentes, com 18 ou mais anos, desde 1999. A nossa pesquisa incidiu sobre os idosos participantes na referida coorte $(\mathrm{N}=1222)$.

No seu conjunto esta amostra sustentou a análise extensiva, com o recurso à aplicação presencial de um inquérito por questionário a uma amostra final de 678 indivíduos com 60 e mais anos, para numa fase posterior, sustentar, de igual modo, a realização do estudo qualitativo, a partir da aplicação de 45 entrevistas semiestruturadas, para aprofundamento de algumas das dimensões analíticas supramencionadas. 
Os resultados evidenciam, que o abuso psicológico é o mais prevalente na nossa amostra $(19,9 \%)$, seguido do abuso financeiro $(5,6 \%)$, com as mulheres a destacarem-se no plano das ocorrências, embora não o suficiente para a diferença em relação aos homens ser estatisticamente significante. Os abusos são igualmente prevalentes nos diferentes grupos etários, nos contextos de conjugalidade ou coabitação com outras pessoas e/ou familiares, em diferentes níveis de escolaridade elevados. Onde a diferença emerge de forma claríssima é quando olhamos para os contextos materiais e financeiros em que os inquiridos vivem: a ocorrência de situações de abuso é substancialmente maior entre os que percebem o rendimento familiar como sendo insuficiente ou que pertencem a domicílios com insegurança alimentar. Igualmente significante é a relação entre a ocorrência e abuso e um conjunto de indicadores que remetem para o domínio do estado de saúde e bem-estar e para o campo dos comportamentos de autocuidado. Assim, os participantes que apresentam mais sintomas depressivos, que são mais negativos na avaliação do seu estado geral de saúde, que falham a toma de medicação ou tratamentos médicos, são aqueles onde as situações de abuso mais ocorrem. Quando considerada a redução de gastos/despesas do agregado familiar, bem como a alteração de determinadas circunstâncias da vida quotidiana, em virtude da crise económica, a prevalência de abuso aumenta, o que revela que a crise económica dos últimos anos aumentou significativamente o risco de exposição dos idosos ao abuso, nomeadamente daqueles que já se encontravam em situação de vulnerabilidade económica. Os resultados evidenciam ainda a existência de efeitos de acumulação de vulnerabilidade em torno da exposição ao abuso. Ou seja, a grande evidência alcançada com esta investigação, consiste em demonstrar que a vulnerabilidade se acumula naquilo que se designa por coocorrência de desvantagem, o que reforça a importância de as políticas sociais e de saúde colocarem no centro das suas agendas a problemática dos abusos entre a população mais velha tendo em conta precisamente tais desvantagens.

O Relatório está estruturado em cinco partes. A primeira corresponde ao enquadramento teórico e metodológico do estudo. Na segunda apresenta-se os principais resultados quantitativos relativos aos grandes objetivos do projeto e na terceira parte procede-se à apresentação do estudo qualitativo, ou seja, dos resultados das 45 entrevistas aplicadas aos participantes da amostra original do inquérito por questionário com vista ao aprofundamento das representações e significados que atribuem ao fenómeno dos abusos e violência sobre a população mais velha. Da triangulação metodológica aplicada neste estudo obteve-se conhecimento, simultaneamente, objetivo e significante sobre as determinantes sociais, económicas e de saúde do abuso e da violência sobre as pessoas mais velhas em Portugal.

Ao longo dos diversos pontos analíticos do relatório são apresentadas algumas narrativas de abuso e violência, que culminam, na última parte, com a apresentação de 
alguns recortes biográficos, dando-se assim voz aos principais interlocutores do presente estudo. O relatório é ainda composto por um conjunto de conclusões finais e de recomendações de forma a que as políticas sociais e de saúde relativas a esta problemática tenham em linha de conta precisamente as diferentes vulnerabilidades que se acumulam na idade avançada. 


\section{"Há dias que até olho para o espelho e gosto de mim, há outros dias que não gosto. Prontos, vivo assim".}

\section{(Isaura, 75 anos, casada, Ensino Básico)}

Isaura tem 75 anos e vive só com o marido que sofreu um AVC, razão pela qual gasta "muito dinheiro em medicação". Vale-Ihe ter sido sempre muito poupada, o que lhe permitiu apoiar os netos a quem dava o almoço em período escolar: "fazia tudo por eles e com todo o prazer". Vive "melhor agora" do que há 10 anos atrás. Não se trata de "ter fartura", tem "pró dia-a-dia" e não deve "nada a ninguém", mas ainda lhe "falta muita coisa". As suas condições de vida alteraramse, sobretudo com a doença do marido, aumentando os gastos com a medicação, alimentação, mas também com a renda da casa. A sua vida e a "de todos" foi muito afetada no período de crise económica, em Portugal. Apenas conseguiu ultrapassar essa fase porque diz ser uma pessoa cujo "viver é muito equilibrado". Não sendo "uma pessoa de passeios", há muita coisa que evita "comprar, porque os dinheiros não chegam". Porém, nunca precisou de "apoio nenhum". A deterioração da sua condição de saúde deve-se "à velhice" e não à crise económica que assolou o nosso país. Por essa razão, meteu-se "no ginásio três dias por semana", admitindo que se está "a sentir bem", tanto mais que encontra "pessoas com quem conversa e assim". Considera que, atualmente, não pode "dizer que vive pior" e que "não tem comparação possível" com a do tempo dos seus pais: "Antigamente a vida era muito má. A minha mãe foi uma pessoa de muito trabalho, de muitos sacrifícios para criar três filhos".

Para Isaura ser idoso é "olhar para o espelho e ver que não tem a cara que tinha". Reconhece que, com o avançar da idade, se sente "um bocado limitada": "não posso lavar uns vidros, não me posso pôr em cima de um banco, eu dantes fazia tudo", mas o pior é proibi-la de conduzir o seu automóvel: "o carro faz jeito por causa da saúde, até nem é para passear, é mais por causa do meu marido, para o trazer ao hospital". Refere que "é com a idade que se envelhece" e quando "olha para o espelho, aí, de facto" admite: "estou velha". No entanto, tem dias: se se "levanta maldisposta, nem quer ver o espelho"; se "dormir bem, acorda bem-disposta", olha "para o espelho e até gosta de se ver". A propósito das alterações físicas que a idade acarreta, conta já ter presenciado situações em que "duas mocitas novas", descritas como "egoístas", fizeram "troça" de uma Senhora de mais idade porque "o corpo delas não é igual ao nosso".

Embora refira, com orgulho, que "nem toda a gente tem a sorte de ter a família que eu tenho", Isaura confidencia que, nos primeiros anos do seu casamento, foi "vítima de agressões": "o meu marido era um bocado agressivo". Recordar a sua "história", fá-la sentir-se "triste", porém, reconhece que nunca ponderou abandonar o marido porque "precisava dele" para "criar" os filhos. Isaura assegura que o marido "podia fazer barulho, mas chegava ao fim do mês ou aos fins de semana e tinha sempre que dar". Fazer queixa à polícia também não foi opção: "acha que há 50 anos, à quase 60, que valia a pena a gente ir à polícia? Os polícias ainda se riam". Por isso, a "gente sofre calada". 


\section{I - Introdução: Enquadramento Teórico e Metodológico do estudo}

\section{Enquadramento Teórico}

Desde meados dos anos 1970 que o abuso de idosos tem vindo a conquistar uma atenção crescente, sendo reconhecido, atualmente, como um sério problema de saúde pública e, nos anos mais recentes, também como uma questão de direitos humanos (Podnieks et al., 2010). Tal reconhecimento, conduziu instituições internacionais relevantes, como é o caso da Organização Mundial da Saúde (OMS/WHO) e das Nações Unidas, a considerar que o abuso de idosos constituiu um dos comportamentos que afeta milhões de pessoas em todo o mundo, e que tem consequências graves a nível individual, familiar e social, contribuindo para o aumento das taxas de mortalidade e de morbilidade na idade avançada (Pillemer et al., 2016). Nos nossos dias, estima-se que 1 em cada 6 idosos tenha sofrido algum tipo de violência nos últimos 12 meses (WHO, 2017), e que em cerca de $90 \%$ dos casos os perpetradores têm uma relação de intimidade/parentesco com eles, embora também possam ser vítimas de violência em contexto institucional, sendo aqui a violência infligida por cuidadores formais e outros profissionais ligados à prestação de serviços e cuidados médico-sociais (Pillemer et al., 2016).

Os estudos disponíveis reportam diferentes níveis de prevalência de abuso de idosos nos países europeus (Lindert et al., 2013), atingindo, segundo Aseem et al. (2019), 61.1\%. Em Portugal, de acordo com o estudo Abuel (2009), o fenómeno tem uma prevalência de $27,4 \%$, ocorrendo maioritariamente entre as mulheres mais velhas $(29,6 \%)$, por comparação com os homens (24,4\%) (Fraga et al., 2014). Na linha desta preocupação, no nosso país, os estudos realizados têm-se focado quer na análise da prevalência do fenómeno, quer nas dinâmicas de violência vividas pelas vítimas com 60 e mais anos (Gil et al., 2014; Pires, 2009; Ferreira-Alves \& Santos, 2010; Soares et al., 2010; Fraga, Lucas, Costa \& Barros, 2013; Luoma et al., 2011). No entanto, outros estudos têm vindo a demonstrar que existe uma associação entre as desigualdades socioeconómicas (Fraga et al., 2014); a ausência de uma rede sociofamiliar de apoio; o declínio do estado de saúde geral e o abuso de idosos (Melchiorre et al., 2013; Soares et al., 2013). Atualmente a preocupação dirige-se para o abuso como uma violação dos direitos humanos, assim como para as questões de género associadas quer à maior longevidade das mulheres, quer à acumulação de um conjunto de experiências de discriminação e opressão acumuladas ao longo do ciclo de vida (WHO, 2002a). 
Como já foi antes referido, o ponto de partida deste projeto foi precisamente o reconhecimento da ausência de estudos que evidenciassem os efeitos da crise socioeconómica na população mais velha (60 e mais) e sua relação com o abuso de idosos, ocorrendo o trabalho de campo, já num período de recuperação económica em Portugal (2017).

\subsection{O abuso de idosos: definição do conceito, teorias e fatores de risco}

Tendo sido, inicialmente, designado por "granny battering" em 1975 na Grã-Bretanha, o conceito de abuso de idosos emergia para dar conta da violência perpetrada sobre as pessoas idosas, sobretudo em contexto familiar, o que fez com que fosse considerado, por algum tempo, como uma forma de violência doméstica (Baker, 1975; Mysyuk et al., 2013). Ficara, desde logo, aberta a porta para o debate, até hoje inacabado, acerca da sua definição. Porém, logo se evidenciou as suas limitações no campo da análise e intervenção, pois a atenção era sobretudo orientada para as mulheres idosas vulneráveis, dependentes, enfermando de visões estereotipadas e idadistas acerca da população mais velha (Mysyuk et al., 2013). O conceito foi, progressivamente, alargando o seu campo semântico e de aplicação, passando, nas décadas seguintes, a integrar, para além da agressão física, outros tipos de violência (e.g., psicológica, emocional, financeira, negligência, abandono), a considerar outros tipos de agressores (e.g., cuidadores formais, vizinhos, amigos), bem como a admitir a possibilidade de qualquer idoso, e não somente aqueles em situação de dependência ou vulnerabilidade socioeconómica, poder ser vítima potencial de violência (Mysyuk et al., 2013; Dias, Lopes \& Lemos, 2019a). A noção de abuso de idosos apresentada pela Action on Elder Abuse (1995), na Grã-Bretanha, e posteriormente adotada pela Organização Mundial da Saúde (OMS), não só marca a sua autonomia concetual e metodológica face ao conceito de violência doméstica e às limitações das suas formulações anteriores, como, nos anos 1990 e posteriores, acabou por ser a mais utilizada quer em meio académico, quer pelas agências internacionais e médico-sociais (Dias, Lopes \& Lemos, 2019a). Assim, na presente investigação foi operacionalizado o conceito de abuso de idosos tal como é definido pela OMS, o qual é entendido como "qualquer ato isolado ou repetido, ou ausência de uma ação apropriada, que ocorre no âmbito de qualquer relacionamento onde haja uma expetativa de confiança, causador de dano ou incómodo a uma pessoa idosa" (WHO, 2002a). Apesar das virtualidades acima descritas, reconhece-se que uma limitação ainda presente neste conceito reside no facto de não contemplar atos de violência aleatórios ou criminosos infligidos contra pessoas idosas, especialmente em espaço público (Dias, Lopes \& Lemos, 2019a). Ainda assim, o conceito revelou-se heurística e metodologicamente capaz de dar conta de uma grande variedade de ações e omissões que se expressam sob a forma de abuso físico (inclui atos que causam dor 
e/ou lesões físicas), abuso psicológico ou emocional (refere-se a ações que conduzem a um mal-estar psíquico, emocional e mental), abuso material ou financeiro (consiste na apropriação indevida dos recursos, bens e propriedades da pessoa idosa), abuso sexual (reporta-se a ações com carga sexual ou atividade sexual não consentida pelo idoso) e negligência ativa e passiva (consiste na não satisfação das necessidades de um idoso pondo em causa o seu bem-estar) (Pillemer et al., 2016; Gil et al., 2012). No plano empírico, este conceito e os seus diferentes tipos, foi medido através da Conflict Tactics Scales (CTS2) (Straus et al., 1996).

Ainda no contexto do desenvolvimento teórico, desde cedo, se constatou que a identificação de fatores de risco/fatores de proteção do abuso, era uma condição necessária para a implementação de programas de prevenção neste domínio (Pillemer et al., 2016). Assunção que conduziu ao desenvolvimento de várias perspetivas teóricas que identificavam os referidos fatores, a saber: as dinâmicas intra-individuais (foca-se na interação entre os cuidadores informais e as características comportamentais e de saúde dos idosos); a transmissão intergeracional do comportamento violento (salienta o risco de exposição a comportamentos violentos na infância e a probabilidade da sua reprodução na idade adulta); o stress dos cuidadores (identifica acontecimentos vividos pelos indivíduos na estrutura social que são potenciadores de stress e conflitualidade) e a perspetiva do isolamento social (enfatiza a ausência de redes sociais como fatores de risco) (Wolf e Pillemer, 1989).

Não obstante a ausência de teorias explicativas integradas neste âmbito, atualmente, o modelo sociológico veio acrescentar aos fatores de risco supramencionados, a incapacidade funcional e mental da pessoa idosa; problemas de saúde mental no cuidador; problemas económicos; comportamentos aditivos do agressor (e.g., alcoolismo, toxicodependência, vício do jogo); situações de isolamento, pobreza e exclusão social, entre outros (Dias, Lopes \& Lemos, 2019b). Por seu turno, o modelo socioecológico, largamente utilizado pela OMS, vê o abuso de idosos como um fenómeno complexo ancorado numa configuração analítica multinível composta por subsistemas distintos, nomeadamente: o nível macro (e.g., determinantes estruturais e sistema de crenças, normas e atitudes face à pessoa idosa); exo e meso (e.g., sistema de relações de trabalho, redes sociais de suporte formal e informal) e o nível micro (e.g., tipo de relações familiares conjugais, filiais, contexto familiar, isolamento social) (Gil, 2014; Schiamberg \& Gans, 1999; Dias, Lopes \& Lemos, 2019a).

Apesar de reconhecermos a robustez do modelo socioecológico, enquanto teoria integradora com capacidade para explicar a heterogeneidade dos fatores subjacentes ao abuso de idosos, a presente investigação também teve por referência o contributo de quadros concetuais que propõem argumentos alternativos, nomeadamente as 
teorias feministas que dão conta que as desigualdades de género e a exposição das mulheres aos ciclos de pobreza e a carreiras contributivas precárias e irregulares, expõem-nas, na idade avançada, mais do que aos homens, a situações de exclusão social e de violência (Whittaker, 1995). As teorias feministas enfatizam assim a necessidade de a pesquisa nesta área prestar mais atenção ao impacto conjugado do idadismo, sexismo e patriarcalismo também na idade avançada, mostrando que muitos dos fatores de risco existentes em relações abusivas continuam a estar presentes na idade avançada. Estas teorias consideram ainda que o conceito de abuso de idosos permanece neutro do ponto de vista do género, o que obscurece o facto de as vítimas mais velhas serem frequentemente as mulheres e os ofensores continuarem a ser homens, embora não exclusivamente (WHO, 2002b). 


\section{Enquadramento Metodológico}

\subsection{Métodos e desenho da investigação}

Para a realização do presente estudo, recorreu-se a uma abordagem metodológica mista, através da recolha de dados de natureza quantitativa e qualitativa. Na primeira fase da investigação, foi aplicado um inquérito por questionário a uma amostra de idosos que integram a coorte EPIPorto (ISPUP), e que foram anteriormente avaliados no estudo "Abuse of the elderly in the European Region" (ABUEL) ${ }^{1}$ (Soares et. al, 2010). Esta fase envolveu a aplicação de um inquérito por questionário a uma amostra final de 677 participantes, com o recurso ao método CAPI (Computer Assisted Personal Interviewing).

O questionário é composto por 16 dimensões analíticas centrais para a demonstração dos objetivos deste projeto, designadamente: 1 . Características sociodemográficas dos participantes; 2. Características da habitação; 3. Estilos de vida: tabaco e álcool; 4. Refeições; 5. Suporte social percebido (MSPSS- Multidimensional scale of perceived social support); 6. Utilização de cuidados de saúde e de apoio social; 7. Doenças; 8. Medicação; 9. Dores físicas/estado físico (GBB-24); 10. Qualidade de vida (World Health Quality of Life - WHOQOL - OLD); 11. Geriatric Depression Scale: Short Form; 12. Stressful Life Events Screening Questionnaire; 13. Violência/abuso/negligência; 14. Atividades de lazer; 15. Caracterização socioeconómica; 16. Religião. Paralelamente foram preservadas as variáveis que permitissem assegurar a comparabilidade dos resultados do projeto HARMED com os do projeto ABUEL (Soares et. al, 2010).

Na segunda fase do projeto foi desenvolvido um estudo qualitativo, complementar, sustentado na aplicação de entrevistas em profundidade a alguns idosos selecionados a partir da amostra original. Sendo definida como um método que permite o acesso aos significados atribuídos pelos sujeitos ao fenómeno em análise, a entrevista em profundidade emergiu como um modo de questionamento e de escuta atenta, proporcionando, por isso, neste projeto, conhecimento igualmente testável (Kvale, 1996).

\subsection{Amostra e procedimentos}

Como foi antes referido, a seleção dos participantes neste estudo teve por base a coorte EPIPorto, criada e coordenada pelo ISPUP, que acompanha, desde 1999, 2485 residentes na cidade do Porto - Portugal, com 18 ou mais anos. Trabalhou-se com dados em painel

\footnotetext{
${ }^{1}$ Abuse of the elderly in the European region (ABUEL): é um estudo transversal Europeu que incluiu durante janeiro a julho de 2009 participantes com idades compreendidas entre os 60-84 anos, residentes na Alemanha, Grécia, Itália, Lituânia, Portugal, Espanha e Suécia (Soares et al., 2010).
} 
no sentido em que este estudo faz parte de uma sequência de avaliações realizadas à referida base. A primeira reavaliação ocorreu entre 2005-2008, através do projeto ABUEL (Soares et. al, 2010), a segunda entre 2014-2015 e a terceira integra o presente estudo, o qual contou com 1222 indivíduos que cumpriam o critério idade (ter 60 anos ou mais), no período da sua realização (2017-2018). Entre os participantes elegíveis, 244 recusaram participar e 281 nunca se conseguiu contatar (e.g. alteração da residência ou do contato telefónico, falecimento). Dos 697 indivíduos que aceitaram, 19 foram excluídos após a aplicação do Mini-Mental State Examination score <24 (Folstein M.F., Folstein, S. E. \& McHugh, 1975), pelo que se obteve uma amostra final de 678 participantes. Um dos participantes acabaria por não responder ao questionário na totalidade pelo que a amostra final com informação completa foi de 677 indivíduos.

Neste estudo foram seguidos os procedimentos de contacto com os participantes estabelecidos no protocolo da coorte EPIPorto (ISPUP) (Ramos, E; Lopes, C. \& Barros, H., 2004). Inicialmente, foi enviada uma carta de apresentação do estudo a todos aqueles que preenchiam o requisito de elegibilidade. Posteriormente, fez-se um novo contato, por telefone, com vista ao agendamento da aplicação dos questionários. Estes foram administrados presencialmente através do método CAPI (Computer Assisted Personal Interviewing), nas instalações do Departamento de Ciências da Saúde Pública e Forenses, e Educação Médica da Faculdade de Medicina da Universidade do Porto. Antes da aplicação dos mesmos era feita a colheita de vestígios biológicos (urina e sangue) e a realização de exames físicos sob a responsabilidade de profissionais de saúde, assim como era avaliado o estado cognitivo dos participantes através do MiniMental State Examination score <24 (Folstein M.F., Folstein, S. E. \& McHugh, 1975). No caso dos idosos com reduzida mobilidade ou que manifestavam qualquer tipo de indisponibilidade, era-lhes proposto a possibilidade de os entrevistadores se deslocarem aos seus domicílios.

Concluído o trabalho de aplicação dos inquéritos por questionário, e já em posse dos resultados preliminares, avançou-se para o estudo qualitativo. Neste âmbito, foram realizadas 45 entrevistas semiestruturadas em profundidade, a idosos selecionados a partir da amostra original. Nesta fase, e tendo igualmente por referência a necessidade de dar cumprimento ao objetivo de assegurar alguma comparabilidade entre os resultados deste projeto e os do estudo ABUEL (Soares et. al, 2010), a equipa de investigação identificou, na base, a existência de perfis diversificados no que concerne à vivência de abusos, os quais serviram de ponto de partida para a constituição de uma amostra qualitativa final de 45 participantes, designadamente: i) apresentar experiência de vitimização desde 2009; ii) ter tido experiência de vitimização na avaliação de 2009 mas não em 2017; iii) não ser vítima na avaliação de 2009, mas sim em 2017; iv) sem experiência de vitimização na avaliação de 2009 e de 2017; e, por fim, primeira vez que 
um membro da coorte EPIPorto participa na avaliação dos 60 anos e mais e é sinalizado como vítima em 2017. A partir destes critérios foram selecionados 20 homens e 25 mulheres, com idades compreendidas entre os 60 e os 85 anos e mais. Foi cumprido o requisito metodológico de saturação empírica da amostra, o qual permitiu a generalização dos resultados qualitativos ao grupo de idosos participante, ou seja, permitiu a sua generalização empírico-analítica (Guerra, 2006).

Assim, foi construído um guião comum aplicável à diversidade dos perfis dos participantes na amostra qualitativa, tendo-lhes sido proposto que abordassem alguns tópicos, antes evidenciados aquando da aplicação do questionário e da análise quantitativa dos resultados, desejando-se, através das entrevistas, o seu aprofundamento. Para o efeito, o guião foi composto essencialmente por duas grandes dimensões temáticas: 1. Perceção sobre as condições socioeconómicas; 2. Representações sociais sobre o fenómeno do abuso de idosos. No âmbito da primeira dimensão, foi possível aprofundar os seguintes subtemas: avaliação das condições de vida na atualidade e há 10 anos atrás; domínios em que as condições de vida se alteraram; perceção do impacto da crise económica e domínios de agravamento; apoios no período de crise económica em Portugal; impacto da crise económica na saúde. No grande tema das "Representações sociais sobre o fenómeno do abuso de idosos", foram colocadas questões sobre o grau de conhecimento do fenómeno da violência contra pessoas idosas, contextos e razões de ocorrência, tipos de violência e de agressores, sentimentos face ao fenómeno, reações das vítimas, meio social e redes de vizinhança, papel do Estado, políticas sociais, saúde, segurança, autoproteção, expetativas e bemestar.

O contato dos idosos obedeceu igualmente aos princípios estipulados no protocolo da coorte EPIPorto (Ramos, E; Lopes, C. \& Barros, H., 2004). Todas as entrevistas foram realizadas nas instalações do Departamento de Ciências da Saúde Pública e Forenses, e Educação Médica da Faculdade de Medicina da Universidade do Porto, sob a garantia de anonimato e confidencialidade da informação, salvaguardada pela assinatura prévia da Declaração do Consentimento Informado.

Algumas limitações do estudo devem ser consideradas, nomeadamente as experiências de abuso foram autoreportadas, o que pode ter contribuído para subestimar a prevalência desses comportamentos devido à representação de conveniência social. A divulgação de experiências de violência depende muito da disponibilidade e vontade do indivíduo em reconhecer o seu envolvimento numa situação violenta. Além disso, a violência doméstica é um crime público em Portugal, o que contribuiu para aumentar a consciência social sobre o problema, mas, por outro lado, também reforça a necessidade da sua ocultação. No entanto, os procedimentos do estudo foram apropriados às 
diretrizes da OMS (WHO, 2002a) e as entrevistas foram realizadas por entrevistadores treinados, pelo que acreditamos que tal contribuiu para minimizar o possível viés de subnotificação.

As entrevistas foram gravadas e integralmente transcritas. A sua codificação e tratamento foi realizada com o apoio do Software NVivo 12, adequado a estudos qualitativos e a informação não estruturada, como é o caso das entrevistas em profundidade. Seguiu-se uma análise de conteúdo temática e a elaboração de pequenas narrativas, num registo biográfico (Gonçalves, 2000), que permitem a ilustração de representações e vivências de abuso em contexto de crise socioeconómica em Portugal.

\subsection{Medidas}

\subsubsection{Variáveis e escalas}

Foi recolhida informação sociodemográfica através das seguintes variáveis: sexo, idade, nível de escolaridade, composição do agregado familiar, estado civil, profissão e condição perante o trabalho. A variável idade foi agregada em três escalões etários (6069; 70-79 e mais de 79 anos). Pontualmente, e quando se pretendeu uma análise mais fina, intervalos etários de menor amplitude foram considerados. A variável nível de escolaridade, originalmente, era composta por 11 níveis, no entanto, foi agregada para três tendo por base o ISCED 2011- International Standard Classification of Education (ISCED 0-1= Escolaridade baixa; ISCED 2-3= Escolaridade média; ISCED 4-8=Escolaridade alta) ${ }^{2}$. A variável estado civil também foi reagrupada, tendo sido colocados no mesmo grupo os indivíduos que, à data do inquérito, não viviam em conjugalidade (viúvos, separados/divorciados e solteiros) e os que viviam em conjugalidade (casados e união de facto). Esta opção metodológica decorreu do facto se ser central, no presente estudo, identificar o efeito da presença de um cônjuge ou equivalente na probabilidade de ocorrer violência, daí a opção pelo agrupamento proposto, o que poderá ser, ainda assim, questionado, pois na literatura o idoso «solteiro» também é destacado como uma vítima particularmente vulnerável à violência e ao abuso. Por seu turno, a classificação das profissões foi realizada com o recurso à Classificação Nacional das Profissões 2010 (INE, 2015).

A condição socioeconómica dos participantes foi avaliada através da principal fonte de rendimento dos inquiridos (e.g., salários e vencimentos do trabalho; pensão de reforma;

\footnotetext{
2 ISCED 0-1= Escolaridade baixa (Educação pré-escolar- Ensino básico 2.o ciclo); ISCED 2-3= Escolaridade média (Ensino básico 3. ciclo-Ensino secundário); ISCED 4-8=Escolaridade alta (Ensino pós-secundárioEnsino superior - doutoramento pré-Bolonha). Ver Deliberação no343/2017 publicada em DR no84/2017, Série II de 2017-05-02.
} 
pensão de reforma por invalidez; pensão de pré-reforma; outras fontes de rendimento; não tem qualquer apoio financeiro); do rendimento por adulto equivalente (resulta da ponderação do rendimento médio mensal do agregado familiar pela dimensão do agregado harmonizada de acordo com a escala modificada da OCDE: peso do 10 adulto $=1$; peso dos adultos seguintes $=0,5$; peso de cada criança $=0,3)$, o qual foi categorizado em três escalões: elevado (>1500€; intermédio=1001-1500€; baixo=<1001€).

Através da variável perceção sobre o rendimento atual procurou-se aferir a avaliação subjetiva do inquirido em relação à capacidade financeira do seu agregado familiar para fazer face às despesas, a partir de quatro categorias ( $O$ rendimento atual permite viver confortavelmente; O rendimento atual dá para viver; É difícil viver com o rendimento atual; É muito difícil viver com o rendimento atual). Esta variável foi transformada numa variável sintetizada, denominada "perceção do rendimento do agregado como insuficiente», composta por duas categorias: sim (que agrega os níveis da variável original "é difícil viver com o rendimento atual» e "é muito difícil viver com o rendimento atual»); e não (que agrega os níveis "o rendimento atual permite viver confortavelmente» e "o rendimento atual dá para viver»). Mediu-se igualmente a segurança alimentar do agregado familiar através do indicador US Household Food Security Survey Module, Economic Research Service (2006), composto por três categorias: Segurança alimentar alta ou ligeira; Segurança alimentar baixa; Segurança alimentar muito baixa (Blumberg, Bialostosky, Hamilton e Briefel, 1999).

Foi, de igual modo, avaliado o suporte social e a qualidade de vida dos participantes. No primeiro caso, recorreu-se à escala multidimensional de suporte social percebido (MSPSS). Trata-se de uma escala de autorrelato por 12 itens, cujas respostas são fornecidas numa escala de tipo Likert de 7 pontos, que varia entre 1 (Discordo completamente) e 7 (Concordo completamente) (Zimet et al., 1988), correspondendo elevadas pontuações (num total de 84 pontos) a um suporte social alto. Em Portugal, a escala foi validada por Carvalho et al. (2011).

Por seu turno, a qualidade de vida foi medida a partir da escala proposta pela WHOWorld Health Organization Quality of Life Group, nomeadamente através do módulo WHOQOL-OLD destinado a adultos idosos (Power et al., 2005; World Health Organization, 2006; Fleck et al., 2006). Esta escala é composta por 24 itens, medidos através de uma escala de tipo Likert com valores entre 1 e 5 pontos. Os 24 itens estão segmentados em seis facetas (com 4 questões cada), nomeadamente: i) Capacidades Sensoriais - Funcionamento sensorial, impacto da perda de capacidades sensoriais na qualidade de vida; ii) Autonomia - Independência na velhice, capacidade ou liberdade de viver de forma autónoma e de tomada de decisões; iii) Atividades do passado, presente e do futuro - Satisfação em relação às conquistas na vida e coisas a que se 
anseia; iv) Participação social - Participação nas atividades quotidianas, especialmente na comunidade; v) Morte e morrer - Preocupações, inquietações e temores sobre a morte e sobre morrer; vi) Intimidade - Capacidade de ter relacionamentos pessoais e íntimos. As pontuações mais baixas representam uma baixa qualidade de vida e as mais elevadas correspondem uma qualidade de vida alta.

As pontuações das facetas foram apresentadas de três formas diferentes, a saber: i) a partir da soma dos valores pertencentes a cada um dos 4 itens de cada faceta (podendo variar entre 4 e 20); ii) a pontuação média relativa a cada item (variando entre 1 e 5); iii) a pontuação transformada, que é calculada a partir da conversão da pontuação bruta para uma escala de 0 a 100.

A presença de sintomas depressivos entre os participantes foi avaliada através da Escala de Depressão Geriátrica (15 itens) validada para a população portuguesa (Sheikh \& Yesavage, 1986; Pocinho, Farate, Dias, Lee \& Yesavage, 2009). Das 15 questões, 10 indicam a presença de depressão quando respondidas positivamente, enquanto as demais (questões $1,5,7,11,13$ ) indicam depressão quando negativamente respondidas. As pontuações superiores a 4 indicam depressão. A partir da referida escala desenvolveu-se uma escala agregada de depressão geriátrica composta por quatro categorias. Mais concretamente, na primeira (Sem depressão), foram agrupados os scores entre 0 e 4, representando assim os inquiridos que não apresentam depressão; na segunda (Depressão leve), os scores entre 5 e 8; na terceira (Depressão moderada), os scores entre 9 e 11; e na quarta (Depressão severa), os scores entre 12 e 15.

A exposição dos participantes ao longo da vida a eventos traumáticos foi medida através do Stressful Life Events Screening Questionnaire (Goodman et al., 1998). Trata-se de uma medida de autorrelato composta por 13 itens, incidindo 11 sobre categorias específicas de eventos e dois deles sobre acontecimentos gerais como, por exemplo, um acidente ou doença com risco de vida, a morte de um parente ou amigo próximo, o abuso físico ou sexual de um familiar. Para cada evento, os participantes indicavam "sim" ou "não".

Por último, o abuso contra pessoas idosas foi avaliado, na nossa amostra, a partir de 52 questões baseadas na Conflict Tactic Scales 2 (CTS 2) (Straus et al., 1996), bem como no inquérito britânico sobre abuso/negligência de idosos (O'Keeffe et al., 2007). Mais concretamente, o abuso psicológico foi medido a partir de 11 questões (e.g., "alguém o(a) insultou ou lhe praguejou; o(a)rebaixou ou menosprezou o que o(a) Senhor(a) faz?"), das quais 6 consubstanciavam atos graves. O abuso físico foi medido através de 17 questões (e.g., "[...] alguém usou uma faca, uma pistola ou outra arma contra si?"), das quais 10 compreendiam atos graves. 0 abuso físico com lesão, foi avaliado em 7 questões (e.g., "[...] desmaiou porque Ihe bateram na cabeça?"), das quais 4 
compreendiam atos graves; o abuso sexual, em 8 questões (e.g., "[...] tentou ter relações sexuais consigo contra a sua vontade?"), das quais 5 consubstanciavam atos graves; e o abuso financeiro envolveu a resposta a 9 questões (e.g., "[...] tentou, através de fraude, tirar-Ihe dinheiro, bens materiais ou propriedades?"), das quais 5 compreendiam atos graves.

Os atos de abuso podem ter ocorrido uma vez, duas vezes, 3 a 5, 6 a 10, 11 a 20 ou mais de 20 vezes nos últimos 12 meses. No entanto, também era apresentada a hipótese de, tendo acontecido, não terem ocorrido nos últimos 12 meses. Para cada um dos comportamentos abusivos respondidos positivamente, foi solicitado aos participantes que indicassem pelo menos um agressor, que podia incluir o cônjuge/companheiro(a), filhos(as), netos(as), genros e noras, outros membros da família, vizinhos, amigos, colegas de trabalho, profissionais dos sectores médico e social, outros profissionais remunerados ou ainda outras pessoas.

\subsubsection{Análise dos dados}

Os dados foram analisados por intermédio de técnicas descritivas (e.g., médias, percentagem). As diferenças entre as variáveis categoriais foram calculadas usando a estatística qui-quadrado e foi considerado estatisticamente significativo o valor $p<0,05$. Para estas foram também calculados os odds ratio brutos e os valores do risco relativo. As diferenças para variáveis contínuas foram avaliadas em termos de significância estatística com recurso a testes de hipóteses paramétricos ou com os equivalentes não paramétricos quando os pressupostos dos primeiros não foram verificados. A análise foi realizada com o recurso ao SPSS v. 26 (IBM Corp, 2016).

\subsubsection{Questões éticas}

O projeto HARMED - O abuso de idosos: determinantes sociais, económicas e de saúde, foi aprovado pela Comissão de Ética para a Saúde do Centro Hospitalar de São João/Faculdade de Medicina da Universidade do Porto a 6 de janeiro de 2016. A salvaguarda dos princípios de confidencialidade dos dados, anonimato e de uma participação voluntária e informada no estudo, foi garantida através dos documentos designados por "Informação ao Participante" e "Declaração do Consentimento Informado". Estes documentos eram apresentados aos participantes antes da aplicação do questionário. Na circunstância de ser identificado um caso positivo de abuso, eram consideradas as diretrizes da OMS para a investigação da violência (WHO, 2001). 


\section{"O idoso às vezes é considerado uma espécie de empecilho".}

(Manuel, 70 anos, casado, Ensino Básico)

Manuel considera que há "pouco cuidado com as pessoas de idade". Desde logo, comportamentos expectados em sociedade, como a cedência de "lugar no autocarro", são desrespeitados, bem como as próprias famílias que "desprezam um bocado a terceira idade, é assim uma coisa um bocado descartável". A nível pessoal, contraria esta visão mais pessimista, demonstrando como aprendeu a apreciar esta fase da vida: "tenho o tempo completamente livre e isso para mim, se calhar até é o melhor da reforma, é a falta de compromisso com horas, com tarefas, eu se me apetecer faço, se não me apetecer, não faço". Porém, outros reformados: "sentem-se inúteis, sentem que já estão arrumados, eu felizmente não me sinto assim". 0 aspeto negativo que aponta tem a ver com a natural deterioração do seu estado de saúde: "Umas dorezinhas aqui e acolá", o que não o impede de manter-se ativo: "Faço caminhada há muitos anos, mas noto que tenho que adequar o exercício à idade e à capacidade física, mas sinto-me bem". Quanto à relação com a sua família, apesar de não manter "um convívio muito estreito", refere que "as coisas estão normais, pelo menos, há uma relação de amizade". No futuro, caso perca a autonomia, pondera "arranjar um sítio para onde ir e estar bem", embora Ihe "agradasse muito mais estar em casa".

O período de crise económica forçou Manuel a reduzir "alguns gastos, mais ou menos, considerados supérfluos", como férias e viagens, mas também outro tipo de consumos, nomeadamente a "eletricidade", usando "menos o aquecimento". Assume ter sentido "alguma ansiedade e ter mais cuidado com as contas", afirmando que isso o "perturbava um bocado". Durante a crise garantiu, também, apoio financeiro ao filho.

A crise agravou a situação de violência contra as pessoas mais velhas: "Quem sofreu foram os idosos. Por um lado, porque já tinham pouco rendimento e, por outro, porque aqueles familiares que até tinham algum rendimento começaram a exercer alguma pressão no sentido de obterem mais dinheiro". Esta situação pode, contudo, variar consoante a família, já que nas "famílias mais carenciadas" há "uma violência, digamos, mais visível e mais selvagem", enquanto nas famílias de "outro patamar, são coisas assim menos visíveis, mais camufladas". Para Manuel, a proteção dos adultos mais velhos pode consolidar-se com a existência de uma rede social de suporte, uma vez que "as pessoas isoladas são ainda mais vulneráveis". 


\section{II - Estudo quantitativo: Determinantes sociais, económicas e de saúde do abuso de idosos}

\section{Principais Resultados e Discussão}

A apresentação dos resultados decorrentes do estudo quantitativo corresponde a um formato que se considerou o mais adequado para salientar a demonstração dos diferentes objetivos analíticos que o presente projeto integra. Embora sejam apresentados em pontos autónomos, os resultados mantêm uma interdependência interna, por força das opções teóricas e metodológicas que sustentaram a sua análise. A sua prossecução conduziu a um enfoque analítico que partiu, num primeiro momento, da caracterização sociodemográfica e da situação socioeconómica dos participantes no inquérito por questionário.

A descrição dos resultados centrou-se, no segundo momento, nas dimensões ligadas aos principais objetivos do projeto e está organizada nas seguintes seções: caracterização sociodemográfica e socioeconómica da amostra inquirida; análise das condições de saúde e bem-estar, físico e psicológico da amostra inquirida; prevalência de abuso e suas determinantes socioeconómicas e de saúde; análise dos perfis dos agressores; discussão sobre reações ao abuso; análise dos impactos da crise económica na prevalência de abuso; discussão sobre os efeitos do abuso no estado de saúde física e psicológica dos participantes. $O$ estudo quantitativo termina com uma síntese geral das principais conclusões. 


\section{Características sociodemográficas, económicas, psicossociais e de habitação dos participantes no inquérito por questionário}

\subsection{Caracterização sociodemográfica}

No presente estudo foram aplicados 678 inquéritos por questionário a uma amostra de idosos com idades entre os 60 e os 95 anos.

Quadro 1. Caracterização sociodemográfica da amostra

\begin{tabular}{|c|c|c|}
\hline & $\mathbf{n}$ & $\%$ \\
\hline \multicolumn{3}{|l|}{ Sexo } \\
\hline Feminino & 428 & 63,1 \\
\hline Masculino & 250 & 36,9 \\
\hline \multicolumn{3}{|l|}{ Grupos etários agregados } \\
\hline$<70$ anos & 306 & 45,1 \\
\hline 70 a 79 anos & 244 & 36,0 \\
\hline$>79$ anos & 128 & 18,9 \\
\hline \multicolumn{3}{|l|}{ Estado civil } \\
\hline Solteiro(a) & 32 & 4,7 \\
\hline Casado(a) & 417 & 61,5 \\
\hline União de facto & 2 & 0,3 \\
\hline Divorciado(a)/Separado(a) & 73 & 10,8 \\
\hline Viúvo(a) & 154 & 22,7 \\
\hline \multicolumn{3}{|l|}{ Tem filhos } \\
\hline Sim & 610 & 90,1 \\
\hline Não & 67 & 9,9 \\
\hline \multicolumn{3}{|l|}{ Composição do agregado doméstico } \\
\hline Vive sozinho(a) & 153 & 22,6 \\
\hline Vive apenas com Marido/Esposa/Companheiro(a) & 320 & 47,3 \\
\hline Vive com Marido/Esposa/Companheiro(a) e com filho(s) & 90 & 13,3 \\
\hline Vive com Marido/Esposa/Companheiro(a) e com outros familiares & 20 & 3,0 \\
\hline Vive com filhos & 65 & 9,6 \\
\hline Vive com outros familiares/outras pessoas & 29 & 4,3 \\
\hline \multicolumn{3}{|l|}{ Nível de escolaridade* } \\
\hline Baixo (ISCED 0 a 1) & 248 & 36,6 \\
\hline Médio (ISCED 2 e 3) & 157 & 23,2 \\
\hline Alto (ISCED 4 a 8) & 272 & 40,2 \\
\hline
\end{tabular}

Como traço geral, esta é uma amostra que reflete as principais características da composição sociodemográfica do grupo populacional representado, com um peso maior do grupo feminino, com uma distribuição equilibrada pelos grupos etários longevos, 
destacando-se o peso significativo do grupo dos mais velhos entre os mais velhos (quase 1 em cada 4 inquiridos tinha 80 ou mais anos). Na amostra há um peso claramente maior dos que vivem em conjugalidade, com o grupo dos viúvos a adquirir uma projeção também importante, de resto expectável dado o grupo etário em foco.

No que diz respeito aos contextos familiares onde os inquiridos vivem, estres refletem, em certa medida, o estado civil dos mesmos, com uma incidência de indivíduos a viverem sozinhos que decalca a tendência nacional e com um peso substancial dos que vivem com cônjuge/companheiro. A esmagadora maioria declarou ter filhos.

O indicador onde a amostra construída para o estudo apresenta alguns elementos de distinção é no indicador relativo ao nível de escolaridade. De facto, e contrariando uma certa literatura que vem destacando os generalizadamente baixos níveis de escolaridade da população mais velha em Portugal, na amostra do estudo HARMED existe um desequilíbrio favorável aos níveis de escolaridade mais elevados. Não existe evidência suficiente para poder afirmar uma explicação para este facto. Podemos estar perante um efeito de enviesamento amostral intrínseco ao painel, ou podemos estar perante um fenómeno de atrição amostral onde as desigualdades sociais na saúde se estejam a manifestar. Neste espaço apenas se podem avançar com hipóteses.

Quadro 2. Condição perante o trabalho

\begin{tabular}{lcc}
\hline Condição perante o trabalho & $\mathbf{n}$ & $\mathbf{\%}$ \\
\hline Exerce uma profissão a tempo inteiro & 83 & 12,2 \\
Exerce uma profissão a tempo parcial & 21 & 3,1 \\
Desempregado(a) & 10 & 1,5 \\
Doméstica(o) / Ocupa-se exclusivamente das tarefas do lar & 37 & 5,5 \\
Reformado(a) & 509 & 75,1 \\
Incapacitado(a) para o trabalho / Invalidez & 18 & 2,7 \\
\hline Total & 678 & 100,0 \\
\hline
\end{tabular}

Sobre a condição atual perante o trabalho, considerando o tipo de população alvo do estudo, 3 em cada 4 inquiridos encontra-se reformado (75,1\%) (Quadro 2). No entanto, $12,2 \%$ ainda exerce uma profissão a tempo inteiro. As restantes categorias apresentam valores residuais.

A análise das profissões dos inquiridos foi desenvolvida com recurso à Classificação Nacional das Profissões (INE, 2015). As profissões enquadradas na categoria dos especialistas das atividades intelectuais e científicas são predominantes na amostra $(26,0 \%)$ (Quadro 3). O segundo grupo profissional mais representado é o do pessoal administrativo $(17,2 \%)$, seguido pelos trabalhadores dos serviços pessoais, de proteção e segurança e vendedores $(14,0 \%)$ e pelos técnicos e profissões de nível intermédio 
$(11,2 \%)$. Cada um dos restantes grupos profissionais apresenta uma proporção inferior a $10 \%$.

Quadro 3. Profissão (atual ou última antes de situação de desemprego, incapacidade para o trabalho ou reforma) segundo a Classificação Nacional das Profissões

\begin{tabular}{lcc}
\hline Profissão (atual ou última) & $\mathbf{n}$ & $\mathbf{\%}$ \\
\hline Representantes do poder legislativo e de órgãos executivos, dirigentes, & 40 & 6,3 \\
diretores e gestores executivos & 165 & 26,0 \\
Especialistas das atividades intelectuais e científicas & 71 & 11,2 \\
Técnicos e profissões de nível intermédio & 109 & 17,2 \\
Pessoal administrativo & 89 & 14,0 \\
Trabalhadores dos serviços pessoais, de proteção e segurança e & 62 & 9,8 \\
vendedores & 43 & 6,8 \\
Trabalhadores qualificados da indústria, construção e artífices & 55 & 8,7 \\
Operadores de instalações e máquinas e trabalhadores da montagem & 634 & 100,0 \\
Trabalhadores não qualificados & $\quad$ enquadramento numa das categorias profissionais & \\
\hline Total & & \\
\hline Nota: existe 1 caso omisso na questão do nível de escolaridade e 43 casos na classificação das profissões &
\end{tabular}

Em síntese, a amostra do estudo é composta na sua maioria por mulheres (63,1\%). No que diz respeito à idade, a maioria dos inquiridos tem menos de 75 anos de idade $(66,4 \%)$ e são casados ou em união de facto (61,8\%). Em termos de escolaridade, trata-se de uma amostra marcada por níveis sobretudo médios a elevados $(63,4 \%)$, indicador que acaba depois por estar ligado ao tipo de profissão exercida (no presente ou no passado), com relevo para profissões de qualificação intermédia e elevada, nomeadamente os especialistas das atividades intelectuais e científicas $(26,0 \%)$ e pessoal administrativo (17,2\%). A maioria encontra-se reformada (75,1\%), situação que é expectável tendo em consideração que a população alvo do estudo tem 60 ou mais anos. Finalmente, no que concerne à forma como os indivíduos se organizam em agregados familiares, $77,4 \%$ vive com a companhia de outras pessoas, no entanto, $22,6 \%$ vivem em agregados unipessoais.

\subsection{Caracterização socioeconómica dos participantes}

Neste ponto, apresenta-se um conjunto de indicadores que permitem uma caracterização socioeconómica da amostra do estudo quantitativo. A pensão de reforma por velhice surge, como se esperaria, como a fonte principal de rendimentos para a maioria dos inquiridos (64,0\%). É ainda de salientar que 14,5\% aufere salários e/ou vencimentos do trabalho e $8,0 \%$ menciona outras fontes de rendimento (Quadro 4). 
Quadro 4. Principal fonte de rendimentos do inquirido

\begin{tabular}{lcc}
\hline Principal fonte de rendimento do inquirido & $\mathbf{n}$ & $\mathbf{\%}$ \\
\hline Pensão de reforma por idade & 433 & 64,0 \\
Salários e vencimentos do trabalho & 98 & 14,5 \\
Pensão de reforma por invalidez & 44 & 6,5 \\
Pensão de pré-reforma & 23 & 3,4 \\
Pensão de viuvez & 19 & 2,8 \\
Outras fontes de rendimento ${ }^{3}$ & 54 & 8,0 \\
Não tem qualquer apoio financeiro & 6 & 0,9 \\
\hline Total & 677 & 100,0 \\
\hline \multicolumn{2}{c}{ Nota: Existe um caso omisso que corresponde a resposta "recusa". }
\end{tabular}

Obteve-se igualmente informação sobre a principal fonte de rendimento considerando todas as pessoas que compõem o agregado familiar. A distribuição desta variável acompanha a tendência descrita anteriormente, sendo a pensão de reforma por idade $(59,4 \%)$ a mais assinalada, seguida pelos salários e/ou vencimentos do trabalho $(23,1 \%)$ e outras fontes de rendimento (5,6\%) (Ver Quadro 5). As duas distribuições em conjunto afirmam, sem margem para dúvida, a importância das transferências sociais nos modos de vida quotidianos da nossa amostra, sendo, por isso, expectável que flutuações nessas transferências (nomeadamente as decorrentes de cortes em período de austeridade) se saldem num abaixamento relevante das condições materiais-financeiras dos respetivos agregados familiares. Isso, combinado com a razoável falta de elasticidade dos rendimentos nesta franja etária, marca o contexto de referência no estudo para avaliação dos impactos das condições económicas de vida nos fenómenos de abuso e negligência.

Quadro 5. Principal fonte de rendimentos das pessoas que vivem na mesma casa e que pertencem ao agregado familiar ( $n$ - . total de agregados $=520$ )

\begin{tabular}{lcc}
\hline Principal fonte de rendimento dos elementos do agregado & $\mathbf{n}$ & $\mathbf{\%}$ \\
\hline Pensão de reforma por idade & 309 & 59,4 \\
Salários e vencimentos do trabalho & 120 & 23,1 \\
Pensão de reforma por invalidez & 28 & 5,4 \\
Pensão de pré-reforma & 18 & 3,5 \\
Outras fontes de rendimento & 29 & 5,6 \\
Não tem qualquer apoio financeiro & 16 & 3,1 \\
\hline \multicolumn{2}{c}{ Nota: nesta variável estão excluídos 153 casos de inquiridos que vivem sozinhos e 5 } \\
\multicolumn{2}{c}{ casos omissos que correspondem à resposta "recusa" / "não sabe". }
\end{tabular}

\footnotetext{
${ }^{3}$ Nas outras fontes de rendimentos estão incluídos, entre outros: subsídio de desemprego; rendimento social de inserção, transferências financeiras de ex-cônjuge; heranças; rendimentos prediais e agrícolas.

${ }^{4}$ Ver nota anterior.
} 
A análise aos valores efetivos dos rendimentos auferidos sugere, como discutido na secção anterior, uma condição relativamente confortável para o indivíduo médio da amostra. Foi recolhida informação quer sobre o rendimento mensal do próprio, quer sobre o rendimento mensal do agregado familiar depois dos descontos obrigatórios para contribuições e impostos. A informação recolhida foi utilizada para derivar o valor do rendimento mensal do adulto equivalente com harmonização de acordo com a escala modificada da OCDE .

De acordo com a leitura do quadro seguinte (Quadro 6), constata-se que existe uma grande amplitude de rendimentos mensais por adulto equivalente (de 183,33€ a $8666,67 €$ ), o que se traduz numa média dos rendimentos de $1305,78 €$ (d.p.=996,47). A mediana, porém, ao situar-se nos $1.000,00 €$, reflete as já amplamente documentadas assimetrias da distribuição dos rendimentos na população idosa em Portugal, aliás caracterizada por um nível de desigualdade particularmente marcado (Lopes, 2015).

Quadro 6. Rendimento mensal líquido do adulto equivalente

\begin{tabular}{lcc}
\hline $\mathbf{N}$ & $\begin{array}{c}\text { Respostas válidas } \\
\text { Não responde }\end{array}$ & 629 \\
\hline Média & 49 \\
Mediana & $1305,78 €$ \\
Desvio padrão & $1000,00 €$ \\
Amplitude & $996,47 €$ \\
Mínimo & $8483,33 €$ \\
Máximo & $183,33 €$ \\
\hline
\end{tabular}

Para efeitos de desenvolvimento da análise ao longo do estudo quantitativo, optou-se por agrupar a variável rendimento por adulto equivalente em 4 escalões de rendimento. Um pouco mais de metade da amostra $(51,4 \%)$ possui rendimento por adulto equivalente até $1000 €$. Ainda assim, $14,3 \%$ tem rendimento inferior a $501 €$ mensais. 0 escalão mais expressivo é o dos $501 €$ aos $1000 €(37,0 \%)$, seguido pelo escalão de rendimento superior a $1500 €(28,9 \%)$.

\footnotetext{
${ }^{5}$ Resulta da ponderação do rendimento médio mensal do agregado familiar pela dimensão do agregado harmonizada de acordo com a escala modificada da OCDE (peso do 1 o adulto = 1 ; peso dos adultos seguintes $=0,5$; peso de cada criança $=0,3$ ) (Hagenaars, A., K. de Vos \& M.A. Zaidi, 1994).
} 
Quadro 7. Escalões de rendimento do adulto equivalente

\begin{tabular}{lccc}
\hline Escalões de rendimento por adulto equivalente & $\mathbf{n}$ & $\mathbf{\%}$ & \% acumulada \\
\hline$<501 €$ & 90 & 14,3 & 14,3 \\
$501 €-1000 €$ & 233 & 37,0 & 51,4 \\
$1001 €-1500 €$ & 124 & 19,7 & 71,1 \\
$>1500 €$ & 182 & 28,9 & 100,0 \\
\hline Total & 629 & 100,0 & - \\
\hline \multicolumn{4}{l}{ Nota: nesta variável estão excluídos 48 casos para os quais não foi possível medir o rendimento. }
\end{tabular}

A perceção sobre o rendimento atual constitui uma variável que procura aferir a avaliação subjetiva do inquirido em relação à capacidade financeira do seu agregado familiar para fazer face às despesas. Pela leitura do quadro seguinte (Quadro 8), observa-se que grande parte dos inquiridos considera que o rendimento do seu agregado familiar dá para viver $(49,6 \%)$, seguindo-se os que referem que esse rendimento permite viver confortavelmente (34,8\%). Apenas 3,6\% dos inquiridos considera que é muito difícil viver com o rendimento atual.

Quadro 8. Perceção sobre o rendimento atual

\begin{tabular}{lcc}
\hline Perceção sobre o rendimento atual & $\mathbf{n}$ & \% \\
\hline O rendimento atual permite viver confortavelmente & 235 & 34,8 \\
O rendimento atual dá para viver & 335 & 49,6 \\
É difícil viver com o rendimento atual & 81 & 12,0 \\
É muito difícil viver com o rendimento atual & 24 & 3,6 \\
\hline Total & 675 & 100,0 \\
\hline Nota: Existem 3 casos omissos que correspondem a respostas "recusa" e "não sabe".
\end{tabular}

As análises estatísticas desenvolvidas nos pontos seguintes recuperam esta variável transformada numa versão sintetizada, denominada por «perceção do rendimento do agregado como insuficiente», composta por duas categorias: sim (que agrega os níveis da variável original «é difícil viver com o rendimento atual» e "é muito difícil viver com o rendimento atual»); e não (que agrega os níveis "o rendimento atual permite viver confortavelmente» e "o rendimento atual dá para viver»).

Paralelamente, procurou-se saber até que ponto a população em estudo tem garantido o acesso a alimentos e nutrientes necessários a uma vida saudável. A insegurança alimentar pode estar relacionada com a falta de poder de compra ou com uma deficiente planificação, distribuição e/ou preparação dos alimentos no contexto do agregado familiar (Blumberg, Bialostosky, Hamilton e Briefel, 1999). Neste sentido, a segurança alimentar do agregado familiar foi medida através do indicador US Household Food Security Survey Module, Economic Research Service, 2006) (Blumberg, Bialostosky, Hamilton e Briefel, 1999). No quadro seguinte (Quadro 9), exibem-se os resultados apurados, constatando-se que $93,4 \%$ dos inquiridos possui um nível alto ou moderado 
de segurança alimentar. Porém, embora pouco expressivo em termos amostrais, sublinha-se que o grupo de indivíduos que revelam uma segurança alimentar insuficiente, i.e. baixa, ou muito baixa, representa uma proporção de $6,6 \%$ da amostra.

Quadro 9. Segurança alimentar do agregado familiar

\begin{tabular}{lcc}
\hline Segurança alimentar do agregado & $\mathbf{n}$ & $\mathbf{\%}$ \\
\hline Segurança alimentar alta ou moderada & 633 & 93,4 \\
Segurança alimentar baixa & 34 & 5,0 \\
Segurança alimentar muito baixa & 11 & 1,6 \\
\hline Total & 678 & 100,0 \\
\hline
\end{tabular}

\subsection{Caracterização psicossocial: suporte social e qualidade de vida}

No ponto seguinte, procurou-se conhecer, de igual modo, a perceção dos inquiridos face ao suporte social que têm (ou não). O suporte social (informal ou formal) pode ser definido como o provimento de determinados recursos afetivos, instrumentais ou informacionais que visam a promoção do bem-estar do seu recetor (Brownell \& Shumacher, 1984). No entanto, o suporte social percebido é determinado, em termos cognitivos, ou seja, relaciona-se com a perceção do seu recetor face à obtenção desses recursos, o que não determina, necessariamente, que os receba nem que esses recursos Ihe sejam úteis. Sendo assim, recorreu-se à utilização da escala multidimensional de suporte social percebido (MSPSS) de 12 itens (Zimet et al., 1988).

Como se pode verificar pela análise do quadro seguinte, a maioria dos inquiridos reporta um nível de suporte social elevado (68,4\%). Por sua vez, a proporção da amostra que reporta um nível moderado de suporte social situa-se nos $29,8 \%$ e apenas $1,8 \%$ dos indivíduos o perceciona como sendo baixo (Quadro 10).

Quadro 10. Suporte social percebido

\begin{tabular}{lcc}
\hline Suporte social percebido & $\mathbf{n}$ & $\mathbf{\%}$ \\
\hline Baixo suporte & 12 & 1,8 \\
Suporte moderado & 200 & 29,8 \\
Alto suporte & 459 & 68,4 \\
\hline Total & 671 & 100,0 \\
\hline Nota: Os 7 casos omissos correspondem a situações em que os inquiridos responderam "recusa" ou \\
"não sabe" a pelo menos um dos itens que compõe a escala. A classificação dos inquiridos na escala \\
de suporte social percebido foi realizada apenas para os que responderam a todos os itens da escala.
\end{tabular}

A caracterização da qualidade de vida, foi realizada a partir da escala proposta pelo World Health Organization Quality of Life Group, nomeadamente através da aplicação do módulo WHOQOL-OLD (Power et al., 2005; World Health Organization, 2006; Fleck et al., 2006). Este módulo foi desenvolvido no sentido de adaptar o WHOQOL a adultos 
idosos, sendo composto por 24 questões segmentadas em seis facetas (4 questões cada), nomeadamente: i) Capacidades Sensoriais - Funcionamento sensorial, impacto da perda de capacidades sensoriais na qualidade de vida; ii) Autonomia - Independência na velhice, capacidade ou liberdade de viver de forma autónoma e de tomada de decisões; iii) Atividades do passado, presente e do futuro - Satisfação em relação às conquistas na vida e coisas a que se anseia; iv) Participação social - Participação nas atividades quotidianas, especialmente na comunidade; v) Morte e morrer - Preocupações, inquietações e temores sobre a morte e sobre morrer; vi) Intimidade - Capacidade de ter relacionamentos pessoais e íntimos.

O cálculo das pontuações do WHOQOL-OLD (Score total) deve ser obtido, segundo Pedroso et al. (2011), depois de verificado o preenchimento do total das 24 questões (escala de Likert com valores entre 1 e 5) e assegurado o sentido da escala (pontuação mais baixas representam uma baixa qualidade de vida, pontuações mais elevadas representam uma qualidade de vida mais alta). As pontuações das facetas podem ser apresentadas de três formas diferentes, ou seja: i) A partir da soma dos valores pertencentes a cada um dos 4 itens de cada faceta (podendo variar entre 4 e 20); ii) A pontuação média relativa a cada item (variando entre 1 e 5); iii) A pontuação transformada, que é calculada a partir da conversão da pontuação bruta para uma escala de 0 a 100. O cálculo total do WHOQOL-OLD também pode ser apresentado nestes três formatos. Sendo assim, a partir do cálculo da pontuação transformada (0$100)$, podemos verificar que em termos globais, os inquiridos reportam, em média, um nível de qualidade de vida de 66.26 pontos ( $D P=12.73 ; \mathrm{N}=660$ ), valor muito semelhante à média obtida entre os centros de investigação participantes no estudo do WHOQOL Group, que se situou nos 66.22 pontos ( $D P=13.64 ; N=4470$ ) e que permitiu validar 0 módulo WHOQOL-OLD, (Power, et al., 2005, p.46).

Quadro 11. Dados de referência para a pontuação bruta transformada (intervalo de 0 a 100) da pontuação total do módulo WHOQOL-OLD (Estudo HARMED)

\begin{tabular}{lccc}
\hline Facetas & M & DP & N \\
\hline Capacidades Sensoriais & 77.96 & 19.30 & 677 \\
Autonomia & 66.23 & 15.08 & 674 \\
Atividades do passado, presente e do futuro & 67.12 & 17.22 & 671 \\
Participação social & 66.83 & 17.32 & 674 \\
Morte e morrer & 57.06 & 26.63 & 675 \\
Intimidade & 61.09 & 31.14 & 674 \\
\hline Score total & 66.26 & 12.73 & 660 \\
\hline
\end{tabular}


É, igualmente, de destacar a pontuação média relativa às facetas sobre as «capacidades sensoriais» $(M=77.96 ; D P=19.30)$, sobre as "atividades do passado, presente e do futuro» ( $M=67.12 ; \quad D P=17.22)$, a «participação social» $(M=66.83 ; D P=17.32)$ e «autonomia» $(M=66.23 ; \mathrm{DP}=15.08)$. Por outro lado, a pontuação mais baixa foi obtida em relação às preocupações, inquietações e temores sobre a morte e sobre morrer faceta «morte e morrer» ( $M=57.06 ; D P=26.63)$ (Quadro 11).

As pontuações da escala de qualidade de vida, tendo em consideração as facetas, foram apreciadas em função de alguns fatores de variação: sexo, idade e nível de escolaridade. Os resultados apresentam-se no quadro 12 abaixo.

Como conclusão principal, e focando os valores médios do score total, as três dimensões de diferenciação consideradas apresentam-se, efetivamente, com capacidade discriminante significante. Concretamente, os homens apresentam um score médio superior às mulheres, reforçando o estatuto de vulnerabilidade amiúde associado à condição feminina na velhice; a relação da qualidade de vida com a idade é de tipo linear inverso, ou seja, à medida que avança a idade parece decrescer a qualidade de vida; e com a escolaridade temos uma relação linear positiva, ou seja, indivíduos com níveis de escolaridade superiores apresentam, em média, maiores valores nos scores de qualidade de vida.

No que diz respeito à análise das pontuações tendo em consideração as diferentes facetas, verifica-se que se mantém genericamente a mesma tendência. 
Quadro 12. Dados de referência para a pontuação bruta transformada (intervalo de 0 a 100) das facetas/Score total do módulo WHOQOL-OLD, por sexo.

\begin{tabular}{|c|c|c|c|c|c|c|c|c|c|c|c|}
\hline \multirow[b]{3}{*}{ Facetas } & & & \multicolumn{7}{|c|}{ Sexo } & & \multirow{3}{*}{ p-value } \\
\hline & & & \multicolumn{4}{|c|}{ Masculino } & \multicolumn{2}{|c|}{ Feminino } & & & \\
\hline & & & \multicolumn{2}{|c|}{ M } & DP & $\mathrm{N}$ & M & DP & & & \\
\hline \multicolumn{3}{|l|}{ Capacidades Sensoriais } & \multicolumn{2}{|c|}{78,98} & 17,81 & 250 & $77,37 \quad 2$ & 20,12 & 427 & 52017 & 0,573 \\
\hline \multicolumn{3}{|l|}{ Autonomia } & \multicolumn{2}{|c|}{67,90} & 14,04 & 250 & 65,24 & 15,60 & 424 & 47928 & 0,036 \\
\hline \multicolumn{3}{|c|}{ Atividades do passado, presente e do futuro } & \multicolumn{2}{|c|}{68,63} & 15,47 & 250 & 66,231 & 18,14 & 421 & 50009 & 0,278 \\
\hline Participação social & & & 67 & & 5,96 & 250 & 66,521 & 18,08 & 424 & 52925 & 0,975 \\
\hline Morte e morrer & & & 62 & & 5,09 & 250 & $53,82 \quad 2$ & 27,01 & 425 & 43239 & $<0,001$ \\
\hline Intimidade & & & 71 & & 1,42 & 247 & 54,90 & 34,09 & 427 & 39433 & $<0,001$ \\
\hline Total & & & 69 & & 1,06 & 247 & 64,3 & 13,26 & 413 & 39671 & $<0,001$ \\
\hline & & & & rupose & etários a & agregad & dos & & & Teste de & \\
\hline & & 70 anos & & & $0-79$ an & nos & & $>79$ an & nos & Kruskal- & p-value \\
\hline Facetas & $\mathbf{M}$ & DP & $\mathbf{N}$ & $\mathbf{M}$ & DP & $\mathbf{N}$ & $\mathbf{M}$ & DP & $\mathbf{N}$ & Wallis & \\
\hline Capacidades Sensoriais & 81,15 & 17,06 & 306 & 77,57 & 19,74 & 243 & 71,09 & 21,66 & 128 & 22,88 & $<0,001$ \\
\hline Autonomia & 67,75 & 14,31 & 306 & 65,39 & 15,88 & 242 & 64,14 & 15,09 & 126 & 7,34 & 0,025 \\
\hline $\begin{array}{l}\text { Atividades do passado, } \\
\text { presente e futuro }\end{array}$ & 68,91 & 15,79 & 306 & 65,86 & 17,78 & 242 & 65,14 & 19,12 & 123 & 5,79 & 0,055 \\
\hline Participação social & 68,30 & 15,90 & 306 & 66,49 & 18,39 & 243 & 63,90 & 18,22 & 125 & 4,70 & 0,095 \\
\hline Morte e morrer & 55,21 & 27,67 & 306 & 57,35 & 26,41 & 244 & 61,00 & 24,12 & 125 & 3,52 & 0,172 \\
\hline Intimidade & 66,43 & 27,61 & 305 & 57,84 & 32,17 & 244 & 54,40 & 35,06 & 125 & 13,31 & 0,001 \\
\hline Total & 67,92 & 11,20 & 305 & 65,38 & 13,56 & 240 & 63,67 & 14,19 & 115 & 8,63 & 0,013 \\
\hline & & & & Nível o & de escol & laridade & & & & & \\
\hline & & $\begin{array}{r}\text { Baixo } \\
1<5 \text { ano } \\
\end{array}$ & & & $\begin{array}{l}\text { Médio } \\
5-9 \text { ano }\end{array}$ & & & $\begin{aligned} & \text { Alto } \\
&> 9 \text { ano } \\
&\end{aligned}$ & & $\begin{array}{l}\text { Teste de } \\
\text { Kruskal- } \\
\text { Wallis }\end{array}$ & p-value \\
\hline Facetas & $\mathbf{M}$ & DP & $\mathbf{N}$ & $\mathbf{M}$ & DP & $\mathbf{N}$ & $\mathbf{M}$ & DP & $\mathbf{N}$ & & \\
\hline Capacidades Sensoriais & 76,39 & 20,09 & 247 & 79,58 & 18,32 & 157 & 78,61 & 18,96 & 272 & 2,889 & 0,236 \\
\hline Autonomia & 63,96 & 15,17 & 244 & 64,01 & 16,31 & 157 & 69,58 & 13,65 & 272 & 20,913 & $<0,001$ \\
\hline $\begin{array}{l}\text { Atividades do passado, } \\
\text { presente e futuro }\end{array}$ & 63,60 & 20,02 & 244 & 66,45 & 15,97 & 155 & 70,73 & 14,29 & 271 & 16,805 & $<0,001$ \\
\hline Participação social & 64,87 & 18,73 & 245 & 65,30 & 17,31 & 156 & 69,44 & 15,68 & 272 & 7,516 & 0,023 \\
\hline Morte e morrer & 56,50 & 27,60 & 246 & 56,73 & 26,28 & 156 & 57,72 & 26,07 & 272 & 0,143 & 0,931 \\
\hline Intimidade & 57,01 & 33,35 & 246 & 59,12 & 32,03 & 157 & 65,97 & 27,86 & 270 & 8,006 & 0,018 \\
\hline Total & 64,04 & 14,15 & 237 & 65,53 & 12,35 & 153 & 68,66 & 11,18 & 269 & 13,726 & 0,001 \\
\hline
\end{tabular}




\subsection{Caracterização da habitação}

No presente estudo foram analisadas, igualmente, as condições da habitação dos participantes, incluindo a respetiva zona envolvente. Sobre o regime de propriedade da habitação, destaca-se que a maioria $(63,4 \%)$ vive em habitação própria, $26,8 \%$ vive numa habitação arrendada e 5,3\% numa habitação social (Quadro 13).

Quadro 13. Tipo de regime de propriedade da habitação

\begin{tabular}{lcc}
\hline Tipo de regime de propriedade & $\mathbf{n}$ & $\mathbf{\%}$ \\
\hline Habitação própria & 430 & 63,4 \\
Habitação arrendada & 182 & 26,8 \\
Habitação de um familiar & 22 & 3,2 \\
Habitação social & 36 & 5,3 \\
Habitação cedida gratuitamente & 8 & 1,2 \\
\hline Total & 678 & 100,0 \\
\hline
\end{tabular}

Relativamente ao tipo de edifício, a maioria $(76,2 \%)$ dos respondentes vive em apartamentos e $22,5 \%$ vive em moradias (Quadro 14 ).

Quadro 14. Tipologia do alojamento

\begin{tabular}{lcc}
\hline Tipologia do alojamento & $\mathbf{n}$ & $\mathbf{\%}$ \\
\hline Edifício com 3 a 8 apartamentos & 274 & 40,4 \\
Edifício com 9 ou mais apartamentos, mas com menos de 8 andares & 184 & 27,1 \\
Edifício alto com 9 ou mais andares & 59 & 8,7 \\
Moradia (uni)familiar geminada & 87 & 12,8 \\
Moradia (uni)familiar independente $^{\text {Outro }^{1}}$ & 66 & 9,7 \\
\hline Total $^{1}$ & 5 & 1,1 \\
\hline
\end{tabular}

${ }^{1} \mathrm{~A}$ categoria outro inclui os seguintes tipos de alojamento: quinta e "ilha".

No que concerne às condições da habitação, verifica-se que quase a totalidade dos inquiridos tem boas condições ao nível de equipamentos sanitários. Ainda assim, regista-se a inexistência de sanita no interior da habitação para uso exclusivo do agregado na habitação de 2 inquiridos, bem como a inexistência de banheira/duche na habitação de 4 participantes. Ao nível de equipamentos de aquecimento, 10,3\% dos inquiridos tem privação desse tipo de equipamento na habitação. Acrescenta-se ainda que $85,0 \%$ dos inquiridos menciona que a habitação tem varanda, terraço ou jardim (Quadro 15). 
Quadro 15. Condições da habitação (n=678)

\begin{tabular}{lcc}
\hline Condições da habitação & $\mathbf{n}$ & \% \\
\hline $\begin{array}{l}\text { Tem uma banheira e/ou um chuveiro dentro de casa para uso } \\
\text { exclusivo do seu agregado familiar }\end{array}$ & 674 & 99,4 \\
$\begin{array}{l}\text { Tem uma sanita dentro de casa para uso exclusivo do seu } \\
\text { agregado familiar }\end{array}$ & 676 & 99,7 \\
$\begin{array}{l}\text { Tem equipamentos de aquecimento (como por exemplo } \\
\text { aquecedor a óleo, aquecimento central, termoacumulador) }\end{array}$ & 608 & 89,7 \\
\begin{tabular}{l} 
Tem varanda, terraço ou jardim \\
\hline
\end{tabular}
\end{tabular}

As principais carências apontadas à habitação pelos participantes referem-se ao facto de ser muito cara face ao rendimento disponível para o dia-à-dia $(25,7 \%)$, e à falta de instalações de aquecimento adequadas em todas as divisões da casa $(16,4 \%)$ (Quadro 16).

Quadro 16. Carência das condições de habitação

\begin{tabular}{lcc}
\hline Carência das condições de habitação & $\mathbf{n}$ & $\mathbf{\%}$ \\
\hline Tem falta de espaço ( $\mathrm{n}=678$ ) & 65 & 9,6 \\
É muito cara em relação ao rendimento que tem para o seu & 174 & 25,7 \\
dia-a-dia ( $\mathrm{n}=678$ ) & & \\
Tem falta de luz ( $\mathrm{n}=678)$ & 20 & 2,9 \\
Tem falta de instalações de aquecimento adequadas em todas as & 111 & 16,4 \\
divisões da casa ( $n=677)$ & & \\
\hline
\end{tabular}

Em relação às condições da zona envolvente à habitação onde residem os inquiridos, pode-se destacar que a quase totalidade $(96,3 \%)$ considera que a zona onde reside apresenta uma oferta suficiente/razoável de infraestruturas, tal como farmácias, apoio médico, mercearia, sendo que estas se encontram a uma distância razoável. No que diz respeito à mobilidade urbana, 94,1\% assinala ter uma oferta razoável de transportes públicos. No entanto, dois aspetos da zona envolvente apresentam uma avaliação menos satisfatória, designadamente ao nível de poluição, barulho e outros problemas ambientais (43,5\%) e de vandalismo e criminalidade (23,7\%) (Quadro 17).

Quadro 17. Condições da zona envolvente à habitação (mais do que uma resposta possível) $(n=678)$

\begin{tabular}{lcc}
\hline Condições da zona envolvente & $\mathbf{n}$ & \% \\
\hline Tem uma oferta suficiente/razoável de infraestruturas tal como & 653 & 96,3 \\
farmácias, apoio médico, mercearias, e estas encontram-se a uma & & \\
distância razoável & & \\
Tem uma oferta razoável de transportes públicos & 638 & 94,1 \\
Tem poluição, barulho e outros problemas ambientais & 295 & 43,5 \\
Tem problemas de vandalismo e crime & 161 & 23,7 \\
\hline
\end{tabular}




\section{Condições de saúde}

O conceito de saúde é definido pela Organização Mundial de Saúde (OMS, 1946) ${ }^{6}$ como um estado completo de bem-estar físico, mental e social dos indivíduos, e não apenas como a ausência de doença ou enfermidade. Nos últimos anos, o conceito viu alargado o seu campo semântico, passando a considerar dimensões psíquicas, sociais e ambientais, por força do contributo de outras perspetivas para a sua definição, designadamente: a perspetiva psicossocial, que define saúde como a ausência de malestar, estado de segurança e conforto; a perspetiva político-legal, promotora do equilíbrio dos indivíduos e da comunidade e a perspetiva económica, mais focada no impacto da saúde ao nível da afetação de recursos e de desenvolvimento económico (Coelho, 2016; Nunes e Rego, 2002). Ao incluir dimensões subjetivas, como as psíquicas e sociais, tornou-se mais difícil a determinação e avaliação do conceito, mas, ao mesmo tempo, tal exige que se pense a saúde e a doença numa perspetiva múltipla, nomeadamente que se considere a dimensão física, biológica, química, psicológica, social, cultural e ambiental, constituindo qualquer ameaça a este equilíbrio ecológico um fator de risco ao suposto estado completo de bem-estar (Coelho, 2016).

Está mais do que demonstrado que os determinantes individuais, biológicos, genéticos, psicológicos, económicos e socioculturais contribuem para a forma como envelhecemos e para a ocorrência de doenças ao longo da vida, mas a saúde decorre, igualmente, das experiências passadas em termos de estilos de vida, da exposição aos ambientes onde se vive e dos cuidados de saúde que se recebe ao longo do ciclo de vida humana (Dias e Marianela, 2014). A promoção da saúde e os cuidados de prevenção dirigidos aos idosos aumentam a longevidade e melhoram a sua qualidade de vida. Mas este crescimento da esperança de vida favoreceu, de igual modo, a expansão da doença crónica e de comorbilidades que conduzem a um crescimento das necessidades em cuidados, serviços e produtos de saúde. Conduziu ainda ao aumento da incapacidade e dependência dos mais velhos com carga variável para a família e para o sistema de saúde (e.g., maior procura de procedimentos de diagnóstico, terapêuticos, de reabilitação física e de saúde mental) (Dias e Lopes, 2016).

São, por isso, inúmeros os fatores que influenciam a condição de saúde das pessoas mais velhas, nomeadamente a herança genética, os contextos físicos e sociais (eg., as condições de habitação, comunidade e redes de vizinhança) e as características pessoais (e.g. género, etnicidade estatuto socioeconómico). No entanto, a experiência do

\footnotetext{
${ }^{6}$ Consultar Preamble to the Constitution of WHO as adopted by the International Health Conference, New York, 19 June - 22 July 1946; signed on 22 July 1946 by the representatives of 61 States (Official Records of WHO, no. 2, p. 100) and entered into force on 7 April 1948. A definição de saúde não foi alterada desde 1948.
} 
envelhecimento é desigual, biológica, psicológica e socialmente, pelo que o desafio consiste em compreendermos em que medida parte da diversidade das vivências na velhice se deve ao impacto cumulativo das desigualdades experimentadas pelas pessoas mais velhas na saúde e no seu acesso (WHO, 2018). Por outro lado, não obstante o agravamento da condição de saúde dos mais velhos poder ser uma consequência da exposição a situações de abuso, também é um facto que a vulnerabilidade na saúde e na doença representa um fator de risco a inúmeras formas de violência e maus-tratos vividos pelas pessoas nesta fase do ciclo de vida (Dong et al., 2012). O abuso de idosos constitui um problema de saúde público, multifacetado, com efeitos negativos ao nível da saúde física e mental e está associado ao aumento do risco de mortalidade e morbilidade das pessoas mais velhas (Dong et al., 2012).

A identificação das condições de saúde dos idosos, enquanto variáveis explicadas e/ou explicativas de situações de abuso e de violência, tem merecido particular atenção da investigação nesta área. Na perspetiva da teoria da dependência, por exemplo, assumese que quando o estado de saúde do idoso se agrava a sua condição de vulnerabilidade aumenta, tal como o nível de stress dos cuidadores, potenciando-se assim o risco de abuso (Baltes, 1996; Soares et al., 2010). Vários estudos referem que o declínio das condições económicas, a pobreza, a doença e a deficiência são fatores que podem limitar ou restringir a capacidade de autonomia e de liberdade dos idosos. Tais condições emergem como fatores críticos que podem agravar a exposição dos idosos ao abuso e à violência (Soares et al., 2010; Barros et al., 2013; Fraga et al., 2014). Outros estudos têm ainda evidenciado a importância dos fatores de proteção da violência e do abuso, nomeadamente a existência de uma rede médico-social de apoio próxima que atenue o stresse dos cuidadores, mas também as limitações das pessoas mais velhas em termos de atividades da vida diária (AVD) (e.g. higiene, mobilidade física, alimentação, etc.) (Baltes \& Baltes, 1990).

Nos pontos seguintes, procede-se a uma caracterização global das condições de saúde, das suas especificidades em função das características sociodemográficas dos participantes e dá-se, igualmente, conta dos cuidados de saúde e das redes de apoio social a que têm acesso, para de seguida se avançar para a análise da prevalência de abusos e a exploração da sua relação com as dimensões de caracterização da amostra até aqui exploradas.

\subsection{Caracterização global das condições de saúde}

Neste ponto faz-se uma análise global das condições de saúde dos inquiridos. Para o efeito, foram mobilizadas inúmeras variáveis, como a avaliação da condição de saúde pelos participantes, a prevalência de doença, o consumo de fármacos, as razões para a não aquisição dos mesmos, inclusive, em caso de necessidade, mas também a perceção 
dos idosos sobre a satisfação com a vida, nomeadamente através da Escala de Depressão Geriátrica (Sheikh \& Yesavage, 1986; Pocinho et al., 2009; Apóstolo, 2011; Gomez-Angulo \& Campo-Arias, 2011).

Começando pela análise da distribuição relativa à autoavaliação da condição de saúde dos participantes, verifica-se que de um total de 678 indivíduos, a maioria avaliam-na como sendo "razoável" (47,8\%) ou "boa" (38,8\%). Aliás, 93,4\% dos inquiridos avaliam a sua saúde como "muito boa", "boa" ou "razoável", destacando-se assim a baixa proporção dos que avaliam negativamente a sua condição de saúde (Quadro 18).

Quadro 18. Autoavaliação da condição de saúde

\begin{tabular}{lccc}
\hline Como avalia a sua saúde em geral? & $\mathbf{n}$ & \% & \% acumulada \\
\hline Muito boa & 46 & 6,8 & 6,8 \\
Boa & 263 & 38,8 & 45,6 \\
Razoável & 324 & 47,8 & 93,4 \\
Má & 33 & 4,9 & 98,2 \\
Muito má & 12 & 1,8 & 100,0 \\
\hline Total & 678 & 100,0 &
\end{tabular}

Apesar da autoavaliação da condição de saúde globalmente ser positiva, quando analisamos a prevalência de um qualquer tipo de doença, verifica-se que a larga maioria dos inquiridos afirma sofrer, pelo menos, de uma doença $(93,8 \%)$, sendo que apenas 6,2\% afirma não sofrer de qualquer doença (Quadro 19).

Quadro 19. Prevalência de doença

\begin{tabular}{lcc}
\hline Sofre de alguma doença? & $\mathbf{n}$ & $\mathbf{\%}$ \\
\hline Sim & 636 & 93,8 \\
Não & 42 & 6,2 \\
\hline Total & 678 & 100,0 \\
\hline
\end{tabular}

Neste sentido, importa traçar o panorama geral dos diferentes tipos de doença reportados pelos participantes. Através da análise do quadro seguinte (Quadro 20), observa-se que, mais de metade da amostra, afirma sofrer de "Tensão arterial alta ou hipertensão" (50,4\%), quase metade diz ter "Colesterol" (49\%), 33\% diz sofrer de "Ansiedade, depressão ou outros transtornos afetivos ou emocionais, incluindo nervosismo ou problemas psiquiátricos" e $27,3 \%$ sofre de "Doenças dos olhos". As doenças menos reportadas são o "Hipotiroidismo" (1,8\%), a "Doença de Parkinson" $(1,0 \%)$ e a "Doença de Alzheimer, demência, síndrome cerebral orgânica, senilidade ou qualquer outra perturbação grave da memória" $(0,4 \%)$. 
Quadro 20. Prevalência por tipo de doença (mais do que uma resposta possível) ( $n=678$ )

\begin{tabular}{lcc}
\hline Atualmente tem alguma das seguintes doenças? & $\mathbf{n}$ & $\%$ \\
\hline Problemas cardíacos (angina de peito, enfarte do miocárdio, insuficiência & & \\
cardíaca ou qualquer outro, doença isquémica cardíaca) & 150 & 22,1 \\
Tensão arterial alta ou hipertensão & 342 & 50,4 \\
Trombose ou acidente vascular cerebral (AVC) & 32 & 4,7 \\
Doenças pulmonares (Bronquite crónica, enfisema pulmonar, outro) & 52 & 7,7 \\
Alergias & 157 & 23,2 \\
Asma & 41 & 6,0 \\
Diabetes & 117 & 17,3 \\
Hipertiroidismo & 22 & 3,2 \\
Hipotiroidismo & 12 & 1,8 \\
Colesterol & 332 & 49,0 \\
Cancro & 20 & 2,9 \\
Doença renal crónica & 18 & 2,7 \\
Doença do estômago ou intestino & 141 & 20,8 \\
Doença do fígado (ex. hepatite) & 22 & 3,2 \\
Artrite reumatoide & 52 & 7,7 \\
Osteoporose & 123 & 18,1 \\
Doenças dos olhos (ex. cataratas) & 185 & 27,3 \\
Doença de Parkinson & 7 & 1,0 \\
Doença de Alzheimer, demência, síndrome cerebral orgânica, senilidade ou & & \\
qualquer outra perturbação grave da memória & 3 & 0,4 \\
Ansiedade, depressão ou outros transtornos afetivos ou emocionais, incluindo & & \\
nervosismo ou problemas psiquiátricos & 224 & 33,0 \\
Outra(s) doença(s) & 101 & 14,9 \\
Não tenho nenhuma doença & 42 & 6,2 \\
Não sabe/não responde & 1 & 0,1 \\
\hline
\end{tabular}

O consumo de medicação é outro dos aspetos relacionados com o estado de saúde. Sendo assim, analisou-se o tipo de medicamentos consumidos pelos idosos que participaram neste estudo. Neste sentido, verifica-se que $65,6 \%$ dos inquiridos toma (ou já tomou) medicamentos para as dores, 38,6\% para dormir, 22,4\% para o coração e $19 \%$ faz (ou já fez) medicação para a ansiedade. Registe-se, ainda, que uma larga maioria dos inquiridos (73,7\%) toma (ou tomou) outro(s) tipo(s) de medicamentos. Os medicamentos para a asma $(4,4 \%)$ e para a psicose $(0,6 \%)$ são os menos consumidos (Quadro 21). 
Quadro 21. Consumo de fármacos (mais do que uma resposta possivel) $(N=678)$

No que concerne ao consumo diário de fármacos, destaca-se que, dos 570 inquiridos que tomam medicação diariamente, 30\% consome medicamentos para dormir, 25,1\% para o coração e $20 \%$ para a diabetes. Também, neste caso, a larga maioria $(81,1 \%)$ toma diariamente outro(s) tipo(s) de medicamentos. Por outro lado, os menos consumidos são os medicamentos para as alergias (3\%) e os medicamentos para a asma (2,3\%) (Quadro 22).

Quadro 22. Consumo diário de fármacos (mais do que uma resposta possível) ( $N=570)$

\begin{tabular}{lcc}
\hline Medicação que toma diariamente & $\mathbf{n}$ & $\mathbf{\%}$ \\
\hline Medicamentos para as dores & 48 & 8,4 \\
Medicamentos para dormir & 171 & 30,0 \\
Medicamentos para a depressão & 89 & 15,6 \\
Medicamentos para a ansiedade & 84 & 14,7 \\
Medicamentos para psicose & 4 & 0,7 \\
Medicamentos para a alergia & 17 & 3,0 \\
Medicamentos para a asma & 13 & 2,3 \\
Medicamentos para o coração & 143 & 25,1 \\
Medicamentos para a diabetes & 114 & 20,0 \\
Medicamentos naturais e de ervanárias (ex. homeopatia) & 58 & 10,2 \\
Outros medicamentos & 462 & 81,1 \\
\hline
\end{tabular}

Outro aspeto importante que pode influenciar o estado de saúde dos idosos relacionase com a não aquisição de medicação, mesmo no caso de se possuir receita médica. Nesse sentido, perguntou-se aos participantes se, nos últimos 12 meses, deixaram de comprar medicamentos mesmo tendo receita. Verifica-se que a larga maioria dos respondentes $(93,9 \%)$ refere que nos últimos 12 meses não deixou de comprar os medicamentos necessários (Quadro 23).

Quadro 23. Aquisição de medicação

\begin{tabular}{lcc}
\hline $\begin{array}{l}\text { Nos últimos } \mathbf{1 2} \text { meses deixou de comprar medicamentos } \\
\text { mesmo tendo receita médica? }\end{array}$ & $\mathbf{n}$ & \% \\
\hline Sim & 40 & 6,1 \\
Não & 611 & 93,9 \\
\hline Total & 651 & 100,0 \\
\hline \multicolumn{4}{c}{ Nota: 27 inquiridos não tomam atualmente qualquer medicação. }
\end{tabular}

Aos inquiridos que afirmaram não estar a fazer qualquer tipo de medicação $(n=27)$ foi perguntado se, apesar dessa situação, deixaram de comprar medicamentos, mesmo tendo uma receita médica. Verifica-se que, neste caso, a proporção dos que declaram ter deixado de comprar medicamentos aumenta, ou seja, $14,8 \%$ responde que, mesmo 
tendo receita médica, não comprou os medicamentos, isto é, não aderiu à terapia prescrita (Quadro 24).

Quadro 24. Não adesão à terapia prescrita, apesar de não tomar medicação

\begin{tabular}{lcc}
\hline Disse que não toma medicamentos, mas ainda assim, os últimos & & \\
$\mathbf{1 2}$ meses deixou de comprar medicamentos mesmo tendo & & \\
receita médica? & $\mathbf{n}$ & $\%$ \\
\hline Sim & 4 & 14,8 \\
Não & 23 & 85,2 \\
\hline Total & 27 & 100,0 \\
\hline
\end{tabular}

Questionou-se, igualmente, os inquiridos sobre a possibilidade de terem deixado de fazer tratamentos nos últimos 12 meses, mesmo tendo receita médica para esse efeito. Verifica-se que a proporção dos que declararam não ter realizado os tratamentos necessários é inferior, ou seja, apenas 4,9\% dos inquiridos afirma ter deixado de realizar tratamentos, mesmo tendo receita médica. (Quadro 25).

Quadro 25. Realização de tratamentos prescritos nos últimos 12 meses

\begin{tabular}{lcc}
\hline Nos últimos $\mathbf{1 2}$ meses deixou de fazer tratamentos & & \\
mesmo tendo receita médica? & $\mathbf{n}$ & $\mathbf{\%}$ \\
\hline Sim & 33 & 4,9 \\
Não & 645 & 95,1 \\
\hline Total & 678 & 100,0 \\
\hline
\end{tabular}

Na sequência do anteriormente descrito, importa igualmente perceber as principais razões da não adesão à toma de medicação e/ou da não realização dos tratamentos prescritos. Sendo assim, perguntou-se aos participantes ( $n=62)$ o(s) motivo(s) de não terem comprado os medicamentos ou de não terem realizado o(s) tratamento(s) prescrito(s), mesmo tendo receita médica para esse efeito. Os principais motivos indicados estão relacionados com o receio dos efeitos secundários $(30,6 \%)$, a falta de dinheiro para os pagar (21\%) e ainda terem disponíveis doses dos medicamentos (12,9\%) (Quadro 26). 
Quadro 26. Motivos para a não aquisição de medicação ou a não realização de tratamentos (mais do que uma resposta possível)

\begin{tabular}{lcc}
\hline & $\mathbf{n}$ & \% \\
\hline Os problemas desapareceram & 2 & 3,2 \\
Teve medo dos efeitos secundários & 19 & 30,6 \\
Teve experiências negativas com medicamentos ou tratamentos & 4 & 6,5 \\
anteriores & 13 & 21,0 \\
Não tinha dinheiro para pagar & 2 & 3,2 \\
Não teve tempo & 8 & 12,9 \\
$\begin{array}{l}\text { Ainda tinha medicamentos } \\
\text { Evita medicação/não gosta da medicação, nem do preço/passa bem sem } \\
\text { medicação/falta de vontade/não acha necessário }\end{array}$ & 7 & 11,3 \\
A medicação não estava a surtir o efeito desejado/era redundante, já & 4 & 6,5 \\
estava a tomar medicação/ o medicamento não era apropriado/consegue & & \\
controlar as dores & & \\
A medicação terminou/esqueceu-se de tomar a medicação/sentia-se em & 4 & 6,5 \\
baixo, não quis tomar/porque tinha de deixar de beber & & \\
Optou por fazer uma medicação natural de homeopatia/as opiniões & 2 & 3,2 \\
médicas eram diferentes & & \\
\hline
\end{tabular}

Ainda no âmbito da avaliação das condições de saúde dos participantes analisou-se a perceção dos inquiridos acerca da satisfação com a vida. O grau de satisfação com a vida não só pode ter influência no estado de saúde dos idosos, como é altamente afetado pela vivência de situações abusivas (Soares et al, 2010:26). Para o efeito, aplicou-se a Escala de Depressão Geriátrica validada para a população portuguesa (Sheikh \& Yesavage, 1986; Pocinho et al., 2009; Apóstolo, 2011; Gomez-Angulo \& Campo-Arias, 2011). Mais concretamente, procurou-se perceber como os inquiridos se sentiam na semana anterior à aplicação do inquérito por questionário. Verifica-se que a maioria (54\%) afirma preferir ficar em casa, em vez de sair e fazer outras coisas. Destaca-se ainda que $40,1 \%$ dos inquiridos menciona que anda muitas vezes aborrecido(a); 39,2\% sentese sem energia; $35,7 \%$ abandonou muitas das suas atividades e interesses; $30,6 \%$ sente que a sua vida está vazia e $29,8 \%$ assume que anda com medo que aconteça alguma coisa má (ver Quadro 27). 
Quadro 27. Satisfação com a vida (mais do que uma resposta possível) ( $N=543)$

\begin{tabular}{lcc}
\hline Como se sentiu nos últimos 7 dias/na última semana & $\mathbf{n}$ & \% \\
\hline Está insatisfeito(a) com a sua vida atual & 96 & 17,7 \\
Sente-se desanimado(a) e sem disposição a maior parte do tempo & 156 & 28,7 \\
Sente-se infeliz a maior parte do tempo & 129 & 23,8 \\
Atualmente, sente-se muito descontente por estar vivo & 26 & 4,8 \\
Sente-se sem energia & 213 & 39,2 \\
Abandonou muitas das suas atividades e interesses & 194 & 35,7 \\
Sente que a sua vida está vazia & 166 & 30,6 \\
Anda muitas vezes aborrecido(a) & 218 & 40,1 \\
Anda com medo que lhe vá acontecer alguma coisa má & 162 & 29,8 \\
Sente-se muitas vezes desamparado(a) ou desprotegido(a) & 138 & 25,4 \\
Prefere ficar em casa, em vez de sair e fazer outras coisas & 293 & 54,0 \\
Acha que tem mais problemas de memória do que as outras pessoas & 112 & 20,6 \\
Sente que, nas condições atuais, é um pouco inútil & 99 & 18,2 \\
Sente que para a sua situação não há qualquer esperança & 85 & 15,7 \\
Julga que a maior parte das pessoas passa bem melhor do que o(a) & & 156 \\
senhor(a) & 28,7 \\
\hline
\end{tabular}

A partir destes indicadores de satisfação com a vida (Escala de Depressão Geriátrica de 15 itens) desenvolveu-se uma escala agregada de depressão geriátrica composta por quatro categorias. Mais concretamente: na primeira (Sem depressão), são agrupados os scores entre 0 e 4, representando assim os inquiridos que não apresentam depressão; na segunda (Depressão leve), os scores entre 5 e 8; na terceira (Depressão moderada), os scores entre 9 e 11; e na quarta (Depressão severa), os scores entre 12 e 15. A proporção de respondentes que apresentam indicadores de depressão são de $16,9 \%$ para a forma leve, $7,2 \%$ para a forma moderada e $3,2 \%$ para depressão severa $(3,2 \%)$ (ver Quadro 28).

Quadro 28. Classificação na escala de depressão com 4 níveis

\begin{tabular}{lccc}
\hline & $\mathbf{n}$ & $\mathbf{\%}$ & \% acumulada \\
\hline Sem depressão (normal) & 473 & 72,7 & 72,7 \\
Depressão leve & 110 & 16,9 & 89,6 \\
Depressão moderada & 47 & 7,2 & 96,8 \\
Depressão severa & 21 & 3,2 & 100,0 \\
\hline Total & 651 & 100,0 & \\
\hline
\end{tabular}

Considerando que na variável anterior existe um nível com maior peso na distribuição e os restantes três apresentam valores baixos ou residuais, uma nova agregação permitiu compor dois grupos de níveis relativos à depressão com uma presença expressiva na amostra e a partir dos quais se desenvolveram algumas das análises estatísticas que se 
apresentam nos próximos pontos (ponto de corte: maior ou igual a 5). Com esta opção, focada na simplificação da variável, pressupõe-se que a presença, ou não, de depressão se traduz numa condição diferenciada de vulnerabilidade psicológica, com implicações nas atitudes e comportamentos dos idosos. Sendo assim, apresenta-se no quadro seguinte (Quadro 29) a proporção de inquiridos sem depressão (72,7\%) e com depressão $(27,3 \%)$.

Quadro 29. Presença de depressão (ponto de corte: maior ou igual a 5)

\begin{tabular}{lcc}
\hline & $\mathbf{n}$ & $\mathbf{\%}$ \\
\hline Sem depressão & 473 & 72,7 \\
Com depressão & 178 & 27,3 \\
\hline Total & 651 & 100,0 \\
\hline Nota: existem 27 casos omissos que correspondem a "não sabe ou não responde".
\end{tabular}

Para concluir a caracterização global das condições de saúde, podemos salientar a aparente clivagem entre a autoavaliação da condição de saúde e a presença de doença. Por um lado, a larga maioria dos respondentes avalia a sua saúde como "muito boa", "boa" ou "razoável" $(93,4 \%)$, por outro, praticamente a mesma proporção afirma sofrer de, pelo menos, uma doença $(93,8 \%)$.

No que diz respeito às doenças assinaladas, destaca-se a "Tensão arterial alta ou hipertensão", o "Colesterol", a "Ansiedade, depressão ou outros transtornos afetivos ou emocionais, incluindo nervosismo ou problemas psiquiátricos" e as "Doenças dos olhos". Doenças essas que, na sua maioria, foram diagnosticadas sobretudo nas últimas duas décadas.

Em termos de medicação, os medicamentos para as dores surgem como os mais utilizados pelos respondentes, seguidos dos medicamentos para dormir, para o coração e a ansiedade. No entanto, diariamente, os medicamentos mais consumidos pelos participantes são para dormir, para o coração e para a diabetes. Em termos gerais, a maioria dos inquiridos adquire a medicação necessária e realiza os tratamentos prescritos. Porém, quando isso não acontece as razões evocadas estão relacionadas sobretudo com o receio dos efeitos secundários e com a falta de dinheiro para os pagar. Em relação à satisfação com a vida, verifica-se que a maioria dos inquiridos prefere ficar em casa, em vez de sair e fazer outras coisas, salientando-se igualmente a proporção dos que dizem andar muitas vezes aborrecido, dos que se sentem sem energia, dos que dizem ter abandonado muitas das atividades e interesses e dos que experimentam um sentimento de vazio na vida. A partir destes indicadores desenvolveu-se uma escala agregada de depressão geriátrica (15 itens) que nos permite afirmar que mais de um quarto dos inquiridos apresentam sintomas depressivos. 


\subsection{Condições de saúde segundo as características sociodemográficas}

No âmbito dos objetivos do presente estudo, foi realizada, igualmente, uma análise focada na distribuição das condições globais de saúde dos idosos tendo em consideração algumas das suas características sociodemográficas. Os resultados são apresentados no quadro 30 abaixo.

Quadro 30. Autoavaliação da condição de saúde segundo um conjunto de indicadores sociodemográficos ( $n=678)$

\begin{tabular}{|c|c|c|c|c|c|}
\hline & \multicolumn{3}{|c|}{ Autoavaliação da condição de saúde } & \multirow[b]{2}{*}{$x^{2}$} & \multirow[b]{2}{*}{ p-value } \\
\hline & $\begin{array}{c}\text { Boa ou muito } \\
\text { boa } \\
n(\%)\end{array}$ & $\begin{array}{l}\text { Razoável } \\
\text { n (\%) }\end{array}$ & $\begin{array}{c}\text { Má ou } \\
\text { muito má } \\
\text { n (\%) }\end{array}$ & & \\
\hline \multicolumn{6}{|l|}{ Sexo } \\
\hline \multirow[t]{2}{*}{ Feminino } & 156 & 239 & 33 & & \\
\hline & $(36,4)$ & $(55,8)$ & $(7,7)$ & & \\
\hline \multirow[t]{2}{*}{ Masculino } & 153 & 85 & 12 & 39,0 & $<0,001$ \\
\hline & $(61,2)$ & $(34,0)$ & $(4,8)$ & & \\
\hline \multicolumn{4}{|c|}{ Grupos etários agregados } & & \\
\hline \multirow[t]{2}{*}{$<70$ anos } & 152 & 144 & 10 & & \\
\hline & $(49,7)$ & $(47,1)$ & $(3,3)$ & & \\
\hline \multirow[t]{2}{*}{70 a 79 anos } & 107 & 116 & 21 & 12,9 & 0,012 \\
\hline & $(43,9)$ & $(47,5)$ & $(8,6)$ & & \\
\hline \multirow[t]{2}{*}{$>79$ anos } & 50 & 64 & 14 & & \\
\hline & $(39,1)$ & $(50,0)$ & $(10,9)$ & & \\
\hline \multicolumn{4}{|c|}{ Nível de escolaridade } & & \\
\hline \multirow[t]{2}{*}{ Baixo } & 79 & 141 & 28 & & \\
\hline & $(31,9)$ & $(56,9)$ & $(11,3)$ & & \\
\hline \multirow[t]{2}{*}{ Médio } & 74 & 76 & 7 & 40,1 & $<0,001$ \\
\hline & $(47,1)$ & $(48,4)$ & $(4,5)$ & & \\
\hline \multirow[t]{2}{*}{ Alto } & 156 & 106 & 10 & & \\
\hline & $(57,4)$ & $(39,0)$ & $(3,7)$ & & \\
\hline \multicolumn{4}{|c|}{$\begin{array}{l}\text { Autorrepresentação da dificuldade } \\
\text { económica }\end{array}$} & & \\
\hline \multirow[t]{2}{*}{ Baixa } & 277 & 270 & 23 & & \\
\hline & $(48,6)$ & $(47,4)$ & $(4,0)$ & 47,0 & $<0,001$ \\
\hline \multirow[t]{2}{*}{ Alta } & 29 & 54 & 22 & & \\
\hline & $(27,6)$ & $(51,4)$ & $(21,0)$ & & \\
\hline
\end{tabular}

Repetindo, em larga medida, as tendências que tinham sido já sinalizadas a propósito de análise semelhante ao indicador de qualidade de vida, os fatores de diferenciação considerados apresentam-se com poder discriminante significante e nos mesmos sentidos antes detetados: mulheres com menor satisfação com a vida; satisfação com a 
vida diminui à medida que avança a idade; satisfação com a vida maior entre os mais escolarizados e, sobretudo, entre os que se encontram em melhor situação financeira.

De seguida, efetua-se o mesmo tipo de análise, mas tendo em consideração outra variável caracterizadora da condição de saúde dos idosos, nomeadamente "a presença (ou não) de doença”. Os resultados apresentam-se no quadro 31 abaixo.

Quadro 31. Presença de doença segundo um conjunto selecionado de indicadores de caracterização sociodemográfica $(N=678)$

\begin{tabular}{|c|c|c|c|c|}
\hline & \multicolumn{2}{|c|}{ Presença de doença } & \multirow[b]{2}{*}{$x^{2}$} & \multirow[b]{2}{*}{ p-value } \\
\hline & $\begin{array}{c}\text { Sim } \\
\mathrm{n}(\%)\end{array}$ & $\begin{array}{l}\text { Não } \\
\text { n (\%) }\end{array}$ & & \\
\hline \multicolumn{3}{|l|}{ Sexo } & \multirow{5}{*}{4,63} & \multirow{5}{*}{0,031} \\
\hline \multirow[t]{2}{*}{ Feminino } & 408 & 20 & & \\
\hline & $(95,3)$ & $(4,7)$ & & \\
\hline \multirow[t]{2}{*}{ Masculino } & 228 & 22 & & \\
\hline & $(91,2)$ & $(8,8)$ & & \\
\hline \multicolumn{3}{|c|}{ Grupos etários agregados } & \multirow{7}{*}{12,7} & \multirow{7}{*}{0,002} \\
\hline \multirow[t]{2}{*}{$<70$ anos } & 276 & 30 & & \\
\hline & $(90,2)$ & $(9,8)$ & & \\
\hline \multirow[t]{2}{*}{70 a 79 anos } & 237 & 7 & & \\
\hline & $(97,1)$ & $(2,9)$ & & \\
\hline \multirow[t]{2}{*}{$>79$ anos } & 123 & 5 & & \\
\hline & $(96,1)$ & $(3,9)$ & & \\
\hline \multicolumn{3}{|c|}{ Nível de escolaridade } & \multirow{7}{*}{4,03} & \multirow{7}{*}{0,133} \\
\hline \multirow[t]{2}{*}{ Baixo } & 237 & 11 & & \\
\hline & $(95,6)$ & $(4,4)$ & & \\
\hline \multirow[t]{2}{*}{ Médio } & 149 & 8 & & \\
\hline & $(94,9)$ & $(5,1)$ & & \\
\hline \multirow[t]{2}{*}{ Alto } & 249 & 23 & & \\
\hline & $(91,5)$ & $(8,5)$ & & \\
\hline \multicolumn{3}{|c|}{ Autorrepresentação da dificuldade económica } & \multirow{5}{*}{1,12} & \multirow{5}{*}{0,29} \\
\hline \multirow[t]{2}{*}{ Baixa } & 533 & 37 & & \\
\hline & $(93,5)$ & $(6,5)$ & & \\
\hline \multirow[t]{2}{*}{ Alta } & 101 & 4 & & \\
\hline & $(96,2)$ & $(3,8)$ & & \\
\hline
\end{tabular}

Os resultados obtidos, que se poderia argumentar assentam numa medição mais objetiva da condição de saúde, não decalcam inteiramente aqueles que se obteve com a abordagem subjetiva. Na realidade, a diferença de género, apesar de ainda se esboçar, tem um carácter mais residual (embora continue defavorável às mulheres), mantendose apenas claramente significante a variação etária. No entanto, mesmo esta sofre alguma mudança, com a diferença significante a ser detetada apenas no que distingue 
o grupo etário mais jovem do resto da amostra. Quanto ao poder discriminante das variáveis escolaridade e condição económica, o seu efeito diferenciador desaparece, numa aparente contradição com o que é a vivência subjetiva da condição de bem-estar.

Como referido anteriormente, o consumo de medicação é outro dos aspetos relacionados com o estado de saúde dos idosos. Neste contexto, repetiu-se então a análise de diferenciação sociodemográfica.

Quadro 32. Aquisição de medicação nos últimos 12 meses por fatores sociodemográficos $(N=651)$

\begin{tabular}{|c|c|c|c|c|}
\hline & Falhou na a & e medicação & & \\
\hline & e/ou realiz & atamentos & $v^{2}$ & p- \\
\hline & Sim & Não & & \\
\hline & $n(\%)$ & n (\%) & & \\
\hline Sexo & & & & \\
\hline Feminino & 38 & 390 & & \\
\hline & $(8,9)$ & $(91,1)$ & 0,236 & 0,627 \\
\hline Masculino & 25 & 225 & & \\
\hline & $(10,0)$ & $(90,0)$ & & \\
\hline Grupos etári & & & & \\
\hline$<70$ anos & 35 & 271 & & \\
\hline & $(11,4)$ & $(88,6)$ & & \\
\hline 70 a 79 anos & 24 & 220 & 7,53 & 0,023 \\
\hline & $(9,8)$ & $(90,2)$ & & \\
\hline$>79$ anos & 4 & 124 & & \\
\hline & $(3,1)$ & $(96,9)$ & & \\
\hline Nível de esco & & & & \\
\hline Baixo & 27 & 221 & & \\
\hline & $(10,9)$ & $(89,1)$ & & \\
\hline Médio & 9 & 148 & 3,23 & 0,198 \\
\hline & $(5,7)$ & $(94,3)$ & & \\
\hline Alto & 27 & 245 & & \\
\hline & $(9,9)$ & $(90,1)$ & & \\
\hline Autorreprese & hica & & & \\
\hline Baixa & 47 & 523 & & \\
\hline & $(8,2)$ & $(91,8)$ & 5,12 & 0,024 \\
\hline Alta & 16 & 89 & & \\
\hline & $(15,2)$ & $(84,8)$ & & \\
\hline
\end{tabular}

Relativamente a esta dimensão, voltamos a sinalizar algumas variações nos efeitos antes discutidos. Na realidade, no campo da medicação/tratamentos, uma vez mais a diferença de género desaparece, assim como a diferenciação associada a níveis de escolaridade. A discriminação etária, embora não avassaladora, surge no sentido de ser menos provável falhar medicação/tratamentos à medida que a idade avança. A relação 
com a dificuldade económica percebida alinha com o esperado, com aqueles a declarar maior dificuldade económica a terem maior presença na falha na medicação/tratamentos.

Finalmente, e ainda na exploração da capacidade discriminantes dos fatores sociodemográficos nos indicadores de saúde dos inquiridos, apreciou-se a incidência de quadros de depressão pelos mesmos fatores trabalhados acima. Os resultados exibemse no quadro 33 abaixo.

Quadro 33. Presença de depressão segundo o sexo dos inquiridos ( $N=651)$

\begin{tabular}{|c|c|c|c|c|}
\hline & \multicolumn{2}{|c|}{ Presença de depressão } & \multirow[b]{2}{*}{$x^{2}$} & \multirow[b]{2}{*}{ p-value } \\
\hline & $\begin{array}{c}\text { sem } \\
\text { depressão } \\
\mathrm{n}(\%)\end{array}$ & $\begin{array}{c}\text { com } \\
\text { depressão } \\
\mathrm{n}(\%)\end{array}$ & & \\
\hline \multicolumn{3}{|l|}{ Sexo } & & \\
\hline \multirow[t]{2}{*}{ Feminino } & 288 & 123 & & \\
\hline & $(70,1)$ & $(29,9)$ & 3,75 & 0,053 \\
\hline \multirow[t]{2}{*}{ Masculino } & 185 & 55 & & \\
\hline & $(77,1)$ & $(22,9)$ & & \\
\hline \multicolumn{3}{|c|}{ Grupos etários agregados } & & \\
\hline \multirow[t]{2}{*}{$<70$ anos } & 240 & 56 & & \\
\hline & $(81,1)$ & $(18,9)$ & & \\
\hline \multirow[t]{2}{*}{70 a 79 anos } & 162 & 72 & 23,9 & $<0,001$ \\
\hline & $(69,2)$ & $(30,8)$ & & \\
\hline \multirow[t]{2}{*}{$>79$ anos } & 71 & 50 & & \\
\hline & $(58,7)$ & $(41,3)$ & & \\
\hline \multicolumn{3}{|c|}{ Nível de escolaridade } & & \\
\hline \multirow[t]{2}{*}{ Baixo } & 141 & 91 & & \\
\hline & $(60,8)$ & $(39,2)$ & & \\
\hline \multirow[t]{2}{*}{ Médio } & 108 & 43 & 32,4 & $<0,001$ \\
\hline & $(71,5)$ & $(28,5)$ & & \\
\hline \multirow[t]{2}{*}{ Alto } & 223 & 44 & & \\
\hline & $(83,5)$ & $(16,5)$ & & \\
\hline \multicolumn{3}{|c|}{ Autorrepresentação da dificuldade económica } & & \\
\hline \multirow[t]{2}{*}{ Baixa } & 429 & 124 & & \\
\hline & $(77,6)$ & $(22,4)$ & 48,2 & $<0,001$ \\
\hline \multirow[t]{2}{*}{ Alta } & 41 & 54 & & \\
\hline & $(43,2)$ & $(56,8)$ & & \\
\hline
\end{tabular}

Para este importante indicador de saúde e bem-estar, curiosamente, voltamos a encontrar um quadro geral de fortíssima associação do risco de depressão a um conjunto de características sociodemográficas. A diferença de género é, de todos os indicadores, a que menos se destaca, com uma apenas residual diferença desfavorável 
às mulheres. Já para os restantes indicadores as significâncias são muito fortes, com a idade mais avançada, a baixa escolaridade e a insegurança económica a emergirem como fatores propiciadores da depressão.

\subsection{Cuidados de saúde e redes de apoio médico-social}

A utilização dos cuidados de saúde e das redes de apoio social pelas pessoas com 60 ou mais anos são componentes fundamentais para a promoção da sua qualidade de vida, não só porque influenciam positivamente a sua condição de saúde, mas também porque desempenham um papel protetor fundamental em caso de abusos e violência (Barros et al, 2013).

No nosso estudo, estas redes foram estudadas a partir de variáveis como: o acesso e a frequência do contacto com profissionais de saúde e apoio social; o acesso aos serviços de saúde (públicos e/ou privados); o nível de satisfação em relação aos serviços de saúde (públicos e/ou privados); a ausência de utilização de serviços de saúde; as principais razões para a não utilização desses serviços de saúde.

Começando por descrever a frequência do contacto com profissionais de saúde (nos últimos 12 meses), verifica-se que a larga maioria dos respondentes $(88,5 \%)$ refere ter contactado com um médico de clínica geral uma vez por mês ou menos, sendo que apenas $0,3 \%$ dos respondentes assumem ter contactado um médico de clínica geral várias vezes por semana. Por outro lado, destaca-se o facto de $8,7 \%$ dos inquiridos referir não ter contactado um médico de clínica geral nos últimos 12 meses (ver Quadro 34).

Quadro 34. Frequência do contacto com um Médico de clínica geral

\begin{tabular}{lccc}
\hline Nos últimos $\mathbf{1 2}$ meses com que frequência & & & \\
contactou um Médico de clínica geral & $\mathbf{n}$ & $\mathbf{\%}$ & \% acumulada \\
\hline Nunca & 59 & 8,7 & 8,7 \\
1 vez por mês ou menos & 599 & 88,5 & 97,2 \\
2 a 4 vezes por mês & 16 & 2,4 & 99,6 \\
1 vez por semana & 1 & 0,1 & 99,7 \\
Várias vezes por semana & 2 & 0,3 & 100,0 \\
\hline \multicolumn{4}{c}{ Total } \\
\multicolumn{4}{c}{ Nota: Existe 1 caso omisso que corresponde à resposta "não sabe". }
\end{tabular}

Em relação ao contacto com um médico dentista, podemos verificar que, apesar da maioria dos inquiridos (53,3\%) contactar um dentista uma vez por mês ou menos, $42,4 \%$ assumem nunca o ter feito nos últimos 12 meses (ver Quadro 35). 
Quadro 35. Frequência do contacto com um Dentista

\begin{tabular}{lccc}
\hline $\begin{array}{l}\text { Nos últimos } \mathbf{1 2} \text { meses com que frequência } \\
\text { contactou um Dentista }\end{array}$ & $\mathbf{n}$ & $\mathbf{\%}$ & \% acumulada \\
\hline Nunca & 287 & 42,4 & 42,4 \\
1 vez por mês ou menos & 361 & 53,3 & 95,7 \\
2 a 4 vezes por mês & 23 & 3,4 & 99,1 \\
1 vez por semana & 2 & 0,3 & 99,4 \\
Várias vezes por semana & 4 & 0,6 & 100,0 \\
\hline Total & 677 & 100,0 \\
\hline \multicolumn{4}{c}{ Nota: Existe 1 caso omisso que corresponde à resposta "não sabe". }
\end{tabular}

No que concerne ao contacto com um Oftalmologista verificamos que a maioria dos respondentes $(51,3 \%)$ nunca o fez nos últimos 12 meses, sendo que, no entanto, 48,2\% fizeram-no uma ou menos vezes por mês (ver Quadro 36).

Quadro 36. Frequência do contacto com um Oftalmologista

\begin{tabular}{lccc}
\hline Nos últimos $\mathbf{1 2}$ meses com que frequência & & & \\
contactou um Oftalmologista & $\mathbf{n}$ & $\mathbf{\%}$ & $\mathbf{\%}$ acumulada \\
\hline Nunca & 347 & 51,3 & 51,3 \\
1 vez por mês ou menos & 326 & 48,2 & 99,4 \\
2 a 4 vezes por mês & 4 & 0,6 & 100,0 \\
\hline Total & 677 & 100,0 \\
\hline \multicolumn{4}{c}{ Nota: Existe 1 caso omisso que corresponde à resposta "não sabe". }
\end{tabular}

Quanto ao contacto com outro Médico especialista, para além do Médico de clínica geral, do Dentista e do Oftalmologista, verifica-se que a maioria dos inquiridos $(53,2 \%)$ refere tê-lo feito uma vez por mês ou menos. Porém, destaca-se que $45,1 \%$ dos participantes garantem nunca o ter feito nos últimos 12 meses (ver Quadro 37).

Quadro 37. Frequência do contacto com outro Médico especialista, para além do Dentista e Oftalmologista

\begin{tabular}{lccc}
\hline $\begin{array}{l}\text { Nos últimos } \mathbf{1 2} \text { meses com que frequência } \\
\text { contactou um outro Médico especialista, para } \\
\text { além do Dentista e Oftalmologista }\end{array}$ & $\mathbf{n}$ & $\mathbf{\%}$ & \% acumulada \\
\hline Nunca & 305 & 45,1 & 45,1 \\
1 vez por mês ou menos & 360 & 53,2 & 98,2 \\
2 a 4 vezes por mês & 10 & 1,5 & 99,7 \\
1 vez por semana & 2 & 0,3 & 100,0 \\
\hline Total & 677 & 100,0 & \\
\hline
\end{tabular}

Nota: Existe 1 caso omisso que corresponde à resposta "não sabe".

Também, em relação ao contacto com um Enfermeiro, verifica-se que a maioria dos respondentes $(65,3 \%)$ nunca o fez nos últimos 12 meses. Porém, 30,6\% referem ter 
recorrido a um enfermeiro uma vez por mês ou menos. Destaca-se, ainda, que $0,4 \%$ de indivíduos recorrem diariamente a cuidados de enfermagem (ver Quadro 38).

Quadro 38. Frequência do contacto com um Enfermeiro

\begin{tabular}{lccc}
\hline Nos últimos $\mathbf{1 2}$ meses com que & & & \\
frequência contactou um Enfermeiro & $\mathbf{n}$ & $\mathbf{\%}$ & \% acumulada \\
\hline Nunca & 442 & 65,3 & 65,3 \\
1 vez por mês ou menos & 207 & 30,6 & 95,9 \\
2 a 4 vezes por mês & 7 & 1,0 & 96,9 \\
1 vez por semana & 6 & 0,9 & 97,8 \\
Várias vezes por semana & 12 & 1,8 & 99,6 \\
Diariamente & 3 & 0,4 & 100,0 \\
\hline Total & 677 & 100,0 \\
\hline \multicolumn{4}{c}{ Nota: Existe 1 caso omisso que corresponde à resposta “não sabe”. }
\end{tabular}

No que diz respeito ao contacto com um Psicólogo, praticamente a totalidade dos inquiridos (96,5\%) nunca o fez, sendo que apenas 3,1\% afirma tê-lo feito, uma ou menos vezes por mês, nos últimos 12 meses (Ver Quadro 39).

Quadro 39. Frequência do contacto com um Psicólogo

\begin{tabular}{lccc}
\hline Nos últimos $\mathbf{1 2}$ meses com que frequência & & & \\
contactou um Psicólogo & $\mathbf{n}$ & $\mathbf{\%}$ & \% acumulada \\
\hline Nunca & 654 & 96,5 & 96,5 \\
1 vez por mês ou menos & 21 & 3,1 & 99,6 \\
2 a 4 vezes por mês & 1 & 0,1 & 99,7 \\
1 vez por semana & 1 & 0,1 & 99,9 \\
Várias vezes por semana & 1 & 0,1 & 100,0 \\
\hline Total & 678 & 100,0 & \\
\hline
\end{tabular}

No caso do contacto com um Assistente Social, constata-se que o quadro é muito semelhante ao anterior, ou seja, praticamente a totalidade dos respondentes $(96,9 \%)$ declaram nunca ter contactado um(a) Assistente social nos últimos 12 meses. Contudo, existem 20 respondentes que afirmam tê-lo feito uma ou menos vezes por mês (2,9\%) e um caso que assume contactar um assistente social diariamente (ver Quadro 40).

Quadro 40. Frequência do contacto com um Assistente Social

\begin{tabular}{lccc}
\hline Nos últimos $\mathbf{1 2}$ meses com que frequência & & & \\
contactou um Assistente Social & $\mathbf{n}$ & $\mathbf{\%}$ & \% acumulada \\
\hline Nunca & 657 & 96,9 & 96,9 \\
1 vez por mês ou menos & 20 & 2,9 & 99,9 \\
Diariamente & 1 & 0,1 & 100,0 \\
\hline Total & 678 & 100,0 & \\
\hline
\end{tabular}

Finalmente, em relação à frequência do contacto com qualquer outro profissional de saúde ou de apoio social para além dos anteriormente referidos, podemos verificar que 
a larga maioria dos inquiridos (95\%) nunca o fez. Porém, neste caso, existem 3,2\% dos inquiridos que afirmam ter contactado outro profissional de saúde ou de apoio social uma ou menos vezes por mês (e.g. fisioterapeuta, nutricionista ou técnico de acupuntura) (ver Quadro 41).

Quadro 41. Frequência do contacto com outro profissional de saúde ou de apoio social

\begin{tabular}{lccc}
\hline Nos últimos $\mathbf{1 2}$ meses com que frequência contactou & & & \\
outro profissional de saúde ou de apoio social & $\mathbf{n}$ & $\mathbf{\%}$ & \% acumulada \\
\hline Nunca & 644 & 95,0 & 95,0 \\
1 vez por mês ou menos & 22 & 3,2 & 98,2 \\
2 a 4 vezes por mês & 4 & 0,6 & 98,8 \\
Várias vezes por semana & 7 & 1,0 & 99,9 \\
Diariamente & 1 & 0,1 & 100,0 \\
\hline Total & 678 & 100,0 & \\
\hline
\end{tabular}

Relativamente ao acesso a serviços de saúde, podemos destacar que a larga maioria dos respondentes (78,6\%) recorreu a um Centro de Saúde nos últimos 12 meses, 61,5\% a uma Clínica/Hospital privado e 38,9\% recorreu a consultas externas num Hospital público. Destaca-se ainda o facto de apenas $1,8 \%$ dos inquiridos afirmarem não ter recorrido a nenhum serviço de saúde (público ou privado) nos últimos 12 meses (ver Quadro 42).

Quadro 42. Acesso a serviços de saúde nos últimos 12 meses (mais do que uma resposta possivel) $(N=678)$

\begin{tabular}{lcc}
\hline Nos últimos $\mathbf{1 2}$ meses a que serviços de saúde recorreu? & $\mathbf{n}$ & $\mathbf{\%}$ \\
\hline Centro de saúde & 533 & 78,6 \\
Hospital público, em consultas externas & 264 & 38,9 \\
Hospital público, em internamento & 30 & 4,4 \\
Clínica/Hospital privado & 417 & 61,5 \\
Não recorri a nenhum serviço de saúde & 12 & 1,8 \\
\hline
\end{tabular}

No que diz respeito ao nível de satisfação em relação aos serviços de saúde públicos, verifica-se que, de um total de 567 respondentes que afirmam ter utilizado esse tipo de serviços nos últimos 12 meses, a maioria (54,7\%) declara-se satisfeito, 32,6\% assume estar muito satisfeito, sendo que apenas $4,6 \%$ afirmam estar insatisfeitos ou muito insatisfeitos com os serviços de saúde públicos ( $n=26)$ (ver Quadro 43) 
Quadro 43. Nível de satisfação em relação aos serviços de saúde públicos ( $N=567)$

\begin{tabular}{lccc}
\hline $\begin{array}{l}\text { Qual o seu grau de satisfação em relação a } \\
\text { esses serviços de saúde públicos? }\end{array}$ & $\mathbf{n}$ & $\mathbf{\%}$ & \% acumulada \\
\hline Muito insatisfeito & 7 & 1,2 & 1,2 \\
Insatisfeito & 19 & 3,4 & 4,6 \\
Nem satisfeito nem insatisfeito & 46 & 8,1 & 12,7 \\
Satisfeito & 310 & 54,7 & 67,4 \\
Muito satisfeito & 185 & 32,6 & 100,0 \\
\hline Total & 567 & 100,0 & \\
\hline
\end{tabular}

No caso do nível de satisfação em relação aos serviços de saúde privados, podemos verificar que, de um total de 417 respondentes que afirmam ter utilizado esse tipo de serviços nos últimos 12 meses, a maioria (54,7\%) declara-se satisfeito e 40,8\% muito satisfeito, sendo que apenas $2,6 \%$ afirma estar insatisfeito ou muito insatisfeito com os serviços de saúde privados ( $n=11$ ) (ver Quadro 44). Assim, podemos afirmar que no caso dos serviços de saúde privados existe uma proporção ligeiramente superior de inquiridos que se declaram satisfeitos ou muito satisfeitos com esses serviços.

Quadro 44. Nível de satisfação em relação aos serviços de saúde privados

\begin{tabular}{lccc}
\hline $\begin{array}{l}\text { Qual o seu grau de satisfação em relação a } \\
\text { esses serviços de saúde privados? }\end{array}$ & $\mathbf{n}$ & $\mathbf{\%}$ & \% acumulada \\
\hline Muito insatisfeito & 3 & 0,7 & 0,7 \\
Insatisfeito & 8 & 1,9 & 2,6 \\
Nem satisfeito nem insatisfeito & 8 & 1,9 & 4,6 \\
Satisfeito & 228 & 54,7 & 59,2 \\
Muito satisfeito & 170 & 40,8 & 100,0 \\
\hline Total & 417 & 100,0 & \\
\hline
\end{tabular}

No que concerne à ausência de utilização de serviços de saúde nos últimos 12 meses, constata-se que apenas $9 \%$ dos respondentes afirma ter deixado, por alguma razão, de utilizar algum serviço de saúde ( $n=61$ ), apesar de ter essa necessidade (ver Quadro 45).

Quadro 45. Ausência de utilização de serviços de saúde

\begin{tabular}{lcc}
\hline Nos últimos $\mathbf{1 2}$ meses precisou de ir a algum serviço & & \\
de saúde, mas acabou por não ir? & $\mathbf{n}$ & $\mathbf{\%}$ \\
\hline Sim & 61 & 9,0 \\
Não & 617 & 91,0 \\
\hline Total & 678 & 100,0 \\
\hline
\end{tabular}

Já em relação às principais razões para não terem utilizado os serviços de saúde, podemos verificar que desses $24,6 \%$ referem que deixaram de recorrer a serviços de saúde porque os problemas de saúde desapareceram. Destaca-se, igualmente, a 
proporção dos que referem que a lista de espera era muito longa $(21,3 \%)$ e os que respondem que não conseguiram uma marcação (18\%) (ver Quadro 46).

Quadro 46. Principais razões para não ter utilizado os serviços de saúde (mais do que uma resposta possível) $(\mathrm{N}=61)$

\begin{tabular}{lcc}
\hline Quais as razões para não ter ido a esses serviços de saúde? & $\mathbf{n}$ & $\mathbf{\%}$ \\
\hline Os problemas desapareceram & 15 & 24,6 \\
Lista de espera muito longa & 13 & 21,3 \\
Os serviços de saúde foram difíceis de contactar & 2 & 3,3 \\
Os serviços de saúde não estavam disponíveis & 6 & 9,8 \\
Não teve uma marcação & 11 & 18,0 \\
Não tinha dinheiro para pagar & 6 & 9,8 \\
Não teve tempo & 4 & 6,6 \\
Não podia faltar ao trabalho & 2 & 3,3 \\
Não sabia quem contactar & 3 & 4,9 \\
Outra razão & 14 & 23,0 \\
\hline
\end{tabular}

No que concerne aos respondentes que indicam outros motivos para não ter utilizado os serviços de saúde, podemos destacar a "falta de vontade" (35,7\%), o "esquecimento" $(21,4 \%)$ e a "necessidade de prestar apoio a um familiar" (14,3\%) (ver Quadro 47).

Quadro 47. Outra(s) razões para não ter utilizado os serviços de saúde ( $N=14)$

\begin{tabular}{lcc}
\hline Quais as razões para não ter ido a esses serviços de saúde? & $\mathbf{n}$ & $\mathbf{\%}$ \\
\hline Apoio a familiar & 2 & 14,3 \\
Estava de férias & 1 & 7,1 \\
Estava fora da cidade & 1 & 7,1 \\
Falta de vontade & 5 & 35,7 \\
Por esquecimento & 3 & 21,4 \\
Porque achou que não valia a pena & 1 & 7,1 \\
Porque o marido impediu-a de ir ao médico & 1 & 7,1 \\
\hline Total & 14 & 100,0 \\
\hline
\end{tabular}

Sintetizando, o contacto com profissionais de saúde é principalmente marcado pela consulta com um médico de clínica geral, embora a maioria dos respondentes também admita ter contactado nos últimos 12 meses um dentista, bem como outro(s) médico(s) especialista(s). No entanto, nos outros médicos especialistas mais contactados, não se inclui o Oftalmologista, já que mais de metade dos respondentes admite nunca o ter feito nos últimos 12 meses. A larga maioria dos inquiridos também admite não ter contactado no último ano um enfermeiro, psicólogo, assistente social, bem como com qualquer outro profissional de saúde ou de apoio social para além dos acima referidos.

Relativamente ao acesso a serviços de saúde nos últimos 12 meses, podemos destacar que a larga maioria dos respondentes recorre principalmente aos centros de saúde e/ou 
a clínicas/hospitais privados. Aliás, poucos são aqueles que assumem não ter recorrido a nenhum serviço de saúde (público ou privado) nos últimos 12 meses (apenas 1,8\%). Por outro lado, o nível de satisfação em relação aos serviços de saúde públicos é, em termos gerais, ligeiramente inferior ao verificado em relação aos serviços de saúde privados.

Por fim, verifica-se que menos de $10 \%$ dos respondentes deixaram, por alguma razão, de utilizar algum serviço de saúde nos últimos 12 meses, apesar de terem essa necessidade. No entanto, entre os que admitem ter deixado de o fazer, surgem o desaparecimento dos sintomas, as listas de espera, a falta de disponibilidade dos serviços e a falta de dinheiro, como as principais razões invocadas. 


\section{Prevalência de abuso}

Neste ponto, apresentam-se os resultados obtidos para três dos objetivos centrais deste estudo, designadamente: identificar a prevalência dos diferentes tipos de abusos entre os participantes e os fatores que aumentam o risco de exposição a comportamentos abusivos e violentos; avaliar se o declínio das condições socioeconómicas conduziu à ocorrência de abusos; analisar em que medida o agravamento dos indicadores gerais de saúde, tornou os participantes no estudo mais vulneráveis à violência.

Importa, porém, referir que apesar de a amostra do estudo ser composta por 678 indivíduos, existe um caso do sexo masculino que recusou responder a todas as questões sobre esta temática. Optou-se por tratar esse caso como omisso pelo que nas análises seguintes se assume que a dimensão da amostra é de 677 indivíduos. No primeiro subponto é analisada a prevalência de abuso global, procurando-se identificar os grupos de maior exposição ao fenómeno.

\subsection{Prevalência de abuso segundo as características sociodemográficas e económicas das vítimas}

A prevalência de abuso global, independentemente do tipo de abuso, é de $23,9 \%$. Cerca de 1 em cada 4 inquiridos reporta ter vivenciado, pelo menos, uma situação de abuso nos 12 meses anteriores à aplicação do questionário (Quadro 48).

Quadro 48. Prevalência de abuso

\begin{tabular}{lcc}
\hline Presença de qualquer tipo de abuso & $\mathbf{n}$ & $\mathbf{\%}$ \\
\hline Sim & 162 & 23,9 \\
Não & 515 & 76,1 \\
\hline Total & 677 & 100,0 \\
\hline
\end{tabular}

A partir da sinalização da ocorrência de situações de abuso, procurou perceber-se e identificar-se, na exploração dos perfis sociodemográficos dos que o experienciam, tendências estatisticamente significantes que auxiliem a compreender os contextos de vida em que o abuso é propiciado.

No enquadramento teórico que serviu de referência a este estudo foram identificados inúmeros fatores de risco como a interação entre os cuidadores informais e formais e as características comportamentais e de saúde dos idosos; problemas económicos; comportamentos aditivos do agressor; situações de isolamento e pobreza (Dias, Lopes \& Lemos, 2019b; Wolf e Pillemer, 1989); determinantes estruturais e sistema de crenças, normas e atitudes face à pessoa idosa; relações familiares, conjugais, filiais, contexto familiar (Gil, 2014; Schiamberg \& Gans, 1999; Dias, Lopes \& Lemos, 2019a), mas também as desigualdades de género e a exposição das mulheres aos ciclos de 
pobreza o que as expõe, mais do que aos homens, a situações de exclusão social e de violência (Whittaker, 1995).

Quadro 49. Prevalência de abuso segundo um conjunto de indicadores sociodemográficos (OR brutos e risco relativo)

\begin{tabular}{|c|c|c|c|c|c|}
\hline & $\begin{array}{l}\text { Prevalência } \\
\text { de abuso \% }\end{array}$ & $\chi^{2}$ & p-value & $\begin{array}{c}\text { OR } \\
\text { [IC 95\%] }\end{array}$ & $\begin{array}{c}\text { Risco } \\
\text { relativo } \\
\text { [IC 95\%] }\end{array}$ \\
\hline \multicolumn{6}{|l|}{ Sexo } \\
\hline Feminino & 26,2 & 3,21 & 0,073 & 0,709 & 0,924 \\
\hline Masculino & 20,1 & & & {$[0,486-1,03]$} & {$[0,849-1,00]$} \\
\hline \multicolumn{6}{|l|}{$\overline{\text { Grupos etários agregados }}$} \\
\hline$<70$ anos & 22,9 & \multirow{4}{*}{5,08} & & 0 & \multirow{4}{*}{$\mathrm{n} / \mathrm{a}$} \\
\hline 70 a 79 anos & 28,3 & & 0,079 & $\begin{array}{c}1,329 \\
{[0,904-1,955]}\end{array}$ & \\
\hline \multirow[t]{2}{*}{$>79$ anos } & 18,1 & & & 0,746 & \\
\hline & & & & {$[0,441-1,26]$} & \\
\hline \multicolumn{6}{|l|}{ Nível de Escolaridade } \\
\hline Baixo & 23,1 & \multirow{3}{*}{5,07} & & 0 & \multirow{3}{*}{$\mathrm{n} / \mathrm{a}$} \\
\hline Médio & 18,5 & & 0,079 & $\begin{array}{c}0,755 \\
{[0,458-1,245]}\end{array}$ & \\
\hline Alto & 27,9 & & & $\begin{array}{c}1,293 \\
{[0,869-1,923]}\end{array}$ & \\
\hline \multicolumn{6}{|l|}{ Composição do agregado doméstico } \\
\hline $\begin{array}{l}\text { Sozinho(a) } \\
\text { Cônjuge/Companheiro(a) e/ou outras } \\
\text { pessoas/familiares }\end{array}$ & 25,4 & 2,69 & 0,101 & $\begin{array}{c}1,45 \\
{[0,928-2,28]}\end{array}$ & $\begin{array}{c}1,09 \\
{[0,991-1,19]}\end{array}$ \\
\hline \multicolumn{6}{|l|}{ Situação perante a conjugalidade } \\
\hline Vive em conjugalidade & 24,4 & \multirow[t]{2}{*}{0,155} & \multirow[t]{2}{*}{0,694} & 0,929 & \multirow{2}{*}{$\begin{array}{c}0,983 \\
{[0,901-1,07]}\end{array}$} \\
\hline Não vive em conjugalidade & 23,1 & & & {$[0,642-1,34]$} & \\
\hline \multicolumn{6}{|c|}{ Autorrepresentação da dificuldade económica } \\
\hline$\overline{\text { Baixa }}$ & 22,1 & \multirow[t]{2}{*}{7,21} & \multirow[t]{2}{*}{0,007} & 1,84 & \multirow{2}{*}{$\begin{array}{c}1,19 \\
{[1,03-1,37]}\end{array}$} \\
\hline Alta & 34,3 & & & {$[1,17-2,88]$} & \\
\hline \multicolumn{6}{|l|}{ Segurança alimentar do agregado } \\
\hline Alta ou ligeira & 22,8 & \multirow{3}{*}{15,4} & & 0 & \multirow{3}{*}{$\mathrm{n} / \mathrm{a}$} \\
\hline Baixa & 29,4 & & $<0,001$ & $\begin{array}{c}1,412 \\
{[0,66-3,022]}\end{array}$ & \\
\hline Muito Baixa & 72,7 & & & $\begin{array}{c}9,037 \\
{[2,367-34,508]}\end{array}$ & \\
\hline \multicolumn{6}{|l|}{ Suporte social percebido } \\
\hline Baixo & 50,0 & \multirow{3}{*}{6,38} & & 0 & \multirow{3}{*}{$\mathrm{n} / \mathrm{a}$} \\
\hline Moderado & 27,0 & & 0,041 & $\begin{array}{c}0,37 \\
{[0,114-1,196]}\end{array}$ & \\
\hline Alto & 22,1 & & & $\begin{array}{c}0,283 \\
{[0,089-0,896]}\end{array}$ & \\
\hline
\end{tabular}


Contrariamente ao que alguma literatura sugere (Whittaker, 1995; Perel-Levin, 2008), na amostra inquirida a diferença de género não é particularmente significante. Embora seja ligeiramente maior a prevalência de abuso entre as mulheres, a diferença observada não só não é estatisticamente significante, como não se constitui num aparente fator de risco. Na mesma linha segue a leitura ao efeito da variável idade, não existindo, segundo os nossos resultados, evidência que sustente que o avançar da idade se traduzirá numa maior vulnerabilidade face ao risco de abuso. A mesma conclusão ainda se extrai para o efeito de fatores como a escolaridade, o modelo familiar ou a situação conjugal.

Já bem diferente é a conclusão a que chegamos quando procuramos avaliar até que ponto a vulnerabilidade económica se constitui como fator de risco para o abuso. Aqui, e sem grande margem para dúvida, os efeitos são muito significantes, com aqueles numa posição menos favorável nos indicadores que medem condições materiais de vida a exibirem um risco substancialmente maior de exposição a situações de abuso. Aqueles que com maior insegurança económica quase que duplicam o risco de abuso; aqueles com muito baixa segurança alimentar exibem um risco de exposição a abuso cerca de 9 vezes superior ao dos que apresentam muito alta segurança alimentar.

Um efeito menos claro, mas ainda assim significante, e de tipo protetor, foi o efeito identificado para a robustez das redes sociais do inquirido. Aqueles que apresentam redes mais fracas tendem a ter um risco maior de exposição a situações de abuso.

Estes resultados enquadram-se na linha de outros estudos que têm vindo a demonstrar uma associação entre as desigualdades socioeconómicas (Fraga et al., 2014); a ausência de uma rede sociofamiliar de apoio e o abuso de idosos (Melchiorre et al., 2013; Soares et al., 2013). Reforçam ainda o ponto de partida deste estudo que consiste em demonstrar a maior exposição da população mais velha a abusos e violência em contextos de vulnerabilidade económica, tal como foi o período de crise económica vivido em Portugal com particular severidade entre 2008 e 2011.

\subsection{Prevalência de abuso segundo a condição de saúde das vítimas}

Neste ponto procede-se a uma análise focada na prevalência de abuso (qualquer tipo de abuso) segundo as condições de saúde dos idosos, anteriormente descritas no ponto 5. Aqui a finalidade consiste em compreender se a condição de saúde das vítimas é potencialmente explicativa da ocorrência de episódios de abuso e violência. Esta análise tem merecido particular atenção na investigação desenvolvida neste âmbito, demonstrando-se que o estado de saúde do idoso agrava a sua condição de vulnerabilidade, potenciando-se assim o risco de abuso (Baltes, 1996; Soares et al, 2010; Dong et al., 2013). 
Quadro 50. Prevalência de abuso segundo indicadores da condição de saúde ( $N=677)$

\begin{tabular}{|c|c|c|c|c|c|}
\hline & $\begin{array}{l}\text { Prevalência } \\
\text { de abuso \% }\end{array}$ & $x^{2}$ & p-value & $\begin{array}{l}\text { OR } \\
\text { [IC 95\%] }\end{array}$ & $\begin{array}{c}\text { Risco } \\
\text { relativo } \\
\text { [IC 95\%] }\end{array}$ \\
\hline \multicolumn{6}{|l|}{ Autoavaliação da condição de saúde } \\
\hline Razoável, boa ou muito boa & 22,9 & 5,08 & 0,024 & 2,04 & 1,24 \\
\hline Má ou muito má & 37,8 & & & {$[1,09-3,83]$} & {$[0,982-1,56]$} \\
\hline \multicolumn{6}{|l|}{ Presença de doença } \\
\hline Sim & 24,3 & 0,586 & 0,444 & 0,735 & 0,936 \\
\hline Não & 19,0 & & & {$[0,333-1,62]$} & {$[0,803-1,09]$} \\
\hline \multicolumn{6}{|c|}{ Falha na medicação e/ou tratamentos prescritos } \\
\hline Não & 22,1 & 11,5 & $<0,001$ & 2,47 & 1,33 \\
\hline Sim & 41,3 & & & {$[1,44-4,22]$} & {$[1,07-1,64]$} \\
\hline \multicolumn{6}{|l|}{ Presença de depressão } \\
\hline Sem depressão & 18,4 & 26,4 & $<0,001$ & 2,67 & 1,31 \\
\hline Com depressão & 37,6 & & & {$[1,82-3,91]$} & {$[1,16-1,48]$} \\
\hline \multicolumn{6}{|l|}{$\begin{array}{l}\text { Presença de dificuldade na realização de } \\
\text { Atividades da Vida Diária (AVD) }\end{array}$} \\
\hline Sem dificuldade em todas as AVD & 22,0 & 3,27 & 0,071 & 1,42 & 1,09 \\
\hline Com dificuldade em uma ou mais AVD & 28,6 & & & {$[0,97-2,06]$} & {$[0,987-1,21]$} \\
\hline
\end{tabular}

Nesse sentido, começando por analisar a ocorrência de abuso (qualquer tipo) segundo autoavaliação da condição de saúde dos inquiridos (variável agregada), podemos verificar que $22,9 \%$ dos que avaliam a sua saúde como «Muito boa, boa ou razoável afirmam ter sido vítimas de abuso, sendo que no caso dos que avaliam a sua saúde como "Má ou muito má» a proporção dos que reportam um qualquer tipo de abuso é substancialmente superior (37,8\%). Conclui-se, assim que parece existir uma relação entre a autoavaliação negativa da condição de saúde e a ocorrência de abuso (Quadro 50). Pode mesmo afirmar-se que uma autoavaliação da própria saúde menos favoravelmente é mais de duas vezes superior. Curiosamente, a conclusão não se mantém quando a medição da condição de saúde se faz a partir do indicador presença/ausência de doença. $O$ que os resultados indicam é que a presença de doença diagnosticada não tem qualquer efeito no risco de ocorrência de algum tipo de abuso.

Este tipo de aparente contradição pode remeter para domínios de explicação distintos, embora complementares, que são aprofundados no estudo qualitativo. Podemos estar perante um cenário que ilustra a amplamente discutida dicotomia relativa à forma como os sujeitos experienciam a sua saúde e aquilo que são os indicadores clínicos usados para medir saúde (ou doença), dois lados de uma moeda que nem sempre parece ser a mesma. Podemos, ainda, estar a sinalizar os efeitos de uma causalidade sempre discutível, onde causa e efeito têm fronteiras fluídas. Seja como for, a evidência é em si 
muito relevante na medida em que alerta para a importância de dar voz aos sujeitos, nomeadamente na análise do seu estado de saúde, já que essa voz eventualmente contará histórias que os indicadores mais objetivos de condição clínica poderão não captar (WHO/INEPEA, 2002; Fieldstone et al., 2015).

Em relação à prevalência de abuso segundo a presença de sintomas de depressão, verifica-se que $37,6 \%$, dos inquiridos que apresentam sintomas de depressão reportam abuso, uma proporção superior face aos inquiridos que não apresentam sintomas de depressão (18,4\%). A conclusão geral de que a presença de sintomas de depressão está associada a uma maior exposição a situações de abuso tem, uma vez mais, de ser interpretada com alguma cautela já que se trata de um domínio onde, uma vez mais, causa e efeito se podem confundir. Seja como for, e como pista para deteção de situações de vulnerabilidade face ao abuso, indivíduos com sinais de depressão exibem um risco de exposição a abuso que é mais do dobro daquele identificado para quem não tem depressão.

Também significante é a associação entre a não concretização de tratamentos e/ou tomas de medicação e a exposição ao abuso. De novo se coloca o questionamento sobre o que é a causa e o que é o efeito, mas o facto permanece relevante - aqueles que exibem um padrão de menor cuidado com a sua saúde apresentam um risco maior, quase três vezes maior, de exposição a situações de abuso.

Finalmente, olhamos para a relação entre a situação de dependência em AVDs e a ocorrência de abuso (Gil, 2014; Schiamberg \& Gans, 1999; Wolf e Pillemer, 1989), procurando encontrar evidência empírica na nossa amostra que corroborasse a discussão encontrada na literatura sobre o contexto de cuidado como um contexto propiciador de ocorrência de abuso (Pillemer et al., 2016). Na realidade, os resultados a apontar nesse sentido fazem-no com uma significância muito marginal, em todo o caso insuficiente para sustentar tal conclusão.

\subsection{Prevalência de abuso por tipos ${ }^{7}$}

No presente estudo foram considerados cinco tipos de abusos, o que implica que se proceda a uma análise diferenciada da distribuição por tipo de abuso reportado pelos inquiridos. Nesse sentido, podemos verificar que o abuso psicológico assume particular destaque $(19,9 \%, n=135)$. Todos os restantes tipos de abuso apresentam prevalências bastante inferiores, nomeadamente o abuso financeiro $(5,8 \%)$, o abuso físico $(2,5 \%)$, o abuso sexual $(1,9 \%)$ e as lesões físicas $(0,9 \%)$ (ver Quadro 51$)$.

\footnotetext{
${ }^{7}$ Nesta secção, e dados os valores muito baixos para algumas modalidades de abuso, optou-se por não realizar análises de significância estatística, antes retendo a descrição geral que é possível observar nos dados amostrais recolhidos.
} 
Quadro 51. Prevalência por tipo de abuso

\begin{tabular}{lcc}
\hline Tipo de abuso & $\mathbf{n}$ & $\mathbf{\%}$ \\
\hline Abuso psicológico & 135 & 19,9 \\
Abuso financeiro & 39 & 5,8 \\
Abuso físico & 17 & 2,5 \\
Abuso sexual & 13 & 1,9 \\
Lesões físicas & 6 & 0,9 \\
\hline
\end{tabular}

A prevalência de abuso financeiro nos homens $(6,4 \%)$ é ligeiramente superior à das mulheres (5,4\%). No entanto, nos restantes tipos de abusos considerados, as mulheres apresentam prevalências de abuso superiores à dos homens, sobretudo no caso do abuso psicológico (22,7\% contra $15,3 \%$ respetivamente). Podemos assim concluir que, com a exceção do abuso financeiro, as mulheres apresentam uma maior exposição aos diversos tipos de abuso (ver Quadro 52).

Quadro 52. Prevalência por tipo de abuso por sexo

\begin{tabular}{lcccccc}
\hline & & \multicolumn{5}{c}{ Tipo abuso } \\
\cline { 2 - 6 } Sexo & & $\begin{array}{c}\text { Abuso } \\
\text { psicológico }\end{array}$ & $\begin{array}{c}\text { Abuso } \\
\text { financeiro }\end{array}$ & $\begin{array}{c}\text { Abuso } \\
\text { físico }\end{array}$ & $\begin{array}{c}\text { Abuso } \\
\text { sexual }\end{array}$ & $\begin{array}{c}\text { Lesões } \\
\text { físicas }\end{array}$ \\
\hline $\begin{array}{l}\text { Masculino } \\
\text { (n=249) }\end{array}$ & $\mathrm{n}$ & 38 & 16 & 3 & 2 & 0 \\
& $\%$ & 15,3 & 6,4 & 1,2 & 0,8 & 0,0 \\
Feminino & $\mathrm{n}$ & 97 & 23 & 14 & 11 & 6 \\
$(\mathrm{n}=428)$ & $\%$ & 22,7 & 5,4 & 3,3 & 2,6 & 1,4 \\
\hline
\end{tabular}

Relativamente à análise da prevalência segundo a idade dos inquiridos, podemos destacar que o grupo etário composto pelos indivíduos com idades compreendidas entre os 70 e os 79 anos é o que apresenta maior prevalência de abuso em todos os tipos considerados. Por outro lado, com a exceção do abuso financeiro, o grupo etário constituído pelos $80+$ é o que apresenta uma menor exposição a situações de abuso (ver Quadro 53). 
Quadro 53. Prevalência de abuso por idade (agregada)

\begin{tabular}{lcccccc}
\hline \multirow{2}{*}{$\begin{array}{l}\text { Grupos etários } \\
\text { agregados }\end{array}$} & & $\begin{array}{c}\text { Abuso } \\
\text { psicológico }\end{array}$ & $\begin{array}{c}\text { Abuso } \\
\text { financeiro }\end{array}$ & $\begin{array}{c}\text { Abuso } \\
\text { físico }\end{array}$ & $\begin{array}{c}\text { Abuso } \\
\text { sexual }\end{array}$ & $\begin{array}{c}\text { Lesões } \\
\text { físicas }\end{array}$ \\
\hline$<70$ Anos & $\mathrm{n}$ & 59 & 15 & 5 & 5 & 1 \\
(n=306) & $\%$ & 19,3 & 4,9 & 1,6 & 1,6 & 0,3 \\
& & & & & & \\
70 a 79 anos & $\mathrm{n}$ & 58 & 16 & 10 & 8 & 4 \\
(n=244) & $\%$ & 23,8 & 6,6 & 4,1 & 3,3 & 1,6 \\
& & & & & & \\
$>79$ Anos & $\mathrm{n}$ & 18 & 8 & 2 & 0 & 1 \\
$(\mathrm{n}=127)$ & $\%$ & 14,2 & 6,3 & 1,6 & 0,0 & 0,8 \\
\hline
\end{tabular}

Analisando a prevalência tendo em consideração a composição do agregado habitacional (i.e., com quem vive na maioria do tempo, variável agregada), podemos destacar que, com a exceção do abuso sexual, onde existe uma prevalência ligeiramente superior entre as pessoas que vivem num agregado unipessoal (i.e., vivem sozinhos), nos restantes tipos de abuso existe uma maior exposição a situações de abuso entre os indivíduos que partilham o agregado com outras pessoas, seja com o cônjuge, companheiro(a) e/ou outras pessoas ou outros familiares (ver Quadro 54).

Quadro 54. Prevalência de abuso por composição do agregado habitacional

\begin{tabular}{lcccccc}
\hline & \multicolumn{5}{c}{ Tipo abuso } \\
\cline { 2 - 7 } $\begin{array}{l}\text { Com quem vive na } \\
\text { maioria do tempo }\end{array}$ & $\begin{array}{c}\text { Abuso } \\
\text { psicológico }\end{array}$ & $\begin{array}{c}\text { Abuso } \\
\text { financeiro }\end{array}$ & $\begin{array}{c}\text { Abuso } \\
\text { físico }\end{array}$ & $\begin{array}{c}\text { Abuso } \\
\text { sexual }\end{array}$ & $\begin{array}{c}\text { Lesões } \\
\text { físicas }\end{array}$ \\
\hline Sozinho(a) & $n$ & 26 & 6 & 2 & 4 & 1 \\
$(n=153)$ & $\%$ & 17,0 & 3,9 & 1,3 & 2,6 & 0,7
\end{tabular}

Cônjuge/Companheiro

\begin{tabular}{|c|c|c|c|c|c|c|}
\hline pessoas/familiares & $\mathrm{n}$ & 109 & 33 & 15 & 9 & 5 \\
\hline$(n=524)$ & $\%$ & 20,8 & 6,3 & 2,9 & 1,7 & 1,0 \\
\hline
\end{tabular}

A análise dos diferentes tipos de abuso tendo em consideração o nível de escolaridade (variável agregada) permite-nos verificar que os indivíduos que apresentam níveis de escolaridade mais baixos são os que revelam uma prevalência superior de abuso físico $(4,5 \%)$, de abuso sexual $(2,4 \%)$ e de lesões físicas $(2,4 \%)$, quando comparadas com as outras categorias. Os inquiridos que se situam nos níveis escolares mais elevados apresentam maior prevalência de abuso psicológico $(22,8 \%)$ e de abuso financeiro $(7,4 \%)$ (ver Quadro 55). 
Quadro 55. Prevalência de abuso por nível de escolaridade (agregada)

\begin{tabular}{lcccccc}
\hline & & \multicolumn{5}{c}{ Tipo abuso } \\
\cline { 2 - 6 } Nível de & & $\begin{array}{c}\text { Abuso } \\
\text { escolaridade }\end{array}$ & $\begin{array}{c}\text { Abuso } \\
\text { financeiro }\end{array}$ & $\begin{array}{c}\text { Abuso } \\
\text { físico }\end{array}$ & $\begin{array}{c}\text { Abuso } \\
\text { sexual }\end{array}$ & $\begin{array}{c}\text { Lesões } \\
\text { físicas }\end{array}$ \\
\hline Baixa & $\mathrm{n}$ & 49 & 11 & 11 & 6 & 6 \\
$(\mathrm{n}=247)$ & $\%$ & 19,8 & 4,5 & 4,5 & 2,4 & 2,4 \\
& & & & & & \\
Média & $\mathrm{n}$ & 24 & 8 & 2 & 1 & 0 \\
$(\mathrm{n}=157)$ & 15,3 & 5,1 & 1,3 & 0,6 & 0,0 \\
& & & & & & \\
Alta & $\mathrm{n}$ & 62 & 20 & 4 & 6 & 0 \\
$(\mathrm{n}=272)$ & 22,8 & 7,4 & 1,5 & 2,2 & 0,0 \\
\hline
\end{tabular}

Os indivíduos que percecionam o rendimento do seu agregado como insuficiente apresentam uma maior prevalência de abuso psicológico (32,4\%), de abuso físico $(8,6 \%)$, de abuso sexual $(4,8 \%)$ e de lesões físicas $(2,9 \%)$ quando comparado com os indivíduos que consideram o rendimento do agregado suficiente, que apenas apresentam uma prevalência superior no caso do abuso financeiro (6,0\%) (Quadro 56).

Quadro 56. Prevalência de abuso por perceção do rendimento do agregado como insuficiente

\begin{tabular}{|c|c|c|c|c|c|c|}
\hline \multirow{2}{*}{$\begin{array}{l}\text { Perceção do } \\
\text { rendimento do } \\
\text { agregado como } \\
\text { insuficiente }\end{array}$} & & \multicolumn{5}{|c|}{ Tipo abuso } \\
\hline & & $\begin{array}{c}\text { Abuso } \\
\text { psicológico }\end{array}$ & $\begin{array}{c}\text { Abuso } \\
\text { financeiro }\end{array}$ & $\begin{array}{l}\text { Abuso } \\
\text { físico }\end{array}$ & $\begin{array}{l}\text { Abuso } \\
\text { sexual }\end{array}$ & $\begin{array}{l}\text { Lesões } \\
\text { físicas }\end{array}$ \\
\hline Não & $\mathrm{n}$ & 101 & 34 & 8 & 8 & 3 \\
\hline$(n=570)$ & $\%$ & 17,7 & 6,0 & 1,4 & 1,4 & 0,5 \\
\hline Sim & $\mathrm{n}$ & 34 & 5 & 9 & 5 & 3 \\
\hline$(n=105)$ & $\%$ & 32,4 & 4,8 & 8,6 & 4,8 & 2,9 \\
\hline
\end{tabular}

Ao analisarmos a prevalência de cada um dos diferentes tipos de abuso tendo em consideração o nível de segurança alimentar verifica-se que a larga maioria $(72,7 \%)$ dos indivíduos que apresentam uma segurança alimentar muito baixa reporta abuso psicológico. Os indivíduos que apresentam uma segurança alimentar baixa $(n=34)$ destacam-se na prevalência de abuso físico (11,8\%). Já os indivíduos que apresentam uma segurança alimentar média ou alta $(n=632)$, apresentam uma prevalência de abuso psicológico relativamente mais baixa $(18,5 \%)$ quando comparada com as restantes categorias (Quadro 57). 
Quadro 57. Prevalência de abuso por nível de segurança alimentar (agregada)

\begin{tabular}{lcccccc}
\hline $\begin{array}{l}\text { Nível de } \\
\text { segurança }\end{array}$ & & \multicolumn{5}{c}{ Tipo abuso } \\
\cline { 2 - 7 } alimentar & & $\begin{array}{c}\text { Abuso } \\
\text { psicológico }\end{array}$ & $\begin{array}{c}\text { Abuso } \\
\text { financeiro }\end{array}$ & $\begin{array}{c}\text { Abuso } \\
\text { físico }\end{array}$ & $\begin{array}{c}\text { Abuso } \\
\text { sexual }\end{array}$ & $\begin{array}{c}\text { Lesões } \\
\text { físicas }\end{array}$ \\
\hline $\begin{array}{l}\text { Alta ou ligeira } \\
\text { (n=632) }\end{array}$ & $\mathrm{n}$ & 117 & 37 & 12 & 12 & 5 \\
& $\%$ & 18,5 & 5,9 & 1,9 & 1,9 & 0,8 \\
Baixa & $\mathrm{n}$ & 10 & 1 & 4 & 0 & 1 \\
(n=34) & $\%$ & 29,4 & 2,9 & 11,8 & 0,0 & 2,9 \\
& & & & & & \\
Muito baixa & $\mathrm{n}$ & 8 & 1 & 1 & 1 & 0 \\
(n=11) & $\%$ & 72,7 & 9,1 & 9,1 & 9,1 & 0,0 \\
\hline
\end{tabular}

No que diz respeito à prevalência dos diferentes tipos de abuso tendo em consideração os níveis de suporte social percebido, em relação aos indivíduos que indicam um nível de suporte social baixo podemos destacar que a prevalência de abuso psicológico atinge os $50 \%$ e $16,7 \%$ no caso do abuso físico. Nos restantes tipos de abuso a prevalência de casos é muito reduzida. Os indivíduos que indicam um suporte social moderado destacam-se pela prevalência de abuso psicológico (25\%), de abuso financeiro (5,5\%) e de abuso físico (4\%). Relativamente aos indivíduos que percecionam níveis mais elevados de suporte social, destaca-se sobretudo a prevalência de abuso psicológico (17\%) e de abuso financeiro (5,9\%) (ver Quadro 58).

Quadro 58. Prevalência de abuso por nível de suporte social percebido

\begin{tabular}{lcccccc}
\hline & \multicolumn{5}{c}{ Tipo abuso } \\
\cline { 2 - 7 } $\begin{array}{l}\text { Suporte social } \\
\text { percebido }\end{array}$ & & $\begin{array}{c}\text { Abuso } \\
\text { psicológico }\end{array}$ & $\begin{array}{c}\text { Abuso } \\
\text { financeiro }\end{array}$ & $\begin{array}{c}\text { Abuso } \\
\text { físico }\end{array}$ & $\begin{array}{c}\text { Abuso } \\
\text { sexual }\end{array}$ & $\begin{array}{c}\text { Lesões } \\
\text { físicas }\end{array}$ \\
\hline Baixo & $\mathrm{n}$ & 6 & 1 & 2 & 0 & 1 \\
$(\mathrm{n}=12)$ & $\%$ & 50,0 & 8,3 & 16,7 & 0,0 & 8,3 \\
& & & & & & \\
Moderado & $\mathrm{n}$ & 50 & 11 & 8 & 4 & 1 \\
(n=200) & $\%$ & 25,0 & 5,5 & 4,0 & 2,0 & 0,5 \\
& & & & & & \\
Alto & $\mathrm{n}$ & 78 & 27 & 7 & 9 & 4 \\
(n=458) & $\%$ & 17,0 & 5,9 & 1,5 & 2,0 & 0,9 \\
\hline
\end{tabular}

Resumindo, a prevalência de abuso psicológico é claramente mais expressiva entre os diferentes tipos de abuso, bem como em todas as categorias aqui consideradas. No entanto, destaca-se a maior exposição ao abuso psicológico das mulheres, indivíduos com idades compreendidas entre os 70 e os 79 anos, indivíduos que partilham o agregado com outras pessoas, dos que apresentam níveis escolares mais elevados, dos que percecionam o rendimento do seu agregado como insuficiente, dos que apresentam 
uma segurança alimentar muito baixa, bem como dos que percecionam baixo suporte social.

Destaca-se, igualmente, a exposição mais expressiva ao abuso financeiro dos homens, indivíduos com idades compreendidas entre os 70 e os 79 anos, dos que partilham o agregado com outras pessoas, dos que apresentam níveis escolares mais elevados, dos que não percecionam o rendimento do seu agregado como insuficiente, dos que apresentam níveis de segurança alimentar e de suporte social mais baixos.

Por fim, destaca-se uma exposição mais expressiva ao abuso físico das mulheres, indivíduos com idades compreendidas entre os 70 e os 79 anos, dos que partilham o agregado com outras pessoas, dos que apresentam níveis escolares mais baixos, dos que percecionam o rendimento do seu agregado como insuficiente, dos que apresentam uma segurança alimentar baixa, assim como dos que percecionam níveis mais baixos de suporte social. 


\section{Os agressores}

A análise relativa à identificação dos abusadores permite-nos verificar que, independentemente do tipo de abuso considerado, os Maridos, Esposas ou Companheiros(as), são os mais referidos como tendo provocado as situações de abuso, sendo essa opção assinalada por $28,1 \%$ das vítimas. A opção genérica "outros», assinalada por 51 inquiridos, inclui casos em que o laço entre agressor e vítima era outro que não o previsto ou situações em que o abusador não era alguém conhecido da vítima. Esta última situação representa metade dessa categoria genérica (24 casos).

Quadro 59. Identificação do(a) abusador(a) (mais do que uma resposta possível)

\begin{tabular}{lc}
\hline & Tipo de abuso \\
Indique por favor quem é que provocou as & Qualquer tipo de abuso \\
situações que referiu. & $(\mathrm{n}=160)^{\mathrm{a}}$ \\
\hline Marido/Esposa/Companheiro(a) & $28,1 \%$ \\
Filha & $8,1 \%$ \\
Filho & $11,9 \%$ \\
Nora & $1,3 \%$ \\
Genro & $0,0 \%$ \\
Irmã & $9,4 \%$ \\
Irmão & $5,0 \%$ \\
Neta & $0,6 \%$ \\
Neto & $0,0 \%$ \\
Amigo & $2,5 \%$ \\
Amiga & $2,5 \%$ \\
Conhecido/Colega & $3,8 \%$ \\
Conhecida/Colega & $2,5 \%$ \\
Vizinha & $7,5 \%$ \\
Vizinho & $5,0 \%$ \\
Cuidador profissional remunerado & $0,0 \%$ \\
Mulher-a-dias/empregada doméstica & $0,6 \%$ \\
Funcionário(a) do centro de dia & $0,0 \%$ \\
Profissional de saúde (médico, enfermeiro, ...) & $1,3 \%$ \\
Outro(s) & $31,9 \%$ \\
\hline
\end{tabular}

a Existem 2 casos que correspondem a respostas: "recusa".

Porém, quando analisámos a identificação do(s) agressor(es) segundo o tipo de abuso, verifica-se que o padrão de respostas é relativamente diferenciado. Sendo assim, em relação às situações de abuso psicológico destacam-se os Maridos, Esposas ou Companheiros(as) como agressores mais nomeados pelas vítimas $(32,8 \%)$, seguindo-se os filhos $(13,4 \%)$ e outras pessoas para além dos discriminados (20,1\%). Em relação ao abuso físico, a tendência é semelhante, ou seja, as vítimas indicam como agressores, sobretudo, os Maridos, Esposas ou Companheiros(as) (43,8\%) e os filhos (18,8\%). No 
caso do abuso físico com lesões, apesar do número reduzido de casos (5), três dessas vítimas (60\%) indicam como agressor os Maridos, Esposas ou Companheiros(as), uma refere a vizinha (20\%) e outra indica uma pessoa que também não pertence a nenhuma das redes consideradas (20\%). No caso do abuso financeiro, as vítimas indicam principalmente outras pessoas como agressores $(71,1 \%)$, que na sua maioria também não pertencem à rede informal ou formal, sendo desconhecidos. Por fim, em relação ao abuso sexual, as vítimas identificam sobretudo os Maridos, Esposas ou Companheiros(as) como agressores (46,2\%), sendo que existem $15,4 \%$ que indicam os amigos, vizinhos ou outras pessoas para além das discriminadas (ver Quadro 60).

Quadro 60. Identificação do(a) abusador(a), por tipo de abuso (mais do que uma resposta possivel)

\begin{tabular}{|c|c|c|c|c|c|}
\hline \multirow[b]{2}{*}{$\begin{array}{l}\text { Indique por favor quem é que } \\
\text { provocou as situações que referiu. }\end{array}$} & \multicolumn{5}{|c|}{ Tipo de abuso } \\
\hline & $\begin{array}{l}\text { Psicológico } \\
(n=134)^{a}\end{array}$ & $\begin{array}{l}\text { Físico } \\
(n=16)^{a}\end{array}$ & $\begin{array}{l}\text { Físico c/lesões } \\
\qquad(n=5)^{\mathrm{a}}\end{array}$ & $\begin{array}{l}\text { Financeiro } \\
(\mathrm{n}=38)^{\mathrm{a}}\end{array}$ & $\begin{array}{l}\text { Sexual } \\
(n=13)\end{array}$ \\
\hline Marido/Esposa/Companheiro(a) & $32,8 \%$ & $43,8 \%$ & $60,0 \%$ & $7,9 \%$ & $46,2 \%$ \\
\hline Filha & $9,7 \%$ & $6,3 \%$ & $0,0 \%$ & $0,0 \%$ & $0,0 \%$ \\
\hline Filho & $13,4 \%$ & $18,8 \%$ & $0,0 \%$ & $7,9 \%$ & $0,0 \%$ \\
\hline Nora & $1,5 \%$ & $0,0 \%$ & $0,0 \%$ & $0,0 \%$ & $0,0 \%$ \\
\hline Genro & $2,2 \%$ & $0,0 \%$ & $0,0 \%$ & $0,0 \%$ & $0,0 \%$ \\
\hline Irmã & $9,0 \%$ & $0,0 \%$ & $0,0 \%$ & $13,2 \%$ & $0,0 \%$ \\
\hline Irmão & $5,2 \%$ & $0,0 \%$ & $0,0 \%$ & $7,9 \%$ & $0,0 \%$ \\
\hline Neta & $0,7 \%$ & $0,0 \%$ & $0,0 \%$ & $0,0 \%$ & $0,0 \%$ \\
\hline Neto & $0,0 \%$ & $0,0 \%$ & $0,0 \%$ & $0,0 \%$ & $0,0 \%$ \\
\hline Amigo & $1,5 \%$ & $0,0 \%$ & $0,0 \%$ & $0,0 \%$ & $15,4 \%$ \\
\hline Amiga & $3,0 \%$ & $0,0 \%$ & $0,0 \%$ & $0,0 \%$ & $0,0 \%$ \\
\hline Conhecido/Colega & $4,5 \%$ & $0,0 \%$ & $0,0 \%$ & $0,0 \%$ & $0,0 \%$ \\
\hline Conhecida/Colega & $2,2 \%$ & $0,0 \%$ & $0,0 \%$ & $0,0 \%$ & $7,7 \%$ \\
\hline Vizinha & $9,0 \%$ & $6,3 \%$ & $20,0 \%$ & $0,0 \%$ & $0,0 \%$ \\
\hline Vizinho & $5,2 \%$ & $0,0 \%$ & $0,0 \%$ & $0,0 \%$ & $15,4 \%$ \\
\hline Cuidador profissional remunerado & $0,0 \%$ & $0,0 \%$ & $0,0 \%$ & $0,0 \%$ & $0,0 \%$ \\
\hline $\begin{array}{l}\text { Mulher-a-dias/empregada } \\
\text { doméstica }\end{array}$ & $0,0 \%$ & $0,0 \%$ & $0,0 \%$ & $2,6 \%$ & $0,0 \%$ \\
\hline Funcionário(a) do centro de dia & $0,0 \%$ & $0,0 \%$ & $0,0 \%$ & $0,0 \%$ & $0,0 \%$ \\
\hline $\begin{array}{l}\text { Profissional de saúde (médico, } \\
\text { enfermeiro, ...) }\end{array}$ & $0,7 \%$ & $6,3 \%$ & $0,0 \%$ & $0,0 \%$ & $0,0 \%$ \\
\hline Outro & $20,1 \%$ & $18,8 \%$ & $20,0 \%$ & $71,1 \%$ & $15,4 \%$ \\
\hline
\end{tabular}

a Existe 1 caso que corresponde à resposta: "recusa".

Resumindo, podemos afirmar que em termos globais os agressores são sobretudo os cônjuges ou companheiros. Aliás, com a exceção do abuso financeiro, a tendência mantém-se quando analisamos os agressores identificados em cada um dos outros tipos de abuso. No caso do abuso financeiro, a identificação dos agressores remete-nos 
sobretudo para outras pessoas para além das descriminadas, sendo que neste caso essas pessoas não pertencem à rede informal ou formal de relações do inquirido. 


\section{Reações das vítimas ao abuso}

Uma análise às reações dos idosos às situações de violência por eles vivenciadas, independentemente do tipo de abuso, revela que a reação verbal é a resposta mais prevalente, sendo assinalada pela maioria dos idosos vítimas de abuso (56,5\%). Por sua vez, verifica-se que a não reação aos abusos foi a opção seguida por mais de 1 em cada 3 idosos (37,3\%), um contingente maior face aos que optaram por relatar o incidente $(26,1 \%)$ (ver Quadro 61).

Contudo, observa-se que o padrão de respostas é diferenciado segundo o tipo de abuso, o que importa especificar. Assim, o perfil de reações às situações de abuso psicológico segue o descrito para o abuso em geral. Relativamente às reações ao abuso físico, grande parte concentra-se na reação verbal $(47,1 \%)$, sendo de assinalar que é o tipo de abuso que apresenta uma maior proporção de idosos nas seguintes reações: reação emocional $(29,4 \%)$, de pedido de ajuda ou aconselhamento/orientação sobre o que deveria fazer $(23,5 \%)$, reação física $(23,5 \%)$ e foi embora, saiu de casa $(23,5 \%)$, o que poderá sugerir que o abuso físico desencadeia uma maior diversidade de reações nos idosos. No entanto, este tipo de violência apresenta das mais baixas percentagens de idosos que opta por relatar o incidente $(17,6 \%)$. No que diz respeito ao abuso físico com lesões, a leitura dos dados é de alguma forma limitada por se reportar a 6 casos, destacando-se ainda assim a maior expressão da reação verbal e relato do incidente. Ao nível do abuso sexual, os idosos reagem sobretudo de forma verbal $(84,6 \%)$ sendo que entre os diferentes tipos de abuso é no abuso sexual que o relato assume menor expressão $(15,4 \%)$.

Por último, o abuso financeiro apresenta um perfil distinto de respostas por parte dos idosos sendo o único em que o relato do incidente é a reação mais mencionada $(41,0 \%)$ por contraposição aos restantes tipos de abuso nos quais, tal como referido anteriormente, os idosos reagem predominantemente de forma verbal. Neste, a reação verbal foi opção para 38,5\% dos idosos. Também importa destacar que a totalidade de casos de abuso financeiro reagiu de alguma forma à situação, já que nenhum idoso assinalou a opção «não reagiu» (ver Quadro 61). 
Quadro 61. Reações à situação de violência, por tipo de abuso (mais do que uma resposta possivel)

\begin{tabular}{|c|c|c|c|c|c|c|}
\hline \multirow[b]{2}{*}{$\begin{array}{l}\text { Reações à situação de } \\
\text { violência }\end{array}$} & \multicolumn{6}{|c|}{ Tipo de abuso } \\
\hline & $\begin{array}{l}\text { Abuso } \\
\text { em geral } \\
(n=161)^{a}\end{array}$ & $(n=135)$ & $(n=17)$ & $\begin{array}{l}\text { Físico } \\
\text { c/lesões } \\
(\mathrm{n}=6)\end{array}$ & $\begin{array}{l}\text { Financeiro } \\
(n=38)^{a}\end{array}$ & $(n=13)$ \\
\hline Reação Verbal & $56,5 \%$ & $54,8 \%$ & $47,1 \%$ & $33,3 \%$ & $38,5 \%$ & $84,6 \%$ \\
\hline Reação Física & $5,6 \%$ & $3,0 \%$ & $23,5 \%$ & $0,0 \%$ & $5,1 \%$ & $15,4 \%$ \\
\hline Reação Emocional & $19,3 \%$ & $20,0 \%$ & $29,4 \%$ & $0,0 \%$ & $15,4 \%$ & $7,7 \%$ \\
\hline $\begin{array}{l}\text { Pediu ajuda ou } \\
\text { aconselhamento/orientaç } \\
\text { ão sobre o que devia fazer }\end{array}$ & $13,0 \%$ & $11,1 \%$ & $23,5 \%$ & $16,7 \%$ & $15,4 \%$ & $7,7 \%$ \\
\hline Relatou o incidente & $26,1 \%$ & $21,5 \%$ & $17,6 \%$ & $33,3 \%$ & $41,0 \%$ & $15,4 \%$ \\
\hline Foi embora, saiu de casa & $6,2 \%$ & $5,9 \%$ & $23,5 \%$ & $0,0 \%$ & $15,4 \%$ & $0,0 \%$ \\
\hline Não reagiu & $37,3 \%$ & $38,5 \%$ & $11,8 \%$ & $16,7 \%$ & $0,0 \%$ & $15,4 \%$ \\
\hline Outra & $5,0 \%$ & $2,2 \%$ & $0,0 \%$ & $0,0 \%$ & $10,3 \%$ & $0,0 \%$ \\
\hline
\end{tabular}

Para os participantes que assinalaram ter pedido ajuda ou aconselhamento/orientação sobre o que deviam fazer, foi perguntado a quem solicitaram esse pedido. Os dados revelam a importância dos profissionais de saúde na primeira linha de apoio aos idosos vítimas, na medida em que $28,6 \%$ contactou um membro deste grupo profissional a propósito da situação de abuso. Os advogados surgem como a segunda opção mais assinalada por $23,8 \%$ dos inquiridos. Por sua vez, verifica-se a mesma proporção de idosos $(19,0 \%)$ que dirigiram o seu pedido de apoio às autoridades policiais ou a pessoas da sua esfera de rede informal, nomeadamente filho(s), filha(s) e amigo/a(s) bem como a outro(s) (e.g., associação de moradores, sobrinha, superiores hierárquicos, terapeuta ocupacional) (ver Quadro 62).

Não obstante a importância desta leitura mais geral relativamente a quem pede apoio/ajuda, uma análise por tipo de abuso revela algumas especificidades que importa reter. O abuso psicológico segue a mesma distribuição de respostas para o abuso em geral. Já nos casos de abuso físico prevalece a procura de ajuda ou aconselhamento junto das autoridades policiais $(50,0 \%)$, ao passo que no abuso financeiro os idosos optam, na sua maioria, por recorrer ao apoio profissional de um advogado (66,7\%). Porém, é importante assinalar que o recurso a organizações formais de apoio a vítimas de violência, como linha de apoio, associações de apoio/voluntariado não constituíram, para os participantes no estudo, uma opção na procura de ajuda ou aconselhamento/orientação (ver Quadro 62). 
Quadro 62. A quem pediu ajuda ou aconselhamento/orientação sobre o que devia fazer, por tipo de abuso (mais do que uma resposta possível)

\begin{tabular}{|c|c|c|c|c|c|c|}
\hline \multirow[b]{2}{*}{$\begin{array}{l}\text { A quem pediu ajuda e/ou } \\
\text { aconselhamento/orientação }\end{array}$} & \multicolumn{6}{|c|}{ Tipo de abuso } \\
\hline & $\begin{array}{l}\text { Abuso } \\
\text { em geral } \\
(n=21)\end{array}$ & Psicológico & $(n=4)$ & $\begin{array}{c}\text { Físico } \\
\text { c/lesões } \\
(n=1)\end{array}$ & Financeiro & $(n=1)$ \\
\hline Amigo/a(s) & $19,0 \%$ & $13,3 \%$ & $25,0 \%$ & $100,0 \%$ & $33,3 \%$ & $100,0 \%$ \\
\hline Filho(s) & $19,0 \%$ & $20,0 \%$ & $0,0 \%$ & $0,0 \%$ & $33,3 \%$ & $0,0 \%$ \\
\hline Filha(s) & $19,0 \%$ & $20,0 \%$ & $0,0 \%$ & $0,0 \%$ & $33,3 \%$ & $0,0 \%$ \\
\hline Cônjuge & $9,5 \%$ & $0,0 \%$ & $0,0 \%$ & $0,0 \%$ & $33,3 \%$ & $0,0 \%$ \\
\hline Vizinhos & $0,0 \%$ & $0,0 \%$ & $0,0 \%$ & $0,0 \%$ & $0,0 \%$ & $0,0 \%$ \\
\hline Profissionais de saúde & $28,6 \%$ & $33,3 \%$ & $25,0 \%$ & $0,0 \%$ & $0,0 \%$ & $0,0 \%$ \\
\hline Assistente social & $0,0 \%$ & $0,0 \%$ & $0,0 \%$ & $0,0 \%$ & $0,0 \%$ & $0,0 \%$ \\
\hline Autoridades policiais & $19,0 \%$ & $20,0 \%$ & $50,0 \%$ & $0,0 \%$ & $0,0 \%$ & $0,0 \%$ \\
\hline Cuidador profissional & $0,0 \%$ & $0,0 \%$ & $0,0 \%$ & $0,0 \%$ & $0,0 \%$ & $0,0 \%$ \\
\hline Linha de apoio & $0,0 \%$ & $0,0 \%$ & $0,0 \%$ & $0,0 \%$ & $0,0 \%$ & $0,0 \%$ \\
\hline Advogado & $23,8 \%$ & $6,7 \%$ & $0,0 \%$ & $0,0 \%$ & $66,7 \%$ & $0,0 \%$ \\
\hline Ministério Público & $14,3 \%$ & $13,3 \%$ & $25,0 \%$ & $0,0 \%$ & $16,7 \%$ & $0,0 \%$ \\
\hline $\begin{array}{l}\text { Associações de } \\
\text { apoio/voluntariado }\end{array}$ & $0,0 \%$ & $0,0 \%$ & $0,0 \%$ & $0,0 \%$ & $0,0 \%$ & $0,0 \%$ \\
\hline Padre & $0,0 \%$ & $0,0 \%$ & $0,0 \%$ & $0,0 \%$ & $0,0 \%$ & $0,0 \%$ \\
\hline Outra(s) pessoas ou familiares & $19,0 \%$ & $26,7 \%$ & $25,0 \%$ & $0,0 \%$ & $0,0 \%$ & $0,0 \%$ \\
\hline
\end{tabular}

Para os participantes que assinalaram ter relatado o incidente, foi questionado a quem fizeram esse relato. Assim, considerando o abuso em geral, independentemente do tipo de abuso, verifica-se que quase 1 em cada 3 idosos vítima de abuso e que opta por relatar o incidente fá-lo às autoridades policiais $(31,0 \%), 23,8 \%$ relata a filhos do sexo masculino, seguido pela filha(s), amigo/a(s) ou outro (19,0\%). Uma vez mais, importa focar a análise por tipo de abuso, uma vez que se encontram diferenças que há que assinalar. Para os casos de abuso psicológico, os idosos optam por relatar o incidente predominantemente a pessoas da sua esfera amical $(27,6 \%)$ ou familiar $(20,7 \%$ filho(s) e $17,2 \%$ filha(s)), sendo que o relato à autoridade policial é opção apenas em $17,2 \%$ dos casos. Nas situações de abuso físico o relato é realizado na sua maioria ao Ministério Público e/ou Associações de apoio/voluntariado (66,7\% para ambas as opções). Nos dois casos de abuso físico com lesões os idosos recorreram às autoridades policiais e associações. Nos casos de abuso financeiro os idosos recorrem, na sua maioria, às Autoridades Policiais para relatar o incidente (56,3\%). Por fim, nos dois casos de abuso sexual, as vítimas relataram o incidente ao(s) filho(s) ou aos vizinhos, mas em ambos os casos também relataram a outras pessoas ou outros familiares (ver Quadro 63). 
Quadro 63. A quem relatou o incidente, por tipo de abuso (mais do que uma resposta possível)

\begin{tabular}{lcccccc}
\hline & \multicolumn{7}{c}{ Tipo de abuso } \\
\cline { 2 - 7 } A quem relatou o & $\begin{array}{c}\text { Abuso em } \\
\text { geral }\end{array}$ & Psicológico & Físico & $\begin{array}{c}\text { Físico } \\
\text { c/lesões }\end{array}$ & Financeiro & Sexual \\
incidente & $(\mathrm{n}=41)$ & $(\mathrm{n}=29)$ & $(\mathrm{n}=3)$ & $(\mathrm{n}=2)$ & $(\mathrm{n}=16)$ & $(\mathrm{n}=2)$ \\
\hline Amigo/a(s) & $19,0 \%$ & $27,6 \%$ & $0,0 \%$ & $0,0 \%$ & $0,0 \%$ & $0,0 \%$ \\
Filho(s) & $23,8 \%$ & $20,7 \%$ & $33,3 \%$ & $0,0 \%$ & $18,8 \%$ & $50,0 \%$ \\
Filha(s) & $19,0 \%$ & $17,2 \%$ & $0,0 \%$ & $0,0 \%$ & $18,8 \%$ & $0,0 \%$ \\
Cônjuge & $16,7 \%$ & $13,8 \%$ & $0,0 \%$ & $0,0 \%$ & $18,8 \%$ & $0,0 \%$ \\
Vizinhos & $2,4 \%$ & $0,0 \%$ & $33,3 \%$ & $0,0 \%$ & $0,0 \%$ & $50,0 \%$ \\
Profissionais de saúde & $9,5 \%$ & $13,8 \%$ & $33,3 \%$ & $0,0 \%$ & $6,3 \%$ & $0,0 \%$ \\
Assistente social & $0,0 \%$ & $0,0 \%$ & $0,0 \%$ & $0,0 \%$ & $0,0 \%$ & $0,0 \%$ \\
Autoridades policiais & $31,0 \%$ & $17,2 \%$ & $33,3 \%$ & $100,0 \%$ & $56,3 \%$ & $0,0 \%$ \\
Cuidador profissional & $0,0 \%$ & $0,0 \%$ & $0,0 \%$ & $0,0 \%$ & $0,0 \%$ & $0,0 \%$ \\
Linha de apoio & $0,0 \%$ & $0,0 \%$ & $0,0 \%$ & $0,0 \%$ & $0,0 \%$ & $0,0 \%$ \\
Advogado & $9,5 \%$ & $3,4 \%$ & $0,0 \%$ & $0,0 \%$ & $18,8 \%$ & $0,0 \%$ \\
Ministério Público & $0,0 \%$ & $10,3 \%$ & $66,7 \%$ & $50,0 \%$ & $12,5 \%$ & $0,0 \%$ \\
Associações de & $7,1 \%$ & $3,4 \%$ & $66,7 \%$ & $100,0 \%$ & $12,5 \%$ & $0,0 \%$ \\
apoio/voluntariado & & & & & & \\
Padre & $0,0 \%$ & $0,0 \%$ & $0,0 \%$ & $0,0 \%$ & $0,0 \%$ & $0,0 \%$ \\
Outra(s) pessoas ou & $19,0 \%$ & $13,8 \%$ & $33,3 \%$ & $0,0 \%$ & $18,8 \%$ & $100,0 \%$ \\
outros familiares & & & & & & \\
\hline
\end{tabular}

No que diz respeito às razões pelas quais as vítimas de abuso não pediram ajuda e/ou relataram o incidente, podemos destacar que, independentemente do tipo de abuso, quase metade das vítimas $(47,7 \%)$ tendem a desvalorizar o incidente (i.e., afirmando que "o incidente não foi grave") e $28,8 \%$ acreditam ter conseguido resolver a situação e solucionado o problema sem ter necessidade de pedir ajuda ou de relatar o incidente. Focando a análise nos diferentes tipos de abuso, encontramos algumas diferenças que importa assinalar. Para os casos de abuso psicológico, a distribuição de respostas segue a mesma tendência do abuso em geral. Porém, nos casos de abuso físico, prevalece o sentimento de vergonha (40\%) e o medo de represálias e agravamento da situação (30\%). Em relação ao abuso físico com lesões, nos 3 casos em que não existiu um pedido de ajuda e/ou relato do incidente, todos referem não o ter feito por razões familiares (e.g., "A família é muito importante"), sendo que em dois desses casos é mencionado o "medo de represálias e agravamento da situação" e outras razões. Relativamente ao abuso financeiro, prevalece a desvalorização do incidente, bem como a importância atribuída à família. Por fim, em relação ao abuso sexual, destaca-se sobretudo a desvalorização do incidente (ver Quadro 64). 
Quadro 64. Razões pelas quais não pediu ajuda e/ou relatou o incidente de abuso, por tipo de abuso (mais do que uma resposta possivel)

\begin{tabular}{|c|c|c|c|c|c|c|}
\hline \multirow[b]{2}{*}{$\begin{array}{l}\text { Razões pelas quais não } \\
\text { pediu ajuda e/ou relatou o } \\
\text { incidente }\end{array}$} & \multicolumn{6}{|c|}{ Tipo de abuso } \\
\hline & $\begin{array}{l}\text { Abuso } \\
\text { em geral } \\
(n=111)^{a}\end{array}$ & $\begin{array}{l}\text { Psicológico } \\
(n=93)\end{array}$ & $\begin{array}{l}\text { Físico } \\
(n=10)\end{array}$ & $\begin{array}{l}\text { Físico } \\
\text { c/lesões } \\
(n=3)\end{array}$ & $\begin{array}{l}\text { Financeiro } \\
(n=19)^{a}\end{array}$ & $\begin{array}{l}\text { Sexual } \\
(n=10)\end{array}$ \\
\hline $\mathrm{O}$ incidente não foi grave & $47,7 \%$ & $46,2 \%$ & $10,0 \%$ & $0,0 \%$ & $36,8 \%$ & $50,0 \%$ \\
\hline $\begin{array}{l}\text { A família é muito } \\
\text { importante para mim }\end{array}$ & $18,9 \%$ & $18,3 \%$ & $20,0 \%$ & $100,0 \%$ & $21,1 \%$ & $20,0 \%$ \\
\hline $\begin{array}{l}\text { Devido ao afeto/amor que } \\
\text { sinto pela pessoa que me } \\
\text { fez essas coisas }\end{array}$ & $13,5 \%$ & $14,0 \%$ & $10,0 \%$ & $33,3 \%$ & $10,5 \%$ & $10,0 \%$ \\
\hline $\begin{array}{l}\text { Por medo de represálias e } \\
\text { agravamento da situação }\end{array}$ & $9,9 \%$ & $9,7 \%$ & $30,0 \%$ & $66,7 \%$ & $5,3 \%$ & $10,0 \%$ \\
\hline $\begin{array}{l}\text { Receio de que ninguém } \\
\text { acreditasse em mim } \\
\text { Não tenho informação }\end{array}$ & $2,7 \%$ & $2,2 \%$ & $10,0 \%$ & $33,3 \%$ & $5,3 \%$ & $0,0 \%$ \\
\hline $\begin{array}{l}\text { sobre a quem recorrer } \\
\text { nestas situações }\end{array}$ & $3,6 \%$ & $2,2 \%$ & $20,0 \%$ & $0,0 \% \%$ & $10,5 \%$ & $0,0 \%$ \\
\hline $\begin{array}{l}\text { Dependo financeiramente } \\
\text { da pessoa que me fez } \\
\text { essas coisas }\end{array}$ & $1,8 \%$ & $2,2 \%$ & $10,0 \%$ & $33,3 \%$ & $5,3 \%$ & $10,0 \%$ \\
\hline Por vergonha & $11,7 \%$ & $10,8 \%$ & $40,0 \%$ & $33,3 \%$ & $5,3 \%$ & $20,0 \%$ \\
\hline $\begin{array}{l}\text { Acredito que consigo } \\
\text { resolver a situação e } \\
\text { encontrar uma solução }\end{array}$ & $28,8 \%$ & $30,1 \%$ & $10,0 \%$ & $33,3 \%$ & $10,5 \%$ & $10,0 \%$ \\
\hline $\begin{array}{l}\text { Porque me sinto } \\
\text { financeiramente }\end{array}$ & & & & & & \\
\hline $\begin{array}{l}\text { responsável pela família/ } \\
\text { sou a principal fonte de } \\
\text { rendimento }\end{array}$ & $7,2 \%$ & $8,6 \%$ & $20,0 \%$ & $0,0 \%$ & $0,0 \%$ & $0,0 \%$ \\
\hline Outra(s) & $14,4 \%$ & $11,8 \%$ & $30,0 \%$ & $66,7 \%$ & $31,6 \%$ & $20,0 \%$ \\
\hline
\end{tabular}

No que diz respeito à forma como as vítimas se sentiram afetadas pela situação ou situações de abuso vivenciada $(s)^{8}$, podemos destacar que, no caso do abuso psicológico, a larga maioria das vítimas sentiram-se desgostosas e tristes (90,5\%), aborrecidas $(89,7 \%)$, preocupadas (77\%) e furiosas/com raiva ( $72,2 \%)$. No caso de abuso físico, todas se se sentiram desgostosas e tristes e, na sua larga maioria, sentiram-se aborrecidas $(94,1 \%)$, preocupadas $(88,2 \%)$, furiosas/com raiva $(76,5 \%)$, assustadas $(76,5 \%)$ e/ou envergonhadas (70,6\%). Em relação ao abuso físico com lesões, a distribuição de

\footnotetext{
${ }^{8}$ As variáveis originais são compostas por 4 categorias, em que 1 = nada afetado; 2 = de alguma forma; $3=$ moderadamente; 4 = muito afetado e foram sujeitas a uma transformação de dicotomização em que 1 = nada afetado $(1=1)$ e 2 = afetado $(2+3+4)$. A tabela sintetiza os valores do 2 (afetado).
} 
respostas segue a mesma tendência do abuso físico. No que concerne ao abuso financeiro, as vítimas referem, sobretudo, ter-se sentido desgostosas e tristes $(90,6 \%)$, aborrecidas (87,5\%), furiosas/com raiva (78,1\%) e/ou preocupado(a) (65,6\%). Por fim, em relação ao abuso sexual, todas as vítimas se sentiram aborrecidas e a larga maioria sentiram-se furiosas/com raiva $(90,9 \%)$, desgostosas e tristes $(81,8 \%)$, envergonhadas $(63,6 \%)$ e/ou isoladas e sozinhas $(63,6 \%)$. Concluiu-se assim que, em termos gerais, as vítimas de abuso, independentemente do tipo, tendem a sentir-se sobretudo desgostosas, tristes, aborrecidas e/ou furiosas/com raiva pelas situações de abuso vividas (ver Quadro 65).

Quadro 65. Sentir-se afetado pelas situações de abuso, por tipo de abuso (mais do que uma resposta possível)

\begin{tabular}{|c|c|c|c|c|c|}
\hline \multirow[b]{2}{*}{$\begin{array}{l}\text { Como se sentiu afetado com a } \\
\text { situação de abuso? }\end{array}$} & \multicolumn{5}{|c|}{ Tipo de abuso } \\
\hline & $\begin{array}{l}\text { Psicológico } \\
\qquad(n=126)\end{array}$ & $\begin{array}{l}\text { Físico } \\
(n=17)\end{array}$ & $\begin{array}{c}\text { Físico } \\
\text { c/lesões } \\
(n=6)\end{array}$ & $(n=32)^{a}$ & Sexual \\
\hline $\begin{array}{l}\text { Sentiu-se excluído(a) da sua } \\
\text { família e amigos }\end{array}$ & $20,6 \%$ & $29,4 \%$ & $16,7 \%$ & $28,1 \%$ & $0,0 \%$ \\
\hline Sentiu-se furioso(a)/com raiva & $72,2 \%$ & $76,5 \%$ & $83,3 \%$ & $78,1 \%$ & $90,9 \%$ \\
\hline Sentiu-se assustado(a) & $32,5 \%$ & $76,5 \%$ & $83,3 \%$ & $40,6 \%$ & $36,4 \%$ \\
\hline Sentiu-se aborrecido(a) & $89,7 \%$ & $94,1 \%$ & $100,0 \%$ & $87,5 \%$ & $100,0 \%$ \\
\hline Sentiu-se envergonhado(a) & $38,9 \%$ & $70,6 \%$ & $83,3 \%$ & $34,4 \%$ & $63,6 \%$ \\
\hline Sentiu-se preocupado(a) & $77,0 \%$ & $88,2 \%$ & $83,3 \%$ & $65,6 \%$ & $54,5 \%$ \\
\hline Sentiu-se desgostoso(a) e triste & $90,5 \%$ & $100,0 \%$ & $100,0 \%$ & $90,6 \%$ & $81,8 \%$ \\
\hline Sentiu-se culpado(a) & $19,8 \%$ & $17,6 \%$ & $16,7 \%$ & $15,6 \%$ & $18,2 \%$ \\
\hline Sentiu-se isolado e sozinho(a) & $44,4 \%$ & $76,5 \%$ & $83,3 \%$ & $28,1 \%$ & $63,6 \%$ \\
\hline Outros sentimentos & $5,6 \%$ & $11,8 \%$ & $16,7 \%$ & $6,3 \%$ & $18,2 \%$ \\
\hline
\end{tabular}

Resumindo, no que diz respeito às reações face a situações de violência, independentemente do tipo de abuso considerado, destaca-se principalmente a reação verbal ou a não reação, o que aliás também sucede com o abuso psicológico. Nos restantes tipos de abuso, para além da prevalência da reação verbal, destaca-se a reação emocional, no abuso físico e o relato do acidente, no caso das lesões e no abuso financeiro.

Em relação aos pedidos de ajuda ou aconselhamento/orientação, verifica-se que, independentemente do tipo de abuso considerado, os profissionais de saúde assumem particular relevância, o mesmo acontecendo no caso do abuso psicológico. Nas situações de abuso físico, as vítimas recorrem sobretudo às autoridades policiais. No caso do abuso físico com lesões e no abuso sexual, as vítimas pediram ajuda ou 
aconselhamento a amigos(as). Por fim, em relação ao abuso financeiro, a preferência recai no advogado.

No que diz respeito ao relato do(s) incidente(s), podemos afirmar que, em termos gerais, as vítimas fazem-no sobretudo junto das autoridades policiais e/ou dos filhos. Porém, a análise por tipo de abuso considerado revela um padrão de respostas diferenciado, designadamente: no caso do abuso psicológico as vítimas recorrem aos amigos e/ou aos filhos; no caso do abuso físico dirigem-se ao ministério público e /ou associações de apoio/voluntariado; no caso do abuso físico com lesões vão às autoridades policiais e/ou às associações de apoio/voluntariado; no caso do abuso financeiro procuram as autoridades policiais e, por fim, relativamente ao abuso sexual, as vítimas recorrem a outras pessoas ou a outros familiares para além dos cônjuges, filhos(as) ou amigos(as).

Relativamente às principais razões invocadas pelas vítimas para não terem pedido ajuda e/ou relatado o incidente de abuso, podemos afirmar que, independentemente do tipo de abuso considerado, prevalece uma tendência para a desvalorização do incidente e a crença na capacidade de resolução do problema sem ter necessidade de pedir ajudar ou relatar a ocorrência, o que aliás também acontece com os casos de abuso psicológico. No caso do abuso físico, prevalece a vergonha e o medo de represálias e agravamento da situação. Já no abuso físico com lesões, destaca-se a valorização da família, bem como o medo de represálias e agravamento da situação e/ou outros motivos para além dos apresentados. No abuso financeiro e sexual, as vítimas para além de desvalorizarem o incidente, alegam outros motivos para além dos apresentados.

Finalmente, no que diz respeito à forma como as vítimas se sentiram afetadas pelas situações de abuso vivenciadas, podemos afirmar que globalmente as vítimas de abuso sentem-se sobretudo desgostosas, tristes e aborrecidas com a situação. No entanto, apesar desta tendência, podemos assinalar dois padrões relativamente distintos na prevalência de sentimentos, ou seja, a distribuição de respostas segue uma tendência mais semelhante nos casos de abuso psicológico e financeiro e o mesmo acontece com os casos de abuso físico e abuso físico com as lesões. No caso do abuso sexual, apesar de seguir uma tendência relativamente semelhante aos abusos físicos (com ou sem lesões), difere destes sobretudo pela maior proporção de vítimas que dizem ter-se sentido furiosas e/ou com raiva. 


\section{Crise socioeconómica e prevalência de abusos}

Retomando o objetivo central do presente estudo, neste ponto relaciona-se o impacto da crise económica dos últimos anos na prevalência de abuso na nossa amostra. Neste sentido, começando por analisar o impacto global da crise económica na aquisição de bens e serviços, observa-se que a maioria dos respondentes $(65,1 \%)$ afirma ter reduzido as suas despesas em virtude da referida crise (ver Quadro 66).

Quadro 66. Impacto da crise económica na aquisição de bens e serviços ( $n=677)$

\begin{tabular}{lcc}
\hline Reduziu a despesa/gasto com determinados bens e & & \\
serviços em virtude da crise? & $\mathbf{n}$ & \% \\
\hline Não reduziu o gasto/despesa & 236 & 34,9 \\
Reduziu o gasto/despesa & 441 & 65,1 \\
\hline Total & 677 & 100,0 \\
\hline
\end{tabular}

Tendo verificado o impacto global da crise económica na aquisição de bens e serviços, analisa-se de seguida os bens e serviços em que existiu redução da despesa/gasto. Mais concretamente, dos 441 respondentes que reduziram as despesas com bens e serviços em virtude da crise, destaca-se a proporção dos que afirmam ter reduzido as suas despesas com vestuário (62,4\%), restaurantes $(48,1 \%)$, viagens e/ou férias $(46,9 \%)$, bem como com transportes e combustíveis (36,1\%). Assim, podemos afirmar que globalmente a redução de despesas com bens e serviços refletiu-se sobretudo nos bens de consumo, lazer e na alimentação (ver Quadro 67).

Quadro 67. Redução de despesas com bens e serviços em virtude da crise ( $n=441)$

\begin{tabular}{lcc} 
Desde que se começou a sentir a crise económica em Portugal, na & & \\
última meia dúzia de anos, reduziu a despesa/gasto com: & $\mathbf{n}$ & $\%$ \\
\hline Alimentação & 150 & 34,0 \\
Vestuário & 275 & 62,4 \\
Transportes e combustíveis & 159 & 36,1 \\
Eletricidade/gás/água & 107 & 24,3 \\
Saúde & 27 & 6,1 \\
Viagens e /ou férias & 207 & 46,9 \\
Atividades de lazer & 143 & 32,4 \\
Compras de eletrodomésticos ou móveis & 123 & 27,9 \\
Restaurantes & 212 & 48,1 \\
Serviços de apoio a pessoas dependentes (pessoas idosas, pessoas & & \\
com deficiência, ...) & 9 & 2,0 \\
Contratação de serviços domésticos (limpeza, etc.) & 50 & 11,3
\end{tabular}

Quando inquiridos sobre se a crise económica havia alterado alguma coisa nas suas vidas quotidianas, quase metade dos idosos declarou que sim (ver Quadro 68) 
Quadro 68. Impacto da crise económica na vida quotidiana em virtude da crise ( $n=677)$

\begin{tabular}{lcc}
\hline $\begin{array}{l}\text { Houve alterações na sua vida quotidiana em virtude } \\
\text { da crise? }\end{array}$ & $\mathbf{n}$ & $\mathbf{\%}$ \\
\hline Não & 383 & 56,6 \\
Sim & 294 & 43,4 \\
\hline Total & 677 & 100,0 \\
\hline
\end{tabular}

Porém, apesar da análise anterior, importa perceber quais as situações e/ou circunstâncias da vida quotidiana que os inquiridos que responderam afirmativamente à questão anterior tiveram de alterar em virtude da crise. Assim, podemos verificar que a larga maioria dos respondentes (69\%) passou a ajudar a pagar despesas dos filhos(as) ou netos(as) e/ou passou a dar dinheiro todos os meses ao filho/a(s) (35,4\%). Concluise, deste modo, que os impactos da crise económica na vida quotidiana dos idosos verificaram-se sobretudo ao nível do apoio financeiro aos descendentes, nomeadamente filhos(as)/netos(as) (ver Quadro 69).

Quadro 69. Situações ocorridas em virtude da crise $(n=294)$

\begin{tabular}{lcc}
\hline Na última meia dúzia de anos, ou seja, nos últimos $\mathbf{6}$ anos, & & \\
aconteceram as situações: & $\mathbf{n}$ & $\mathbf{\%}$ \\
\hline Deixou de viver num lar ou residência para idosos. & 3 & 1,0 \\
Deixou de frequentar o centro de dia & 9 & 3,1 \\
Foi viver para a casa de um filho/filha. & 10 & 3,4 \\
Um filho/filha foi viver consigo. & 47 & 16,0 \\
Acolheu na sua casa netos por força da emigração de um filho/a. & 6 & 2,0 \\
Acolheu na sua casa outros familiares. & 47 & 16,0 \\
Passou a dar dinheiro todos os meses ao seu filho/a(s). & 104 & 35,4 \\
Passou a ajudar a pagar despesas dos seus filhos/as ou netos/as. & 203 & 69,0 \\
Foi obrigado a mudar de casa para reduzir despesas. & 9 & 3,1 \\
\hline
\end{tabular}

$\mathrm{Na}$ sequência das análises anteriores, importa perceber se a redução das despesas/gastos e da necessidade de passar por determinadas situações em virtude da crise económica em Portugal tiveram algum efeito na prevalência de abuso. Mais concretamente, analisando a prevalência de abuso (e.g., de qualquer tipo) tendo em consideração a redução (ou não) de despesas com determinados bens e serviços, podemos verificar que no caso dos respondentes que não tiveram necessidade de reduzir as suas despesas com bens e serviços em virtude da crise a proporção dos que apresentam um qualquer tipo de abuso é de $16,9 \%$, sendo de $27,7 \%$ no caso dos respondentes que, em virtude da crise, reduziram as suas despesas com bens e serviços. Sendo assim, a necessidade de redução de despesas em virtude da crise, reveladora de maior vulnerabilidade económica, tende a aumentar o risco de abuso dos idosos (ver Quadro 70). 
Quadro 70. Prevalência de abuso, por redução de gastos/despesas em virtude da crise ( $n=677)$

\begin{tabular}{|c|c|c|}
\hline \multirow[b]{2}{*}{$\begin{array}{l}\text { Presença de um qualquer tipo de abuso nos } \\
\text { últimos } 12 \text { meses }\end{array}$} & \multicolumn{2}{|c|}{$\begin{array}{c}\text { Reduziu a despesa/gasto com } \\
\text { determinados bens e serviços em virtude } \\
\text { da crise? }\end{array}$} \\
\hline & $\begin{array}{c}\text { Não reduziu } \\
\mathrm{n}(\%)\end{array}$ & $\begin{array}{l}\text { Reduziu } \\
\mathrm{n}(\%)\end{array}$ \\
\hline \multirow[t]{2}{*}{ Sem abuso } & 196 & 319 \\
\hline & $(83,1)$ & $(72,3)$ \\
\hline \multirow[t]{2}{*}{ Com abuso } & 40 & 122 \\
\hline & $(16,9)$ & $(27,7)$ \\
\hline \multirow[t]{2}{*}{ Total } & 236 & 441 \\
\hline & $(100,0)$ & $(100,0)$ \\
\hline
\end{tabular}

Relativamente à análise da prevalência de abuso (e.g., de qualquer tipo) tendo em consideração a alteração (ou não) de determinadas circunstâncias da vida quotidiana em virtude da crise, podemos destacar que, apesar da maioria dos idosos não ter tido necessidade de passar por determinadas situações em virtude da crise, a proporção dos que apresentam algum tipo de abuso é claramente superior entre aqueles que assumem ter tido necessidade alterar alguma(s) circunstância(s) da sua vida quotidiana (30,3\%) (ver Quadro 71), traço que reforça a narrativa de vulnerabilidade económica que se foi construindo ao longo do texto na procura das causas e dos contextos do abuso.

Quadro 71. Prevalência de abuso, por alteração de circunstâncias da vida em virtude da crise $(n=677)$

\begin{tabular}{lcc}
\hline & \multicolumn{2}{c}{$\begin{array}{c}\text { Teve necessidade de passar por } \\
\text { determinadas situações em virtude da } \\
\text { crise? }\end{array}$} \\
\cline { 2 - 3 } Presença de um qualquer tipo de abuso nos & \multicolumn{2}{c}{ Não } \\
últimos 12 meses & $\mathrm{n}(\%)$ & $\mathrm{n}(\%)$ \\
\hline Sem abuso & 310 & 205 \\
& $(80,9)$ & $(69,7)$ \\
Com abuso & 73 & 89 \\
& $(19,1)$ & $(30,3)$ \\
\hline Total & 383 & 294 \\
& $(100,0)$ & $(100,0)$ \\
\hline
\end{tabular}

Em seguida, analisa-se a prevalência dos diferentes tipos de abuso considerando a necessidade (ou não) de redução das despesas/gastos em virtude da crise económica em Portugal. Nesse sentido, podemos verificar que entre os respondentes que declaram ter reduzido a despesa com determinados bens e serviços a prevalência dos diferentes tipos de abuso é sempre superior à dos que afirmam não ter tido necessidade de reduzir 
as suas despesas/gastos, destacando-se a prevalência de abuso psicológico $(23,6 \%)$ e de abuso financeiro (6,1\%) (ver Quadro 72).

Quadro 72. Prevalência por tipo de abuso, por redução de gastos/despesas em virtude da crise

\begin{tabular}{lcccccc}
\hline $\begin{array}{l}\text { Reduziu a despesa } \\
\text { com determinados } \\
\text { bens e serviços em } \\
\text { virtude da crise? }\end{array}$ & & $\begin{array}{c}\text { Abuso } \\
\text { psicológico }\end{array}$ & $\begin{array}{c}\text { Abuso } \\
\text { financeiro }\end{array}$ & $\begin{array}{c}\text { Abuso } \\
\text { físico }\end{array}$ & $\begin{array}{c}\text { Abuso } \\
\text { sexual }\end{array}$ & $\begin{array}{c}\text { Lesões } \\
\text { físicas }\end{array}$ \\
\cline { 2 - 7 } $\begin{array}{l}\text { Não reduziu } \\
\text { (n=236) }\end{array}$ & $\mathrm{N}$ & 31 & 12 & 3 & 3 & 2 \\
& 13,1 & 5,1 & 1,3 & 1,3 & 0,8 \\
$\begin{array}{l}\text { Reduziu } \\
\text { (n=441) }\end{array}$ & $\mathrm{n}$ & 104 & 27 & 14 & 10 & 4 \\
\hline
\end{tabular}

No que concerne à análise da prevalência dos diferentes tipos de abuso considerando a necessidade de passar por determinadas situações em virtude da crise económica em Portugal, verifica-se uma maior prevalência dos diferentes tipos de abuso entre os respondentes que declaram ter tido necessidade de alterar determinadas circunstâncias da vida em virtude da crise, com destaque para a prevalência de abuso psicológico $(25,9 \%)$ e para o abuso financeiro (6,5\%) (ver Quadro 73$)$.

Quadro 73. Prevalência por tipo de abuso, por alteração de circunstâncias da vida em virtude da crise

\begin{tabular}{|c|c|c|c|c|c|c|}
\hline \multirow[b]{2}{*}{$\begin{array}{l}\text { Teve necessidade de } \\
\text { passar por } \\
\text { determinadas } \\
\text { situações em virtude } \\
\text { da crise? }\end{array}$} & & \multicolumn{5}{|c|}{ Tipo abuso } \\
\hline & & $\begin{array}{c}\text { Abuso } \\
\text { psicológico }\end{array}$ & $\begin{array}{c}\text { Abuso } \\
\text { financeiro }\end{array}$ & $\begin{array}{l}\text { Abuso } \\
\text { físico }\end{array}$ & $\begin{array}{l}\text { Abuso } \\
\text { sexual }\end{array}$ & $\begin{array}{l}\text { Lesões } \\
\text { físicas }\end{array}$ \\
\hline Não & $\mathrm{n}$ & 59 & 20 & 7 & 4 & 3 \\
\hline$(n=383)$ & $\%$ & 15,4 & 5,2 & 1,8 & 1,0 & 0,8 \\
\hline Sim & $\mathrm{n}$ & 76 & 19 & 10 & 9 & 3 \\
\hline$(n=294)$ & $\%$ & 25,9 & 6,5 & 3,4 & 3,1 & 1,0 \\
\hline
\end{tabular}

Sintetizando, em termos globais podemos concluir que a maioria dos idosos teve necessidade de reduzir as suas despesas/gastos em virtude da crise, sendo que essa redução de despesas se refletiu sobretudo nos bens de consumo, no lazer, na alimentação e na realização de refeições fora de casa.

A maioria dos idosos não teve necessidade de alterar situações da sua vida quotidiana em virtude da crise. No entanto, os idosos que tiveram necessidade de passar por essas situações, sentiram-nas principalmente ao nível do apoio financeiro aos descendentes, nomeadamente filhos(as)/netos(as). Concomitantemente, a necessidade de redução de despesas em virtude da crise, indiciadora de uma maior debilidade económica, tende a 
aumentar o risco de abuso dos idosos. O mesmo acontece em relação àqueles que tiveram necessidade de passar por determinadas situações em virtude da crise.

Por fim, verifica-se uma maior prevalência dos diferentes tipos de abuso entre os idosos que declaram ter reduzido a despesa com determinados bens e serviços, bem como entre os que assumem ter tido necessidade de alterar determinadas circunstâncias da sua vida. Em ambos os casos, destaca-se a prevalência de abuso psicológico e do abuso financeiro. 


\section{Impactos do abuso nas condições de saúde}

Um último objetivo do estudo quantitativo consistiu na análise do impacto da ocorrência de abuso (qualquer tipo de abuso), nas condições de saúde, avaliadas neste caso a partir dos seguintes indicadores: estado de saúde percebido, presença de doença diagnosticada, presença de depressão, falha na toma de medicação/tratamento prescrito. Esta perspetiva tem merecido uma atenção particular na investigação nesta área, assumindo-se que quando o idoso é vítima de violência a vulnerabilidade da sua condição de saúde aumenta, podendo também refletir-se no declínio da qualidade de vida, em geral, e no relaxamento dos comportamentos de autoproteção (Soares et al., 2010; Dong et al., 2013).

Quadro 74. Impacto do abuso num conjunto de indicadores de saúde ( $n=677)$

\begin{tabular}{|c|c|c|c|c|c|c|}
\hline & $\begin{array}{r}\text { Sofreu } \\
\text { nos últi } \\
\text { mese }\end{array}$ & $\begin{array}{l}\text { buso } \\
\text { los } 12 \\
(\%)\end{array}$ & & & & \\
\hline & Não & Sim & $\chi^{2}$ & $\begin{array}{c}p- \\
\text { value }\end{array}$ & $\begin{array}{c}\text { OR } \\
\text { [IC 95\%] }\end{array}$ & $\begin{array}{c}\text { Risco } \\
\text { relativo } \\
\text { [IC 95\%] }\end{array}$ \\
\hline \multicolumn{7}{|l|}{ Estado de saúde percebido } \\
\hline Muito bom, bom, razoável & 94,6 & 89,5 & 5,08 & 0,024 & 2,04 & 1,24 \\
\hline Mau, muito mau & 5,4 & 10,5 & & & {$[1,09-3,83]$} & {$[0,982-1,56]$} \\
\hline \multicolumn{7}{|c|}{ Presença de doença diagnosticada } \\
\hline Sim & 93,4 & 95,1 & 0,586 & 0,444 & \multirow{2}{*}{\multicolumn{2}{|c|}{ Não significante }} \\
\hline Não & 6,6 & 4,9 & & & & \\
\hline \multicolumn{7}{|l|}{ Presença de depressão } \\
\hline Não & 77,6 & 56,5 & 26,4 & $<0,001$ & 2,67 & 1,31 \\
\hline Sim & 22,4 & 43,5 & & & {$[1,82-3,91]$} & {$[1,16-1,48]$} \\
\hline \multicolumn{7}{|c|}{ Falha na medicação/tratamento prescrito } \\
\hline Não & 92,8 & 84,0 & 11,15 & $<0,001$ & 2,47 & 1,33 \\
\hline Sim & 7,2 & 16,0 & & & {$[1,44-4,22]$} & {$[1,07-1,64]$} \\
\hline
\end{tabular}

A evidência disponível parece apontar, genericamente, na mesma direção da discussão antes desenvolvida e que colocava o abuso no lado do efeito. De uma forma transversal, a presença de abuso parece traduzir-se, efetivamente, numa condição de vulnerabilidade, pelo menos sentida, no plano da saúde e bem-estar, sendo inclusive dissuasora da adequação de comportamentos e consumos de autocuidado. Mais se destaca que a presença de abuso aumenta, de forma muito substancial o risco de ocorrência de quadros de depressão, praticamente triplicando esse risco. Este resultado vai ao encontro de outros estudos que colocam em evidência a depressão como um fator de risco significativo associado ao abuso e à negligência entre a população mais velha (Dong, et al., 2008; Pillemer \& Prescott, 1988). 


\section{Conclusão}

O estudo quantitativo foi realizado com uma amostra de 678 inquéritos por questionário aplicados a idosos que integram a coorte EPIPorto, dos quais $63,1 \%(n=428)$ são do sexo feminino e $36,9 \%$ ( $n=250$ ) do sexo masculino. A idade média dos participantes situa-se nos 72 anos (d.p.=7,9) e a mediana nos 71 anos. É maioritária a proporção dos idosos que possuem escolaridade alta $(40,2 \%)$, seguida por aqueles que têm escolaridade baixa $(36,6 \%)$ e média $(23,2 \%)$. À medida que a idade aumenta, os níveis de escolaridade diminuem, ou seja, os escalões etários até aos 70 anos apresentam níveis de escolaridade mais elevados, por oposição aos participantes com idades superiores a 70 anos.

Paralelamente, a maioria dos idosos é casada $(61,8 \%)$ ou está em situação de viuvez $(27,2 \%)$. Os divorciados/separados $(10,8 \%)$ e os solteiros $(4,7 \%)$ são os grupos estatisticamente menos expressivos da amostra. A maioria $(77,4 \%)$, vive num agregado composto por mais de uma pessoa, contra $22,6 \%$ que vive num agregado unipessoal. Por seu turno, a proporção de inquiridos a viver sozinho aumenta com a idade, ou seja, cerca de $37,5 \%$ dos idosos com 90 e mais anos vive só, para $14,8 \%$ dos indivíduos situados no escalão etário dos 60 aos 64 anos.

Trata-se de uma população maioritariamente reformada, porém, 12,2\% ainda exerce uma profissão a tempo inteiro. Quando profissionalmente ativos, esta amostra está enquadrada, à luz do CPN (INE, 2015), principalmente, nos especialistas das atividades intelectuais e científicas, surgindo depois o pessoal administrativo e os trabalhadores dos serviços pessoais, de proteção e segurança e vendedores e os técnicos e profissões de nível intermédio como os grupos com mais expressão. A sua principal fonte de rendimento provém, para a maioria dos inquiridos, da pensão de reforma (64,0\%), sendo que $14,5 \%$ aufere salários e/ou vencimentos do trabalho e $8,0 \%$ menciona outras fontes de rendimento. Esta tendência mantém-se em relação à principal fonte de rendimento do agregado familiar, com $59,4 \%$ a referir a pensão de reforma por idade. Apesar da grande amplitude de rendimentos mensais por adulto equivalente, na nossa amostra a média dos rendimentos situa-se nos $1305,78 €$ (d.p.=996,47). Mais de metade $(51,4 \%)$ possui rendimento por adulto equivalente até $1000 €$, porém, $14,3 \%$ tem rendimento inferior a $501 €$ mensais. No entanto, a maioria $(84,4 \%)$, entende que o rendimento atual do agregado é suficiente para viver contra $15,6 \%$ que considera que o rendimento do agregado é insuficiente.

Em termos globais, os inquiridos reportam, em média, um nível de qualidade de vida de 66.26 pontos ( $D P=12.73 ; \mathrm{N}=660$ ). Porém, em média, o nível percebido de qualidade de vida diminui à medida que a idade aumenta, ou seja, a pontuação varia entre os 67.92 ( $D P=11.20 ; n=305)$, no caso dos indivíduos com idades compreendidas entre os 60 e os 
69 anos de idade, e os 63.67 ( $D P=14.19 ; n=115)$, no caso dos indivíduos com idades superiores a 79 anos.

A maioria dos participantes (63,4\%) vive em habitação própria, $26,8 \%$ vive numa habitação arrendada e 5,3\% numa habitação social. As principais carências apontadas à habitação pelos participantes referem-se ao fato de ser muito cara face ao rendimento disponível para o dia-à-dia e à falta de instalações de aquecimento adequadas em todas as divisões da casa. A quase totalidade considera que a zona onde reside apresenta uma oferta suficiente/razoável de infraestruturas, serviços e oferta de transportes públicos. A poluição, o barulho, problemas ambientais, de vandalismo e criminalidade apresentam uma avaliação menos satisfatória.

A identificação das condições de saúde dos idosos, enquanto variável associada às situações de abuso e de violência, mereceram uma particular atenção neste projeto. Apesar da autoavaliação da condição de saúde dos participantes, globalmente, ser positiva, quando analisamos a prevalência de um qualquer tipo de doença, verifica-se que a larga maioria afirma sofrer, pelo menos, de uma doença $(93,8 \%)$, sendo que apenas 6,2\% afirma não sofrer de qualquer doença. A hipertensão, o colesterol, a ansiedade, depressão, outros transtornos afetivos ou emocionais, incluindo nervosismo ou problemas psiquiátricos e as doenças dos olhos surgem como as mais prevalentes. Porém, a análise da condição de saúde dos idosos, a partir da "a presença (ou não) de doença" mostra-nos que apesar de a diferença de género se esboçar, mantém-se apenas claramente significante a variação etária, a ser detetada no que distingue o grupo etário mais jovem do resto da amostra. Por seu turno, o poder discriminante das variáveis escolaridade e condição económica, desaparece numa aparente contradição com o que é a vivência subjetiva da condição de bem-estar. No que diz respeito ao campo da medicação/tratamentos, uma vez mais a diferença de género desaparece, assim como a diferenciação associada a níveis de escolaridade. A discriminação etária surge no sentido de ser menos provável falhar medicação/tratamentos à medida que a idade avança. A relação com a dificuldade económica percebida alinha com o esperado, com aqueles a declarar maior dificuldade económica a terem maior presença na falha na medicação/tratamentos.

A partir da escala agregada de depressão geriátrica composta por dois grupos, foi possível constatar que $72,7 \%$ dos participantes não apresentam depressão, para $27,3 \%$ com depressão, o que se traduz numa condição diferenciada de vulnerabilidade psicológica, com implicações na saúde e bem-estar geral dos mais participantes. Porém, a análise da incidência de quadros de depressão pelos mesmos fatores de diferenciação sociodemográfica, revela que a diferença de género é, de todos os indicadores, o que menos se destaca, com uma apenas residual diferença desfavorável às mulheres. Já para 
os restantes indicadores as significâncias são muito fortes, com a idade mais avançada, a baixa escolaridade e a insegurança económica a emergirem como fatores propiciadores da depressão (Cf. Dong, et al., 2008).

O recurso ao médico de clínica geral tem uma grande importância para a maioria dos participantes. Contrariamente a outros profissionais, como enfermeiros, psicólogos, assistentes sociais ou outros profissionais de saúde ou de apoio social, cuja maioria refere não ter recorrido no último ano, à data do questionário. É, portanto, de destacar a relevância que o médico (especialista ou não) tem para os participantes. Esta relevância volta a ser evidenciada no facto de a larga maioria dos respondentes recorrer principalmente aos centros de saúde e/ou a clínicas/hospitais privados. No entanto, o nível de satisfação em relação aos serviços de saúde públicos é, em termos gerais, ligeiramente inferior ao verificado em relação aos serviços de saúde privados.

No estudo, a prevalência de abuso global, independentemente do tipo de abuso, é de $23,9 \%$, o que significa que cerca de 1 em cada 4 inquiridos reporta ter vivenciado, pelo menos, uma situação de abuso nos 12 meses anteriores à aplicação do questionário. Na amostra inquirida a diferença de género não é particularmente significante. Embora seja ligeiramente maior a prevalência de abuso entre as mulheres, a diferença observada não só não é estatisticamente significante, como não se constitui num aparente fator de risco. Na mesma linha segue a leitura ao efeito da variável idade, segundo os nossos resultados, não existindo evidência que sustente que o avançar da idade se traduzirá numa maior vulnerabilidade face ao risco de abuso. A mesma conclusão, ainda, se extrai para o efeito de fatores como a escolaridade, o modelo familiar ou a situação conjugal.

Já bem diferente é a conclusão a que chegamos quando procuramos avaliar até que ponto a vulnerabilidade económica se constitui como fator de risco para o abuso. De uma forma sistemática, todos os indicadores que captam facetas de uma condição de vida materialmente menos favorável aparecem de forma estatisticamente significante associados à prevalência de abusos, seja qual for o tipo. Esta é uma tendência particularmente relevante, não porque signifique que a violência só acontece em contextos de pobreza, mas porque reflete a importância dos contextos de vida marcados por privação como potenciadores de abusos. Esta é uma conclusão que reforça a necessidade de políticas sociais mais abrangentes, focadas nos contextos de vida, quando se discute a questão do abuso e da violência.

Muito importante também é destacar a forte associação entre a ocorrência de abuso e um conjunto variado de indicadores de saúde. Concluiu-se assim que parece existir uma relação entre a autoavaliação negativa da condição de saúde e a ocorrência de abuso ou entre a presença de sintomas de depressão e a exposição a situações de abuso. Naturalmente que a relação de causalidade, aqui, pode ser colocada em ambas as 
direções, com o abuso a aparecer como uma condição de vulnerabilidade, pelo menos sentida, no plano da saúde e bem-estar, sendo inclusive dissuasora da adequação de comportamentos e consumos de autocuidado. Mais se destaca que a presença de abuso aumenta, de forma muito substancial, o risco de ocorrência de quadros de depressão, praticamente triplicando esse risco.

Independentemente de olharmos para as complexas relações entre o campo da saúde e o abuso de uma ou outra perspetiva, o facto que permanece é o da forte associação, motivo mais do que suficiente para refletir sobre os contextos de prática clínica enquanto contextos particularmente bem posicionados para sinalizar estas situações e sobre elas intervir. 
Figura 1. Infografia-resumo do estudo quantitativo

\section{harmed}

o abuso de idosos determinantes sociais, económicas e de saúde
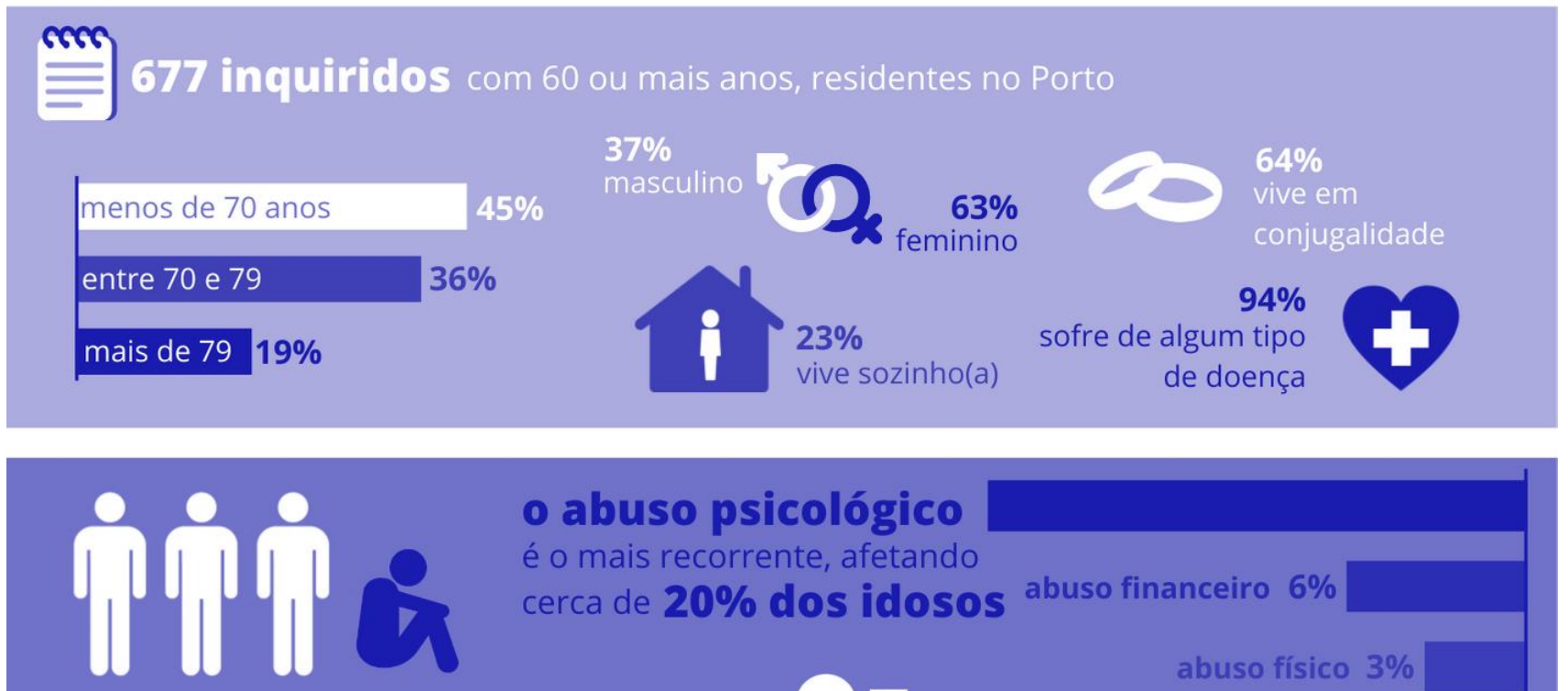

- abuso psicológico

é o mais recorrente, afetando

cerca de $\mathbf{2 0} \%$ dos idosos abuso financeiro $6 \%$

cerca de 1 em 4 idosos reportam terem sofrido algum

tipo de abuso no último ano

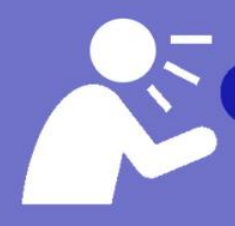

abuso físico $3 \%$ abuso sexual $2 \%$

lesões físicas $1 \%$

os idosos sujeitos a cenários privação material estão mais expostos a

situações de abuso

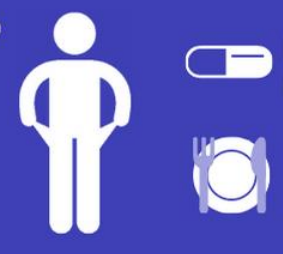

$€$ dificuldade

aumento do risco de abuso

privação de

medicação

privação

alimentar

baixo suporte social

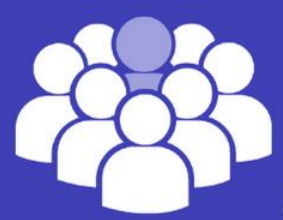
em torno do idoso faz a probabilidade de ocorrência de abuso triplicar

$20 \%$ filhos

os cônjuges / companheiros

das vítimas são os principais responsáveis,

provocando $\mathbf{2 8 \%}$ dos abusos reportados

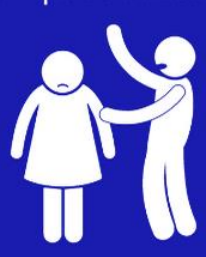

mais de 2/3 dos idosos

vítimas de abuso opta por não pedir ajuda ou relatar os incidentes

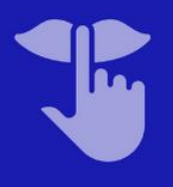




\section{"Muita revolta, muito sofrimento, muita dor, sei lá, alguns até pensarão assim: "O que é que eu ando aqui a fazer? Mais valia morrer do que estar a ser maltratada."}

\section{(Maria, 71 anos, solteira, Ensino Superior)}

Maria vive sozinha, é solteira e não tem filhos. No entanto, em momentos pontuais, partilha a casa com um familiar. Refere que não é uma pessoa solitária, já que considera ter "uma família muito unida", cuja presença corresponde às suas necessidades e expectativas "a 100\%, tudo que é preciso fazer". No entanto, até então, tem sido "muito autónoma": "tenho carro e deslocome". Menciona, igualmente, como companhia, os vizinhos que são "boas pessoas, pessoas disponíveis, dispostas a ajudar". Uma vez reformada, passou a dedicar o seu tempo ao voluntariado, "ali na porta solidária, onde eu vou todos os dias". O facto de ter mais de 70 anos de idade, não a faz sentir idosa, até porque diz conhecer pessoas da mesma idade "cheias de genica, muito ativas, muito bem-dispostas, com um ar feliz".

No presente, Maria considera a sua situação económica como sendo "satisfatória": "não tenho problemas financeiros, tenho uma aposentação razoável". Comparativamente a anos anteriores afirma estar "sensivelmente da mesma maneira". Todavia, em resultado da progressiva deterioração do seu estado de saúde, despende agora "mais dinheiro em medicamentos". Diz não ter sido afetada pela crise económica, por isso, não precisou de receber apoio. Contudo, ofereceu a um familiar apoio "financeiro e até, de certo modo, logístico".

O fenómeno da violência contra os mais velhos suscita, em Maria, um sentimento de "revolta": "sendo mais frágeis, quem atira ou dá um empurrão a um idoso sabe que ali não há defesa". Embora tenha a "impressão" de que nunca viveu um episódio destes, descreve uma situação ocorrida em espaço público, em que lhe "tentaram tirar a carteira, mas não conseguiram" e uma outra vez em que foi "perseguida por um indivíduo". Nesta situação, sentiu necessidade de "pedir ajuda". Como acredita que há "muito mais violência" na atualidade, sendo as mulheres as principais vítimas, toma determinadas precauções, nomeadamente "ter a casa sempre com a porta fechada à chave", "não andar com muito dinheiro" e "estar atenta". Quando reflete sobre o que é a felicidade para as pessoas mais velhas, Maria considera que "ela é tão efémera". No entanto, para ela "felicidade é não faltar nada de nada, é ser tudo bom é difícil de se alcançar". 


\section{III - Estudo qualitativo: Representações, significados e narrativas sobre $o$ abuso de pessoas mais velhas}

\section{Introdução: 0 estudo qualitativo}

Nesta investigação, procurou-se realizar uma abordagem integrada, sustentada no recurso a dados de natureza quantitativa e qualitativa com base em amostras com dimensões distintas. Assim, na segunda fase do estudo, foi desenvolvida uma abordagem qualitativa, com o recurso a entrevistas em profundidade (Kvale, 2008), centradas na análise da perceção do impacto da crise socioeconómica vivida em Portugal nos últimos anos, nas condições de vida dos participantes e na identificação dos significados que eles atribuem ao fenómeno do abuso de idosos. Procedeu-se, deste modo, a uma triangulação metodológica, embora o método quantitativo tenha, neste estudo, predominância sobre o qualitativo, este último apenas com um estatuto complementar (Flick, 2008; 2018).

O recurso a ambos os métodos permitiu diferentes olhares analíticos sobre os dados, proporcionando-nos, simultaneamente, a identificação de padrões de prevalência de abuso, mas também identificar, a partir dos pontos de vista dos participantes, as racionalidades e emoções associadas às diferentes formas de violência perpetradas sobre as pessoas mais velhas. Por outras palavras, através da análise quantitativa e qualitativa, obteve-se, neste estudo, um retrato objetivo e, simultaneamente, significante acerca do fenómeno em análise (Kvale, 2009).

Para o efeito, foram realizadas 45 entrevistas aos participantes da amostra original do inquérito por questionário. Foi construído um guião comum aplicável à diversidade dos perfis dos participantes na amostra qualitativa. Depois de integralmente transcritas e codificadas com o recurso ao software NVIVO 12, procedeu-se a uma análise de conteúdo temática das entrevistas (Flick, 2018), que obedeceu aos eixos analíticos tributários da análise dos dados quantitativos e que se desejavam ver aprofundados no estudo qualitativo, quer para se trabalhar o domínio das representações, sabendo-se que estas orientam as práticas sociais (Jodelet, 1993), quer para se identificar possíveis experiências de vitimização, umas sinalizadas no estudo ABUEL (2009) (Soares et. al, 2010), outras no Harmed (2017), quer ainda para se observar em que medida tais vivências se refletem nas narrativas dos participantes sobre o fenómeno em análise.

Todo o trabalho de realização e revisão das entrevistas foi acompanhado por reuniões mensais entre os membros da equipa. Nestas sessões de trabalho foram feitas análises ao conteúdo das entrevistas a nível vertical (análise de cada entrevista por dimensões temáticas) e horizontal (permitindo uma comparação por tema entre as diferentes 
entrevistas) (Kvale, 2009; Guerra, 2006). Esta abordagem analítica permitiu identificar os temas-chave, em consonância com os objetivos do estudo, e evidenciar os significados e os sentimentos associados ao abuso como problema social e de saúde pública (Dias, Lopes \& Lemos, 2019; Fraga, Lucas, Costa \& Barros, 2013).

A apresentação da informação ora privilegia a demonstração da interpretação, a partir dos excertos das entrevistas, ora socorre-se de um registo co-autoral, que sintetizando o essencial dos conteúdos das entrevistas (paráfrases) dá-nos conta dos significados presentes nas mesmas (Guerra, 2006). Privilegia-se também um olhar que, estando focado nas singularidades discursivas e representacionais dos participantes, procura igualmente identificar os traços que têm em comum (Guerra, 2006; Flick, 2018). A análise das entrevistas começa pelo eixo analítico das representações sobre o envelhecimento, em geral, e sobre o abuso de idosos, em particular. Depois avança para a perceção das condições socioeconómicas e o seu impacto no agravamento das situações de violência sobre as pessoas mais velhas. Porém, importa, num primeiro momento, dar a conhecer a amostra qualitativa, de forma a compreendermos os discursos dos entrevistados no contexto das suas características sociodemográficas.

\section{Sociografia da amostra qualitativa}

Tendo por referência os resultados do estudo quantitativo e os do estudo ABUEL (2009) (Soares et. al, 2010), os participantes no estudo qualitativo foram selecionados em função dos seguintes critérios: i) apresentar experiência de vitimização em 2009 e em 2017; ii) ter tido experiência de vitimização na avaliação de 2009 mas não em 2017; iii) não era vítima na avaliação de 2009, mas sim em 2017; iv) sem experiência de vitimização na avaliação de 2009 e de 2017 ; v) primeira vez que um membro da coorte EPIPorto participa na avaliação dos 60 anos e mais e é sinalizado como vítima em 2017. Desta forma, foi construída uma amostra de conveniência (Guerra, 2006), cuja sociografia se apresenta na tabela seguinte. 
Quadro 75. Sociografia da amostra qualitativa: Entrevistas

\begin{tabular}{|c|c|c|}
\hline Caracterização sociodemográfica & $\mathbf{n}$ & $\%$ \\
\hline \multicolumn{3}{|l|}{ Sexo } \\
\hline Masculino & 20 & 44,4 \\
\hline Feminino & 25 & 55,6 \\
\hline \multicolumn{3}{|l|}{ Escalões etários } \\
\hline $60-64$ anos & 8 & 17,8 \\
\hline $65-74$ anos & 21 & 46,7 \\
\hline $75-84$ anos & 14 & 31,1 \\
\hline 85 ou mais anos & 2 & 4,4 \\
\hline \multicolumn{3}{|l|}{ Nível de escolaridade } \\
\hline Ensino básico 10 ciclo incompleto & 3 & 6,7 \\
\hline Ensino básico 1ำ ciclo completo & 13 & 28,9 \\
\hline Ensino básico 20 ciclo & 3 & 6,7 \\
\hline Ensino básico 3o ciclo & 5 & 11,1 \\
\hline Ensino secundário & 4 & 8,9 \\
\hline Ensino superior & 17 & 37,8 \\
\hline \multicolumn{3}{|l|}{ Estado civil } \\
\hline Solteiro & 2 & 4,4 \\
\hline Casado & 33 & 73,3 \\
\hline Divorciado & 1 & 2,2 \\
\hline Viúvo & 9 & 20,0 \\
\hline \multicolumn{3}{|l|}{ Situação perante o trabalho } \\
\hline Reformado & 35 & 77,8 \\
\hline Exerce profissão a tempo inteiro & 7 & 15,6 \\
\hline Desempregado & 1 & 2,2 \\
\hline Invalidez & 2 & 4,4 \\
\hline
\end{tabular}

A amostra participante na situação de entrevista é composta por 20 homens e 25 mulheres, com idades compreendidas principalmente entre os 65 e 74 anos e com um nível de escolaridade que se divide entre o ensino básico 1. ciclo completo e o ensino superior. É uma população predominantemente casada, destacando-se, de seguida, o estado civil de viúvo/a. A situação na profissão dos entrevistados é principalmente a de reformado/a.

Atendendo ao tema central do projeto, apresenta-se, de igual modo, uma caracterização dos entrevistados no que diz respeito à vivência, ou não, de abusos e violência. 
Quadro 76. Trajetória de vitimização da amostra qualitativa

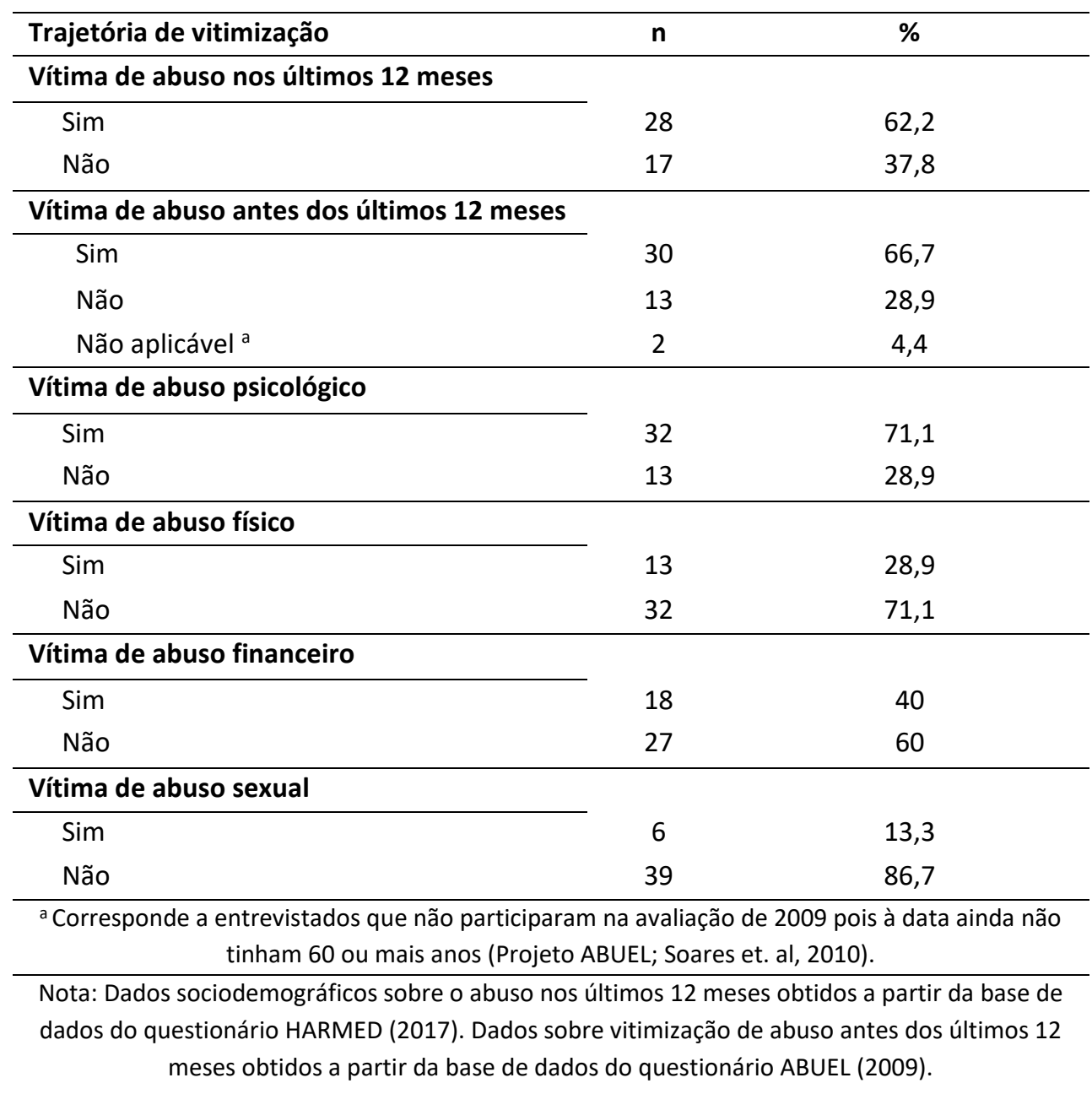




\section{Representações e discursos sobre o envelhecimento e os abusos na idade avançada: o significado das determinantes socioeconómicas e de saúde}

Assumindo-se que na pesquisa qualitativa são os dados que sustentam a interpretação e constroem teoria (Flick, 2008), as decisões acerca do guia analítico decorrem do próprio investigador, pelo que as entrevistas foram essencialmente analisadas a partir das seguintes dimensões: conhecer as representações dos participantes sobre o envelhecimento nas sociedades atuais; identificar o que, no plano representacional, constitui abuso, as suas principais modalidades, dinâmicas e reações à violência; compreender, segundo o ponto de vista dos entrevistados, a relação entre abusos e condições socioeconómicas, agravadas pela crise económico-financeira que afetou Portugal entre 2008 e 2011.

\subsection{Representações sobre a velhice e o envelhecimento: Ser idoso nas sociedades atuais}

\subsubsection{Os ganhos de longevidade e a recusa do critério cronológico}

O envelhecimento demográfico integra-se numa tendência comum a todos os países de economias desenvolvidas e, em rigor, a todo o globo, tendo vindo a acentuar-se, em Portugal, nas últimas três décadas (Dias \& Lopes, 2016). É um fenómeno que decorre do efeito conjugado do aumento da esperança média de vida e da quebra acentuada na natalidade, conduzindo à reconfiguração do equilíbrio entre grupos etários e ao aumento do peso dos idosos mais velhos (Dias, Lopes \& Lemos, 2018). Porém, o processo de envelhecimento da população portuguesa é marcado por inúmeras vulnerabilidades, como é o caso da ausência de recursos materiais, de redes de suporte social e de prestação de cuidados, enquanto componentes-chave para a promoção da qualidade de vida entre os adultos mais velhos (Grundy, 2006). É marcado, igualmente, por um discurso binário que ora acentua uma visão otimista que faz a apologia do envelhecimento saudável e bem-sucedido, ora enfatiza o declínio, a não produtividade e a dependência na idade avançada, alimentando assim o idadismo prevalecente no imaginário coletivo e que é interiorizado pelos cidadãos mais velhos (Sandberg, 2013; Miller, 2019). Assim, a nossa análise começa, nas entrevistas, por conhecer as representações dos mais velhos sobre o que é ser idoso nas sociedades atuais e qual é a perceção que eles têm acerca do fenómeno do envelhecimento populacional. Desde logo, o aumento da esperança média de vida, os progressos da ciência, em particular da Medicina, são apontados como as causas dos ganhos de longevidade sobretudo após a reforma, o que é percecionado de forma positiva, tal como é ilustrado nos seguintes testemunhos: 
"Eu acho que felizmente se evoluiu muito. Eu lembro-me de conversas lá em casa, as pessoas reformavam-se, era eu miúdo, conversas à mesa, e depois vinha sempre a história do "Olha, reformou-se, já morreu e tal", quer dizer, estavam às vezes um dia ou dois reformados e morriam. E aquilo não era estorvo nenhum porque as pessoas, claro, libertavam-se do pai e da mãe porque morria-se cedo. Agora, morre-se muito mais tarde, felizmente".

(Homem, 70 anos, Ensino Superior, sinalizado como vítima de abuso psicológico).

"Talvez a Medicina que está muito adiantada e, claro, as pessoas têm mais facilidade para se tratarem. A alimentação também hoje será outra".

(Homem, 87 anos, Ensino Básico, vítima de abuso).

Desta forma, conseguir alcançar uma idade avançada é encarado, pelos entrevistados, como uma verdadeira conquista: "Há alguns que num chegam à idade que eu tenho".

(Mulher, 85 anos, Ensino Básico, não sinalizada como vítima).

Todavia, esta perceção otimista e apelativa associada aos ganhos de longevidade, coexiste ora com discursos negativos e fatalistas sobre o que é ser idoso na modernidade, ora com discursos de aceitação da fase do ciclo de vida em que se encontram. Assim, é entre os entrevistados abaixo dos 75 anos que se observa uma certa reatividade às imagens estereotipadas da velhice e a recusa do critério cronológico usado, de forma geral, para definir quem é velho nas nossas sociedades:

"Considero, com o aumento da esperança de vida, que hoje as pessoas idosas são dos 75-85 anos para cima. Eu não me considero velho".

(Homem, Ensino Secundário, sinalizado como vítima de abuso).

"A idade que eu demonstro não tem a ver com a idade do bilhete de identidade".

(Homem, Ensino Secundário, sinalizado como vítima de abuso).

Os entrevistados acima dos 75 anos revelam uma atitude de maior naturalização desta fase do ciclo de vida, o que não implica necessariamente a aceitação da estereotipia que frequentemente lhe está associada:

"Eu gosto de ser velho, porque num tenho outra hipótese".

(Homem, 75 anos, Ensino Secundário, vítima de abuso).

"Eu vivo bem com o meu envelhecimento. Sou elegante, não sou desdentado, não sou careca, etc. Mas encaro a velhice, o envelhecimento, com alguma naturalidade porque ele é irreversível, se a pessoa for viva tem que envelhecer".

(Homem, 70 anos, Ensino Secundário, não sinalizado como vítima). 
Embora a entrada na velhice corresponda, então, a uma fase da vida convencional, na qual as regulamentações sociais neutralizam as repercussões biológicas diferenciáveis da idade, não significa que deva ser percecionada como "a tradução real da perda, ou redução de certos atributos físicos ou psicológicos, pois o processo de envelhecimento biológico é variável consoante os indivíduos" (Cardoso et. al, 2012:608). A heterogeneidade é assim um traço presente no discurso dos entrevistados, cujas representações sociais são muito marcadas pela rejeição do idadismo prevalecente nas sociedades modernas.

\subsubsection{Ser idoso versus ser velho: das limitações físicas à doença e à discriminação}

Apesar dos ganhos de longevidade, nas nossas sociedades, é difícil envelhecer porque, entre outras razões, a velhice continua a ser representada como um tempo de dependência e de segregação do mundo socialmente ativo e que todos valorizamos (Dias, 2005). Nas entrevistas, procuramos, então, compreender porque é que os participantes não querem ser classificados como velhos, a par da diversidade de critérios que consolida a representação de um quadro social de velhice fragilizada.

Em primeiro lugar, constata-se, no discurso de alguns entrevistados, a distinção entre ser idoso e ser velho. Embora ambas as categorias se sustentem nas alterações físicas que ocorrem com o avançar da idade, ser idoso implica não deixar de ter um estilo de vida ativo, característico das restantes faixas etárias, enquanto ser velho é ser dependente e incapacitado:

"Um idoso é um indivíduo que tem ideais, que continua a viver a vida e um velho não. Um velho é aquele indivíduo que se incapacita: "Vamos ver a televisão, vamos ver a internet, pouco saímos". Essa é a minha interpretação de ser velho e ser idoso e o meu medo é exatamente esse, é de estar a passar de idoso para velho".

(Homem, 70 anos, Ensino Superior, vítima de abuso).

Observa-se, em segundo lugar, um grande enfoque, por parte dos entrevistados, nas limitações físicas do corpo envelhecido representado como problemático, desarmonioso, não produtivo e indesejável (Sandberg, 2013; Miller, 2019). Os seguintes excertos são ilustrativos destas representações, as quais alimentam fortemente o conceito de velhice deficitária muito assente na noção de velhice física ou biológica.

"É a gente ir perdendo as faculdades que tinha, não é? Por exemplo, eu desde os 80 anos perdi muita mobilidade, é a falta de vista, é a falta de dentes, é num andar grande coisa, é a respiração que agora me está a faltar. Quer dizer, são os problemas da velhice".

(Homem, 81 anos, ensino básico, não sinalizado como vítima). 
"Olharmo-nos para o espelho todos os dias, vermos fotografias nossas $e$ sabermos que estamos mais velhos".

(Homem, 63 anos, ensino superior, sinalizado como vítima de abuso).

Paralelamente, alguns entrevistados fazem uma distinção clara entre idade biológica e idade psicológica (Paúl, 1997), queixando-se do desencontro entre ambas: "A mente num envelhece, o corpo é que envelhece". (Homem, 82 anos, Ensino Superior, não sinalizado como vítima).

"Eu tenho uma cabeça que não é para este corpo. Eu gostaria de fazer outras coisas, de ser ativo em muitas coisas e começo a notar, lentamente, que o meu corpo parece que já não quer acompanhar as minhas iniciativas, a minha vontade em muitos campos, até no meu hobbie principal que é a música".

(Homem, 71 anos, Ensino Básico, não sinalizado como vítima).

A idade física é assim um potencial indicador do que é ser idoso. A esta representação junta-se a noção de envelhecimento igual a doença, dependência e morte (Dias, 2005), tal como referem alguns entrevistados:

"Algumas pessoas que considero idosas são aquelas que já têm a doença de Alzheimer ou demência".

(Mulher, 75 anos, Ensino superior, não sinalizada como vítima).

"É a morte! Eu vou para a cama à noite, vou dormir e penso, será que eu vou acordar amanhã? É o tal sentimento, o pensamento da morte".

(Homem, 70 anos, Ensino Secundário, não sinalizado como vítima).

Do ponto de vista do envelhecimento social (Fonseca, 2004), isto é, dos papéis sociais apropriados às expectativas da sociedade para este nível etário, alguns entrevistados reportam experiências positivas:

"A velhice até acho interessante! É muito bom entrar no metro e oferecerem-me o lugar. Às vezes chego a casa e digo: "mais um dia que eu estou velha". E o meu filho pergunta: "Porquê mãe?" Mais um jovem que me ofereceu o lugar. Quando eu vou a atravessar a rua, às vezes perguntam: "A Senhora precisa de ajuda?". É uma sensação, olhe que é bom! É ser velho. A vida está no limite, mas é agradável".

(Mulher, 77 anos, Ensino Básico, vítima de abuso).

Esta última descrição, exemplificadora de uma discriminação positiva, contraria outras mobilizações discursivas assentes em comportamentos negligentes e em evidências de exclusão social:

"Eu costumo, às vezes, dizer que hoje a juventude não liga para um idoso. Se vai num passeio, vão dois ou três jovens, o idoso tem que descer o passeio porque 
eles não se desviam para o idoso passar. Pronto, é uma maneira de subestimar o idoso".

(Homem, 69 anos, Ensino Básico, vítima de abuso).

"No autocarro, por exemplo, há aqueles lugares próprios para a pessoa de idade mas, no geral, estão sempre ocupados. Antigamente, os mais novos, nem era preciso haver local próprio, uma pessoa dava o lugar à pessoa de idade. Hoje não dão. E sentam-se ali e sabe qual é a resposta: "Eu já paguei o meu passe". É totalmente diferente. A gente nova hoje não tem aquele amor ao próximo".

(Homem, 81 anos, Ensino Básico, vítima de abuso).

"No dia-a-dia a gente vê na rua, não se ajuda uma pessoa porque a velhotinha coitadinha caiu, porque há pessoas que têm o costume, já muitas velhas, mas ainda vão fazer as suas compras, e eu não vejo uma pessoa a ajudar, a pegarIhe no saco. Acho que são muito maltratados os velhos".

(Mulher, 77 anos, Ensino Básico, vítima de abuso).

Assim, vai-se consolidando uma progressiva falta de respeito pela figura da pessoa idosa, sustentada em crenças e representações idadistas ${ }^{9}$. Tal é ilustrado nos atributos sociais e nos adjetivos que os participantes usam para descrever o modo como o idoso é representado pela sociedade: lixo ${ }^{10}$, estorvar ${ }^{11}$, arrumado a um canto ${ }^{12}$, atrapalhar a vida de alguém ${ }^{13}$, elo mais fraco ${ }^{14}$, descartáveis ${ }^{15}$, empecilho ${ }^{16}$, trapo velho ${ }^{17}$, peso ${ }^{18}$. Tendo presente que se vive num tempo que valoriza a juventude e repele a velhice e a doença, os entrevistados consideram que "não há humanidade para os velhos" (Mulher, 79 anos, ensino básico, vítima de abuso).

\footnotetext{
${ }^{9}$ Corresponde à discriminação com base na idade, refletindo numa particular sociedade os estereótipos, preconceitos e atitudes baseadas em perceções globais sobre a idade e a velhice, em particular (WHO, 2002a).

${ }^{10}$ Homem, 66 anos, ensino secundário, vítima de abuso.

${ }^{11}$ Homem, 87 anos, ensino básico, vítima de abuso.

12 Mulher, 68 anos, ensino superior, vítima de abuso.

${ }^{13}$ Homem, 70 anos, ensino secundário, não sinalizado como vítima.

${ }^{14}$ Homem, 70 anos, ensino secundário, não sinalizado como vítima.

${ }^{15}$ Mulher, 74 anos, ensino superior, não sinalizado como vítima.

${ }^{16}$ Mulher, 71 anos, ensino básico, vítima de abuso.

${ }_{17}$ Mulher, 79 anos, casada, ensino básico, vítima de abuso.

${ }^{18}$ Mulher, 75 anos, ensino superior, não sinalizada como vítima.
} 


\subsubsection{Individualismo e nexo geracional: os desequilibrios}

Os participantes revelam alguma descrença no sistema de valores que enquadra atualmente a vida coletiva, o qual surge desfasado da representação tradicionalista dos mais velhos como pessoas veneradas e respeitadas pela família e a sociedade, tal como sucedia no passado (Dias, 2005). Assim, nos seus discursos, há, desde logo, uma forte incidência na questão da educação e na falta dela, em geral. Esta constatação é feita a partir de uma análise comparativa entre a sociedade atual e a sociedade tal como existia no tempo em que eram jovens:

"Sinto-me um derrotado porque acho que a culpa disto tudo também é um bocado minha e da nossa geração, da geração à qual eu pertenço. Porque foi uma geração que levou valores que estão por aí. Isto num nasceu por acaso, o egoísmo e a falta de educação das pessoas."

(Homem, 66 anos, Ensino Secundário, vítima de abuso).

"Há falta de educação para saber envelhecer".

(Mulher, 77 anos, viúva, Ensino Básico, vítima de abuso).

"Dantes respeitava-se os mais velhos, porque o meu pai se me visse a fazer alguma coisa, ele só bastava olhar para mim. Desde criança ensinaram-me que se devia respeitar os mais velhos. Hoje não há valores. É tudo muito permissivo".

(Mulher, 63 anos, Ensino Superior, vítima de abuso).

Para além da falta de educação e respeito para com os mais velhos, também é referida a ausência de sentimentos e de afetividade, o que é muito enfatizado no discurso feminino:

"Antigamente havia amor, havia carinho, respeito pelos velhinhos. Agora não. Agora dá-se mais valor ao cão e as leis até saem, por exemplo, um animal já pode entrar num restaurante".

(Mulher, 68 anos, Ensino Superior, vítima de abuso).

"Há menos essa cultura do afeto".

(Mulher, 75 anos, viúva, Ensino Superior, não sinalizada como vítima).

O egoísmo e o individualismo são termos chave usados para descrever a indiferença com que, segundo os entrevistados, os mais velhos são tratados na nossa sociedade, refletindo assim argumentos da teoria da modernização que, a partir de premissas estruturo-funcionalistas e normativas, explica o declínio do estatuto dos idosos nas nossas sociedades (Dias e Rodrigues, 2012): 
"Eu sinto uma tristeza muito grande porque sinto que há um egoísmo, quer dizer, hoje há muito individualismo, muito egoísmo, é só eu, eu e eu. Eu sou o centro de tudo e tudo tem que andar à minha volta".

(Homem, 79 anos, Ensino Superior, sem experiência de vitimação).

"Acho que a sociedade é mais egoísta, as pessoas vivem mais para si próprias, não se incomodam muito com o que está a acontecer aos outros, eu penso que nesse aspeto foi a sociedade que promoveu isso. A história do "salve-se quem puder". Primeiro eu, depois eu, de maneira que eu acho que os idosos nesse aspeto perderam um bocado, perderam".

(Homem, 70 anos, Ensino Superior, vítima de abuso).

A erosão dos valores, na transição entre gerações, é igualmente reportada no plano da família, enquanto reduto de normas e práticas tradicionalistas que marcaram a geração dos entrevistados. Como refere Pais (1998:41), "se a família é um lugar de trocas simultaneamente afetivas e instrumentais, essas trocas parecem escapar, nos dias que correm, às dinâmicas autoritárias que caracterizavam a estrutura hierárquica das famílias tradicionais". A mudança ao nível das relações familiares, da estrutura e dos papéis desempenhados pelos seus membros, é vista pelos participantes como uma ameaça à estabilidade familiar, levando-os a responsabilizar o comportamento dos mais jovens pela sua desagregação.

"As famílias para já são disfuncionais. Depois acabam por descarregar, muitas frustrações: "Não tenho tempo, eu tenho mais que fazer, eu não sei quê, não sei quantos». Prontos, tudo isso afeta a relação familiar, acho que é por aí."

(Homem, 66 anos, Ensino Secundário, vítima de abuso).

"No tempo em que eu era pequeno, os idosos eram muito respeitados porque o conceito de família era muito mais próximo do que é agora. Existe muito mais o conceito de família na minha casa e das pessoas próximas com quem eu vivia. As famílias eram grandes, havia sempre avós, tios mais idosos que eram respeitados e que davam ali algum equilíbrio às relações."

(Homem, 62 anos, Ensino Superior, vítima de abuso).

Associada à representação de instabilidade dos vínculos familiares, encontra-se a desvalorização, pelos mais jovens, da noção de casamento como sacramento e, consequentemente, do casamento religioso e a sua substituição pela noção de casamento como um contrato, a qual tem subjacente a possibilidade da sua dissolução (Leandro, 2001), o que conduziu, segundo os entrevistados à banalização do divórcio.

"A evolução dos tempos, o mundo, virou tudo de baixo para cima. Quem conheceu isto há 100 anos ou há 50 ou 60, isto era uma paz, um sossego. A guerra sempre houve, num é? Mas havia muitos casamentos, havia tudo. Hoje 
as pessoas nem se casam nem nada, hoje nem se namora. Namorava-se sobretudo no casamento. Hoje juntam-se dois ou três dias e já são capazes de se juntarem, nem há namoro, nem há nada. É as famílias de hoje".

(Homem, 87 anos, Ensino Básico, vítima de abuso).

"Antigamente, por exemplo, não havia divórcios. A pessoa casava, era para toda a vida e às vezes era um sofrimento horrivel, num é? Agora há divórcios, ora porque fez a sopa mal feita, ora porque não tinha sal ou qualquer coisa já fazem o divórcio."

(Homem, 81 anos, Ensino Básico, não sinalizado como vítima).

A respeito das diferenças geracionais, os entrevistados criticam a progressiva perda da influência da Igreja Católica na regulação dos comportamentos individuais e coletivos. Nos seus discursos, a prática religiosa ressente-se, como autoridade social ou moral, principalmente devido ao absentismo dos mais jovens e, em razão disso, aliena-se do seu papel.

"Têm falta daquilo que nós tínhamos quando éramos crianças. Nós íamos à catequese, mas também havia a parte religiosa na escola, em que nos ensinavam que isto era o bem e que aquilo era o mal, e que devíamos respeitar os mais velhos e isto e aquilo."

(Mulher, 80 anos, viúva, Ensino Secundário, não sinalizada como vítima).

Observa-se, de igual modo, alguma incompatibilidade ao nível geracional, que poderá ser interpretada como "descontinuidades que terão que ver com diferentes níveis de adesão substantiva, por parte de distintas gerações, quer em relação a valores societais (religiosos, políticos, etc.), quer no que respeita a valores de quotidianidade (hábitos de consumo, convivialidade, intimidade, etc.) (Pais, 1998:20), o que é ilustrado nos seguintes testemunhos:

"Não se pode conversar com eles [jovens]. Os mais velhos só falam no «meu tempo, ai no meu tempo», as pessoas estão desencontradas e não dão importância nenhuma. O mundo de hoje não tem nada a ver com o mundo onde eu nasci. Nada! E as pessoas têm lá agora paciência para aturar um velhote"

(Homem, 82 anos, Ensino Superior, não sinalizado como vítima).

"Os mais velhos estão a viver muito no passado, têm ideias retrógradas e às vezes isso magoa os mais novos".

(Mulher, 71 anos, Ensino Básico, vítima de abuso).

Quando alimentado de estereótipos negativos socialmente compartilhados, este confronto de valores geracionais resulta na discriminação das pessoas com base na idade. As atitudes idadistas acabam por ser interiorizadas pelos idosos, traduzindo-se 
numa postura negativa perante a vida, levando-os, muitas vezes, a comportarem-se de uma forma menos ativa, física e mentalmente (Fonseca, 2004). Traduzem-se, de igual modo, numa menor participação social, política e económica, sobretudo após a reforma. Sendo a sociedade contemporânea muito estruturada pelo trabalho, a entrada na reforma, marca cronológica estandardizada, surge, no discurso dos entrevistados, como uma exclusão do mercado de trabalho imposta aos mais velhos. À desvalorização social, decorrente da expulsão dos mais velhos do mundo ativo, associa-se a desvalorização económica decorrente da fraqueza das pensões de reforma (Dias \& Lopes, 2016):

"Acho que há muito desperdício, as pessoas consideradas mais velhas, podiam fazer muito em prol da sociedade"

(Homem, 66 anos, casado, Ensino Secundário, vítima de abuso).

"Gostava de estar a trabalhar".

(Mulher, 72 anos, Ensino Básico, vítima de abuso).

"Uma medida que poderia trazer qualidade de vida aos idosos era apoiar o emprego das pessoas seniores, porque são pessoas que têm muita experiência e poderiam ser úteis do ponto de vista social e económico".

(Homem, 63 anos, Ensino Superior, vítima de abuso).

A discriminação negativa, que condensa as representações da velhice como um grupo homogéneo, isto é, como se os mais velhos chegassem todos a esta fase da vida e se esbatessem todas as diferenças individuais, associada à sua inatividade, é interiorizada levando os idosos a sentirem-se inúteis. Tal não só aumenta fortemente o risco de exposição a processos de vulnerabilidade social (Lopes, 2014), mas também o desencantamento com a vida o que os leva, por vezes, a pensar na morte.

"Eu digo muitas vezes que não me importa de morrer, eu não me importa. Já sei que tenho de morrer, por isso, morrer hoje ou morrer amanhã para mim é igual. Agora o que eu não queria era estar a dar trabalho a ninguém".

(Mulher, 79 anos, Ensino Básico, vítima de abuso).

"Acho que eles olham para as pessoas mais velhas e acham que eles que não servem para nada, penso eu. Que pensam que aquilo é um bocado de carne que anda por ali a passear e que só estorvam".

(Homem, 63 anos, Ensino Básico, vítima de abuso).

Por seu turno, cada cultura desenvolve olhares particulares sobre a velhice, afirmandose esta como uma construção social histórica e socialmente variável (Dias, 2005). Neste sentido, os entrevistados reconhecem que as atitudes face às pessoas mais velhas variam consoante as sociedades e as culturas, as quais definem o lugar que elas ocupam, assim como as suas possibilidades e interesses (Idem): 
"O chinês diz que o velho tem muita sabedoria, mas o português não, diz que o velho não presta".

(Mulher, 71 anos, Ensino Básico, vítima de abuso).

"Os idosos ainda existem. São seres humanos".

(Homem, 82 anos, Ensino Superior, não sinalizado como vítima).

Em suma, observa-se no discurso dos entrevistados a representação de que a longevidade, enquanto conquista da modernidade, é acompanhada por visões idadistas e discriminatórias, que são agravadas pelo individualismo e egoísmo que caracterizam, segundo eles, as relações sociais do nosso tempo, mas também pela falha do "nexo geracional" (Mendes, 2005) que assegurava, tradicionalmente, as solidariedades intergeracionais. Todavia, reconhecem igualmente que cada sociedade e cultura tem uma relação diferente com a velhice, variando a sua construção social, mas também os seus limites e oportunidades.

\subsection{Representações sobre o abuso e violência contra as pessoas idosas: 0 desempoderamento dos mais velhos}

\subsubsection{O abuso enquanto crime e violação dos direitos humanos}

A análise prévia das representações e significados da velhice permitiu-nos um melhor enquadramento da questão do abuso de idosos, enquanto fenómeno autónomo e não equiparável a outras formas de violência doméstica, como é o caso da violência exercida contras as mulheres e as crianças (Dias, 2010). À semelhança do que se fez antes, partiuse da análise das representações sociais presentes entre os entrevistados sobre o que é abuso e o que pensam sobre o fenómeno. Os entrevistados desaprovam, por unanimidade, a prática de atos abusivos e violentos sobre os mais velhos, considerando que tal não só é o reflexo da sociedade, doente e violenta, em que vivemos, como este fenómeno deve ser alvo de criminalização.

"É o reflexo da sociedade, isto é, eu penso que a sociedade não pode estar isenta desses crimes porque uma sociedade doente vai refletir a sua doença de qualquer maneira, porque hoje não há emprego, não há ocupação de tempos livres, comunica-se pouco".

(Homem, 70 anos, Ensino Secundário, não sinalizado como vítima).

"A violência é um crime. Não é só contra as pessoas de idade! É contra as pessoas de idade, é contra as pessoas novas, é contra tudo e contra todos. Seja ela qual for, seja violência doméstica, seja violência sexual, seja a violência que for. A violência é um crime".

(Homem, 77 anos, Ensino Básico, não sinalizado como vítima). 
"Agora cada vez que há agressões é um crime público, a lei diz claramente, é um crime público. As pessoas devem-se queixar para que a própria sociedade se aperceba que essas situações não devem ficar incólumes porque senão continuamos com o velho ditado: "Entre marido e mulher não metas a colher»".

(Homem, 62 anos, Ensino Superior, vítima de abuso).

"Se alguém abandona uma pessoa idosa é um crime".

(Homem, 72 anos, Ensino Básico, vítima de abuso).

A forte consciencialização da gravidade do problema dos abusos e violência contra as pessoas idosas está presente tanto entre os entrevistados sinalizados como vítimas, como por aqueles que até à data de realização das entrevistas (2017) não apresentavam qualquer experiência de vitimização. Tais comportamentos abusivos, acomodados na organização social, são inclusive representados como uma forte violação dos direitos humanos:

"Todo o tipo de violência, seja ela qual for, é sempre uma falta de respeito enorme pela pessoa. A pessoa humana é a entidade mais digna, mais nobre à face da terra. Nós temos que pensar que essa pessoa, enfim, foi uma jovem graciosa, foi um homem elegantíssimo, foi um grande técnico, foi um grande industrial, foi um grande médico, foi um grande professor, mas a sua fragilidade humana vem-Ihe com o tempo. Mas ela, apesar de ter perdido essas qualidades todas continua a ser um ser humano $e$, portanto, o ser humano deve ser respeitado na totalidade das suas fragilidades".

(Homem, 79 anos, Ensino Superior, não sinalizado como vítima).

\subsubsection{Razões da violência: da assimetria do poder à desvalorização social da pessoa idosa na modernidade}

$\mathrm{Na}$ nossa análise procuramos também conhecer as razões que, na perspetiva dos entrevistados, estão na origem dos abusos sobre as pessoas mais velhas, ou seja, porque razão os "idosos são um alvo mais fácil"19 de violência nas nossas sociedades?

Na resposta a esta questão predomina, entre os entrevistados, a representação da violência como uma manifestação da assimetria de poder existente entre o agressor e a vítima mais velha, argumentação que encontra sustentação empírica na própria literatura, como é o caso dos trabalhos de Pagelow (1984). Esta autora, "define poder como a capacidade de realizar a própria vontade e assumir controlo sobre os demais, com ou sem legitimidade, fundamentado na distribuição de recursos físicos, psicológicos e/ou materiais" (p. 98). Assim, para os entrevistados, o agressor corresponde ao sujeito

\footnotetext{
${ }^{19}$ Mulher, 64 anos, ensino básico, vítima de abuso.
} 
com mais poder, enquanto a vítima é representada como uma pessoa "indefesa, frágil, fraca e sem apoio"20, tal como se ilustra de seguida:

"A violência pratica-se sempre da mesma maneira quando uma pessoa quer magoar outra e se sente mais forte, abusa e faz. Como os velhos estão velhos, são como as crianças e as mulheres, têm menos força, há abusos! É sempre a mesma história. Não vale a pena arranjar uma violência só para os idosos, as crianças ou para as mulheres. Há violência! Acabou! E os mais fortes têm tendência, física e psicologicamente, de utilizar esse poder para magoar. As pessoas estão fracas, estão diminuídas perante alguém com um bocadinho mais de poder do que a outra, pronto, tratam mal".

(Homem, 62 anos, Ensino Superior, vítima de abuso).

A vulnerabilidade crescente, o declínio das capacidades físicas, a maior probabilidade de doença, decorrente do envelhecimento biológico, constitui outra razão que está na origem dos abusos e que se encontra presente no discurso dos entrevistados. Embora a idade possa não ser um risco em si mesma, ela poderá aumentar o risco de violência quando associada a uma deterioração do estado de saúde e, consequentemente, ao aumento da incapacidade funcional (Gil, 2014). Assim, as idiossincrasias próprias do envelhecimento biológico, entre outros aspetos, debilitam a capacidade pessoal de defesa dos mais velhos, tal como consideram os seguintes entrevistados:

"Tem muita influência a parte de invalidez do próprio idoso. Quanto mais ele estiver fisicamente debilitado, menos ele é capaz de defesa e é um alvo mais fácil."

(Homem, 71 anos, Ensino Superior, vítima de abuso).

"Em idosos há muito mais violência, porque são pessoas mais indefesas. Eu próprio já tenho alguma reserva porque sei que com a idade que tenho, sintome mais indefeso, naturalmente. Não tenho tanta força, além de que nunca fui um tipo violento".

Homem, 70 anos, Ensino Secundário, não sinalizado como vítima).

"Os idosos são mais frágeis e eles [os agressores] aproveitam-se".

(Homem, 70 anos, Ensino Superior, vítima de abuso).

"A violência é sempre de alguém mais forte sobre alguém que está enfraquecido".

(Homem, 62 anos, Ensino Superior, vítima de abuso).

\footnotetext{
${ }^{20}$ Mulher, 60 anos, ensino superior, vítima de abuso.
} 
Outra razão da violência sobre as pessoas mais velhas encontra-se associada às situações de dependência em que muitos se encontram. Com efeito, há muito que a pesquisa gerontológica tem vindo a demonstrar a associação entre abusos e os níveis de dependência dos idosos face aos cuidados dos membros da família (sobretudo cônjuges e filhos/as), mas também a dependência destes em relação aos idosos, seja no plano financeiro ou ao nível da coresidência, situação que é considerada por muitos investigadores como um fator de risco importante (Wolf \& Pillemer, 1989).

"Muitas vezes as pessoas enfraquecidas não reagem, porque sabem que estão dependentes".

(Homem, 62 anos, Ensino Superior, vítima de abuso).

"Porque eles [idosos] estão fracos, não podem fazer nada e muitos até estão, às vezes, subjugados aos filhos, ou a pessoas que estejam a olhar por eles, só porque eles têm um bocadinho de dinheiro e então vão ajudando. Quando eles não têm dinheiro dão-Ihe com os pés, batem-Ihes, isso é um abuso de confiança".

(Homem, 63 anos, Ensino Básico, vítima de abuso).

O desempoderamento das pessoas mais velhas acentua-se na ausência de suporte familiar e quando os níveis de rendimento são mais fracos: "Determinadas pessoas são abandonadas e dizem assim: "É pá, como é que isto é possível? Esta pessoa não tem família?". É aquilo que eu digo, as reformas de 200 euros não dão nada e os idosos não têm apoio. São esses que a gente vê na televisão, na freguesia X um Senhor com 85 anos estava abandonado, na outra freguesia um Senhor com 90 anos estava abandonado, $o$ outro morreu sozinho em casa. É a sociedade de hoje" (Homem, 72 anos, Ensino Básico, vítima de abuso).

Por último, a elevada prevalência do abuso de idosos deve-se, de acordo com os entrevistados, à atuação e valores da sociedade, bem como ao próprio processo de envelhecimento demográfico, surgindo, agora, a longevidade como um fator de risco.

"No tempo dos meus pais, eu num me lembro de haver violência nenhuma contra os velhotes. Pelo contrário, havia uma proteção grande aos velhinhos".

(Homem, 81 anos, Ensino Básico, não sinalizado como vítima).

"A sociedade era mais interventiva, a sociedade antigamente não tolerava o que se passa hoje. Embora hoje haja mais armas para as pessoas se defenderem, os mais velhos não usam as armas".

(Homem, 66 anos, Ensino Secundário, vítima de abuso).

"Portanto, há mais violência! Ponto final. E há mais velhos, nota-se mais".

(Homem, 62 anos, Ensino Superior, vítima de abuso). 


\subsubsection{Os sentimentos: revolta, impotência e ingratidão}

Abordar o tema dos abusos sobre pessoas idosas suscitou nos entrevistados um conjunto de sentimentos intensos, ilustrando a forte reprovação de tais comportamentos mas, ao mesmo tempo, contraditórios, desde o sentimento de revolta perante a falta de segurança existente nas nossas sociedades, à impotência associada à incapacidade de reação.

"Fico revoltado e penso em coisas que não devo pensar. Penso que os velhos deviam ter uma autodefesa e não têm".

(Homem, 77 anos, Ensino Básico, não sinalizado como vítima).

"Sinto a mesma revolta que sinto quando sei que uns pais tratam mal crianças e a gente vê aquelas notícias escabrosas ou que cada vez há mais violência doméstica e isso tudo. Por isso, não é o paradigma duma sociedade que se pretendia cada vez mais justa, antes pelo contrário".

(Homem, 62 anos, Ensino Superior, vítima de abuso).

"Eu, um homem que vai fazer 77 anos, se me disserem: "Já não podes fazer isso, já estás velho", fico muito ofendido! Fico muito melindrado! Revolto-me, porque no fundo um idoso é como uma criança, está indefeso e sinto uma certa revolta pelos familiares ou até outras pessoas de fora exercerem violência sobre pessoas assim".

(Homem, 75 anos, Ensino Secundário, vítima de abuso).

O sentimento de ingratidão também se encontra muito presente no discurso dos entrevistados, acentuando-se a noção de traição ao "nexo entre gerações" e do qual "depende a continuidade das comunidades humanas para além da duração das vidas dos membros atuais" (Mendes, 2005:1). Assim, é enfatizado a ausência de reconhecimento da dedicação ao longo da vida, por parte dos mais velhos, sobretudo à família e aos filhos:

"Quando eu sou agredido, não é necessário que seja fisicamente agredido, mas quando sou agredido verbalmente ou gestualmente por alguém a quem eu dei tudo e mais alguma coisa... Para mim a ingratidão é das coisas que mais me dói. A coisa que mais me dói a mim é a ingratidão. Nós temos que perdoar e temos que esquecer, mas a ingratidão".

(Homem, 79 anos, Ensino Superior, sem experiência de vitimação).

"Eu acho que hoje há mais violência no sentido de haver mais ingratidão contra os idosos. Se a ingratidão é violência? É, sem dúvida nenhuma. Hoje há mais do que antigamente, porque antigamente as pessoas, mesmo nas cidades, viviam, nasciam e morriam em casa. Hoje as pessoas nascem fora e morrem fora e se morrem em casa é corrê-las logo de casa para fora." 
(Homem, 79 anos, Ensino Superior, não sinalizado como vítima).

Todavia, um dos entrevistados sinalizado como vítima de abuso psicológico e financeiro, revela alguma naturalização do fenómeno: "Aceito como uma coisa muito natural"21 , 0 que poderá indiciar a persistência dos abusos e o sentimento de impotência para reverter a situação.

\subsubsection{Tipos de abuso: definições e condutas}

As dificuldades presentes na definição do conceito de pessoas idosas, cujo campo semântico não pode ficar confinado exclusivamente ao critério cronológico (ter 65 anos e mais), também se refletem na definição do que é abuso e das suas principais modalidades de ocorrência (Dias, Lopes \& Lemos, 2019). No nosso estudo, partimos da definição apresentada pela Action on Elder Abuse (1995), na Grã-Bretanha, adotada depois pela Organização Mundial de Saúde (WHO), que considera abuso como "qualquer ato isolado ou repetido, ou ausência de uma ação apropriada, que ocorre no âmbito de qualquer relacionamento onde haja uma expetativa de confiança, causador de dano ou incómodo a uma pessoa idosa" (WHO, 2002b). Esta definição foi reforçada pelo Conselho da Europa (2002) que se refere ao fenómeno como "todo o ato ou omissão cometido contra uma pessoa idosa, no quadro da vida familiar ou institucional e que atenta contra a sua vida, a segurança económica, a integridade física e psíquica, a sua liberdade ou que comprometa, gravemente, o desenvolvimento da sua personalidade". Tais definições não só enfatizam a intencionalidade presente nos atos abusivos, como alargaram o âmbito dos comportamentos classificados como tal, assim como os contextos da sua ocorrência (Dias, Lopes \& Lemos, 2019).

O fenómeno do abuso subentende assim um conjunto lato de comportamentos, práticas ou omissões infligidos sobre os idosos, designadamente o abuso físico (inclui atos que causam dor e/ou lesões físicas), psicológico ou emocional (refere-se a ações que conduzem a um mal-estar psíquico, emocional e mental), material ou financeiro (consiste na apropriação indevida dos recursos, bens e propriedades da pessoa idosa), sexual (reporta-se a ações com carga sexual ou atividade sexual não consentida pelo idoso) e a negligência ativa e passiva, que consiste na não satisfação das necessidades de um idoso dependente pondo em causa o seu bem-estar (Pillemer et al., 2016:195; Dias, 2010:146; Fonseca et al., 2012:152). Partindo desta tipologia, mais frequentemente utilizada na investigação e intervenção social, articulam-se, neste ponto, as definições científicas com as narrativas dos entrevistados, considerando-se,

\footnotetext{
${ }^{21}$ Homem, 74 anos, ensino básico, vítima de abuso.
} 
ao mesmo tempo, o peso das características sociodemográficas na interpretação das representações dominantes sobre os tipos de abusos perpetrados sobre os mais velhos.

O abuso psicológico é apontado, no discurso dos entrevistados, com um nível elevado de gravidade, desde logo, pelas vítimas deste tipo de violência. Aqui, encontram-se homens com qualificações equivalentes ao ensino secundário/superior, o que demonstra, de certa forma, como o capital escolar pode influenciar a construção dos significados, mas também a perceção e autodesignação deste tipo de vitimação. No entanto, os homens entrevistados representam mais o abuso psicológico através de condutas ativas e omissivas como o desprezo e rejeição, enquanto as mulheres incluem neste tipo de abuso os comportamentos verbais, tal como se ilustra de seguida:

"A violência psicológica é fortíssima e é cada vez mais utilizada e é tão grave! Mas, muitas vezes, infelizmente, só se olha para a violência física e devia-se olhar para esta violência".

(Homem, 62 anos, Ensino Superior, vítima de abuso).

"É a pessoa que está ali, é enxotada para o caixote do lixo".

(Homem, 75 anos, viúvo, Ensino Secundário, vítima de abuso).

"Porque a linguagem hoje em dia é muito violenta. De maneira que quando tratam os velhos, por exemplo, com um palavrão "olha vai pr'aqui, vai pr'acolá», para mim, é como cortar à faca".

(Mulher, 77 anos, Ensino Básico, vítima de abuso).

Em ambos os casos, são referidos comportamentos que, do ponto de vista dos entrevistados, conduzem a um mal-estar psíquico e emocional. Mas, algumas vítimas não só têm dificuldade em reconhecer a sua situação, como, por vezes, têm dificuldade em autodesignar o tipo de abuso de que são alvo. Porém, os custos deste tipo de violência são reconhecidos, sobretudo ao nível das suas consequências duradouras, como é o caso da seguinte entrevistada:

"Definir exatamente o que é mau trato psicológico é difícil porque eu, às vezes, acho que sou vítima de mau trato psicológico, mas é difícil. A violência física, já todos sabemos que ficam marcas no corpo, mas a emocional é muito grave porque as marcas não desaparecem com facilidade".

(Mulher, 69 anos, Ensino Superior, vítima de abuso).

"Quando se chega à agressão já se passou por uma data de fases, não é? Desde o insulto, o tratar mal a pessoa, desde o não se importar com ela e depois isso tudo acaba na agressão. Chegando à agressão, chegou-se ao cúmulo".

(Homem, 71 anos, Ensino Básico, experiência de vitimação). 
Para a descrição do abuso físico são indicadas uma multiplicidade de ações, tais como "bater 22 , espancar 23 , atacar ${ }^{24}$, causar dor e/ou lesões físicas" 25 mas, também são apontados casos como: "acorrentados às camas ${ }^{26}$, marido dá no pelo da mulher"27, havendo ainda referência concreta à morte como consequência deste tipo de violência: "ir a vias de facto ${ }^{28}$, pôr às portas da morte" ${ }^{29}$. Segundo os entrevistados, quem agride fisicamente pode recorrer a qualquer meio:

"Com os mais variados meios, com paus, olhe, com uma caneta, com pistolas, com facas, agora ouve-se mais é facas. Portanto, com vários instrumentos atirados ao corpo".

(Mulher, 66 anos, Ensino Superior, vítima de abuso).

As ações indicadas no âmbito do abuso financeiro encontram-se tanto no discurso de entrevistados vítimas, como naqueles que não são vítimas. Neste tipo de abuso o idoso é indicado, por todos, como sendo a vítima preferencial. Além da referência evidente aos "assaltos"30 por desconhecidos, definidos como a "apropriação indevida de recursos da pessoa idosa"31, os entrevistados do sexo masculino referem que são os filhos os principais perpetradores deste tipo de abuso, os quais, segundo eles, só "visitam os pais para apanhar dinheiro, de resto os pais não servem para mais nada" $32 \mathrm{e}$ "encostam-se à mãe e ao pai pelo fator rendimento"33. Por seu turno, as entrevistadas, ainda que com uma alusão ao apoderamento indevido das "heranças e partilhas" ${ }^{34}$, também incluem neste tipo de abuso situações como "controlar o dinheiro", impedindo os mais velhos do seu acesso e gestão autónoma ${ }^{35}$.

Mas é o abuso sexual que surge como o grande tabu para os entrevistados. Revelandose de debate problemático, pela sociedade em geral, e como uma espécie de falso problema, pois representacionalmente a sexualidade não existe na idade avançada, nem tão pouco a atração sexual (Sandberg, 2013; Miller, 2019), o constrangimento transpareceu nas entrevistas aquando da abordagem deste tipo de abuso. Assim, só

\footnotetext{
${ }^{22}$ Mulher, 78 anos, ensino básico, vítima de abuso.

${ }^{23}$ Homem, 70 anos, ensino superior, vítima de abuso.

${ }^{24}$ Homem, 70 anos, ensino secundário, não sinalizado como vítima de abuso.

${ }^{25} \mathrm{Homem}, 70$ anos, ensino secundário, não sinalizado como vítima de abuso.

${ }^{26}$ Homem, 70 anos, ensino secundário, não sinalizado como vítima de abuso.

${ }^{27}$ Mulher, 71 anos, ensino básico, vítima de abuso.

${ }^{28}$ Homem, 63 anos, ensino básico, vítima de abuso.

${ }^{29}$ Homem, 87 anos, ensino básico, vítima de abuso.

${ }^{30}$ Homem, 66 anos, ensino secundário, vítima de abuso.

${ }^{31}$ Homem, 66 anos, ensino secundário, vítima de abuso.

32 Homem, 81 anos, ensino básico, não sinalizado como vítima.

33 Homem, 71 anos, ensino superior, vítima de abuso.

${ }^{34}$ Mulher, 71 anos, ensino básico, vítima de abuso.

${ }^{35}$ Mulher, 75 anos, ensino básico, vítima de abuso.
} 
muito superficialmente e apenas por entrevistados sinalizados como vítimas, de predominância do sexo feminino e até aos 75 anos, é que o assunto foi abordado. Deste modo, o abuso sexual é descrito como uma "violação" ${ }^{36}$, como "ações não consentidas, por exemplo, forçar ${ }^{37}$ ou obrigar a ter relações sexuais"38 por parte do marido ou desconhecidos. O fator género mantém relevância quando, em determinadas narrativas, se associa exclusivamente este tipo de abuso às mulheres, nomeadamente afirmando-se que o abuso sexual diz respeito a "Senhoras violadas"39, sendo as vítimas apenas do sexo feminino.

Por fim, a negligência assume muita relevância no discurso dos idosos identificados como vítimas, mas também entre aqueles que não reportaram experiência de vitimização. A sua prática, ativa ou passiva, resulta, segundo os entrevistados, na omissão ao nível da "satisfação das necessidades de um idoso pondo em causa o seu bem-estar, na falta de acesso a alimentação e a medicamentos ${ }^{40}$, em não ter ajuda para fazer higiene e deslocações"1, mas também na ausência de "carinho, ternura e compreensão"42, ou de "uma conversa, visita ou apoio"43. A negligência configura-se ainda através do abandono, sobretudo, na "fase de usar fralda"4. Evidencia-se através do "desprezo e inutilidade" com que se tratam os mais velhos: "É a inutilidade: "és um velho jarreta para aí! Já num vales nada pá, vê lá num caias pá". É perspinhar, é mesquinhar, é ridicularizar" (Homem, 82 anos, ensino superior, não sinalizado como vítima).

Na tabela seguinte são apresentados, de forma sistematizada, os diferentes tipos de abuso perpetrados sobre as pessoas mais velhas mais reconhecidos pelos entrevistados, assim como exemplos de condutas referidos ao longo das entrevistas. Nesta tabela é possível observar uma multiplicidade de condutas identificadas pelos entrevistados e que se enquadram nas definições usualmente utilizadas sobre os diferentes tipos de abusos de idosos. A designação destes comportamentos, pelos entrevistados, não só permite identificar o grau de severidade que eles Ihes atribuem, mas também o modo como são subjetivamente interpretados e sentidos. E esta é uma dimensão que os investigadores têm que ter em conta nas suas análises, de forma a poderem classificar comportamentos que têm mais significado e que são causadores de grande sofrimento,

\footnotetext{
${ }^{36}$ Mulher, 63 anos, ensino superior, vítima de abuso.

${ }^{37}$ Mulher, 71 anos, ensino básico, vítima de abuso sexual.

38 Mulher, 69 anos, ensino superior, vítima de abuso sexual.

${ }^{39}$ Homem, 72 anos, ensino básico, vítima de abuso.

${ }^{40}$ Homem, 81 anos, ensino básico, não sinalizado como vítima.

${ }^{41}$ Homem, 72 anos, ensino básico, vítima de abuso.

42 Homem, 79 anos, ensino superior, não sinalizado como vítima.

${ }^{43}$ Homem, 66 anos, ensino secundário, vítima de abuso.

${ }^{44}$ Mulher, 68 anos, ensino superior, vítima de abuso.
} 
como é o caso do abuso psicológico e financeiro, que afeta desproporcionalmente estas pessoas. 
Quadro 77. Diferentes tipos de abuso, segundo o sexo dos entrevistados

\begin{tabular}{|c|c|c|}
\hline \multirow{3}{*}{ Definições } & \multicolumn{2}{|c|}{ Condutas abusivas identificadas pelos entrevistados } \\
\hline & \multicolumn{2}{|c|}{$\begin{array}{ll}\text { Sexo } \\
\end{array}$} \\
\hline & Feminino & Masculino \\
\hline \multirow{10}{*}{$\begin{array}{l}\text { Abuso } \\
\text { psicológico } \\
\text { [ações que conduzem } \\
\text { a um mal-estar } \\
\text { psíquico, emocional e } \\
\text { mental] }\end{array}$} & Aleijar as pessoas verbalmente & \\
\hline & & Impor comportamentos \\
\hline & Não prestas, nunca mais morres & \\
\hline & & Enxotado para o caixote do lixo \\
\hline & Fazer de conta que é um trapo & \\
\hline & Familiares que os deixam à sua sorte & A senhora sabe onde é que estava bem? Era em casa \\
\hline & & \\
\hline & Não olhar para o idoso na rua & Estás cá a mais \\
\hline & Não integrar, pôr as pessoas de lado & $\begin{array}{l}\text { Pessoas no lar abandonadas, à espera que chegue a } \\
\text { hora }\end{array}$ \\
\hline & Não ter liberdade & \\
\hline \multirow{6}{*}{$\begin{array}{l}\text { Abuso físico } \\
\text { [atos que causam dor } \\
\text { e/ou lesões físicas] }\end{array}$} & Prender às cadeiras & Extorquir \\
\hline & Esfaquear & Tiro \\
\hline & Marido dar no pelo da mulher & Atacar \\
\hline & Matar com excesso de comprimidos & Acorrentar à cama \\
\hline & $\begin{array}{l}\text { Bater com instrumentos - paus, caneta, } \\
\text { pistolas, facas, remédios }\end{array}$ & Ir a vias de facto \\
\hline & & Pôr às portas da morte \\
\hline \multirow{7}{*}{$\begin{array}{l}\text { Abuso financeiro } \\
\text { [apropriação indevida } \\
\text { dos recursos, bens e } \\
\text { propriedades da } \\
\text { pessoa idosa] }\end{array}$} & & Roubar em transportes públicos \\
\hline & & Sacar dinheiro da reforma para vícios \\
\hline & Assaltar pelas heranças e partilhas & Filhos não olham a meios para conseguir dinheiro \\
\hline & Controlo do dinheiro do marido & Quando eles não têm dinheiro dão-Ihe com os pés \\
\hline & Ter interesse nas poupanças dos velhos & Maltratos pela família à procura de dinheiro \\
\hline & & Encostam-se à mãe e ao pai pelo fator rendimento \\
\hline & & $\begin{array}{l}\text { Ou dão dinheiro aos filhos ou tratam-nos como um } \\
\text { animal }\end{array}$ \\
\hline
\end{tabular}

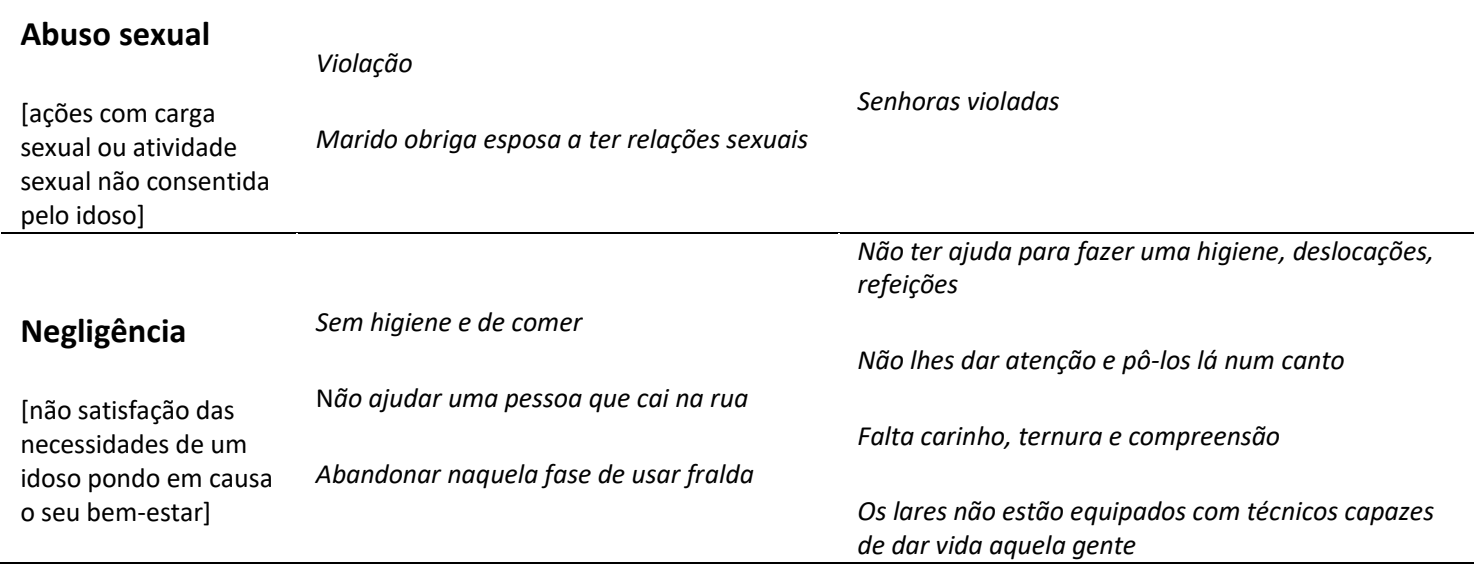

Nota: Consultar: Pillemer et al., 2016; Gil et al., 2012; Dias, 2010; Fonseca et al., 2012. 
No Quadro 78. é repetido exercício metodológico anterior, com a diferença de que agora são apresentados os diferentes tipos de abuso perpetrados e respetivas condutas que estão presentes nos discursos dos entrevistados com e sem experiência de vitimização. Ao nível representacional não se observa diferenças significativas entre eles. Todavia, constata-se um substancial desenvolvimento nas narrativas dos entrevistados sinalizados como vítimas, o que poderá ser explicado pelo facto de, nesta condição, vivenciarem ou já terem vivenciado as condutas que descrevem, mas também porque participaram no estudo qualitativo um maior número de entrevistados sinalizados como vítimas. Mais uma vez, o abuso sexual, não teve qualquer referência pelos entrevistados não sinalizados como vítimas. 
Quadro 78. Diferentes tipos de abuso, segundo a experiência de vitimização/ não vitimização dos entrevistados

\begin{tabular}{|c|c|c|}
\hline \multirow{2}{*}{ Definições } & \multicolumn{2}{|c|}{ Condutas abusivas identificadas pelos entrevistados vítimas e não vítimas } \\
\hline & Vítimas & Não vítimas \\
\hline \multirow{10}{*}{$\begin{array}{l}\text { Abuso psicológico } \\
\text { [ações que conduzem a } \\
\text { um mal-estar psíquico, } \\
\text { emocional e mental] }\end{array}$} & Impor comportamentos & \\
\hline & Enxotado po caixote do lixo & Ser posto de lado \\
\hline & Aleijar as pessoas verbalmente & Pessoas no lar abandonadas à espera \\
\hline & Não ter liberdade & que chegue a hora \\
\hline & Fazer de conta que é um trapo & O meu velho nunca mais morre; \\
\hline & Familiares que os deixam à sua sorte & $\begin{array}{l}\text { Não prestas para nada, já não } \\
\text { consegues fazer nada }\end{array}$ \\
\hline & Não olhar para o idoso na rua & \\
\hline & Tu não prestas, nunca mais morres & \\
\hline & $\begin{array}{l}\text { A senhora sabe onde é que estava bem? Era em casa a } \\
\text { dormir }\end{array}$ & \\
\hline & Estás cá a mais & \\
\hline \multirow{7}{*}{$\begin{array}{l}\text { Abuso físico } \\
\text { [atos que causam dor } \\
\text { e/ou lesões físicas] }\end{array}$} & Tiro; & \\
\hline & Esfaquear & \\
\hline & Prender às cadeiras & Atacar \\
\hline & Marido dar no pelo & Obrigar \\
\hline & Matar com excesso de comprimidos & Acorrentar à cama \\
\hline & $\begin{array}{l}\text { Bater com instrumentos - paus, caneta pistolas, facas; } \\
\text { remédios e droga }\end{array}$ & \\
\hline & Por às portas da morte & \\
\hline \multirow{7}{*}{$\begin{array}{l}\text { Abuso financeiro } \\
\text { [apropriação indevida } \\
\text { dos recursos, bens e } \\
\text { propriedades da pessoa } \\
\text { idosa] }\end{array}$} & Controlo do dinheiro pelo marido & \\
\hline & Roubar em transportes públicos & Ou dão dinheiro aos filhos ou tratam- \\
\hline & Assaltar pelas heranças e partilhas & nos como um animal \\
\hline & Ter interesse nas poupanças dos velhos & $\begin{array}{l}\text { Tomar conta dos pais para usufruir de } \\
\text { qualquer bem }\end{array}$ \\
\hline & Filhos não olham a meios para conseguir dinheiro & Matar mãe por dinheiro da reforma \\
\hline & Quando eles num têm dinheiro dão-Ihe com os pés & para vicios \\
\hline & Encostam-se à mãe e ao pai pelo fator rendimento & \\
\hline $\begin{array}{l}\text { Abuso sexual } \\
\text { [ações com carga sexual } \\
\text { ou atividade sexual não } \\
\text { consentida pelo idoso] }\end{array}$ & $\begin{array}{l}\text { Violar senhoras } \\
\text { Marido obrigar esposa a ter relações sexuais }\end{array}$ & \\
\hline \multirow{4}{*}{$\begin{array}{l}\text { Negligência } \\
\text { [não satisfação das } \\
\text { necessidades de um } \\
\text { idoso pondo em causa o } \\
\text { seu bem-estar] }\end{array}$} & $\begin{array}{l}\text { Não ter ajuda para fazer uma higiene, deslocações, } \\
\text { refeições }\end{array}$ & $\begin{array}{l}\text { Falta de acesso a alimentação e } \\
\text { medicamentos }\end{array}$ \\
\hline & Faltar carinho, ternura e compreensão & \\
\hline & Não ajudar uma pessoa que cai na rua & \\
\hline & Abandonar naquela fase de usar fralda & $\begin{array}{l}\text { técnicos capazes de dar vida aquela } \\
\text { gente }\end{array}$ \\
\hline
\end{tabular}




\section{Formas de violência na idade avançada: agressores e fatores de risco}

O abuso de idosos é um fenómeno complexo e "multidimensional que resulta de um conjunto de fatores de risco relacionados com as características das vítimas, dos agressores e do contexto social" (Gil et al., 2015:175), pelo que a investigação tem vindo a preocupar-se com a identificação dos fatores de risco à exposição ao abuso versus fatores protetores (Dias, Lopes \& Lemos, 2019). Partindo deste enquadramento teórico, nomeadamente articulando perfis de vitimização com fatores potenciadores e protetores da violência, tentamos perceber, de seguida, quais são as formas de violência que estão mais presentes nos universos representacionais dos entrevistados, mas também aquelas que se perpetuam até à idade avançada, tendo sido identificadas quatro formas predominantes.

\subsection{Violência conjugal na idade avançada}

Há muito que a investigação feminista chama a atenção para a violência de género que afeta, de igual modo, as mulheres mais velhas, principalmente aquelas que não se conseguiram libertar do ciclo de violência desde a juventude (Dias, Lopes \& Lemos, 2018). A violência infligida pelo homem sobre a mulher não conhece fronteiras etárias, sendo, segundo os entrevistados, transversal aos casais de todas as idades. Por essa razão, tanto o agressor como a vítima podem ser idosos.

"O mais comum é a violência exercida pelos maridos contra as mulheres. Este tipo de violência eu não consigo entender, fico revoltada. Não compreendo como é que duas pessoas que se casaram, vivem juntas, com certeza gostavam uma da outra, como é que de um momento para outro começam a agredir-se".

(Mulher, 75 anos, Ensino Superior, não sinalizada como vítima).

Esta violência é explicada a partir do contexto social e histórico-cultural, que legitimava a autoridade e dominação masculina e que, progressivamente, foi colidindo com os ideais de democratização das relações sociais e de intimidade, libertando progressivamente a mulher do estatuto desigual e de subalternidade imposto pelo sistema patriarcal (Pedroso \& Branco, 2008: 54; Dias, 2018). Mas se este sistema ajuda os entrevistados a explicar a violência infligida pelos homens sobre as mulheres, a emancipação da mulher e a democratização dos papéis de género na sociedade portuguesa após 1974, também está na origem de episódios violentos, como se observa nos seguintes testemunhos:

"O homem era o Senhor da casa, o homem é que mandava na família, é que batia nas mulheres todas e corria tudo à vassourada. Antigamente era tudo assim. Era o homem que trabalhava, muitas das mulheres não trabalhavam, 
eram domésticas. Portanto, o homem é que dominava a família. As mulheres como eram mais submissas e eram absolutamente dependentes do homem, até economicamente, e tinham que tratar dos filhos, talvez não houvesse tantos problemas como há hoje. Porque hoje a mulher com todo o seu direito e justiça também é independente e tem direito à sua palavra, por isso, surgem as discussões que antigamente não surgiam".

(Homem, 71 anos, Ensino Básico, não sinalizado como vítima).

"As mulheres antigamente eram casadas e casavam-se com a ideia de que tinham de apanhar".

(Mulher, 77 anos, viúva, Ensino Básico, vítima de abuso).

A violência infligida sobre as mulheres assumia múltiplas manifestações, tal como refere a seguinte entrevistada, vítima do marido: "Não me dava um bocado de liberdade para ir com as amigas, pegava por tudo e por nada, agora não me deixa tomar banho dentro de casa, não me deixa usar luz, nem a água. Eu, quer-se dizer, quando ponho a máquina a trabalhar tem que ser às escondidas dele que é para não gastar luz. Ele se me quisesse matar já me tinha matado, já me tinha matado, porque eu via a faca no robe (...) queria abusar-me mas eu não deixei" (Mulher, 71 anos, Ensino Básico, vítima de abuso).

A idade avançada e a longevidade da relação geram a passividade e o conformismo favoráveis à perpetuação dos abusos e da violência: "A gente perdoa, sabe? A idade também já é uma idade avançada. Com 72 anos, vou fazer 73 , também não sou a primeira que vou fazer isto [divórcio]" (Mulher, 71 anos, Ensino Básico, vítima de abuso).

Este testemunho é revelador da reprodução dos argumentos que levam as vítimas a permanecer, em qualquer idade, com os agressores, sustentando o argumento teórico do desânimo aprendido ao longo de anos de violência (Dias, 2010).

\subsection{A violência dos descendentes sobre os pais idosos}

Não obstante a forte presença, nos discursos dos entrevistados, da problemática da violência nas relações verticais (de filhos ou netos), ela nunca foi reconhecida na primeira pessoa. Na origem da sua não denúncia está a profunda vergonha sentida pela pessoa idosa decorrente de tal vivência, associada também a outros sentimentos, designadamente à culpa, ao sentido de falha na educação dos filhos, ao esforço de proteção, mesmo tendo consciência de que se trata de agressores, à minimização ou negação da existência de violência, bem como à ansiedade e preocupação de ficar sem qualquer rede de suporte nos casos em que o agressor também é, supostamente, cuidador, temendo-se que com a denúncia venha a institucionalização do próprio idoso. 
"É que muitas vezes para uma mãe que é violentada que é maltratada pelo filho que está na droga, ou porque está desempregado, etc., continua lá a viver porque de facto aquele filho continua a ser a razão de viver, a amarra que tem à vida. Portanto, isso é muito complicado".

(Homem, 62 anos, Ensino Superior, vítima de abuso).

Mas a dependência é, muitas vezes, bidirecional, consubstanciando-se na partilha de recursos, no apoio financeiro ou, inclusive, no sustento do lar. Nesse sentido, o dinheiro, que provoca os comportamentos abusivos (ou a falta dele), é exigido pelo agressor para o consumo de bens, pagamento de dívidas e a manutenção de consumos aditivos (alcoolismo, toxicodependência, vício do jogo), tendo estes um forte destaque entre os entrevistados:

"Os vícios que eles têm porque os apanharam. (...) E depois pedem dinheiro aos pais, não têm dinheiro e pronto... E o pai leva uma vez um empurrão e estão sempre à espera que ele receba a reforma para sacar o dinheiro, depois o pai não Ihe dá o dinheiro ou a mãe não lhe dá o dinheiro e ele atira-se para cima deles para Ihes bater".

(Homem, 63 anos, Ensino Básico, vítima de abuso).

$\mathrm{O}$ controlo ou exigências dos agressores relativas às poupanças e à reforma dos mais velhos configura, segundo os entrevistados, situações de abuso financeiro: "Sei que muitos dos filhos de alguns vizinhos só vão lá para apanhar dinheiro e alguma coisinha. De resto, os pais não servem para mais nada. Infelizmente, há muitos casos assim" (Homem, 81 anos, Ensino Básico, não sinalizado como vítima).

Ainda assim, este tipo de abuso não é necessariamente um problema que se circunscreve a indivíduos e famílias com boas condições económicas, como denota o seguinte testemunho: "Na classe mais rica é tudo por causa de heranças, dinheiro, terras, ouro, estou a falar em tudo. Nos populares também há violência, é ao murro, com paus e assim (sexo masculino, 77 anos, ensino básico, não sinalizado como vítima). Este testemunho não só reforça a noção de transversalidade da violência, como reflete as subculturas de violência próprias de cada classe e meio social.

Outra explicação apontada para esta dinâmica de abuso incide na própria transmissão intergeracional da violência, considerando os entrevistados que a exposição durante a infância poderá conduzir à aprendizagem e reprodução dos comportamentos abusivos na idade adulta (Dias, 2005):

"De pequenino se torce o pepino. Claro que há pessoas que nascem violentas, mas também é porque viram violência".

(Mulher, 82 anos, Ensino Superior, não sinalizado como vítima). 
"Talvez o histórico da pessoa, qualquer coisa que tenha a ver com o passado e as pessoas queiram cobrar qualquer coisa".

(Homem, 63 anos, Ensino Superior, vítima de abuso).

"É como uma pedra, não sente, mas se calhar também já fez o mal e agora está a recebê-lo. Agora, se for uma pessoa correta, direita e ser maltratado por um filho.... É preferível a morte do que ser maltratado por um filho a quem tanto se deu. Eu num sei bem, a gente ouve dizer "Ui trata mal o velhote", mas às vezes também não são muito bem tratados por eles e depois os filhos vingam-se quando podem".

(Mulher, 71 anos, Ensino Básico, vítima de abuso).

A doença física ou mental surge como outro argumento racionalizador e desculpabilizador do comportamento do agressor, mas também como justificação para as vítimas permanecerem nas relações abusivas:

"Claro que poderá haver casos de esquizofrenia ou coisa assim do género que possa levar essas pessoas a excessos dessa natureza. O agressor tem que ser uma pessoa doente, uma pessoa normal não vai agredir o pai ou a mãe".

(Homem, 70 anos, Ensino Superior, não sinalizado como vítima).

"Não sei bem o que se passa com esta gente, mas eu acho que eles para terem este sangue frio, não podem estar bons da cabeça ou são mesmo maus. Como diz um Senhor meu conhecido: "Isto é tudo influência do diabo, é o diabo que anda a comandar isto tudo".

(Mulher, 71 anos, Ensino Básico, vítima de abuso).

\subsection{A violência perpetrada pelos cuidadores formais e informais}

De acordo com os entrevistados, o risco de exposição ao abuso intensifica-se quando o idoso perde a sua autonomia e se encontra numa situação de dependência de cuidados de terceiros para sobreviver: "É a dependência, porque a dependência tem como contrapartida o quê? Maior exigência da outra parte" (Homem, 66 anos, Ensino Secundário, vítima de abuso).

Os cuidadores informais, como familiares, amigos, colegas de trabalho e vizinhos nem sempre estão devidamente preparados para o cuidado, o qual implica relações de interdependência, laços de obrigação, comprometimento, confiança e lealdade (Dias \& Lopes, 2016). Por outro lado, o grau de dependência do idoso, a necessidade de recursos económicos e a mobilização da família, são fatores que, em conjunto, podem potenciar contextos de conflitualidade e agravarem-se até à agressão:

"Quando os idosos começam a ter algum grau de dependência e começa a ser exigido dinheiro à outra parte, digamos, aos filhos ou aos netos uma 
contribuição, seja em tempo, seja em atenção, seja mesmo monetária, ai é que começa tudo, ai é que começam os problemas".

(Homem, 66 anos, Ensino Secundário, vítima de abuso).

"O somatório de frustrações, de perda de independência ou de vida própria, porque têm que tratar do velho leva à violência".

(Homem, 71 anos, Ensino Básico, não sinalizado como vítima).

Na perspetiva dos entrevistados, as mudanças na estrutura familiar, inclusive no papel da mulher, também estão na origem das práticas abusivas e negligentes face aos idosos:

"Hoje há menos apoio familiar. Antigamente os filhos, os netos tratavam dos pais, hoje se for a tratar é para receber, só se houver algum dinheirito. Portanto, não dão apoio familiar ou porque não podem ou não querem ou porque são muito mais egoístas".

(Mulher, 66 anos, Ensino Superior, vítima de abuso).

Apesar de as mulheres serem historicamente as cuidadoras da família, a conflitualidade pode ser maior quando são as noras a ter que desempenhar esse papel:

"É a tal coisa: "não me és nada, não tenho obrigação de te tratar, não me és nada". A minha cunhada diz que não tem obrigação de tratar a minha mãe, porque ela não lhe é nada, quem tem obrigação de tratar a minha mãe era o filho, o marido dela, o meu irmão, esse é que tem obrigação. Ela não tem obrigação nenhuma e quantas noras têm que ir tratar das velhotas, contrariadas?"

(Mulher, 71 anos, Ensino Básico, vítima de abuso).

A feminização dos cuidados tem sido sustentada por fatores normativos e culturais (Pimentel, 2011:23), que legitimam as disparidades de género e afastam os homens das redes de entreajuda familiar e do cuidar. As mudanças de tais normas de género no espaço doméstico são vistas pelos entrevistados como sendo prejudiciais no plano da prestação de cuidados, podendo favorecer situações de abusos sobre idosos dependentes:

"Antigamente a mulher ficava em casa, era dona de casa, trabalhava mais para os outros, mas convencionou-se dizer que não trabalhava".

(Homem, 70 anos, Ensino Secundário, não sinalizado como vítima).

"Tenho muito respeito por todas as mulheres, de todas as raças, mas a emancipação da mulher tornou a situação pior porque antigamente ela é que ficava em casa, tratava da casa, tratava dos filhos, tratava dos pais e o homem lá trazia o seu provento para as despesas. Hoje a sociedade é tão ávida de venda e os vencimentos, de um modo geral, são baixos para a vida, de modo que a mulher teve que se fazer à vida. $E$, portanto, muitas vezes, as contas até nem são 
bem feitas, é a minha opinião, porque aquilo que se gasta em infantários e em creches e não sei que mais para a mulher poder trabalhar por um ordenado que, normalmente, é relativamente baixo, não compensa. Se eles fizessem as contas é que veriam, bem temos mais 10 euros ou 20 euros ao fim do mês, enfim, uma quantia que não será por aí além... e isso leva ao abandono dos idosos, não é?"

(Homem, 70 anos, Ensino Superior, vítima de abuso).

Paralelamente, observa-se a presença de uma opinião muito crítica acerca do funcionamento das estruturas residenciais para idosos e da ocorrência de abuso institucional. Embora nenhum dos entrevistados esteja institucionalizado, esta ideia é altamente rejeitada, não obstante esse receio ser muito forte sobretudo num cenário futuro de dependência funcional e cognitiva, o que a acontecer será, não por vontade própria, mas por decisão de terceiros:

Eu quando vou a esses lares digo: "Meu Deus, será que é isto que me vai tocar a mim?» Eu preferia morrer logo".

(Homem, 74 anos, Ensino Básico, vítima de abuso).

Curiosamente, no discurso dos idosos o abuso é colocado em três níveis analíticos distintos, designadamente: no plano do Estado e das entidades responsáveis pela gestão das políticas e respostas sociais neste domínio; no plano dos cuidadores formais, muitas vezes acusados de falta de formação e de competências para cuidar, com profissionalismo e empatia, da população idosa e, por fim, no plano das famílias que, egoisticamente acabam por institucionalizar os mais velhos, sem ter em conta a vontade deles, tal como descreve o seguinte entrevistado:

"São maltratadas primeiro pelos filhos porque não os retêm, porque os entregam, porque são poucos os lares da Terceira Idade devidamente equipados e estruturados com técnicos capazes de dar vida aquela gente e de Ihes dar uma qualidade de vida até ao final. Vão para um depósito para morrer. Evidentemente que o Estado tem uma função não só de subsidiar, mas também de fiscalizar. E devia penalizar gravemente todas essas situações de abusos".

(Homem, 79 anos, Ensino Superior, não sinalizado como vítima).

\subsection{A violência perpetrada por desconhecidos}

A violência praticada no espaço público e, por vezes, no espaço privado por desconhecidos encontra-se, de igual modo, no centro das preocupações dos entrevistados. Os assaltos são o cenário clássico, tanto na via pública, como nos transportes ou nas residências particulares dos idosos. Segundo os entrevistados, normalmente, tais assaltos são praticados por indivíduos mais novos, desconhecidos da pessoa idosa: 
"Custa-me aceitar que um tipo relativamente novo, saudável, forte, assalte uma pessoa com 80 anos para a roubar, porque nem é para comer, é para a roubar e exerce violência física sobre uma pessoa que não se pode defender".

(Homem, 70 anos, Ensino Secundário, não sinalizado como vítima).

No discurso dos entrevistados esta forma de violência é associada a indivíduos imigrantes, com problemas financeiros ou dificuldades em manterem uma profissão estável, evidenciando assim uma relação entre a condição socioeconómica e a apropriação indevida dos bens e recursos dos mais velhos, mas também algum xenofobismo:

"Agora há muitos estrangeiros em Portugal, pessoas que vêm de outros países e que não têm de que viver. Depois atacam, roubam e fazem mal às pessoas. Esta crise afetou muito esse género de pessoas, que muitas vezes não trabalham porque não querem. Como recebem uma coisa qualquer mínima do Estado, com o que roubarem já vão vivendo e não querem empregos, porque acham que os empregos pagam tão pouco, que eles fazem melhor vida se adquirirem aquilo que não é deles".

(Mulher, 80 anos, viúva, Ensino Secundário, não sinalizada como vítima).

A violência praticada por estranhos pode envolver agressão física - "é a juventude que quer ferir os velhotes" ${ }^{\prime 4}$, fator que acresce o seu nível de gravidade e a apreensão das vítimas, sendo, de novo, evocados os consumos aditivos do agressor como um fator agravante deste tipo de violência:

"Eles precisam de dinheiro para os cigarros, para o álcool e a para a droga. Portanto, eles têm que fazer violência".

(Homem, 70 anos, Ensino Superior, vítima de abuso).

Por fim, a pessoa idosa torna-se num alvo preferencial destes agressores devido à perceção da sua vulnerabilidade e fragilidade que se acentua com o avançar da idade: "Como os velhos estão velhos, como as crianças são crianças, como as mulheres têm menos força, há abusos!" (Homem, 62 anos, Ensino Superior, vítima de abuso).

Neste ponto, são assim evidenciadas quatro formas de violência que, segundo os entrevistados, são mais frequentemente perpetradas sobre os idosos, nomeadamente a violência conjugal que se perpetua até à idade avançada, mantendo um perfil de violência de género e as dinâmicas que são igualmente encontradas na violência infligida sobre mulheres mais novas; a violência infligida pelos descendentes e que está muito associada a situações de codependência financeira, residencial, mas também a comportamentos aditivos por parte dos agressores; a violência perpetrada pelos

\footnotetext{
${ }^{45}$ Homem, 81 anos, ensino básico, não sinalizado como vítima.
} 
cuidadores formais e informais, surgindo aqui o stress como fator de risco importante, mas também a conflitualidade entre os familiares que têm que prestar cuidados; e por, fim, a violência perpetrada por desconhecidos no espaço público, mas também quando assaltam o próprio domicilio das pessoas idosas. 


\section{Reações das vítimas aos abusos: os perfis}

A capacidade de reação da vítima à violência é sempre mediada por vários fatores, nomeadamente o contexto em que ocorre o episódio violento, a sua duração e severidade, os vínculos afetivos existentes, a trajetória pessoal e de vitimização, a (in)existência de apoios e redes de suporte sociofamiliar, a perceção da resposta das forças de segurança pública e do funcionamento da justiça, entre outros, a partir dos quais são construídos significados, representações e são equacionadas estratégias de superação da situação. Ao mesmo tempo, um ato violento, mesmo com configurações semelhantes, tem sempre significados distintos para as vítimas. Estas refletem sobre os comportamentos violentos, as suas causas, os atores e as dinâmicas sociais, conjugais e familiares envolvidas, acabando por atribuir significados pessoais distintos a experiências situacionalmente localizadas. Assim, as vítimas agem com base no significado que atribuem às situações, estando, por isso, em constante interação com os valores dos contextos sociais em que foram socializadas e a que pertencem (Dias, 2010).

Trata-se aqui de evocar o argumento teórico caro ao interacionismo simbólico de que a violência ocorre em situações particulares, cuja interpretação subjetiva, suscita atitudes e reações diferenciadas nas vítimas. Tal significa que nem sempre a mesma situação objetiva de violência conduz à mesma reação ou resposta entre as vítimas (Holstein \& Miller, 1990). Nesta linha de análise, pretendemos conhecer quais são, na perspetiva dos entrevistados, as reações mais comuns dos idosos vítimas de abusos. Atendendo à singularidade de cada um dos entrevistados, foi-lhes pedido que se imaginassem num cenário de vitimação e que descrevessem a sua possível reação.

Observa-se, como, se ilustra de seguida, uma grande diversidade de perspetivas a propósito das reações à vitimização, destacando-se, desde logo, atitudes reativas, no sentido da vítima confrontar o agressor, como mecanismo de autodefesa:

"É proibido mas os velhos deviam ter uma arma, deviam-se defender."

(Homem, 77 anos, Ensino Básico, não sinalizado como vítima).

"Arranjava um gás lacrimogénio, atirava para os olhos deles [agressores], ou arranjava uma bengala e traz, nas pernas, deitava-o ao chão! Tudo vai das forças de cada um... Isso tudo em defesa".

(Homem, 82 anos, Ensino Superior, não sinalizado como vítima).

A par desta atitude mais defensiva, encontram-se discursos que representam as vítimas como agentes passivos, cuja intimidação constante, foi diminuindo a sua capacidade de reação, a qual é justificada a partir de argumentos desculpabilizadores do comportamento dos agressores, sobretudo entre as entrevistadas sinalizadas como vítimas de abusos: 
"Eu fui aguentando sempre isto, na esperança de que amanhã é melhor, amanhã é melhor".

(Mulher, 79 anos, Ensino Básico, vítima de abuso).

"O meu marido é uma pessoa que verbalmente é um bocadinho violento, fala sempre a ralhar, ele é hiperativo, portanto, eu já o conheço e tento compreender. Não quer dizer que não me afete do ponto de vista emocional, mas o meu marido é assim porque, pronto, a familia, os pais separaram-se e ele ficou sozinho, sentiu-se abandonado."

(Mulher, 69 anos, Ensino Superior, vítima de abuso).

O medo, a vergonha, a culpa, são identificados no discurso dos entrevistados como sentimentos que impedem as vítimas de reagir à violência que Ihes é infligida, incapacitando-as, ao mesmo, tempo, para a procura de ajuda nas redes de apoio, familiares, amicais ou sociais, mas também para a denúncia das situações vivenciadas:

"Tenho medo. Às vezes estou à beira dele e ele está com uma faca na mão e diz: "Qualquer dia ainda te espeto esta faca», e eu "O que é isso» Isso já acabou. Julgas que eu tenho medo de ti, não tenho que tu agora se me empurras vais ao chão". Num Ihe mostro medo, mas sabe Deus".

(Mulher, 75 anos, Ensino Básico vítima de abuso).

"Eu vejo nas aldeias e conheço um caso específico de uma Senhora, cujo marido fez agora 80 anos e que a obriga a ter relações sexuais. A Senhora está doente $e$ ela não quer falar às autoridades, embora os filhos digam: "Vamos falar à Guarda", e ela diz: "Não, de maneira nenhuma, é uma vergonha para mim»".

(Mulher, 69 anos, Ensino Superior, vítima de abuso sexual).

"Faço tudo, preparo-o, que ele à minha beira parece meu patrão, trouxe-o sempre limpo, mas desde nova, tinha muita vaidade nele. As minhas filhas dizem que eu que o habituei muito mal, eu sou culpada deste viver, num tenho volta a dar".

(Mulher, 72 anos, Ensino Básico, vítima de abuso).

Vimos, através das narrativas antes apresentadas que os entrevistados vítimas de abuso projetam nas respostas às reações de vitimização as suas próprias vivências neste domínio. A estas reações os entrevistados acrescentam a esperança na mudança de comportamento dos agressores, o perdão, a desculpabilização, o enfrentamento da situação de violência e no limite a não denúncia, identificando-se um total de 10 perfis, tal como se observa no quadro 79. Nele, sistematiza-se a informação geral relativa às reações à violência que estão presentes nos discursos dos entrevistados, a partir de casos pessoais ou hipotéticos, fazendo-se a separação entre a narrativa dos idosos identificados no estudo como vítimas de abusos, e que acabam por descrever as suas 
próprias reações às situações de violência, e os entrevistados sem experiência de vitimização. 
Quadro 79. (continuação)

Quadro 79. Reações das vítimas: Perfis

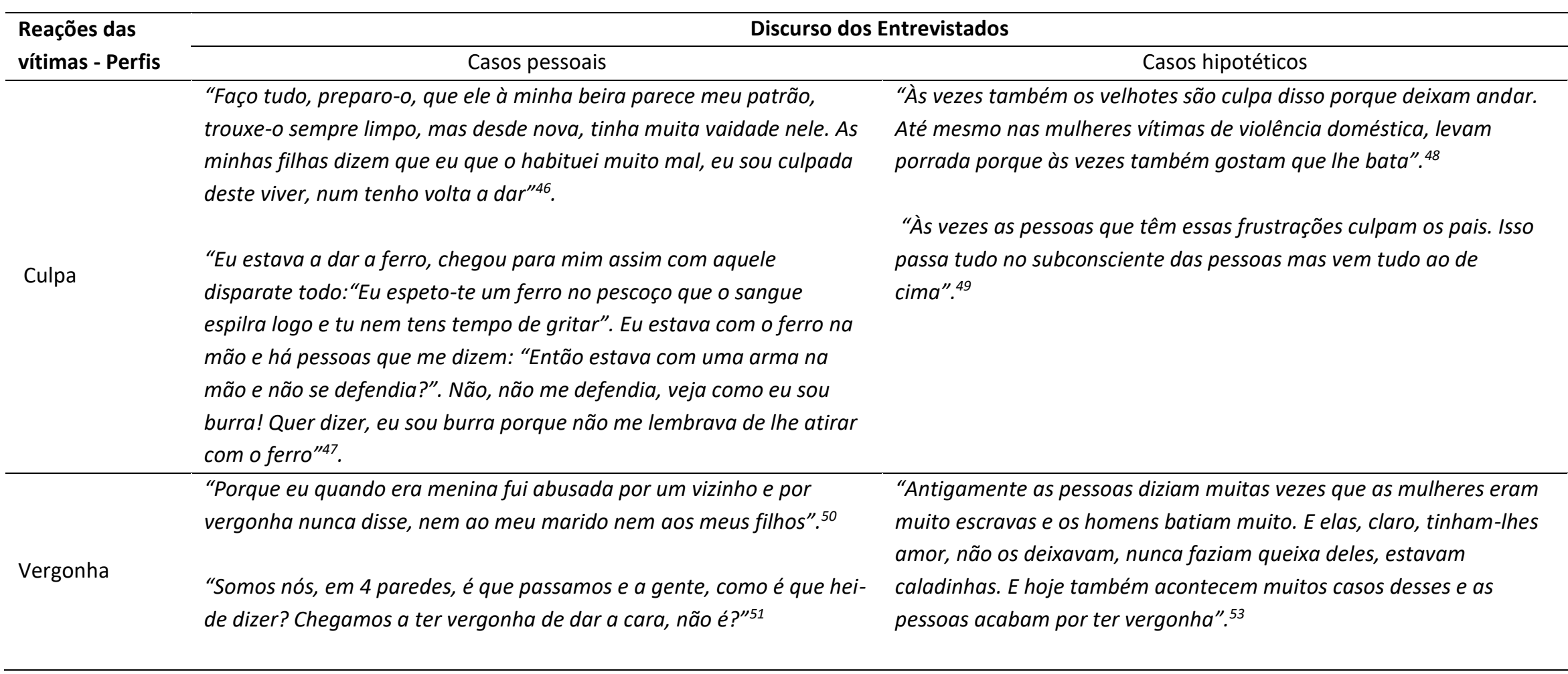

\footnotetext{
${ }^{46}$ Mulher, 72 anos, ensino básico, vítima de abuso.

${ }^{47}$ Mulher, 79 anos, ensino básico, vítima de abuso.

${ }^{48}$ Homem, 63 anos, ensino básico, vítima de abuso.

${ }^{49}$ Homem, 66 anos, ensino secundário, vítima de abuso.

${ }^{50}$ Mulher, 72 anos, ensino básico, vítima de abuso.

${ }^{51}$ Mulher, 71 anos, ensino básico, vítima de abuso.

${ }^{53}$ Homem, 87 anos, ensino básico, vítima de abuso.
} 
Quadro 79. (continuação)

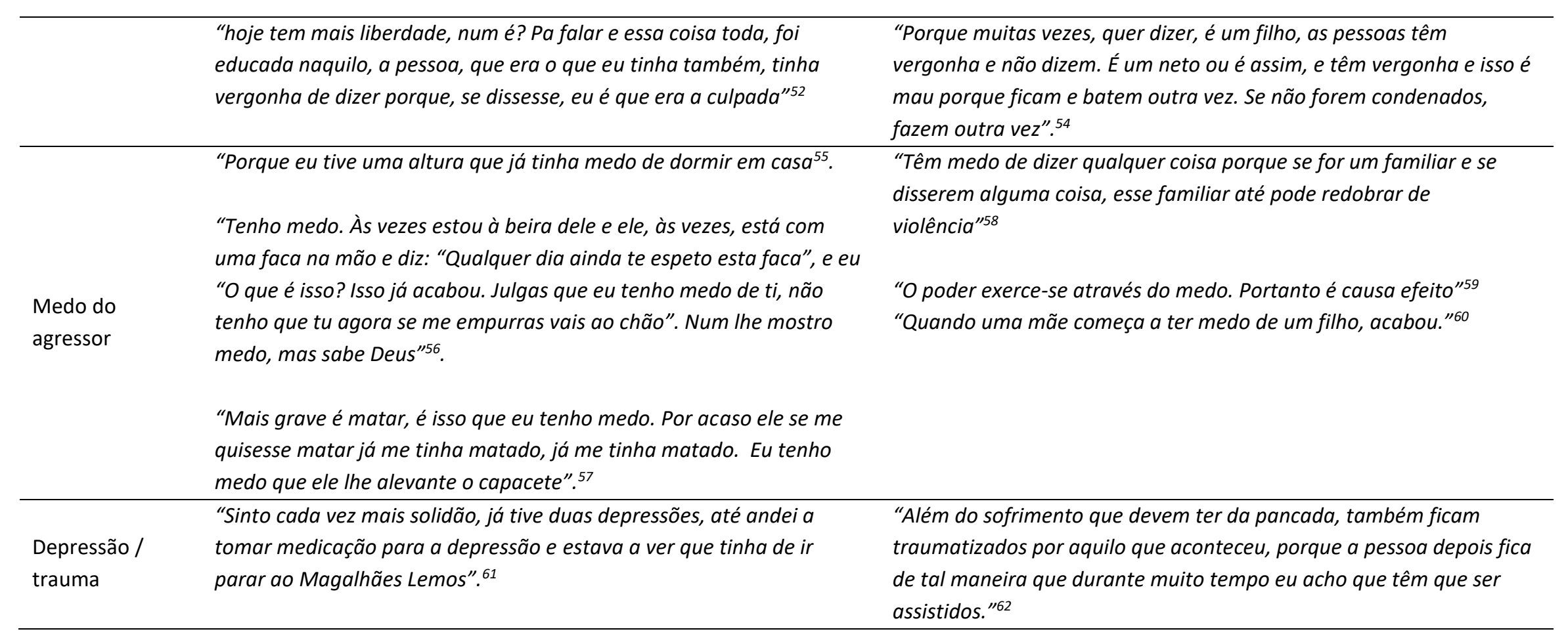

52 Mulher, 79 anos, ensino básico, vítima de abuso.

${ }^{54}$ Homem, 81 amos, ensino básico, não sinalizado como vítima.

${ }^{55}$ Mulher, 79 anos, ensino básico, vítima de abuso.

${ }^{56}$ Mulher, 75 anos, ensino básico, vítima de abuso.

${ }^{57}$ Mulher, 71 anos, ensino básico, vítima de abuso.

58 Mulher, 80 anos, ensino secundário, não sinalizada como vítima.

${ }^{59}$ Homem, 62 anos, ensino superior, vítima de abuso.

${ }^{60}$ Mulher, 77 anos, ensino básico, vítima de abuso.

61 Mulher, 71 anos, ensino básico, vítima de abuso.

62 Mulher, 71 anos, ensino básico, vítima de abuso. 
Quadro 79. (continuação)

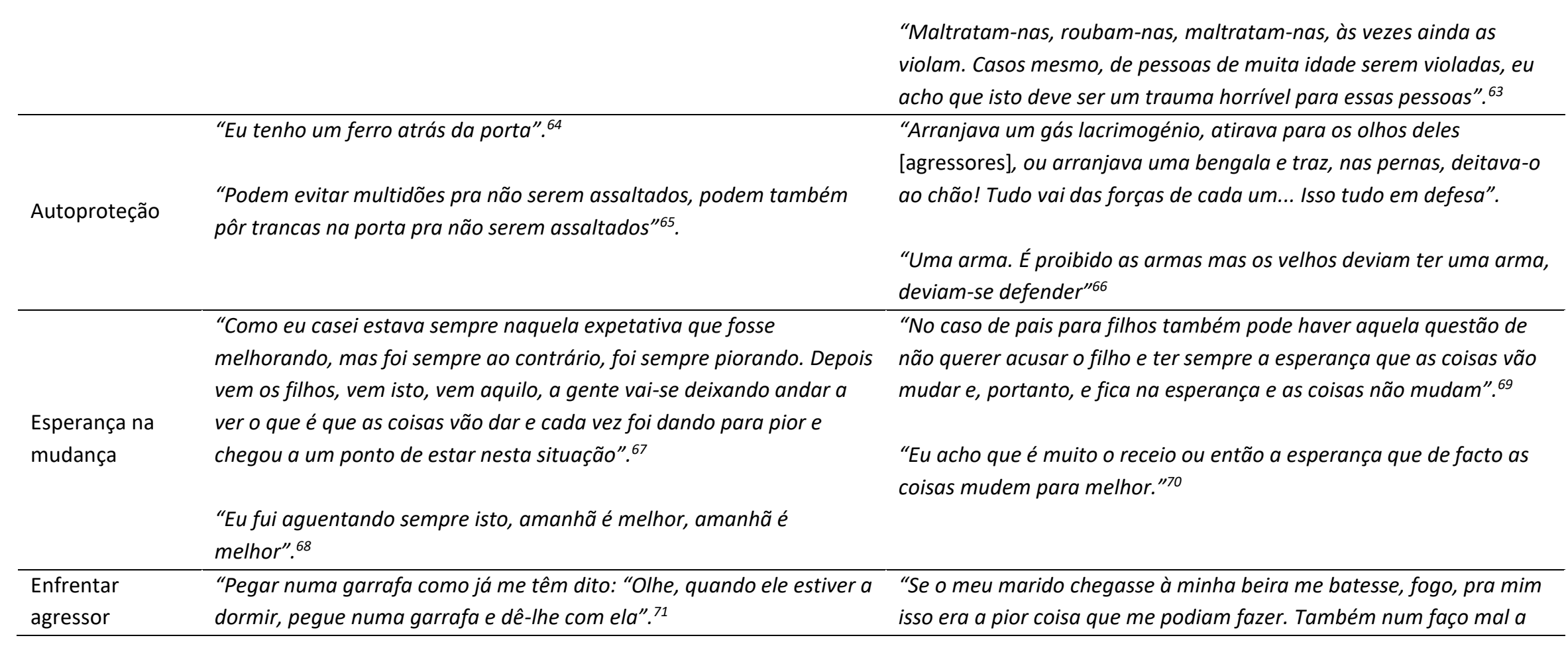

63 Mulher, 63 anos, ensino superior, vítima de abuso.

64 Homem, 77 anos, ensino básico, não sinalizado como vítima.

65 Mulher, 66 anos, ensino superior, vítima de abuso.

${ }^{66}$ Homem, 77 anos, ensino básico, não sinalizado como vítima.

${ }^{67}$ Mulher, 64 anos, ensino básico, vítima de abuso.

68 Mulher, 79 anos, ensino básico, vítima de abuso.

69 Homem, 70 anos, ensino superior, vítima de abuso.

70 Mulher, 71 anos, ensino superior, não sinalizada como vítima.

${ }^{71}$ Mulher, 71 anos, ensino básico, vítima de abuso. 


\section{Quadro 79. (continuação)}

"O que é que me diz? Coisas malcriadas. Já que num Ihe dou, que ele quer ter dinheiro para ir às meninas. Então digo-Ihe que vai um dia que seja preciso, tás aí na cama como um cão, respondo-Ihe assim porque eu também num posso". ${ }^{72}$

"O meu marido é uma pessoa que verbalmente é um bocadinho violento, fala sempre a ralhar, ele é hiperativo, portanto, eu já o conheço e tento compreender. Não quer dizer que não me afete do ponto de vista emocional, mas o meu marido é assim porque, pronto ninguém porque é que é que me vêm bater? Ai, se me batessem a mim? Aí, eu também, também dava, pegava no que fosse ou uma vassoura ou o que eu tivesse na mão". ${ }^{73}$

"Se vai dizer que "Tu num vales nada. És um inútil, uma inútil." Se um dia, um filho me dissesse uma coisa dessas eu num sei se lhe batia, mas ia-Ihe às orelhas e puxava-Ihe as orelhas". ${ }^{74}$

"Imagine que se o meu marido me batesse, eu batia-Ihe a ele também, pronto, defendia-me assim, e se ele me continuasse a bater ia para a polícia, isso não tenho dúvida nenhuma"75.

"A minha ideia era se, por exemplo, fosse com o filho em casa, eu dizia assim "Pronto, tens 24 horas pa arranjar um quarto, sair daqui". ${ }^{76}$

"Quem vier levava logo assim "zás" [exemplifica como se defenderia], um risco na cara". ${ }^{77}$

"Quando um pai ou uma mãe sofre violência por parte dum filho que
é drogado ou qualquer coisa, ou porque tá desempregado e que usa e abusa, é evidente que muitas vezes mais do que tudo é a relação emotiva que se tem com essas pessoas que leva a que eles não

\footnotetext{
72 Mulher, 75 anos, ensino básico, vítima de abuso.

${ }^{73}$ Mulher, 75 anos, ensino básico, vítima de abuso.

${ }^{74}$ Homem, 75 anos, ensino superior, vítima de abuso.

75 Mulher, 69 anos, ensino superior, vítima de abuso.

76 Homem, 62 anos, ensino superior, vítima de abuso.

77 Homem, 77 anos, ensino superior, não sinalizado como vítima.
} 


\section{Quadro 79. (continuação)}

\begin{tabular}{|c|c|c|}
\hline & $\begin{array}{l}\text { a familia, os pais separaram-se e ele ficou sozinho, sentiu-se } \\
\text { abandonado." } 78\end{array}$ & $\begin{array}{l}\text { reajam e que vão mais uma vez desculpar, procurando o melhor para } \\
\text { o filho e muitas vezes se calhar não é, mas é muito difícil a gente, } \\
\text { fazer esses juízos". }{ }^{79}\end{array}$ \\
\hline Perdoar & $\begin{array}{l}\text { "É essa tática que eu tenho usado na minha vida, com aqueles que me } \\
\text { rodeiam e com alguém que já alguma vez me fez algum mal, que tive } \\
\text { realmente assim uns casos desses e eu procurei sempre fazer bem". }\end{array}$ & $\begin{array}{l}\text { "O amor é mais forte do que os tiros e as balas e essas coisas todas, } \\
\text { porque se uma pessoa nos fizer mal e nós passado um tempo, com } \\
\text { uma oportunidade qualquer, Ihes pudermos fazer bem, essa pessoa } \\
\text { fica mais chocada do que se nós Ihe fizermos mal". }{ }^{81}\end{array}$ \\
\hline \multirow{3}{*}{ Não denunciar } & $\begin{array}{l}\text { "Por a minha experiência eu acho que realmente num dá nós } \\
\text { queixarmo-nos, num dá. Num vale a pena, eu por mim falo e por } \\
\text { aquilo que as pessoas se queixam. Uma pessoa vai fazer queixa, não } \\
\text { vale nada". } 82\end{array}$ & $\begin{array}{l}\text { "Se for os próprios elementos da família, é um bocadinho difícil, ela } \\
\text { [idosa] continuará a ser para sempre uma vítima" } 84 \\
\text { "Eles [vítimas] têm que aceitar". }{ }^{85}\end{array}$ \\
\hline & $\begin{array}{l}\text { "Não, não fiz nada, só Ihe disse que tinha uma carta escrita numa } \\
\text { pessoa amiga e que se eu aparecesse morta que era ele". }{ }^{83}\end{array}$ & $\begin{array}{l}\text { "É queixar-se, como é evidente, às autoridades. Mas muitos não } \\
\text { podem ou acham que não o devem fazer porque as consequências } \\
\text { vão ser muito mais graves ainda". }{ }^{86}\end{array}$ \\
\hline & & $\begin{array}{l}\text { "Uma pessoa que é vítima numa casa, acolhida por um filho ou pela } \\
\text { filha, é agredida lá em casa verbalmente, já não digo fisicamente, }\end{array}$ \\
\hline
\end{tabular}

\footnotetext{
${ }^{78}$ Mulher, 69 anos, ensino superior, vítima de abuso.

${ }^{79}$ Homem, 62 anos, ensino superior, vítima de abuso.

80 Mulher, 80 anos, viúva, ensino secundário, não sinalizada como vítima.

${ }^{81}$ Mulher, 80 anos, viúva, ensino secundário, não sinalizada como vítima.

82 Mulher, 78 anos, ensino básico, vítima de abuso.

83 Mulher, 75 anos, ensino básico, vítima de abuso.

${ }^{84}$ Mulher, 68 anos, ensino superior, vítima de abuso.

85 Mulher, 85 anos, ensino básico, não sinalizada como vítima.

${ }^{86}$ Homem, 71 anos, ensino básico, não sinalizado como vítima.
} 
Quadro 79. (continuação)

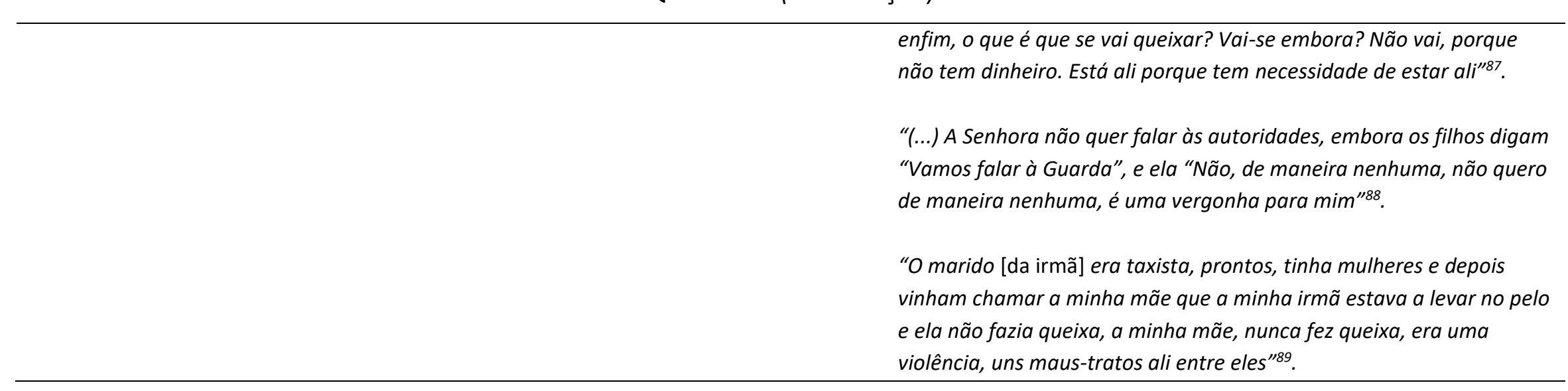

\footnotetext{
${ }^{87}$ Homem, 79 anos, ensino superior, não sinalizado como vítima.

88 Mulher, 69 anos, ensino superior, vítima de abuso sexual.

${ }^{89}$ Mulher, 71 anos, ensino básico, vítima de abuso.
} 
Quadro 79. (continuação)

A análise do Quadro 79. permite evidenciar 10 perfis de reações aos abusos, designadamente: culpa, vergonha, medo, depressão/trauma, autoproteção, esperança na mudança do comportamento do agressor, enfrentar o agressor, desculpabilizar, perdoar e não denunciar às forças de segurança pública. Tal como se ilustrou antes, foram distinguidas as narrativas dos entrevistados com e sem experiência de vitimização, tendo-lhes sido pedido que se pronunciassem sobre este tópico imaginando-se na situação de vítimas. A informação recolhida permitiu-nos constatar que os entrevistados que assumiam a condição de vítimas partiam da sua própria experiência para se pronunciarem sobre as possíveis reações dos idosos vítimas de abuso, enquanto os que não tinham essa experiência socorriam-se de casos hipotéticos ou conhecidos para o efeito. Todavia, é a própria metodologia da entrevista que sai reforçada neste exercício metodológico (Fraga et al., 2011) porque alguns idosos sinalizados como vítimas acabaram por colocar a sua narrativa num plano hipotético, do género, "se isso me acontecesse a mim, eu reagiria assim", quando de facto eles usaram esta "muleta" discursiva para reportarem situações efetivamente vivenciadas, mas não completamente assumidas 


\section{Perceções sobre o impacto da crise socioeconómica}

Está largamente demonstrado que a vulnerabilidade das pessoas idosas é acentuada em períodos de crise socioeconómica por força de um conjunto de circunstâncias que se acumulam na idade avançada, nomeadamente a saída do mercado de trabalho, a perda de rendimentos ou a sua ausência, o declínio das condições de vida, da saúde e da capacidade funcional dos idosos, a perda do cônjuge ou de outros membros da família, a institucionalização (Lopes, 2014:5; Antunes, 2015), a existência de relações conjugais e familiares abusivas, a convivência forçada com os agressores, a dificuldade em pôr termo a relações violentas devido à fase do ciclo de vida em que se encontram, entre outros fatores relevantes (Dias, 2010).

Sendo o impacto da crise socioeconómica no agravamento das situações de abuso um dos objetivos centrais do estudo quantitativo realizado neste estudo, pretendemos, através das entrevistas, aprofundar, de igual modo, a análise das dimensões em que tal se fez mais sentir, assim como o significado que os entrevistados atribuem a essa fase da sua existência pessoal e familiar que afetou, de forma geral, a sociedade portuguesa com maior severidade principalmente entre 2008 e 2011.

\subsection{Família e estilo de vida das pessoas idosas}

As opiniões dos entrevistados sobre o impacto da crise socioeconómica são heterogéneas. Contudo, alguns referem-se há crise vivida entre 2008 e 2011 como um contexto de escassez, mas também de retração do Estado Social, o que teve, segundo os entrevistados, um forte impacto no estilo de vida das pessoas idosas, afetando fortemente as suas famílias e a dos próprios filhos. Referem também que no período de crise muitos idosos viram-se privados dos rendimentos da reforma, mesmo sendo baixos, para pagar as estruturas residenciais em que estavam inseridos e poderem voltar a apoiar financeiramente os familiares, como se ilustra de seguida:

"Há casos em que os filhos não viviam já com os pais, tinham a sua vida independente e perderam as casas. Tiveram que regressar a casa dos pais, com a família aumentada, já com filhos, e esses casos, muitas vezes, criaram problemas enormes aos idosos, aos pais deles."

(Mulher, 74 anos, Ensino Superior, não sinalizada como vítima).

"Houve pessoas, por exemplo, que já tinham os pais até num bom lar e tiveram que os tirar e era o idoso que estava a pagar o seu próprio lar. Trouxeram o idoso para casa, para ter o rendimento do idoso em casa e eles [idosos] ficaram a viver em condições piores do que estavam no lar. Portanto, a crise económica de facto agravou a situação."

(Mulher, 75 anos, Ensino Superior, não sinalizada como vítima). 
"O idoso tem menos apoio social, tem reformas muito baixas, e sabe que o dinheiro relaciona-se sempre com o bem-estar da pessoa, por muito que se queira branquear".

Homem, 70 anos, Ensino Secundário, não sinalizado como vítima).

A crise fez-se sentir também numa maior restrição no consumo de bens alimentares essenciais e de vestuário, o que é mencionado, por exemplo, por mulheres vítimas de abuso, com escolaridade baixa, dificuldades que para algumas ainda se mantêm:

"Não posso comprar carne muito cara, peixe bom só compro uma postinha para a minha mãe".

(Mulher, 71 anos, Ensino Básico, vítima de abuso).

"Por exemplo, se eu quisesse assim mais uma coisa que fizesse bem, fruta, por exemplo, que há aí frutas que fazem muito bem ao organismo, que eles até anunciam na televisão, eu não as compro, com medo daquele dinheiro me faltar".

(Mulher, 78 anos, Ensino Básico, vítima de abuso).

"Podia-me vestir normalmente com roupinha boa, agora não, tenho que me cingir àquilo que já tinha e alguma que compro, compro em segunda mão".

(Mulher, 71 anos, Ensino Básico, vítima de abuso).

As restrições fizeram-se sentir, de igual modo, ao nível dos consumos culturais e de lazer, o que foi apontado por entrevistados com mais escolaridade.

"A minha mulher gostava muito de ir o cinema e ao teatro. Ela era muito virada para as artes e eu acompanhava-a. E deixámos de ir. E quando uma pessoa tem que fugir de se cultivar, estamos num país inculto."

(Homem, 75 anos, Ensino Secundário, vítima de abuso).

"Eu sinto-me privada, por exemplo, de férias, já não faço há uns poucos de anos".

(Mulher, 80 anos, Ensino Secundário, não sinalizada como vítima).

"Senti-me privado de algumas coisas que estava habituado a ter, eu não direi que possa considerá-las supérfluas, na medida em que a vida faz-se de muita coisa, não é só comer e vestir, mas digamos que fazia uma determinada vida social que hoje não faço, por exemplo, já como menos em restaurantes fora, para não dizer quase que não como, também sou capaz de ir menos vezes ao cinema ou ao teatro".

(Homem, 70 anos, Ensino Secundário, não sinalizado como vítima).

Alguns dos entrevistados referem que, para enfrentarem a crise, tiveram que voltar a trabalhar em part-time, gerando assim um rendimento suplementar, mas também 
reconhecem que tiveram que recorrer a familiares ou inversamente apoiar familiares em dificuldade:

"Já estava aposentado, mas tinha aquele part-time em Contabilidade".

(Homem, 75 anos, viúvo, Ensino Secundário, vítima de abuso).

"Quando há assim alguma coisa mais pesada, com alguma dificuldade recorrese a um familiar ou outro".

(Homem, 69 anos, Ensino Básico, vítima de abuso).

"Eu ajudo e depois, sabe, ninguém me ajuda a mim".

(Mulher, 67 anos, Ensino Básico, vítima de abuso).

\subsection{Saúde, bem-estar e papel do Estado}

No discurso dos entrevistados, é evidenciada a associação entre envelhecimento e declínio da condição de saúde dos mais velhos, mas sobretudo o seu agravamento em virtude da crise socioeconómica, sobretudo quando esta coincide com a entrada na reforma:

"A idade é bonita, desde o momento em que haja saúde".

(Homem, 74 anos, Ensino Básico, vítima de abuso).

"Piorou [a saúde] porque enquanto eu ganhava $6 €$ à hora, andava consolada da vida, ganhava o suficiente e não tinha essas doenças que tenho agora e que estou a tomar esta medicação, não tinha nada. Vim para casa, acabei com isso tudo".

(Mulher, 75 anos, Ensino Básico, vítima de abuso).

Evidencia-se, assim, a consciência de um gradiente social em saúde que condiciona o acesso aos cuidados médico-sociais, principalmente entre os grupos socioeconómicos menos favorecidos:

"Não têm posses [idosos], não podem ir a um médico e vão indo até ver se vão para a cova".

(Homem, 63 anos, Ensino Básico, vítima de abuso).

"Outra coisa que também me preocupa muito nos idosos é a saúde. Muitos deles não têm assistência, os poucos que têm assistência não têm dinheiro para depois comprar os comprimidos, os medicamentos e para manter o padrão mínimo. Eu acho que são as duas coisas mais degradantes".

(Homem, 66 anos, Ensino Secundário, vítima de abuso).

A crise económica afetou ainda, o bem-estar geral e a saúde mental de alguns entrevistados, o que os levou à procura de ajuda entre os profissionais de saúde: 
"Eu acho que influenciou bastante porque do ponto de vista emocional mexeu bastante comigo. Eu sou uma pessoa muito sensivel e há certas injustiças que me fazem mal, nomeadamente a nível político e isso criou em mim mais tensão".

(Mulher 69 anos, Ensino Superior, vítima de abuso).

"Por exemplo, tive que recorrer a um psiquiatra porque me senti deprimido, pela primeira vez na minha vida. Tive duas crises de depressão, pronto foi medicado. Portanto, nesse sentido, [a crise] teve uma repercussão significativa".

(Homem, 63 anos, Ensino Superior, vítima de abuso).

O bem-estar geral ficou, ainda, comprometido porque alguns dos participantes viramse condicionados a continuar a praticar atividades promotoras de um estilo de vida saudável:

"Eu fazia natação, fazia ginástica, retirei, não posso pagar, saí da ginástica. Essas coisas fazem-me falta. Além de ser um alívio psicológico, fazia muito bem ao meu organismo que eu estou a sentir que estou a ficar um bocado presa em me movimentar".

(Mulher, 71 anos, Ensino Básico, vítima de abuso).

Por último, os entrevistados criticam o papel do Estado sobretudo na falta de respostas sociais e de serviços de cuidados médico-sociais dirigidos à população mais velha, os quais, na opinião deles, devem ser potenciados:

"Sabe que eu tenho muito medo até no campo da saúde, principalmente. Porque no campo da saúde eu tenho notado, através dos noticiários, do que se lê, que devido, não sei se é à crise, se é ao desinteresse, isso é que me assusta um bocadinho que nós somos descartáveis a partir de uma certa idade. Isso é preocupante, não é? Porque a partir de uma certa idade começam a pensar assim: "Este só dá despesa. Este já está aqui a mais", o próprio Estado está a consumir, verbas que poderiam ser utilizadas noutros campos, no entanto, está a tratar desta velhice toda. Porque o nosso país está a envelhecer a passos largos, isto está um descalabro total, o nosso país."

(Homem, 71 anos, Ensino Básico, não sinalizado como vítima).

\subsection{Crise socioeconómica e violência contra as pessoas idosas: "família onde não há pão todos ralham e ninguém tem razão"}

Analisado no ponto precedente o impacto da crise socioeconómica nas condições de vida, na saúde e no bem-estar geral dos entrevistados, partiu-se para a compreensão da sua influência no campo dos abusos sobre as pessoas idosas. Neste âmbito, evidenciase três grandes tipos de argumentação entre os entrevistados, designadamente os abusos são potenciados com a pobreza e as desigualdades sociais; são um fenómeno 
transversal a todas as classes sociais; são agravados pela associação do declínio das condições económicas e consumos aditivos, como se ilustra de seguida.

\subsubsection{A pobreza e as desigualdades sociais}

"A crise agravou a violência, as coisas ficaram mais caras, o dinheiro não chega para tudo, há que ir aos velhinhos buscar-Ihes as economias. Se os velhinhos não querem dar, eles pimba [agressão] para lhes sacar [as economias]".

(Mulher, 68 anos, Ensino Superior, vítima de abuso).

"Faltando dinheiro tudo se deteriora, as pessoas perdem a cabeça, tudo serve para uma pessoa se zangar e lá está e a despesa que o idoso traz. Porque a reforma do idoso ou não há ou se a tem é pequeníssima que não dá para sustentá-lo a ele próprio, muito menos para os remédios que ele precisa de toma. Portanto, é sempre um problema a questão económica".

(Homem, 71 anos, Ensino Básico, não sinalizado como vítima).

"O mais pobre é o que morre abandonado".

(Homem, 72 anos, Ensino Básico, vítima de abuso).

"Olhe família onde não há pão todos ralham e ninguém tem razão. É verdade, é verdade, essas famílias são muito mais sujeitas".

(Homem, 62 anos, Ensino Superior, vítima de abuso).

\subsubsection{A transversalidade da violência: tipos e (in)visibilidades}

"Como há maior pobreza nos meios populares é natural que essas situações apareçam mais. No meio rico também há, mas há mais possibilidades de ser escamoteado (...). Mas também há essa violência, também há essas situações".

(Homem, 62 anos, Ensino Superior, vítima de abuso).

"Nos ricos, lá está, não quer dizer que seja de violência, de porrada, mas violência psicológica que às vezes dói bem mais na alma".

(Homem, 70 anos, Ensino Superior, vítima de abuso).

"A classe rica mata, dá logo cabo dos familiares e a classe mais baixa agride mais. Na classe mais rica é tudo por causa de heranças, seja ela em dinheiro, em terras, em ouros, estou a falar em tudo. Nos populares é violência, é murro, é com um pau e assim".

(Homem, 77 anos, Ensino Básico, não sinalizado como vítima). 
"[Nos pobres] É uma violência, digamos, mais visível e mais selvagem, entre aspas, digamos selvagem no sentido em que se vê, há agressões. [Nos ricos] as coisas são menos visíveis, mais camufladas, digamos, em determinado tipo de classes ricas".

(Homem, 70 anos, Ensino Superior, vítima de abuso).

\subsubsection{Comportamentos aditivos: o alcoolismo}

O declínio das condições económicas associado a consumos aditivos aumenta igualmente a exposição dos idosos ao risco de abusos. Trata-se aqui do efeito, designado pelos entrevistados, de "pescadinha de rabo na boca"90, como ilustra o seguinte testemunho:

"Embora provavelmente seja mais frequente nos estratos sociais mais baixos, porque nos estratos sociais mais baixos, as pessoas com dificuldades também acrescentam problemas a outros problemas. Por exemplo, têm grandes dificuldades económicas, mas depois para esquecer entram no álcool, há muitos alcoólicos, muitas vezes nos estratos sociais mais desfavorecidos".

(Mulher, 75 anos, ensino superior, não sinalizada como vítima).

\subsection{Representações sobre a (in)segurança dos idosos vítimas de violência}

Para além das vulnerabilidades antes identificadas, os entrevistados evidenciam um conjunto de argumentos que dão conta do contexto de insegurança em que as pessoas idosas vivem, mas também dos fatores que agravam esse sentimento. Assim, começam por referir que os idosos não conseguem reagir à situação de violência em virtude da sua fragilidade física, do medo e do isolamento em que se encontram, o que agrava o referido sentimento, como se ilustra de seguida:

"Por medo, por incapacidade, porque são sempre pessoas mais frágeis não só fisicamente, mas até psicologicamente".

(Homem, 62 anos, Ensino Superior, vítima de abuso).

"O mundo do idoso é muito circunscrito e a capacidade de defesa dele é mínima".

(Homem, 79 anos, Ensino Superior, não sinalizado como vítima).

Segundo os entrevistados, os idosos vítimas também interiorizam a condição de vitimização permanente e a noção de que nunca sairão do ciclo de violência, quer pela proximidade relacional e afetiva que têm com os agressores, quer de novo pelas condições económicas em associação com os comportamentos aditivos dos filhos.

\footnotetext{
${ }^{90}$ Mulher, 69 anos, ensino superior, vítima de abuso
} 
"Estão num beco sem saída porque [os idosos] se são agredidos, vão continuar a ser".

(Mulher, 77 anos, Ensino Básico, vítima de abuso).

"É uma vítima. Vai ser sempre uma vítima. Aliás, o próprio termo vítima é isso mesmo, não é? O que é uma vítima? Ninguém está no papel de vítima porque quer, não é? Uma pessoa é abusada não é por má formação ou porque seja masoquista, não é? A pessoa, 90 e tal por cento ou mais, é porque não tem defesa".

(Homem, 66 anos, Ensino Secundário, vítima de abuso).

"Muitas vezes para uma mãe que é maltratada de uma forma violenta pelo filho porque está na droga ou porque está desempregado, etc.".

(Homem, 62 anos, Ensino Superior, vítima de abuso).

O sentimento de insegurança dos idosos é agravado, na perspetiva dos entrevistados, devido à falta de consciência que eles têm das circunstâncias que os vitimizam e à ausência de informação da legislação que garante a sua proteção e direitos fundamentais:

"Resta saber se a pessoa idosa quando é agredida sabe ou tem a perceção que está a ser agredida".

(Homem, 79 anos, Ensino Superior, não sinalizado como vítima).

"Falta da parte cívica! Quer dizer, os idosos não conhecem os direitos ou não querem exercer os direitos, que algumas pessoas sabem que têm direitos".

(Homem, 66 anos, Ensino Secundário, vítima de abuso).

Nos discursos dos entrevistados volta a ser reforçada a representação de que a acumulação de vulnerabilidades potencia o risco de abusos entre a população idosa, conclusão já evidenciada no estudo quantitativo. 


\section{Papel do Estado, das forças de segurança pública e das redes familiares e comunitárias}

\subsection{Papel do Estado e abuso de idosos}

De acordo com alguns entrevistados a proteção da população é, primordialmente, uma competência do Estado, sobretudo no caso das categorias sociais mais vulneráveis e expostas a situações de pobreza, exclusão social e violência. É no Estado que estas populações devem encontrar resposta para os problemas que os afetam, mais ainda em situações de violência, como refere a seguinte entrevistada:

"Procurar uma ajuda, mas deve ser uma ajuda estatal, não pode ser uma ajuda de um vizinho. Imagine que a minha vizinha é agredida por um filho, eu pego nela, trago-a para a minha casa naquela altura, mas eu estou a cometer um erro. Estou a cometer um erro e uma falha, até posso ser chamada à atenção por fazer uma coisa dessas, vou retirar ao filho uma mãe que não tenho o direito, de maneira que tem de ser o Estado a resolver esse problema".

(Mulher, 77 anos, Ensino Básico, vítima de abuso).

No entanto, em alguns entrevistados encontram-se representações contraditórias acerca do papel do Estado, designadamente uns manifestam uma opinião favorável aos apoios concedidos e às medidas implementadas atualmente, enquanto outros referemse a tais medidas como sendo insatisfatórias, mostrando-se assim mais críticos face à sua atuação:

"A nível financeiro acho que hoje é melhor do que era no tempo dos meus pais. Eu sei que os meus pais para comer tinham que esgravatar, tinham que trabalhar na terra, para ganharem algum, para puderem sobreviver. Hoje, mesmo que não se trabalhe, tem-se o mínimo dos mínimos, diz-me assim: "Não é o suficiente!". É verdade, mas é que antigamente não havia absolutamente apoio nenhum do Estado e hoje há pouco, mas há".

(Mulher, 64 anos, Ensino Básico, vítima de abuso).

"Acho que há muitas mais atividades e preocupação até com a saúde dos idosos porque no Centro de Saúde aconselha-se muito mais, para caminhar, na alimentação e tudo isso ajuda a parte dos idosos, não é? Há passeios para idosos, há as Juntas de Freguesia, acho que estão a desenvolver vários projetos, por exemplo, de irem fazer ginástica, têm de música, piscinas gratuitamente. Têm todas essas atividades que ajudam não só na saúde física, mas mental e obriga-os a sair de casa, a conviver, a criar amigos, portanto, eu acho importante".

(Mulher, 74 anos, Ensino Superior, não sinalizada como vítima). 
"Medidas, medidas, vejo as reformas dos idosos que são muito fracas, mas dão mais dinheiro, dão esses rendimentos mínimos e essas coisas todas a pessoas que num fazem nada, mais do que à reforma dos idosos. Às vezes uma reformazita é uma miséria. O Estado com os velhotes não é que tenha grande prejuízo".

(Homem, 69 anos, Ensino Básico, vítima de abuso).

"Eu não acredito muito nas instituições do Estado, nomeadamente nas polícias e mesmo nos tribunais, aliás vê-se isso, não é preciso ser nenhum catedrático. Mas a falta desses organismos também não resolve nada, pelo contrário. Portanto, nós temos que recorrer a eles porque eles existem, estão lá para nos prestar o serviço e nós devemos exigir que eles funcionem".

(Homem, 66 anos, Ensino Secundário, vítima de abuso).

Assim, os entrevistados ressaltam a importância do seguinte conjunto de medidas de apoio e proteção da população mais velha: incremento dos apoios sociais a idosos com idade avançada e que se encontrem socialmente isolados: "Quando vivem sozinhos nas aldeias isoladas, são agredidos, assaltados, a gente vê nas notícias. Porquê? Por falta de apoio social91"; criação de estruturas residenciais de idosos e centros de dia com profissionais qualificados: "É preciso canalizar os recursos corretamente, mas idealmente para criar instituições para idosos com profissionais preparados para acolhêlos"92; implementação de políticas ativas com vista à satisfação de necessidades essenciais: "O Estado tem que dar aos idosos o essencial que é casa, abrigo, alimentação, saúde, portanto, cuidados de saúde ${ }^{93}$; medidas de promoção do envelhecimento ativo/produtivo: "Uma medida que poderia trazer qualidade de vida aos idosos era apoiar o emprego das pessoas seniores. Porque são pessoas que tem muita experiência e poderiam ser úteis do ponto de vista social e económico"94; eliminação das barreiras arquitetónicas e promoção de espaços seguros: "Há muitos idosos que ainda conseguem ir ao quarteirão, agora se for mais uns quilómetros, não vão. Devia não haver barreiras arquitetónicas porque alguns idosos também já veem mal"95; formação profissional dos técnicos da área da ação social: "É preciso pessoas especializadas tecnicamente para dar apoio aos idosos porque não é só dar de comer, é preciso saber tratar deles"96; programas de formação para agressores: "Chamar o indivíduo, o agressor, a frequentar

\footnotetext{
${ }^{91}$ Homem, 72 anos, ensino básico, vítima de abuso.

92 Homem, 62 anos, ensino superior, vítima de abuso.

${ }_{93}$ Mulher, 66 anos, ensino superior, vítima de abuso.

${ }_{94}$ Homem, 63 anos, ensino superior, vítima de abuso.

${ }_{95}$ Mulher, 75 anos, ensino superior, não sinalizada como vítima.

${ }^{96}$ Homem, 72 anos, ensino básico, vítima de abuso.
} 
cursos de psicologia e tratamento. Isso é fundamental. Num adianta prendê-lo, têm é que Ihes dar formação para eles não voltarem a repetir a violência"g7.

\subsection{As forças de segurança pública e os profissionais de saúde}

A par do Estado, o papel das autoridades policiais é reiteradamente enfatizado no discurso dos entrevistados. Apesar de reconhecerem a escassez de recursos e de meios, alguns consideram que são fundamentais para a proteção e acompanhamento dos idosos:

"Além de proporcionarem segurança, digamos assim, proporcionam conforto em termos psicológicos às pessoas de idade".

(Homem, 70 anos, Ensino Superior, vítima de abuso).

"Coitados, eles nem têm [meios de proteção] para eles próprios, como é que eles vão proteger os outros?"

(Mulher, 63 anos, Ensino Superior, vítima de abuso).

Porém, também está muito presente no discurso dos entrevistados uma atitude crítica da atuação das forças policiais, as quais reproduzem, muitas vezes, velhos estereótipos sobre as vítimas e crenças tradicionalistas sobre a violência doméstica, como se ilustra seguidamente:

"O meu marido chegou-me a bater, mas a gente nem ia à polícia, para quê? Acha que há 50, há quase 60 anos que valia a pena a gente ir à polícia? Os polícias ainda se riam da gente".

(Mulher 75 anos, Ensino Básico, vítima de abuso).

"Eu pedi auxílio à APAV, por ele [marido] se virar para mim com a faca e bateume. Fui para a polícia e não deu em nada. A polícia ainda me trata mal, num é tratar mal, mas é fica-se naquela coisa assim: "Ah, a Senhora tem para onde ir vá, deixe aquela zona". É muito mal, que eles atendem, mais as pessoas de idade do que as pessoas novas".

(Mulher, 78 anos, Ensino Básico, vítima de abuso).

"Quando uma vítima qualquer se apresenta perante as autoridades policiais tem que se acabar com aqueles conceitos de que "entre marido e mulher não metas a colher", isto é, "coisas lá de casa ninguém tem nada a ver com isso." Não! Isto é um crime público, é um crime contra a nossa a civilização, o nosso tipo de sociedade e, portanto, eles [idosos] têm de ser ouvidos e tem que se tomar atitudes para os proteger".

(Homem, 62 anos, Ensino Superior, vítima de abuso).

\footnotetext{
${ }^{97}$ Homem, 71 anos, ensino superior, vítima de abuso.
} 
Neste quadro, os participantes sugerem a criação de uma polícia especializada, assim como "dar às pessoas de idade prioridade em tudo"98, principalmente no atendimento em caso de violência. Esta representação é reforçada pelo seguinte testemunho:

"Devia haver ali uma polícia muito destinada à proteção dos idosos, porque muitas vezes, por exemplo, uma mulher vai lá queixar-se de violência doméstica $e$ eles nem sequer atendem, ou se atendem registam e mandam a mulher embora".

(Mulher, 80 anos, Ensino Secundário, não sinalizada como vítima).

Por último, os profissionais de saúde são representados como um grupo fundamental para os idosos, quer pelos cuidados de saúde que lhes prestam, quer pelo aconselhamento e apoio que lhes dão em vários domínios da vida pessoal.

"Então, se um idoso foi agredido e precisa de tratamento, pronto, o médico tem que dar o tratamento necessário e a ajuda necessária. Ele não é só para prescrever medicamentos, o médico, também é para dar umas palavrinhas."

(Mulher, 66 anos, Ensino Superior, vítima de abuso).

Todavia, alguns entrevistados consideram que o papel destes profissionais nem sempre é adequadamente representado, protagonizando muitos deles atendimentos superficiais e rápidos aos utentes, fazendo com que os idosos se sintam desvalorizados nos seus problemas:

"Eu lembro-me que as pessoas iam ao médico, às vezes, só para conversar um bocadinho com o médico. Agora não, isso é impossível. O médico está stressado, está não sei quê e tal e aquilo tem que ser rápido porque está mais gente à espera e isso tem que mudar também".

(Homem, 70 anos, Ensino Superior, vítima de abuso).

"Fui à polícia, fez sábado oito dias, fazer queixa dele [marido], porque ele mandou-me dois pontapés que me pôs aqui três hematomas e a polícia disse: "Porque é que você não foi ao hospital?" Ao hospital já me fui queixar porque ele me bateu, não ligaram nenhum".

(Mulher, 71 anos, Ensino Básico, vítima de abuso).

Para alguns entrevistados, a ausência de qualidade no atendimento por parte destes profissionais deve-se à falta de condições de trabalho em que eles exercem a sua atividade:

\footnotetext{
98 Mulher, 85 anos, ensino básico, não sinalizada como vítima.
} 
"Não tenho hospital, neste momento não tem condições, nem humanas, nem físicas. $O$ pessoal está a trabalhar numas condições horríveis. Eu não deito a culpa toda ao pessoal."

(Mulher, 77 anos, viúva, Ensino Básico, vítima de abuso).

Os entrevistados consideram que a partir do momento em que os profissionais de saúde tomam conhecimento de situações de violência entre os idosos devem desencadear a intervenção, denunciar e comunicar às autoridades:

"Esses Senhores [profissionais da saúde] também estão numa das linhas da frente. Então, quando chega lá um idoso que tem sinais de agressão eles próprios devem imediatamente desencadear processos junto da autoridade".

(Homem, 66 anos, Ensino Secundário, vítima de abuso).

"Neste momento, claro que é a autoridade mas eu acho que isso tem que começar antes de chegar a esse ponto, devia haver uma parte médica, em que há um psicólogo, em que há um psiquiatra, um neurologista, qualquer coisa, que pega no assunto, até chama lá a pessoa que agride e diz: "Ó pá, estamos aqui perante uma situação que está em causa a saúde e o bem-estar de uma pessoa. Portanto, a partir deste momento é assim, ou efetivamente o Senhor muda a sua atitude ou vamos entregar isto às autoridades competentes" e aí já não é o velhinho a fazer queixa à polícia".

(Homem, 71 anos, Ensino Superior, vítima de abuso).

A intervenção destes profissionais contribui muito para o sentimento de segurança entre as vítimas, conseguindo em alguns casos a cessação dos comportamentos violentos, tal como comprova o seguinte testemunho:

"Já para aí há 20 anos que ele [marido] apanhou a Hepatite $B$, nunca mais me bateu porque eu disse à médica: "A Senhora Doutora proibiu-me de ter relações com ele, só se fosse com proteção, e ele não queria com proteção porque ele apegou-me a mim e a Senhora Doutora disse: "Se ele Ihe bater venha ter comigo que eu faço-Ihe uma cartinha para a Senhora entregar na polícia". Meteu-Ihe medo e ele nunca mais me bateu".

(Mulher, 75 anos, Ensino Básico, vítima de abuso).

Por último, há quem considere que a falta de intervenção na saúde pode intensificar as situações de violência, tal como refere a seguinte entrevistada: " $A$ falta de investimento na saúde, nos últimos anos, também pode ser uma causa de, em última análise, se chegar à violência quer sobre idosos, quer sobre não idosos" (Mulher, 75 anos, Ensino Superior, não sinalizada como vítima) . 
Em suma, está muito presente no discurso dos entrevistados quer o papel relevante que as forças de segurança públicas e os profissionais de saúde desempenham no apoio, proteção e intervenção junto dos mais velhos, mas também uma certa crítica à não valorização efetiva das situações de violência por eles vivenciadas.

\subsection{As Associações de proteção às vítimas e o (des)conhecimento da legislação}

Também se encontra no discurso dos entrevistados referências a Associações voltadas para a proteção das vítimas, com destaque para a Associação Portuguesa de Apoio à Vítima (APAV). Porém, alguns entrevistados enfatizam o seu relativo desconhecimento entre a população mais velha, mas também revelam algum ceticismo face à intervenção deste tipo de associações:

"Seja violência física, maus-tratos, isto ou aquilo, suponhamos que eu tinha um problema qualquer, não sabia onde me dirigir, dirigia-me à APAV e a APAV com certeza que comunica com outras instituições".

(Mulher, 80 anos, Ensino Secundário, não sinalizada como vítima).

"Há organizações contra a violência, mas a maioria dos idosos nem tem conhecimento disso"

(Mulher, 68 anos, Ensino Superior, vítima de abuso).

"É o apoio à vítima, o apoio a isto, o apoio aquilo, agora não falta apoios. Tanto apoio! Mas na verdade não há apoios nenhuns, mas prontos!"

(Mulher, 68 anos, Ensino Superior, vítima de abuso).

"Eu devia de ir para aquelas instituições [casa abrigo] mas recusei-me a deixar a minha casa."

(Mulher, 71 anos, Ensino Básico, vítima de abuso).

No plano da legislação existente, o discurso dos entrevistados é revelador de um relativo desconhecimento:

"Proteção contra a violência, em princípio tem de haver uma lei, há uma lei contra a violência. Tudo que for violência tem que ser crime, não é? Violência sobre seja quem for, é crime. Se há uma lei específica para idosos? Não sei, se há uma lei específica para os idosos."

(Mulher, 75 anos, Ensino Superior, não sinalizado como vítima).

Vimos, assim, que os discursos focam-se na necessidade de medidas dirigidas aos idosos que facultem informações sobre as respostas sociais existentes e de proteção das 
vítimas, mas também no plano da legislação e da justiça que, segundo alguns entrevistados, "protege muito o criminoso"99:

"Uma das medidas é a nível da justiça, essencialmente. Eu acho que devia ser penalizado, mas absolutamente penalizado com muita gravidade, toda a violência contra os idosos. É uma coisa que não se pode tolerar, porque começa com uma cobardia, quer dizer uma pessoa que agride um idoso é a mesma coisa que agredir uma criança. Hoje há leis, uma pessoa não pode dar uma bofetada num filho, porque se dá uma bofetada a um filho se alguém se insurge ou a polícia vê ou não sei quê até podem tirar o filho à pessoa, não é? No entanto, pode-se dar uma bofetada num velhote que também não se pode defender. Nem a criança se pode defender, nem o velhote. Portanto, não há essa proteção dos mais velhos".

(Homem, 71 anos, Ensino Básico, não sinalizado como vítima).

"Porque é que há o tribunal da família, um tribunal para as crianças e não há para os idosos?".

(Homem, 71 anos, Ensino Superior, vítima de abuso).

"Há idosos que muitas vezes são maltratados e não sabem como hão de agir, a quem recorrer e, portanto, talvez com maior informação e uma maior proteção os ajudasse".

(Mulher, 68 anos, Ensino Superior, vítima de abuso).

Alguns entrevistados referem a existência de um desfasamento entre o que está legislado e a prática da lei, pelo deveria haver uma reforma do sistema jurídico-penal:

"É mais uma lei que não vai ser cumprida. Portanto, eu acho que se calhar tinha que passar por outras medidas, mais fiscalização, mais vigilância, mais segurança, isto porque podem fazer uma lei excelente, mas depois na prática não funciona. Também acho que as pessoas que, muitas vezes estão a legislar, no caso da Assembleia da República, por exemplo, estão um bocado distantes destes problemas".

(Homem, 70 anos, Ensino Superior, vítima de abuso).

Os entrevistados revelam, assim, um fraco conhecimento das associações que operam em Portugal no domínio da proteção da vítima e da legislação existente neste âmbito. Contudo, têm noção de que se trata de um crime, embora ainda negligenciado, do ponto de vista deles, pela justiça e pelos tribunais. Apelam à criação de um tribunal que trate especificamente os problemas da população mais velha e à implementação de respostas sociais e de saúde mais eficazes, assim como a formação de equipas compostas por profissionais especializados nesta problemática.

\footnotetext{
${ }^{99}$ Mulher, 80 anos, ensino secundário, não sinalizada como vítima
} 


\subsection{As redes: Família e comunidade}

A presença de redes familiares, sociais e comunitárias é descrita, classicamente, como um fator protetor do risco de abuso de idosos. Também, no discurso dos entrevistados são apontadas as redes familiares e amicais como meios de suporte dos idosos em situação de violência:

"Eu espero e estou convencido que a minha família, apesar de a minha família não estar muito próxima de nós, que quando eu tiver necessidade eles me auxiliarão".

(Homem, 62 anos, Ensino Superior, vítima de abuso).

"Eu tenho muita sorte com a minha família".

(Mulher, 69 anos, Ensino Superior, vítima de abuso).

"É sangue do nosso sangue que está sempre disponível para se recorrer".

(Homem, 69 anos, Ensino Básico, vítima de abuso).

"Eu iria sempre ter com as pessoas que achava que deviam ter amor a essa pessoa. Alguém que eu soubesse que gostava dessa pessoa [amigos, vizinhos], fazendo-Ihe ver que ela estava a sofrer. E juntamente com essa pessoa estudar, pensar o destino que se poderia dar a uma pessoa que estava a sofrer".

(Mulher, 80 anos, Ensino Secundário, não sinalizado como vítima).

No entanto, os entrevistados também reconhecem a dimensão paradoxal da família moderna (Dias, 2010), ou seja, a família que maltrata, abandona e negligencia, contrariando neste caso, a expetativa de apoio e segurança entre os mais velhos:

"Há muitas pessoas idosas que estão sozinhas e têm muita família mas cada um, pronto, está ocupado e não tem tempo para lhe dar minimamente apoio. Portanto, eu acho que isso é uma violência".

(Mulher, 74 anos, Ensino Superior, não sinalizada como vítima).

"O idoso, antigamente, era como na família cigana, ou seja, o mais velho era o sábio, era aquele que mandava e, portanto, devia-se seguir aquela linha e aquela educação. Hoje penso que isso está posto de lado".

(Mulher, 66 anos, Ensino Superior, vítima de abuso).

"Tenho impressão que se pudesse falar com a família fá-lo-ia. Só se o agressor fosse da família já não sei bem, só se eu conhecesse outros familiares".

(Mulher, 71 anos, Ensino Superior, não sinalizada como vítima).

As mudanças também se fazem sentir nas relações de vizinhança nas sociedades modernas, as quais são marcadas, segundo os entrevistados, por um certo distanciamento social: 
"A relação de vizinhança, até nisso as coisas mudaram. Porquê? Porque as pessoas de hoje não são iguais às pessoas de há 40 nem de 30 anos atrás".

(Homem, 72 anos, Ensino Básico, vítima de abuso).

Neste domínio, as relações ora são marcadas pela mera cordialidade, ou pela intromissão na vida privada de cada um:

"Quando há muita amizade com os vizinhos, aquilo vai acabar mal e, portanto, é só o "Bom dia» e "Boa tarde», só falo, se for preciso".

(Homem, 70 anos, Ensino Secundário, não sinalizado como vítima).

"A gente ouve falar, por exemplo, nos prédios, que as pessoas praticamente não se conhecem. Cada um fecha-se em casa, tranca-se e depois, se ouvir barulho na vizinha, até põe o rádio mais alto para não se aborrecer".

(Homem, 70 anos, Ensino Superior vítima de abuso).

"Eu vejo lá muitos barulhos mas eu não vou bater à porta de ninguém, nem me meto naquilo".

(Homem, 74 anos, Ensino Básico, vítima de abuso).

Não obstante tais mudanças na estrutura de relações vicinais, para alguns entrevistados, estas ainda são encaradas como redes de suporte em cenários de vitimação, sobretudo quando outros meios de ajuda falham:

"Eu nem número da polícia tenho, eu a única pessoa que podia pedir ajuda era ao meu vizinho da frente que são umas pessoas impecáveis com nós".

(Mulher, 71 anos, Ensino Básico, vítima de abuso).

"Ajudam [vizinhas], até chamaram a polícia. Foram testemunhas, testemunharam. Tudo que seja preciso, tenho sempre auxílio por essas minhas vizinhas."

(Mulher, 71 anos, Ensino Básico, vítima de abuso).

A figura do pároco continua a ser fundamental como elemento de contacto, mas também como fonte de auxílio, aconselhamento e orientação dos idosos:

"Como sou religiosa, falaria primeiro com o Padre lá da minha paróquia, até falaria: "Olhe, estou a sofrer agressões. O que é que o Senhor Padre acha que eu devo fazer?"

(Mulher, 75 anos, Ensino Superior, não sinalizada como vítima).

"Pessoas que sejam religiosas, que sejam católicas, que vão à missa e peçam apoio na igreja ao pároco".

(Mulher, 71 anos, Ensino Superior, não sinalizada como vítima). 
Observa-se, assim, no discurso dos entrevistados uma representação positiva das redes de ajuda familiar, amical e vicinais, não obstante apontarem algumas mudanças nas estruturas do seu funcionamento quando comparadas com as existentes no passado. 0 pároco e as redes existentes na paróquia de pertença ainda continuam a ter um papel relevante de apoio e orientação entre os participantes. 


\section{Mensagens aos idosos vítimas de violência}

No final da entrevista, foi solicitado aos participantes que dirigissem uma mensagem dedicada aos idosos vítimas de abusos. As mensagens são muito heterogéneas apelando à necessidade de denúncia, à procura de apoio, mesmo que não o façam no próprio caso, à autoproteção, à participação na vida social e comunitária, em suma, ao exercício da cidadania, assim como a manterem esperança no espírito de solidariedade da própria sociedade, tal como ilustram os seguintes testemunhos:

"Para [os idosos] terem força e coragem para denunciar. Não se intimidarem, terem força, coragem e não se intimidarem. Porque que se se intimidarem estão a colaborar com os agressores e assim, se não se intimidarem, terão coragem e força para a denúncia".

(Homem, 77 anos, Ensino Básico, não sinalizado como vítima).

"Estou a prevaricar contra mim mesma, mas que denunciem. Eu não faço isso, mas que denunciem, que se manifestem porque não se deve deixar avançar a violência".

(Mulher, 72 anos, Ensino Básico, vítima de abuso).

"Somos nós que temos que nos defender, é a nossa família, são os nossos filhos, é o nosso sangue, mas primeiro nós. Somos nós que lhe damos a vida, temos que ser os primeiros a defendermo-nos".

(Homem, 81 anos, Ensino Básico, vítima de abuso).

"Que tenham uma vida social, sobretudo, com vizinhos e até com associações porque uma pessoa sozinha pode entrar em delírio, em depressão e se tiver um centro onde possa ir passar a tarde, fazer malha, jogar cartas, não sei quê, isso é um alívio para a sua cabeça, penso que isso poderá ser uma parte importante".

(Homem, 70 anos, Ensino Superior, vítima de abuso).

"Que tenham sempre esperança de que a sociedade não os esquece e a sociedade os respeita, e que a sociedade não Ihes quer fazer isso [maltratá-los]. Portanto, se a sociedade em geral não Ihes quer fazer isso, há de haver alguém que se há de interpor entre a pessoa que lhe faz mal e ela [vítima], para que ela se veja livre disso. Portanto, esperança sempre na sociedade, que a sociedade é bem formada, em geral".

(Mulher, 80 anos, Ensino Secundário, vítima de abuso).

Mas, a par destas mensagens de reforço e encorajamento, existem alguns entrevistados com um discurso mais pessimista neste âmbito:

"Eu acho que o mundo do idoso, quer esteja em casa, quer esteja num lar de Terceira Idade, é um mundo muito estreito, onde ele não tem muita capacidade 
de reação, porque tudo the é desfavorável, tudo é desfavorável, porque a envolvente humana desde a Senhora da limpeza, que serve não sei o quê, não sei que mais, estão aí como para a vingança na altura própria".

(Homem, 79 anos, Ensino Superior, não sinalizado como vítima).

"Coitadinhos, olhe, que tenho muita pena deles [idosos vítimas]! Que Deus Ihes dê tudo de bom para o resto da vida".

(Mulher, 71 anos, Ensino Básico, vítima de abuso). 


\section{Expectativas de bem-estar e felicidade}

Após uma longa deambulação sobre a problemática dos abusos de idosos e o impacto da crise socioeconómica neste âmbito e nas condições de vida dos idosos, os entrevistados pronunciaram-se sobre os fatores que, na sua perspetiva, Ihes traria bemestar e felicidade, destacando-se o dinheiro, a saúde, a família, o afeto, entre outros igualmente relevantes, como se pode observar de seguida:

"Principalmente a saúde porque se a gente tiver saúde, tem tudo".

(Mulher, 75 anos, Ensino Básico, vítima de abuso).

"Saúde e dinheiro! Saúde para passear e dinheiro para gastar".

(Homem, 77 anos, Ensino Básico, não sinalizado como vítima).

"Aqueles que os rodeiam têm de lhes dar [aos idosos] comodidade, bem-estar, que não Ihes falte alimentação, que não Ihes falte nada, que não se preocupem com a parte material. A parte material não é para os velhinhos se preocuparem. Já se preocuparam toda a vida!".

(Mulher, 80 anos, ensino secundário, não sinalizada como vítima).

"Sentirem [idosos] que ainda há alguém que os ama, que os estima, que é grato. Os mais novos devem gratidão aos mais velhos".

(Mulher, 75 anos, Ensino Superior, não sinalizada como vítima).

"O carinho, sentirem-se bem, o sentirem-se queridas, apoiadas [idosas]. Saberem que têm alguém do seu lado, é mais importante até do que terem de comer ou de vestir. Acho que é o carinho e eu lembro-me que minha mãe dizia que o que ela tinha medo, o maior medo era morrer só".

(Homem, 70 anos, Ensino Secundário, não sinalizado como vítima).

"Ter uma família amiga, amiga deles [idosos] até à morte".

(Mulher, 78 anos, Ensino Básico, vítima de abuso).

"Haver alguém que Ihes dê [idosos] o conceito do que é ter qualidade de vida, haver um bocado de informação sobre a qualidade de vida a seguir. Até porque vai-se evitar muitas doenças, que vão sobrecarregar os hospitais com despesa pública".

Alguns entrevistados salientam uma dimensão mais espiritual e religiosa no plano das suas expetativas de bem-estar e qualidade de vida:

"Paz, é o que eu mais desejo, é paz e compreensão, mais nada".

(Homem, 74 anos, Ensino Básico, vítima de abuso). 
"Nós pela vida fora é que temos de procurar a nossa felicidade. Porque Deus dános felicidade. Nós somos felizes e o mundo é feliz porque Deus sabe que nos tem cá, Deus acompanha-nos hora a hora, no dia a dia, nós não o vemos, mas ele está aqui a ouvir a nossa conversa".

(Homem, 87 anos, Ensino Básico, vítima de abuso).

Em suma, para os entrevistados, de forma geral, a existência de boas condições materiais, de saúde, familiares, sociais, amicais e ainda no plano religioso e espiritual configuram-se como fatores que, em conjunto, promovem o seu bem-estar e felicidade. 


\section{Conclusão}

O presente estudo, embora tenha partido de uma análise quantitativa enquanto forma mais objetiva de se obter conhecimento sobre as determinantes socioeconómicas e de saúde associadas ao fenómeno do abuso de idosos em Portugal, beneficiou largamente de uma abordagem naturalística e interpretativa (Flick, 2018) das representações e vivências de abuso e violência dos entrevistados.

Deste modo, foi percorrido um caminho analítico diferente, mas complementar à análise quantitativa realizada inicialmente, designadamente operou-se, no estudo qualitativo, por explicitação e aproximação sucessiva aos significados presentes nas representações sociais dos entrevistados que encobriam, por vezes, vivências de violência nem sempre assumidas por força dos mecanismos sociais, familiares, afetivos e simbólicos que continuam a exigir a sua ocultação. Para o efeito, recorreu-se à entrevista semiestruturada que se revelou, neste estudo, como o procedimento metodológico mais ajustado para aceder a dimensões profundas e íntimas da vida dos entrevistados, sem ultrapassar os limites impostos pelo respeito da privacidade (Kvale, 2009). Na situação de entrevista, partiu-se da abordagem das representações sobre o envelhecimento nas sociedades atuais e as condições socioeconómicas, permitindo aos entrevistados refletir sobre um conjunto de questões relevantes para a população mais velha, ao mesmo tempo que se foi introduzindo, progressivamente, os temas essenciais do estudo qualitativo, sempre no cumprimento da liberdade de discurso e de pensamento dos entrevistados e do estipulado no protocolo da coorte EPIPorto (Ramos, Lopes \& Barros, 2004).

Os resultados são reveladores da profundidade dos discursos dos entrevistados e da diversidade de significados presentes nas suas representações sociais, enquanto formas de conhecimento socialmente elaborado e partilhado (Dias, 2010).

Assim, observa-se que os discursos dos entrevistados sobre o envelhecimento e o papel dos idosos nas nossas sociedades oscilam entre o reconhecimento dos ganhos de longevidade, graças aos progressos da ciência e da medicina e a reatividade às imagens estereotipadas da velhice e ao idadismo que os exclui da vida social ativa valorizada nas nossas sociedades. Ao mesmo tempo, coexiste a narrativa do declínio do corpo envelhecido, fraco, não produtivo e dependente (Sandberg, 2013; Miller, 2019), pelo que ser idoso, para os entrevistados, é ser definido a partir do envelhecimento físico e social, mas não tanto do psicológico, porque nem sempre a mente envelhece ao mesmo tempo que o corpo. Esta visão também é reforçada pelo reconhecimento de que atualmente o "nexo geracional" (Mendes, 2005) não funciona nos mesmos termos do passado, o que é agravado pelo individualismo e egoísmo crescentes que caracterizam as relações familiares e as sociedades do presente. 
No plano das representações sociais sobre o fenómeno do abuso de idosos, foi possível compreender como elas funcionam, para os entrevistados, como um sistema de interpretação e de descodificação desta realidade, antecipando, ao mesmo tempo, as suas expetativas e vivências neste âmbito (Abric, 1997). Os discursos apontam para a noção de abuso de idosos simultaneamente como crime e violação de direitos humanos, mas também para algum desconhecimento da legislação que protege os seus direitos fundamentais. Entre as razões mais apontadas para a ocorrência de abusos destaca-se a assimetria de poder entre as vítimas e os agressores, que é agravada pela vulnerabilidade crescente dos mais velhos; a dependência, por vezes mútua, entre ambos (Wolf \& Pillemer, 1989); e a ausência de suporte familiar associada ao declínio do estatuto social dos idosos, tal como argumenta a tese da modernização (Dias, 2005). No confronto analítico com a definição dos diferentes tipos de abuso, os entrevistados não só identificam os tipos mais comuns (o abuso físico, psicológico, financeiro, sexual e a negligência), como descrevem uma série de condutas que ilustram a sua severidade e gravidade. Neste sentido, destacam o abuso físico como sendo o tipo de violência que causa mais dano e lesões, no entanto, também referem o abuso psicológico e financeiro como sendo igualmente graves e prevalentes nesta população. A negligência, quer sob a forma de omissão ao nível da satisfação das necessidades básicas dos idosos, quer sob a forma de abandono, surge, igualmente, em destaque no discurso dos entrevistados. Embora sendo reconhecido, sobretudo pelas mulheres, o abuso sexual foi timidamente apontado, evidenciando os constrangimentos próprios desta geração em abordar temas do foro da sexualidade.

Tentamos, de igual modo, compreender as formas de violência que segundo os entrevistados são mais comuns na idade avançada. Neste sentido, foi possível identificar quatro formas principais, designadamente: violência conjugal; violência dos descendentes sobre os pais idosos; violência perpetrada pelos cuidadores informais e informais; violência perpetrada por desconhecidos. Estas formas de violência não só estão muito relacionadas com as representações sociais dos entrevistados sobre a velhice como dependência e vulnerabilidade, mas também com dinâmicas abusivas experienciadas na conjugalidade e que se perpetuaram até à idade avançada. É de salientar a enfâse dos entrevistados na violência praticada por desconhecidos, assumindo-se inclusive como as vítimas preferenciais deste tipo de agressores. Este resultado, leva-nos a equacionar a necessidade de alargamento do campo semântico do conceito de abuso de idosos que deve passar a incluir, além dos atos infligidos em contexto familiar ou institucional, condutas perpetradas em espaço público por estranhos (cf. WHO, 2002 a e b).

Quando confrontados com a possibilidade, real ou hipotética, de reação a uma situação de violência, foi possível identificar 10 perfis, reveladores de atitudes muito 
diferenciadas, neste âmbito. Assim, identificam-se principalmente reações que reforçam a passividade e a acomodação à situação de violência (e.g. culpa, vergonha, medo, depressão/trauma, esperança na mudança, desculpabilizar, perdoar, não denunciar). Embora menos presentes, também se registam reações que mostram a necessidade de os idosos reagirem às situações de violência quer através do enfrentamento dos agressores, quer adotando estratégias de autoproteção.

Por fim, avaliamos a perceção do impacto da crise socioeconómica, que afetou a sociedade portuguesa entre 2008 e 2011, sobre o fenómeno dos abusos entre a população mais velha. Partindo do reconhecimento do seu impacto ao nível da diminuição de rendimentos, no declínio da saúde, do bem-estar geral, do estilo e condições de vida dos mais velhos, mas também no agravamento da situação familiar, inclusive dos filhos afetados pelo desemprego, os entrevistados reconhecem que a crise socioeconómica teve um efeito potenciador dos abusos sobre os mais velhos e da conflitualidade familiar em todas as classes sociais, embora com graus de (in)visibilidade diferenciados. Ao mesmo tempo, acentuaram-se os comportamentos aditivos, sobretudo associados ao alcoolismo, assim como as desigualdades sociais agravadas por processos de pobreza e exclusão social.

Está assim muito presente, no discurso dos entrevistados, o sentimento de insegurança, principalmente nos idosos que são vítimas de violência, pelo que é muito enfatizado o papel do Estado, que deve responder, em primeira instância, às necessidades de proteção e bem-estar geral desta população, através de um conjunto de medidas promotoras da sua segurança e inclusão social. Embora revelem um desconhecimento relativo da legislação e das associações que intervêm neste âmbito, é ainda enfatizada a necessidade de intervenção junto dos agressores e de formação especializada dos profissionais das forças de segurança pública e da saúde, dado o seu papel crucial na linha da frente da emergência social junto da população mais velha. As redes familiares e comunitárias surgem no discurso dos entrevistados como fatores protetores do risco de violência, todavia, também é reconhecido o papel mais sombrio da família que maltrata e negligencia os seus membros mais velhos. Não obstante, os entrevistados deixam uma mensagem forte dirigida a todos os idosos que são vítimas de violência, incitando-os ao exercício da cidadania através da denúncia dos abusos, mas também a continuarem a acreditar no sentido da civilização, isto é, numa sociedade que "não esquece e que respeita os mais velhos"100. Esta convicção, associada à existência de boas condições materiais e de saúde, de redes familiares, amicais e espirituais emergem, no discurso dos entrevistados, como fatores geradores de bem-estar e de felicidade na idade avançada, mas também como fatores protetores do risco de abusos e de violência.

${ }^{100}$ Mulher, 80 anos, ensino secundário, vítima de abuso. 


\section{"O lugar de um idoso devia ser na família, mas infelizmente não é".}

\section{(José, 78 anos, viúvo, Ensino Básico)}

José é viúvo e considera os filhos como a sua única família: "Graças a Deus tenho uma família, tenho uns filhos muito bons". Acredita que o nível de afinidade que mantém com eles é um privilégio, já que atualmente "os filhos não têm tempo de olhar pelos pais e são obrigados a empurrá-los para um lar". Apesar de viver com um familiar, descreve-se como sendo uma pessoa independente graças à sua reforma que "dá para sobreviver". José planeou a sua saída do mercado de trabalho: "temos que organizar o fim da vida". Por isso, refere que não houve alterações no seu estilo de vida durante a transição para a reforma. O mesmo se passou com a crise económica, porque, sendo poupado, não se sentiu afetado pelo período de recessão: “Eu privei-me sempre de muitas coisas. No ano passado foi o primeiro ano que eu tive uma semana de férias." Contudo, refere ter apoiado financeiramente um filho, que "até é muito trabalhador, só que a crise". Mas, no geral, avalia as atuais condições de vida de forma positiva: "no tempo dos meus pais não havia uma pequena reforma, não havia nada. Hoje, há uma reformazinha".

José critica os consumos das gerações atuais: "antigamente um guarda-vestidos dava para toda a família. Agora, aqui em casa toda a gente tem um guarda vestidos no quarto e já ninguém pode lá meter nada". Para ele envelhecer em Portugal é o resultado da "Medicina que está muito adiantada e, claro, as pessoas têm mais facilidade para se tratar". No entanto, considera que a abordagem nas consultas, piorou: "o médico só escreve, só passa os remédios, nem escuta nem nada".

Embora nunca tenha vivenciado um episódio de violência, "não é o meu caso", José refere-se ao abuso de idosos com "muita tristeza e desgosto". Considera que estas situações são mais frequentes entre os casais, em que o homem é o agressor e a mulher, porque "não pode viver sem um homem", acaba por permanecer com ele e não pedir ajuda. Refere ainda que a violência ocorre ora porque "os pais não deram" educação aos agressores, ora devido à representação de infantilização dos próprios idosos: "às vezes os idosos são meninos outra vez, somos meninos duas vezes". Por seu turno, se o idoso não dá "rendimento, já num trabalha", torna-se numa vítima potencial: "fora daqui que estás a estorvar". A ausência de "umas palavrinhas para os idosos", a incapacidade de "ouvi-los" e a "falta de amor" são a piores formas de violência, que ocorrem, segundo José, principalmente nas famílias com fracas condições económicas. Aos mais velhos, José deixa o conselho para continuarem a "acreditar em Deus e a confiar nele". 


\section{IV - Pessoas: narrativas e vivências de violência na idade avançada}

Na última parte do relatório atribui-se aos participantes neste estudo a condição de autores da sua própria vida (Gonçalves, 2000), tendo-se esboçado, a partir das suas narrativas de abuso e dos significados por eles atribuídos ao processo de envelhecimento, um conjunto de recortes biográficos. Os retratos de seguida apresentados, ilustram o processo de elaboração dos significados atribuídos às suas experiências de vida e de abusos, identificando-se acontecimentos significantes e dimensões de vulnerabilidade que recriam, ao mesmo tempo, condições de existência diferenciadas. Estes recortes biográficos ao ilustrarem alguns perfis-tipo presentes na nossa mostra, revelam-se uma ferramenta metodológica fundamental no plano da intervenção entre a população mais velha, na medida em que permitem a sistematização de informação biográfica em domínios da existência que são apontados, pelos próprios idosos, como sendo críticos e, por isso, geradores de vulnerabilidade na idade avançada (Grundy, 2006). 
Figura 2. Perfil de Isaura

\section{harmed oabuso deidosos determinantes sociais, económicas e de saúde}

\section{conheça a Isaura}

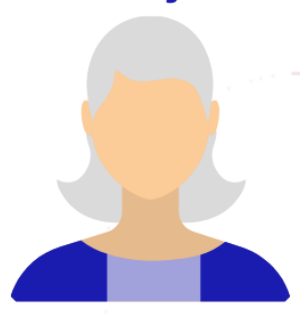

idade - 75 anos

estado civil - casada

escolaridade - ensino básico

situação profissional - reformada

sinalizada como vítima desde 2009

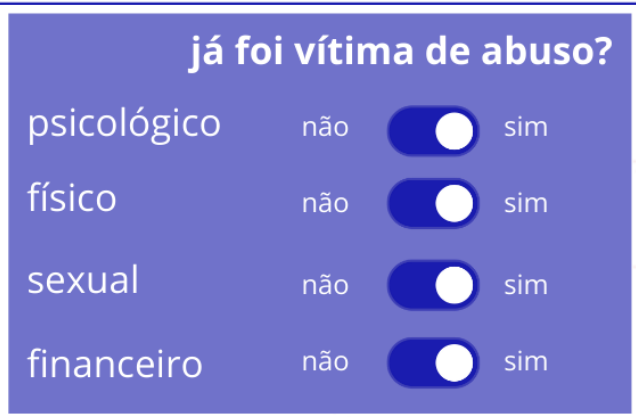

Isaura considera ser uma pessoa saudável. Apesar de reconhecer as limitações físicas advindas do avançar da idade, recusa abandonar um estilo de vida mais ativo e, por isso, mantém-se ocupada ao ajudar os filhos e netos, praticar exercício físico e essencialmente cuidar do marido, que já sofreu um AVC. Partilha episódios de violência física e psicológica vivenciados, no início do seu casamento, que nunca conseguiu denunciar. Acredita, porém, ser uma situação ultrapassada.

o que é importante para Isaura?

- Embora aposentada, Isaura gosta de poder continuar a sentir-se dinâmica e sociável.

- Valoriza os pequenos passeios e convívios com as amigas em cafés.

- A família assume uma presença essencial na vida de Isaura.

- Está preocupada com o seu bem-estar físico e por isso frequenta o ginásio com regularidade.

\section{saúde}

- Isaura sente-se bem, embora já não tão ágil, e discorda da médica quando é advertida a deixar de conduzir.

- Preocupa-se sobretudo com o estado de saúde do marido, que sofreu um AVC e atualmente tem diabetes.

M.

\section{para Isaura ser idoso é...}

Por força do declínio das capacidades físicas, estar limitado na realização das atividades diárias.

- Ter uma aparência indesejada.

- Ser menosprezado pelos mais jovens que são egoístas e sem educação.

\section{experiência de abuso}

- Isaura partilha ter sido vítima do marido aos 20 anos.

- Descreve agressões psicológicas e físicas causadas pelo excesso de ciúmes e controlo.

- O facto do marido ter sempre contribuído financeiramente para a família atenuava a gravidade da violência e coibia Isaura a abandonar a relação.

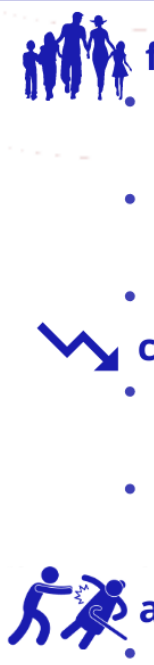

\section{família e comunidade}

O marido é a pessoa mais próxima de Isaura, com quem mantém o casamento de longa data.

- Não vive com os filhos mas visita-os com frequência e procura dar apoio aos netos, por quem demonstra especial angústia.

- A sua relação com os vizinhos é cordial.

\section{crise socioeconómica}

- A fase da crise provocou, em Isaura, medo do futuro, não só por si, como pela sua família.

- Assume não se sentir privada dos bens essenciais apenas por ser uma pessoa poupada.

\section{abuso contra pessoas idosas}

- Para Isaura, a violência ocorre quando o idoso é abandonado e não recebe cuidados como a alimentação ou higiene.

- Embora acredite que os principais agressores sejam os filhos, Isaura afirma que, na geração dos seus pais, havia mais violência da parte dos maridos

- As vítimas remetem-se ao silêncio por vergonha.

\section{segurança e autoproteção}

- A denúncia não era opção para vítimas mulheres, no tempo da juventude de Isaura, que eram desvalorizadas perante as autoridades policiais.

- Atualmente, é reconhecida uma melhor abordagem da parte da polícia, ainda que fosse importante, segundo Isaura, investir em psicólogos nas esquadras. 
Figura 3. Perfil de José

\section{harmed}

\section{conheça o José}

idade - 78 anos
estado civil - viúvo
escolaridade - ensino básico
situação profissional - reformado
sinalizado como vítima em 2009

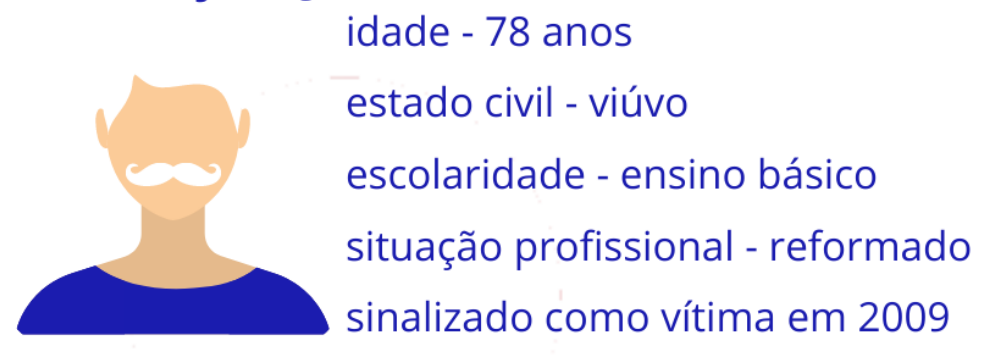

o abuso de idosos determinantes sociais, económicas e de saúde

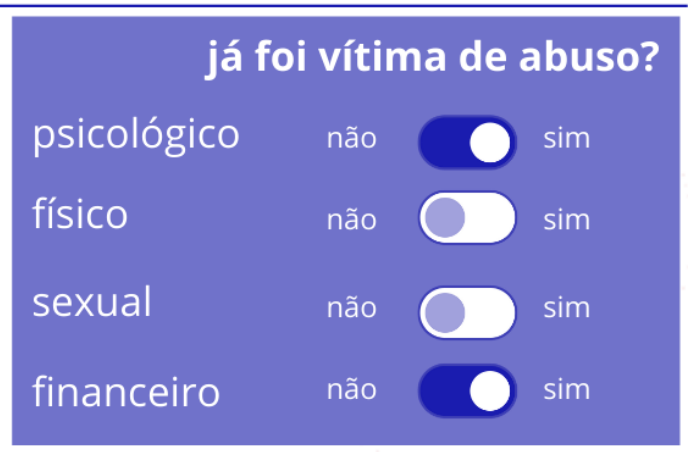

José já não está empregado e vive da sua reforma com uma filha. Avalia as suas condições de vida atuais como positivas. A igreja é uma base de apoio muito importante na sua vida. Demonstra uma visão de desânimo perante o sistema de valores das gerações mais jovens.

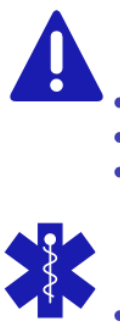

o que é importante para José?

- A família é a rede de apoio de José.

- Evidencia uma forte ligação à Igreja.

- Gosta de fazer voluntariado e de poder ajudar outras famílias.

\section{saúde}

- Embora mencione já ter sofrido alguns problemas de saúde, José desvaloriza e diz sentir-se normal.

\section{para José ser idoso é...}

Ser desprezado pelos filhos que, como não têm disponibilidade para os pais, abandonam-nos nos lares.

- Não ser respeitado, dada a condição etária, e excluído socialmente.

- Sofrer por não ter uma reforma satisfatória.

\section{experiência de abuso}

- Apesar de estar sinalizado como vítima, José não referencia qualquer episódio pessoal de violência, mas sente tristeza e desgosto ao abordar o assunto

- Caso fosse vítima, acredita não ser capaz de reagir e se defender.

\section{segurança e autoproteção}

- Para José, o Estado protege devidamente as pessoas mais velhas em Portugal.

- As autoridades policiais são um recurso, ainda que esteja difundida a crença de que, frequentemente, ignoram os casos e não atuam.

- Os profissionais de saúde deveriam adotar um sistema de visitas domiciliárias aos idosos vítimas de abuso.

\section{família e comunidade}

- Para José, a sua família são os filhos com os quais estabelece uma importante proximidade relacional e afetiva.

- Viveu com a sua esposa durante vários anos, de quem cuidou.

- Refere manter uma boa relação com todos os vizinhos, salientando a comunidade cigana como mais controversa pelos seus costumes distintos.

\section{crise socioeconómica}

- O período de recessão não implicou ajustamentos no estilo de vida de José, que diz que sempre foi poupado.

- Nunca precisou de receber apoio, porém apoiou financeiramente o seu filho mais novo que ficou desempregado.

\section{abuso contra pessoas idosas}

- José perceciona que, atualmente, há mais violência, porque tem um aceso constante a esses casos através da televisão.

- Aponta como potencial causa da violência o decréscimo de casamentos e incremento dos divórcios.

- A violência ocorre nas instituições, onde os profissionais são violentos e negligentes para com os idosos.

- Ocorre, igualmente, entre os casais, em que o homem é o agressor e a mulher a vítima dependente, escrava, que não quer estar sozinha. 
Figura 4. Perfil de Manuel

\section{harmed oabuso de idosos \\ determinantes sociais, económicas e de saúde}

\section{conheça o Manuel}

idade - 70 anos

estado civil - casado

escolaridade - ensino superior

situação profissional - reformado

sinalizado como vítima em 2017

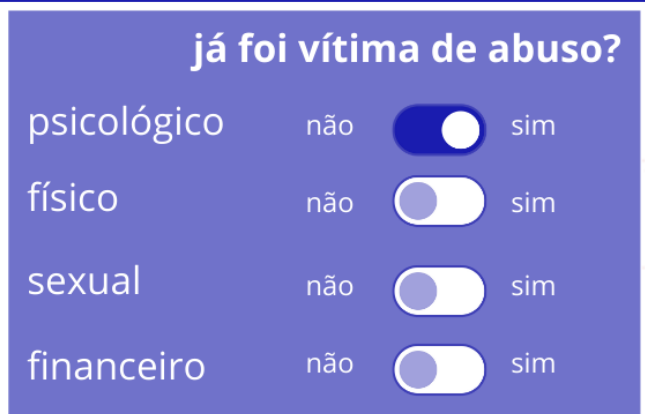

Manuel encara o envelhecimento como uma boa fase do ciclo de vida. Embora reconheça que esta não seja a perceção partilhada pela generalidade da população, testemunha ter aprendido a apreciar este período a fazer o que gosta. A ausência de suporte familiar não o perturba agora, apenas fá-lo recear quanto a um cenário futuro de dependência funcional e cognitiva. Considera a sociedade atual mais violenta e egoísta.

\section{o que é importante para Manuel?}

- Uma vez que está reformado, Manuel usufrui do tempo livre para passear, ler e conviver com amigos.

- A prática de exercício físico é uma constante na sua rotina.

\section{saúde}

- Manuel descreve um gradual declínio nas suas condições de saúde, que encara como próprio da idade, e que, por isso, não o impede de manter-se ativo.

\section{para Manuel ser idoso é...}

- Sentir-se inútil.

- Ser descartado pelas famílias.

- Provocar sacrifício nos cuidadores.

- Morrer sozinho no hospital.

\section{experiência de abuso}

- Manuel assegura nunca ter experienciado uma dinâmica de abuso, embora os seus dados pessoais indiquem o contrário. Num cenário de vitimização, está convicto de que adotaria uma postura reativa como mecanismo de defesa.

\section{segurança e autoproteção}

- O Estado não cumpre com a sua função de proteção, segundo Manuel, já que não tem

- capacidade para acolher os idosos isolados e sem rede social de suporte.

- As forças policiais, além de proporcionarem segurança, deveriam estabelecer um serviço de maior proximidade.

- Os profissionais de saúde podem dispor da sua posição próxima com os idosos para desencadear a intervenção. wh família e comunidade

Manuel denuncia uma relação familiar distante, da qual não espera receber qualquer apoio.

- Evita manter contacto com os vizinhos, devido a conflitos do passado.

\section{y crise socioeconómica}

- Este período obrigou Manuel a reduzir gastos considerados, por si, supérfluos e outros mais de índole indispensável.

- Causou sintomas de ansiedade, tendo comprometido a sua saúde mental.

- Na generalidade, acredita ter agravado a situação de violência contra as pessoas mais velhas devido à perda de rendimento. abuso contra pessoas idosas

- Manuel entende que a violência é ocultada, comumente, em casa, sendo os filhos os principais agressores.

- Os consumos aditivos e as dificuldades económicas são fatores de risco prevalecentes.

- As vítimas idosas suportam os maus tratos por recusarem acusar os seus próprios filhos e manterem a esperança de que os comportamentos vão mudar. 
Figura 5. Perfil de Maria

\section{harmed oabuso de idosos \\ determinantes sociais, económicas e de saúde}

\section{conheça a Maria}

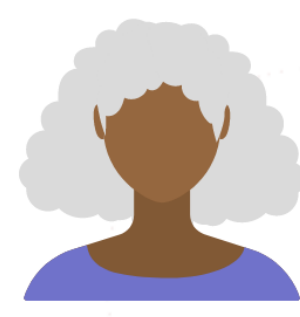

idade - 71 anos

estado civil - solteira

escolaridade - ensino superior

situação profissional - reformada

nunca foi sinalizada como vítima já foi vítima de abuso?

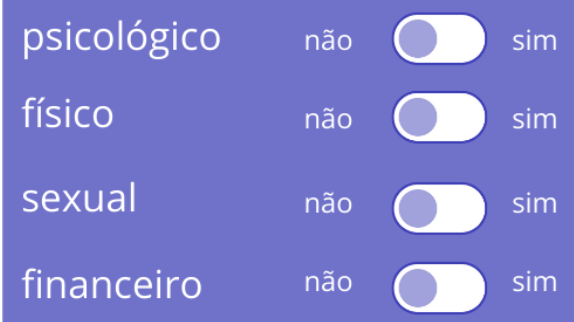

Maria é solteira e vive sozinha. Partilha, por vezes, a casa com uma das suas irmãs, a quem gosta de ajudar. Foi professora, mas agora está reformada e, por isso, ocupa o seu tempo com atividades aprazíveis, nomeadamente o voluntariado. Por manter um estilo de vida ativo, não gosta de se definir como pessoa idosa e demonstra uma certa reatividade às representações negativas associadas à velhice.

o que é importante para Maria?

- Maria preza a sua família, cuja presença corresponde sempre às suas expectativas e necessidades.

- Gosta de se dedicar ao voluntariado para ajudar pessoas sem-abrigo.

\section{saúde}

- Reconhece uma ligeira deterioração do seu estado de saúde que aumentou os custos com os cuidados médicos e sociais.

\section{para Maria ser idoso é...}

- Estar convencionado sobretudo pelo critério cronológico que, para Maria, se situa a partir dos 70 anos.

- Não aceitar as limitações físicas do corpo.

- Estar mais afastado da família porque as mulheres trabalham fora de casa.

\section{experiência de abuso}

- Maria crê nunca ter presenciado qualquer conduta abusiva, apenas uma tentativa de roubo e uma perseguição, da qual conseguiu pedir ajuda.

- Para se precaver, toma determinadas precauções tanto em casa, como na via pública.
Whation

Mamía e comunidade

Mria descreve a relação com a sua família de grande proximidade afetiva e união.

- Os vizinhos representam também uma importante companhia.

\section{Y crise socioeconómica}

- Não se sentiu afetada pela crise, mantém uma situação económica estável com uma aposentação razoável.

- A irmã de Maria careceu do seu apoio financeiro e logístico.

\section{abuso contra pessoas idosas}

- O fenómeno da violência suscita um sentimento de revolta quando as vítimas são idosos porque estão mais debilitados ao nível da sua capacidade pessoal de defesa.

- Idosos que vivem isolados socialmente são mais propensos aos assaltos.

- O aumento do desemprego é um fator potenciador do abuso sobre os mais velhos.

- Maria acredita que a exposição ao abuso é uma experiência de tal forma intensa que leva ao idoso desejar a morte.

\section{segurança e autoproteção}

- Para Maria, seria da competência do Estado proporcionar uma vida com dignidade às pessoas idosas, ao investir em estruturas residenciais de qualidade.

- As autoridades policiais, ainda que fundamentais na proteção, estão desprovidas de recursos.

- O pároco representa um elemento de auxílio e orientação para os idosos. 
Figura 6. Perfil de Amélia

\section{harmed oabuso deidosos determinantes sociais, económicas e de saúde}

\section{conheça a Amélia}

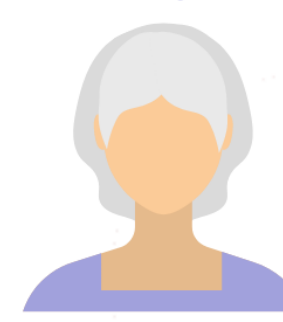

\author{
idade - 64 anos \\ estado civil - casada \\ escolaridade - ensino básico \\ situação profissional - empregada \\ sinalizada como vítima em 2017
}

já foi vítima de abuso?

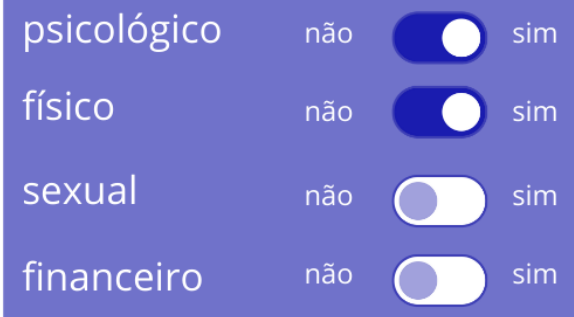

Amélia mantém um trabalho a tempo inteiro como doméstica e equilibra o seu salário com a reforma do marido, a quem foram diagnosticados problemas de saúde. Apresenta um discurso de desaprovação contra as estruturas residenciais para pessoas idosas e teme que as filhas não tomem conta dela, caso perca a sua autonomia, tal como tomou da sua mãe. Vive, há 45 anos, uma relação de conjugalidade abusiva. É a primeira vez que participa na avaliação.

o que é importante para Amélia?

Amélia valoriza o tempo dedicado a cuidar da sua família.

- Acredita que a fé é a base para uma vida de qualidade.

- O trabalho retrata uma fonte de rendimento crucial e uma forma de alienação dos problemas vividos na sua relação conjugal.

\section{saúde}

- Devido ao excesso de trabalho, Amélia sente reduzidas as suas capacidades funcionais e denuncia uma dependência de medicamentos.

\section{para Amélia ser idoso é...}

- Estar no fim da vida.

- Viver num lar sem amor, afeto e atenção.

- Tentar contrariar as representações derrotistas do processo de envelhecimento com uma mentalidade positiva.

\section{experiência de abuso}

- Amélia confessa ser vítima de violência psicológica do marido, a qual se foi intensificando com os anos.

- Legitima as condutas abusivas com as qualidades do marido, nomeadamente o facto de ser trabalhador e cuidadoso com os filhos e netos.

- Ponderou abandonar a relação mas foi dissuadida pelas filhas a não fazê-lo.

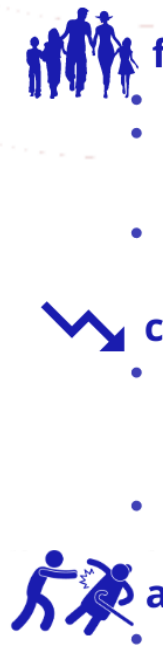

\section{família e comunidade}

- Amélia vive com o marido.

- Procura manter a ligação emocional com as suas duas filhas mas sem intrometer-se na sua vida privada.

- Foi cuidadora da sua mãe já em estado terminal, ainda que sem apoio dos irmãos.

crise socioeconómica

- Por efeito da crise, agravado pela idade avançada e condição de saúde, o marido de Amélia perdeu os trabalhos que realizava, encurtando, assim, o rendimento familiar.

- Reconhece um esforço de poupança, inclusive com os custos da alimentação.

\section{abuso contra pessoas idosas}

- A violência é perpetrada sobretudo por cuidadores, sejam eles filhos ou profissionais.

- O risco de exposição ao abuso intensifica-se quando o idoso perde a sua autonomia e se encontra numa situação de dependência.

- Os maus tratos são uma humilhação para os idosos.

- As vítimas remetem-se ao silêncio por medo.

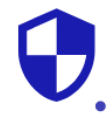

\section{segurança e autoproteção}

- Amélia considera a atuação das autoridades policiais importante principalmente junto dos idosos isolados.

- O contacto com os profissionais de saúde é essencial, até para Amélia, que recorre, com frequência, à sua médica para receber aconselhamento. 


\section{V-Conclusões gerais e recomendações}

O grande objetivo de partida do presente estudo foi conhecer as determinantes sociais, económicas e de saúde associadas ao fenómeno do abuso de idosos em contexto de crise socioeconómica que se viveu, em Portugal, sobretudo entre 2008 e 2011. Foi desenvolvida uma abordagem metodológica mista, tendo conduzido à realização, num primeiro momento, de um estudo quantitativo e, posteriormente, de um estudo qualitativo, cujos resultados principais se sintetizam nas presentes conclusões gerais:

- A prevalência de abuso global, independentemente do tipo de abuso, é de 23,9\%, ou seja, cerca de 1 em cada 4 inquiridos reporta ter vivenciado, pelo menos, uma situação de abuso nos 12 meses anteriores à aplicação do questionário. Tal significa que embora a prevalência de abusos no presente estudo tenha diminuído ligeiramente quando comparada com os resultados do estudo ABUEL (2009) (Soares et al., 2010), Portugal ainda continua a apresentar uma prevalência alta de abusos contra as pessoas mais velhas.

- Não foram observadas diferenças significativas ao nível da prevalência de abuso entre homens e mulheres, exceto no caso do abuso psicológico $(19,9 \%$, $\mathrm{n}=135$ ), que é o tipo mais frequentemente reportado pelas mulheres. Resultado que pode refletir uma diferença de género apenas na maneira como este tipo de abuso é reconhecido e, portanto, reportado pelo género feminino por comparação com o género masculino $(22,7 \%$ vs. $15,3 \%, p=0,020)$.

- Os cônjuges/companheiros das vítimas são os principais responsáveis pela violência infligida aos idosos, provocando $28 \%$ dos abusos reportados. Mais de $2 / 3$ das vítimas optou por não pedir ajuda ou relatar os incidentes de violência.

- Não existe evidência que sustente que o avançar da idade se traduzirá numa maior vulnerabilidade face ao risco de abuso. A mesma conclusão também se extrai para o efeito de fatores como a escolaridade, o modelo familiar ou a situação conjugal.

- Embora não seja possível afirmar se a depressão é causa ou efeito dos abusos, os participantes no estudo com sinais de depressão exibem um risco de exposição ao abuso que é mais do dobro daquele identificado para quem não tem depressão. Esta revela-se assim como uma pista para deteção de situações de vulnerabilidade face ao abuso, sobretudo entre os profissionais da saúde.

- Os participantes que exibem um padrão de menor cuidado com a sua saúde apresentam um risco maior, quase três vezes superior, de exposição a situações de abuso. Ou seja, os idosos que apresentam mais sintomas depressivos, que são mais negativos na avaliação do seu estado geral de saúde, 
que falham a toma de medicação ou tratamentos médicos, são aqueles onde as situações de abuso mais ocorrem.

- A vulnerabilidade económica emerge, neste estudo, como o fator de risco mais relevante para o abuso. Aqui os efeitos são muito significantes, com os participantes numa posição menos favorável nos indicadores que medem condições materiais de vida a exibirem um risco substancialmente maior de exposição a situações de abuso; aqueles com maior insegurança económica quase que duplicam o risco de abuso e, por último, aqueles com muito baixa segurança alimentar exibem um risco de exposição a abuso cerca de 9 vezes superior aos participantes que apresentam muito alta segurança alimentar. Paralelamente, a existência de um baixo suporte social em torno do idoso faz a probabilidade de ocorrência de abuso triplicar. Portanto, o estudo confirma a tendência de que a vulnerabilidade social, económica e de saúde está associada a uma maior prevalência de qualquer tipo de abuso contra os idosos (Fraga et al., 2014; Karanikolos et al., 2013).

- Em suma, os resultados revelam que a crise económica dos últimos anos aumentou significativamente o risco de exposição dos idosos ao abuso, nomeadamente daqueles que já se encontravam em situação de vulnerabilidade económica e de privação material. Evidenciam ainda a existência de efeitos de acumulação de vulnerabilidade em torno da exposição ao abuso, efeito que designamos por coocorrência de desvantagem. Assim, defende-se que as políticas públicas no âmbito dos abusos e violência sobre as pessoas mais velhas devem ser orientadas a partir da problemática da vulnerabilidade (Grundy, 2006), com vista a terem em conta, aquando da sua definição, os diversos eixos de desvantagem e desigualdade social que confluem, de forma mais penalizadora, na idade avançada.

Nesta linha teórica, importa insistir nas seguintes recomendações, no plano da intervenção, nomeadamente:

- Elaboração de programas especificamente voltados para os adultos mais velhos vítimas de violência, defendendo-se a especialização da intervenção ao nível da ação médico-social (e.g., serviços de saúde e sociais especializados; provisão mais alargada de cuidados ao nível do apoio psicólogo e mental; aconselhamento e mediação familiar; acolhimento das vítimas em espaços apropriados e seguros).

- Intensificação das ações de formação interdisciplinares e interinstitucionais dirigidas aos profissionais de diversos campos de intervenção (e.g., associações de apoio à vítima, forças policiais, profissionais da justiça, enfermagem, ação social) com vista à implementação bem-sucedida dos 
procedimentos de triagem e encaminhamento, mas também à melhoria dos níveis de atendimento e comunicação com os cidadãos mais velhos vítimas de violência.

- Promoção de campanhas de autoproteção e de segurança dos mais velhos em contexto familiar, institucional e em espaço público, envolvendo, inclusive, idosos com experiência de vitimização.

- Incremento de campanhas especializadas de combate ao idadismo e à violência em diversos contextos (e.g., comunitário, social, familiar, de saúde, etc.), incorporando outras dimensões como as desigualdades de género, a violação dos direitos humanos, assim como as questões éticas na idade avançada.

- Fomento de processos participativos dos mais velhos em redes sociais e comunitárias enquanto fator protetor do abuso e da violência na idade avançada.

- Promoção de estudos quantitativos (transversais e prospetivos) sobre a prevalência dos diferentes tipos de violência entre os adultos mais velhos em diversos contextos sociais, de forma a permitir a monitorização do fenómeno em algumas coortes populacionais e a identificar necessidades de intervenção. Os referidos estudos devem ser acompanhados por abordagens qualitativas sobre as vivências de abusos, com vista à compreensão, a partir das perspetivas dos mais velhos, dos fatores individuais, psicológicos, familiares, socioeconómicos e de saúde que tornam esta população vulnerável à violência. A conciliação dos dois tipos de estudos, resultará em estratégias de intervenção cientificamente informadas, sendo assim possível definir políticas sociais e de saúde mais ajustadas à gravidade do fenómeno e às necessidades da população mais velha.

Por último, tal como demonstramos antes, a vulnerabilidade na velhice resulta de interações complexas entre a exposição a riscos, a sua materialização e a falta de recursos para lidar com esses riscos (Grundy, 2006). Por isso, ela também é amplamente interpretada como medida de bem-estar, pois reflete as perspetivas futuras dos indivíduos e das políticas públicas que mobilizam recursos para evitar o seu agravamento e a queda das pessoas mais velhas em situações de pobreza, exclusão social e de violência (Chaudhuri, 2003; Lopes, 2011). Por esta razão, os recursos materiais, a família, os amigos, as redes de suporte médico-social e de prestação de cuidados, a saúde (física e mental), as oportunidades de autonomia e de autorrealização surgem como componentes-chave para a promoção da qualidade de vida entre os adultos mais velhos e, por esta, via, para o enfrentamento com sucesso das vulnerabilidades emergentes nesta fase do ciclo de vida (Grundy, 2006; WHO, 2015). 


\section{Referências Bibliográficas}

Abric, J. C. (Dir.) (1997). Pratiques Sociales et Représentations. Paris: PUF.

Antunes, J. A. P. J. (2015). Crise económica, saúde e doença. Psicologia, saúde \& doenças, 16, 267-277.

Aseem, M.; Sandeep, G.; Arun, A.; Mohammad, B. \& Ajit, A. (2019). Prevalence of elder abuse and its association with psychiatric motbidity in a rural setting. Journal of Neuroscience in Rural Practice, 2, 218-224.

Baker, A.A. (1975). Granny-battering. Modern Geriatrics, 5, 20-24.

Blumberg, S. J., Bialostosky, K., Hamilton, W. L., \& Briefel, R. R. (1999). The effectiveness of a short form of the Household Food Security Scale. American journal of public health, 89(8), 1231-1234.

Cardoso et al. (2012). Estado e políticas sociais sobre a velhice em Portugal (1990-2008). Análise Social, 24, 606-630.

Carvalho, S., Pinto-Gouveia, J., Pimentel, P., Maia, D., Mota-Pereira (2011). Psychologica, 54, 331-357.

Conselho da Europa (2002), Recomendação 1582 (2002) I (I).

Dias, I., Lopes, A., \& Lemos, R. (2019a). O Abuso de Pessoas Idosas: Definições e Controvérsias. In M. Paulino \& D. Costa (Coord.), Maus-Tratos a Pessoas Idosas (pp. 1936). Lisboa: Pactor. ISBN: 978-989-693-083-7.

Dias, I., Lopes, A. \& Lemos, R. (2019b). Violência contra pessoas idosas: um olhar sobre o fenómeno em Portugal. Tendencias Sociales. Revista de Sociología. Departamento de Sociología III, UNED. Facultad de Ciencias Politicas Y Sociologia. 4, 42-56. Disponível em: http://revistas.uned.es/index.php/Tendencias/index.

Dias, I., Lopes, A. \& Lemos, R. (2018). Violência contra as mulheres idosas: o peso das assimetrias de género na idade avançada. Revista Feminismos. Universidade Federal da Baia, Núcleo de Estudos Interdisciplinares sobre a Mulher. 6(2), 66-79. Disponível em: http://www.feminismos.neim.ufba.br/index.php/revista.

Dias, I. \& Lopes, A. (2016). Envelhecimento e políticas sociais em Portugal: tendências e desafios". In M. C. Antunes \& M. E. Leandro (Org.), Envelhecimento. Perspetivas, projetos e práticas inovadoras (pp. 67-90). Edições Húmus: Vila Nova de Famalicão. ISBN:978989-755-195-6.

Dias, I. \& Rodrigues, E. V. (2012). Formas de transmissão da infeção VIH/Sida e fontes de apoio social. In I. Dias (Coord.), Diagnóstico da infeção VIH/sida. Representações e efeitos nas condições laborais (pp. 47-64). Lisboa: LIDEL. ISBN: 978-972-757-894-8. 
Dias, I. (2010). Violência na Família. Uma abordagem Sociológica. (2.a ed.). Porto: Edições Afrontamento. ISBN: 978-972-36-0737-9.

Dias, Isabel (2005). Envelhecimento e violência contra os idosos. Sociologia. Revista da Faculdade de Letras do Porto. 15, 249-273.

Fleck, Marcelo, P., Louzada, Sérgio, Xavier, Marta, Chachamovich, Eduardo, Vieira, Guilherme, Santos, Lyssandra, \& Pinzon, Vanessa (2000). Aplicação da versão em português do instrumento abreviado de avaliação da qualidade de vida "WHOQOLbref". Revista de Saúde Pública, 34(2), 178-183. Disponível em: https://dx.doi.org/10.1590/S0034-89102000000200012.

Flick, U. (2018a). Doing Triangulation and Mixed Methods. London: Sage.

Flick, U. (2008b). Designing Qualitative Research. London: Sage.

Folstein, M. F., Folstein, S. E. \& McHugh, P. R. (1975). "Mini-mental state". A practical method for grading the cognitive state of patients for the clinician. Journal of Psychiatric Research. 12(3), 189-198.

Fonseca, R., Gomes, I., Faria, P. L., \& Gil, A. P. (2012). Perspetivas atuais sobre a proteção jurídica da pessoa idosa vítima de violência familiar: contributo para uma investigação em saúde pública. Revista Portuguesa de Saúde Pública, 30, 149-162.

Fonseca, A. M. (2004). O envelhecimento. Uma abordagem psicológica. Lisboa: Universidade Católica Editora.

Fraga, S., Lindert, J., Barros, H, Torres-Gonzalez, F, Ioannidi-Kapolou, Elisabeth, Melchiore, MG, Stankunas, M, Soares, Joaquim F. (2014). Elder Abuse and socieconomic inequalities: a multilevel study in 7 European countries. Preventive Medicine, 61, 42-47.

Fraga, S., Lucas, R., Costa, D., Barros H. (2013). Interviewer effects when investigating abuse were not compatible with effect modification but instead wit confounding. Journal of Clinical Epidemiology, 66 (8), 911-918. Disponível em: https://doi.org/10.1016/j.jclinepi.2012.07.020.

Fraga, S., Costa, D., Dias, S. \& Barros, H. (2011). Does interviw setting influence disclosure of violence? A study of elderly. Age and Ageing, 41, 70-75. doi:10.1093/ageing/afr090.

GIL et al. (2015). Elder abuse in Portugal: Findings from the first national prevalence study. Journal of elder Abuse and Neglect, 27, 174-195.

Gil, A. P. (Ed. Responsável) (2014). Projeto Envelhecimento e Violência. Instituto Nacional de Saúde Dr. Ricardo Jorge, IP, Departamento de Epidemiologia, Lisboa. Disponível em: http://www.insa.min-saude.pt/publicacao-envelhecimento-e-violencia/. 
Gil, A. P., Faria, P. L., Gomes, I, \& Fonseca, R. (2012). Perspetivas atuais sobre a proteção jurídica da pessoa idosa vítima de violência familiar: contributo para uma investigação em saúde pública. Revista Portuguesa de Saúde Pública, 30 (2), 149-162.

Gonçalves, O. (2000). Viver narrativamente - A Psicoterapia como adjetivação da experiência. Coimbra: Quarteto Editora.

Goodman, L.A., Corcoran, C., Turner, K. B., Yuan, N. \& Green, B. L. (1998). Assessing Traumatic Event Exposure: General Issues and Preliminary Findings for the Stressful Life Events Screening Questionnaire. Journal of Traumatic Stress, 11 (3), 521-542.

Grundy, E. (2006). Ageing and vulnerable elderly people: European perspectives. Ageing \& Society, 26, 105-134. doi:10.1017/SO144686X05004484.

Guerra, I. (2006). Pesquisa Qualitativa e Análise de Conteúdo. Estoril: Principia Editores. Holstein, J., \& Miller, G. (1990). Rethinking victimization: An interactional approach to victimology. Symbolic Interaction, 13(1),103-122.

Instituto Nacional de Estatística (INE) (2015). Classificação Nacional das Profissões: 2010. Lisboa: INE.

Jodelet, D. (1993). Les representations sociales. Regard sur la connaissance ordinaire. Sciences Humaines, 27, 22-24.

Kvale, S. (2009). Interviews: Learning the craft of qualitative research Interviewing. London: Sage.

Kvale, S. (2008). Doing Interviews. London: Sage.

Kvale, S. (1996). Interviews - An Introduction to qualitative research interviewing. California: Sage Publications.

Leandro, M. E. (2001). Sociologia da Família nas Sociedades Contemporâneas. Lisboa: Universidade Aberta.

Lindert J; de Luna J; Torres-Gonzales F; Barros H; loannidi-Kopolou E; Melchiorre MG; Stankunas M; Macassa G; Soares JF (2013). Abuse and neglect of older persons in seven cities in seven countries in Europe: a cross-sectional community study. Journal of Public Health, 5, 662-666.

Lopes, A. (2014). Pobres idosos ou idosos pobres?: discussão sobre o tema da pobreza na velhice. 40 anos de democracia(s): progressos, contradições e prospetivas.

Luoma, M.L., Koivusilta, M, Lang, G., Enzenhofer, E., De Donder, L., Verté, D. \& Penhale, B. (2011). Prevalence Study of Abuse and Violence against Older Women. Results of a Multi-cultural Survey Conducted in Austria, Belgium, Finland, Lithuania, and Portugal 
(European Report of the AVOW Project). Finland: National Institute for Health and Welfare (THL).

Melchiorre, M. G. et al. (2013). Social Support, Socio-Economic Status, Health and Abuse among Older People in Seven European Countries. Social Support and Elder Abuse in Europe, 8.

Mendes, F. R. (2005). Conspiração Grisalha. Segurança Social, Competitividade e Gerações. Oeiras: Celta Editora.

Miller, L. R. (2019). The perils and pleasure of aging: how women's sexualities change across life course. The Sociology Quarterly, 3, 371-396.

Mysyuk, Y., Westendorp, R. G., \& Lindenberg, J. (2013). Added value of elder abuse definitions: a review. Ageing Res Rev, 12(1), 50-57. doi:10.1016/j.arr.2012.04.001.

O'Keeffe, M., Hills, A., Doyle, M., McCreadie, C., Scholes, S., Constantine, R., et al. (2007). UK Study of Abuse and Neglect of Older People: Prevalence Survey Report. London.

Pais, J. M. (1998). Gerações e valores : na sociedade portuguesa contemporânea. Lisboa: Instituto de Ciências Sociais. ISBN 972-96629-2-4.

Paúl, C. (1997). Lá para o fim da vida. Idosos, família e meio ambiente. Coimbra: Almedina.

Pagelow, M. D. (1984). Family Violence. Estados Unidos: Praeger Publishers. ISBN: 0-27591623-5.

Pedroso, J. \& Branco, P. (2008). Mudam-se os tempos, muda-se a família. As mutações do acesso ao direito e à justiça de família e das crianças em Portugal. Revista Crítica de Ciências Sociais, 82, 53-8.

Pillemer, K., Burnes, D., Riffin, C., \& Lachs, M. S. (2016). Elder Abuse: Global Situation, Risk Factors, and Prevention Strategies. Gerontologist, 56 (2),194-205. doi:10.1093/geront/gnw004.

Pimentel, L. (2011). O Sexo dos Anjos: os cuidados às pessoas idosas dependentes como uma esfera de acção preferencialmente feminina. Ex æquo, 23, 32-37.

Pocinho, M. T., Farate, C., Dias, C. A., Lee, T. T., \& Yesavage, J. A. (2009). Clinical and psychometric validation of the geriatric depression scale (GDS) for portuguese elders. Clinical Gerontologist, 32(2), 223-236. doi: 10.1080/07317110802678680.

Podnieks, E.; Penhale, B.; Goergen, T.; Biggs, S. \& Han, D. (2010). Elder mistreatment: An international narrative. Journal of Elder Abuse \& Neglect, 22, 131-136.

Power, M., Quinn, K., Schmidt, S., \& WHOQOL-OLD Group (2005). Development of the WHOQOL-Old module. Quality of Life Research, 14 (10), 2197-2214. 
Ramos, E; Lopes, C. \& Barros, H. (2004). Investigating the effect of nonparticipation using a population-based case-control study on myocardial infarction. Annals of Epidemiology, 14(6), 437-41.

Sandberg, L. (2013). Affirmative old age - the ageing body and feminist theories on difference. International Journal of Ageing and Later Life, 8(1), 11-40.

Schiamberg, L. B., \& Gans, D. (1999). An ecological framework for contextual risk factors in elder abuse by adult children. Journal of Elder Abuse \& Neglect, 11, 79-103.

Sheikh, J. I., \& Yesavage, J. A. (1986). Geriatric depression scale (GDS): Recent evidence and development of a shorter version. Clinical Gerontologist, 5(1-2), 165-173. doi: 10.1300/J018v05n01_09.

Soares, J., Sundin, O.; Viitasara, E.; Melchiorre; Stankunas, M.; Lindert, J. ; M.G.; TorresGonzales, F.; Barros, H. \& Ionnidi-Kapolou, E. (2013). Quality of life among persons aged 60-84 years in Europe: The role of psychological abuse and socio-demographic, social and health factors. Biosafety \& Health Education, 1, 101. Doi:10.4172/23320893.1000101.

Soares, J., Barros, H., Torres-Gonzales, F., Ionnidi-Kapolou, E., Lamura, G., Lindert, J. \& Stankunas, M. (2010). Abuse and health among eldery in Europe. Kaunas: Lithuanian University of Health Sciences Press.

Straus, M.A., Hamby, S.L., BoneyMcCoy, S, \& Sugarman, D.B. (1996). The revised Conflict Tactics Scales (CTS2) - Development and preliminary psychometric data. Journal of Family Issues, 17, 283-316.

Whittaker T. (1995). Violence, gender and elder abuse: towards a feminist analysis and practice. Journal Gender Studies, 4: 35-45.

Wolf, R. S. \& Pillemer, K. A. (1989). Helping Elderly Victims - The Reality of Elder Abuse, New York: Columbia University Press.

World Health Organization (WHO) (2017). Elder abuse. Disponível em: http://www.who.int/mediacentre/factsheets/fs357/en/ .

World Health Organization (2006). The WHOQOL-OLD Manual. Geneva: World Health Organization. Disponível em: https://www.who.int/mental_health/evidence/WHOQOL_OLD_Manual.pdf?ua=1.

World Health Organization (WHO) (2002a). Missing voices. Views of older persons on elder abuse.

World Health Organization (WHO) (2002b). The Toronto Declaration on the Global Prevention of Elder Abuse. Geneva: World Health Organization. 
WHO Department of Gender Women and Health (2001). Putting women first: Ethical and safety recommendations for research on domestic violence against women.

Zimet, G.D., Powell, S.S., Farley, G.K., Werkamn, S. \& Berkoff, K.A. (1990). Psychometric characteristics of the Multidimensional Scale of Perceived Social Support. Journal of Personality Assessment, Winter, 55 (3-4), 610-617. 